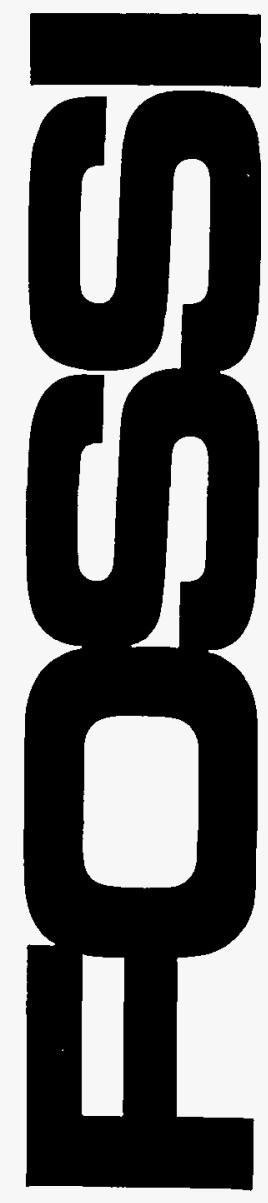




\section{DISCLAIMER}

This report was prepared as an account of work sponsored by an agency of the United States Government. Neither the United States Govemment nor any agency thereof, nor any of their employees, makes any warranty, express or implied, or assumes any legal liability or responsibility for the accuracy, completeness, or usefulness of any information, apparatus, product, or process disclosed, or represents that its use would not infringe privately owned rights. Reference herein to any specific commercial product, process, or service by trade name, trademark, manufacturer, or otherwise does not necessarily constitute or imply its endorsement, recommendation, or favoring by the United States Govemment or any agency thereof. The views and opinions of authors expressed herein do not necessarily state or reflect those of the United States Government or any agency thereof.

This report has been reproduced directly from the best available copy.

Available to DOE and DOE contractors from the Office of Scientific and Technical Information, P.O. Box 62, Oak Ridge, TN 37831; prices available from (615) 576-8401.

Available to the public from the U.S. Department of Commerce, Technology Administration, National Technical Information Service, Springfield, VA 22161, (703) $487-4650$. 


\section{DISCLAIMER}

Portions of this document may be illegible in electronic image products. Images are produced from the best available original document. 


\section{Project Calcium}

\section{Topical Report}

John P. Hurley

Steven A. Benson

Thomas A. Erickson

Sean E. Allan

Jay Bieber

September 1992

Work Performed Under Contract No.: DE-FC2:1-86MC10637

For

U.S. Department of Energy Office of Fossil Energy

Morgantown Energy Technology Center

Morgantown, West Virginia

By

Energy and Environmental Research Center

Grand Forks, North Dakota 


\section{DISCLAIMER}

This report was prepared as an account of work sponsored by an agency of the United States Government. Neither the United States Government nor any agency thereof, nor any of their employees, makes any warranty, express or implied, or assumes any legal liability or responsibility for the accuracy, completeness, or usefulness of any information, apparatus, product, or process disclosed, or represents that its use would not infringe privately owned rights. Reference herein to any specific commercial product, process, or service by trade name, trademark, manufacturer, or otherwise does not necessarily constitute or imply its endorsement, recommendation, or favoring by the United States Government or any agency thereof. The views and opinions of authors expressed herein do not necessarily state or reflect those of the United States Government or any agency thereof.

This report has been reproduced directly from the best available copy.

Available to DOE and DOE contractors from the Office of Scientific and Technical Information, 175 Oak Ridge Turnpike, Oak Ridge, TN 37831; prices available at (615) 576-8401.

Available to the public from the National Technical Information Service, U.S. Department of Commerce, 5285 Port Royal Road, Springfield, VA 22161; phone orders accepted at (703) 487-4650. 


\title{
Project Calcium
}

\section{Topical Report}

\author{
John P. Hurley \\ Steven A. Benson \\ Thomas A. Erickson \\ Sean E. Allan \\ Jay Bieber
}

Work Performed Under Contract No.: DE-FC21-86iMC10637

For

U.S. Department of Energy

Office of Fossil Energy

Morgantown Energy Technology Center

P.O. Box 880

Morgantown, West Virginia 26507-0880

By

Energy and Environmental Research Center

University of North Dakota

Box 8213, University Station

Grand Forks, North Dakota 58202

September 1992 


\section{TABLE OF CONTENTS}

Page

LIST OF FIGURES $\ldots \ldots \ldots \ldots \ldots \ldots \ldots \ldots \ldots \ldots \ldots \ldots \ldots \ldots \ldots \ldots$

LIST OF TABLES $\ldots \ldots \ldots \ldots \ldots \ldots \ldots \ldots \ldots \ldots \ldots \ldots \ldots \ldots \ldots$

ACKNOWLEDGEMENTS ........................ vii

EXECUTIVE SUMMARY $\ldots \ldots \ldots \ldots \ldots \ldots \ldots \ldots \ldots \ldots \ldots \ldots \ldots \ldots \ldots$

Results of Field and Laboratory Testing $\ldots \ldots \ldots \ldots \ldots \ldots \ldots \ldots \ldots \ldots \ldots \ldots$

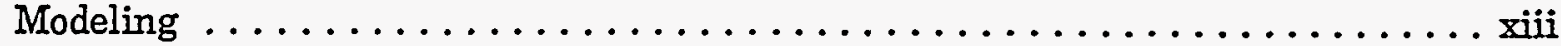

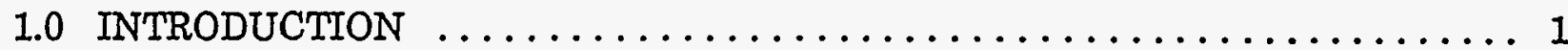

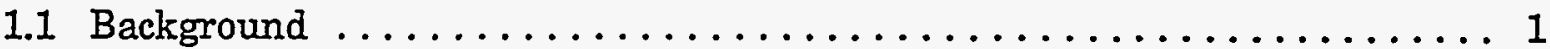

1.2 Project Description and Goals . . . . . . . . . . . . . . . . . 2

1.3 Project Calcium Approach and Accomplishments . . . . . . . . . . . . . 4

1.3.1 Task 1. Boiler Sampling and Characterization ............ 4

1.3.1.1 Northern States Power Company (NSP) Allen S. King

Station Unit $1 \ldots \ldots \ldots \ldots \ldots \ldots \ldots \ldots \ldots \ldots \ldots \ldots \ldots \ldots$

1.3.1.2 Northern Indiana Public Service Company (NIPSCO)

R.M. Schahfer Station Unit $14 \ldots \ldots \ldots \ldots \ldots \ldots \ldots$

1.3.1.3 Northern States Power Company (NSP) Sherburne

County (Sherco) Station Unit $1 \ldots \ldots \ldots \ldots . \ldots . \ldots . \ldots$

1.3.1.4 Otter Tail Power Company Hoot Lake Station Unit $2 \ldots \ldots \ldots \ldots . .9$

1.3.1.5 Southwestern Electric Power Company SWEPCO Welsh Station .. 10

1.3.2 Task 2. Predicting Low-Temperature Ash Deposition ........... 10

1.3.3 Task 3. Laboratory-Scale Studies ................... 11

1.3.4 Task 4. Reporting ....................... 12

2.0 DEFINITION OF LOW-TEMPERATURE DEPOSITION PHENOMENA . . . . 13

2.1 Problem Definition ......................... 13

2.2 Ash Deposition Mechanisms . . . . . . . . . . . . . . . . . 21

2.3 Low-Temperature Deposition Rates ................... 27

2.4 Conclusions About the Types of Low-Temperature Fouling and

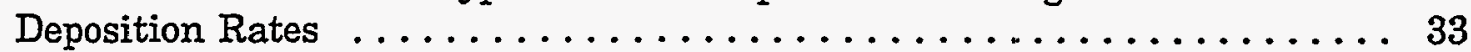

3.0 STRENGTH DEVELOPMENT IN LOW-TEMPERATURE DEPOSITS . . . . . 35

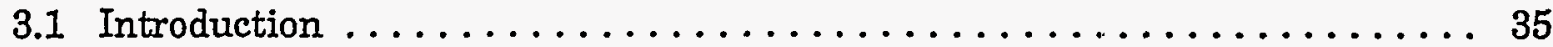

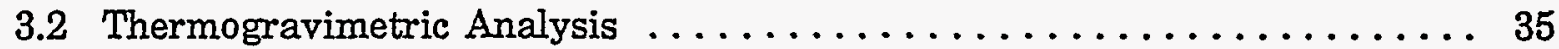

3.3 Low-Temperature Sintering $\ldots \ldots \ldots \ldots \ldots \ldots \ldots \ldots \ldots \ldots \ldots \ldots \ldots$

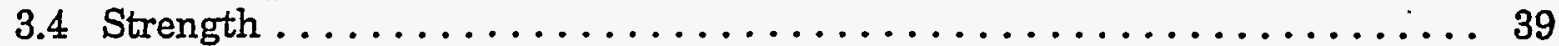

3.5 Composition and Morphology ....................... 43

3.6 Chemical Association of Calcium ...................... 46

3.7 Conclusions About the Development of Strength in Low-

Temperature Deposits . . . . . . . . . . . . . . . . . . 49 
TABLE OF CONTENTS (continued)

Page

4.0 LEADER: LOW-TEMPERATURE ENGINEERING ADVISOR OF DEPOSITION RISK ............................... 51

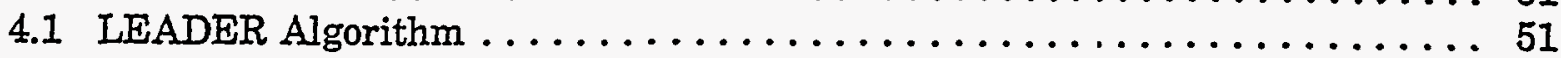

4.1.1 Input--Coal Characterization and Mass Balance ............ 51

4.1 .2 Inorganic Transformations $\ldots \ldots \ldots \ldots \ldots \ldots \ldots \ldots \ldots \ldots, 53$

4.1.2.1 Locked Minerals .......................... 53

4.1.2.2 Liberated Minerals ........................ 54

4.1.2.3 Organically Associated Constituents ................ 54

4.1.3 Transport and Deposition ...................... 54

4.1.4 Strength Development ...................... 55

4.1.5 Heat-Transfer Calculations ..................... 55

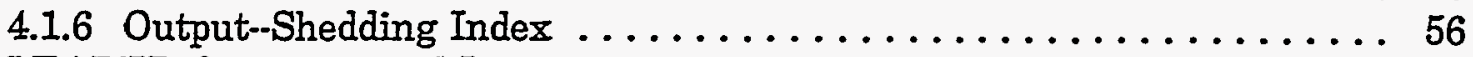

4.2 LEADER Operation and Interpretation of Results ............. 57

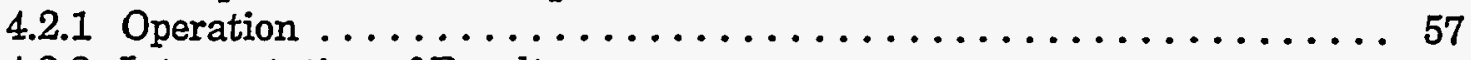

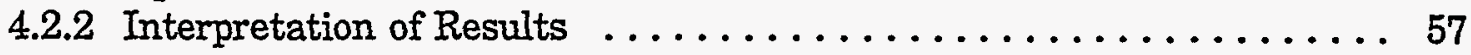

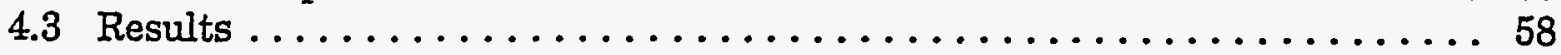

4.3.1 Inorganic Transformations $\ldots \ldots \ldots \ldots \ldots \ldots \ldots \ldots \ldots \ldots \ldots \ldots$

4.3.2 Temperature Distribution in Convective Pass $\ldots \ldots \ldots \ldots \ldots \ldots 61$

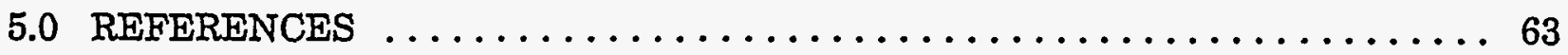

APPENDIX A: LEADER OPERATIONS MANUAL $\ldots \ldots \ldots \ldots \ldots \ldots \ldots \ldots$ A-I

APPENDIX B: COMPARISONS OF MEASURED AND PREDICICED

PARTICLE-SIZE AND COMPOSITION DISTRIBUTTIONS

USING THE LEADER MODEL

B-1 


\section{LIST OF FIGURES}

Eigure

$\underline{\text { Page }}$

1 Long-duration deposition probe $\ldots \ldots \ldots \ldots \ldots \ldots \ldots \ldots \ldots \ldots \ldots$

. Laboratory-scale cyclone furnace $\ldots \ldots \ldots \ldots \ldots \ldots \ldots \ldots \ldots \ldots \ldots$

3 Locations and baseload gas temperatures where off-line deposits were collected $\ldots \ldots \ldots \ldots \ldots \ldots \ldots \ldots \ldots \ldots \ldots \ldots \ldots \ldots \ldots \ldots$

4 Concentrations of silicon, calcium, and sulfur in off-line deposits . . . . . 15

5 Concentrations of phosphorus, sodium, and potassium in off-line deposits .... 16

6 Concentrations of aluminum, iron, and magnesium in off-line deposits ..... 16

7 Upstream side of the deposition probe coupon showing the presence of conventional fouling deposit islands formed at a gas temper:ature above $2000^{\circ} \mathrm{F}$

8 Massive upstream deposits on lead tubes in the reheater tube banks of a boiler burning a high-calcium western U.S. coal . . . . . . . . . . . 18

9 Short-duration deposition probe coupon showing both upstream enamel and downstream powder low-temperature deposits ................. 1

10 Backscattered electron micrograph of the interface between a conventional sintered ash island and the deposition coupon $\ldots \ldots \ldots \ldots \ldots 21$

11 Comparison of the compositions $\left(\mathrm{SO}_{\mathrm{s}}\right.$-free) of the aerodynamically sized entrained ash particles and a conventional fouling deposit ...........

12 The inertial impaction process that leads to the formation of conventional fouling deposits $\ldots \ldots \ldots \ldots \ldots \ldots \ldots \ldots \ldots \ldots \ldots$

13 Backscattered electron micrograph of the interface between an upstream enamel deposit and the deposition coupon $\ldots \ldots \ldots \ldots \ldots \ldots \ldots \ldots$

14 Comparison of the compositions $\left(\mathrm{SO}_{3}\right.$-free) of the aerodynamically sized entrained ash particles and an upstream enamel deposit .............

15 Backscattered electron micrograph of the interface between a downstream powder deposit and the deposition coupon $\ldots \ldots \ldots \ldots \ldots \ldots \ldots \ldots \ldots \ldots$

16 Comparison of the compositions ( $\mathrm{SO}_{3}$-free) of the aerodynamically sized entrained ash particles and a downstream powder deposit ........... 25

17 Backscattered electron micrograph of a cross section of an upstream massive deposit collected from a utility boiler 


\section{LIST OF FIGURES (continued)}

Figure

Page

18 Weight of upstream enamel deposit per unit area of tube versus time as measured in LDDP tests at Hoot Lake and Welsh Stations . . . . . . . . . .

19 The eddy impaction process that leads to the formation of downstream

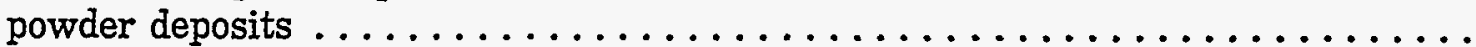

20 Weight of downstream powder deposit per unit area versus time as measured in LDDP tests at Hoot Lake and Welsh Stations . . . . . . . . . . . .

21 The fraction of the ash initially flowing at the IDDP coupons that actually deposited on both the upstream and downstream sides while testing was done at the Welsh Station $\ldots \ldots \ldots \ldots \ldots \ldots \ldots \ldots \ldots \ldots$

22 The TGA curve for heating sulfated Shoshone coal ash in air . . . . . . . . 36

23 The TGA curve for rapid heating then slow cooling of sulfated 5- to 15-micron-aerodynamic-diameter Black Thunder ash . . . . . . . . . . . . .

24 Compressive strength versus sintering times for pellets of 5 - to 15-micron-aerodynamic-diameter Eagle Butte ash sintered in air and simulated flue gas containing $1000-\mathrm{ppm} \mathrm{SO}_{2} \ldots \ldots \ldots \ldots \ldots$

25 Compressive strength versus sintering times for pellets of 5 - to 15-micron-aerodynamic-diameter Shoshone ash sintered in simulated flue gas containing $1000-\mathrm{ppm} \mathrm{SO}_{2}$ at $1450^{\circ}, 1650^{\circ}$, and $1850^{\circ} \mathrm{F}$

26 Compressive strength versus sintering times for pellets of 5- to 15-micron-aerodynamic-diameter Eagle Butte, Antelope, Black Thunder, and Shoshone ash sintered at $1850^{\circ} \mathrm{F}$ in simulated flue gas containing 1000-ppm $\mathrm{SO}_{2}$

27 Comparison of the measured 1-day compressive strengths shown in Figure 26 with the calculated compressive strengths ..............

28 Backscattered electron micrograph of the edge of the Antelope coal ash pellet sintered at $1650^{\circ} \mathrm{F}$ for 10 days in $1000-\mathrm{ppm} \mathrm{SO}_{2} \ldots \ldots \ldots \ldots$

29 Backscattered electron micrograph of the edge of the Eagle Butte coal ash pellet sintered at $1850^{\circ} \mathrm{F}$ for 5 days in $1000-\mathrm{ppm}^{\mathrm{SO}_{2}} \ldots \ldots \ldots \ldots$

30 High-magnification micrograph of a crystal-like region in the Eagle Butte ash pellet sintered at $1850^{\circ} \mathrm{F}$ for 5 days $\ldots \ldots \ldots \ldots \ldots \ldots \ldots$

31 X-ray map of Figure 30 showing the relative concentrations of aluminum, silicon, calcium, and sulfur in the figure 


\section{LIST OF FIGURES (continued)}

Figure

Page

32 ESCA curves for the 1-1-1 mixture and for the Eagle Butte 5- to 15-micron-aerodynamic-diameter ash heated at $1850^{\circ} \mathrm{F}$ for 10 days in 1000-ppm $\mathrm{SO}_{2}$

33 LEADER model algorithm $\ldots \ldots \ldots \ldots \ldots \ldots \ldots \ldots \ldots \ldots \ldots \ldots$

34 Standard boiler design used in boiler algorithm $\ldots \ldots \ldots \ldots \ldots \ldots$

35 Comparison of measured and predicted particle-size distribution for Black Thunder coal burned in a pe unit (Sherco) ................. 59

36 Comparison of measured and predicted particle-size distributions for Black Thunder coal burned in a cyclone unit (King) . . . . . . . . . . . 59

37 Comparison of measured and predicted composition distributions for the Black Thunder (King) 3- to 10 -micron ash particles . . . . . . . . . . . 60

38 Comparison of the measured and predicted composition distributions for the Black Thunder (King) bulk ash

39 Measured versus predicted temperatures throughout the convective pass of a boiler 


\section{LIST OF TABLES}

Table

Page

1 The Composition of the 5- to 15-Micron-Aerodynamic-Diameter Ash Used in the Sintering Tests

2 Peak Positions in the ESCA Analyses of the Strength Development Ash Pellets 


\section{ACKNOWLEDGEMENTS}

As is true in any project, the success of the research is due to the contributions of numerous people in less visible roles. The authors would like to thank Don Toman, Don McCollor, Grant Schelkoph, Jim Ford, Dean Evenstad, Sumitra NJess, Jim Aarstad, Jay Gunderson, and Richard Schulz for their help in power plant sampling and making equipment; Jan Nowok and David Brekke for their help in the laboratory; and Stan Selle, the president of Northwest Research Inc., for helpful discussions and contributions to the power plant sampling effort. 


\section{EXECUTIVE SUMMARY}

Relevant conclusions have been presented in extended form at the end of each appropriate chapter. This section presents a succinct summary of those conclusions.

- Fouling problems in utility boilers have been classified into two principal types: high-temperature and low-temperature fouling.

- A multiclient-sponsored program entitled "Project Calcium: Calcium-Based Ash Deposition in Utility Boilers" was initiated at the Energy and Environmental Research Center (EERC) to better understand the causes of low-temperature fouling when burning high-calcium western U.S. coals. The project was sponsored by the U.S. Department of Energy (DOE), Electric Power Research Institute (EPRI), Northern States Power Company (NSP), Northern Indiana Public Service Company (NIPSCO), Cyprus Coal Company, Wisconsin Power and Light Company, AMAX Coal Sales Company, Otter Tail Power Company, Ontario Hydro, and Babcock and Wilcox Company (B\&W).

- The goals of Project Calcium were to define the low-temperature deposition problem, identify the calcium-based components that are responsible for the formation of the deposits, develop ways to predict their formation, and identify possible methods to mitigate the formation of these deposits.

- To achieve the goals of Project Calcium, detailed sampling of utility boilers and laboratory-scale studies coupled with state-of-the-art methods to determine the inorganic components in coals and coal ash-derived materials were conducted.

- Boiler Sampling: The work involved sampling coal, entrained ash, deposits and slags from five full-scale utility boilers combined with detailed advanced characterization of the materials. The results of this worls aided in identifying the key phenomena to focus the laboratory studies and in model verification. Field testing was conducted at the following utilities for the reasons given.

- NSP Allen S. King Station Unit 1, February 28 - March 2, 1991, Bayport, Minnesota.

- Test two similar coals (Black Thunder and Antelope) under similar conditions in a cyclone-fired unit.

- NIPSCO R.M. Schahfer Station Unit 14, September 10-13, 1991, Wheatfield, Indiana.

- Test one coal (Shoshone) at two different loads.

- NSP Sherburne County (Sherco) Station Unit 1, October 1-4, 1990, Becker, Minnesota.

- Test the same two coals as in the King Station tests, but in a pulverized coalfired unit. 
- Otter Tail Power Company Hoot Lake Station Unit 2, May 15-28, 1991, Fergus Falls, Minnesota.

- Shakedown and test the long-duration deposition probe (LDDP) using Eagle Butte coal.

- SWEPCO Welsh Station, January 23-February 5, 1992, Pittsburg, Texas.

- Test effects of load on development of massive upstream low-temperature fouling deposits, and determine deposition rates of other deposits while firing Eagle Butte Coal.

- The sampling equipment for field testing consisted of high-velocity thermocouple for temperature profiling, probes for collecting entrained ash samples that could readily attach to a multicyclone to classify samples by size, and cooled probes to simulate a convective pass tube for deposit collection.

- Detailed advanced characterization of the components in coals and coal ash derived materials used the following methods.

- Computer-controlled scanning electron microscopy (CCISEM) was used to determine the size, quantity, and composition of the mineral grains in the coal.

- Chemical fractionation was used to determine the abundance of organically associated elements in the coal, based on their extractability with various aqueous solutions. In addition to these techniques, standard methods of coal characterization were used such as proximate, ultimate, sulfur forms, ash fusion, and ash composition.

- The scanning electron microscope point count routine (SEMPC) technique was used to quantitatively determine the distribution of phases in fly ashes, deposits and slags.

- The bulk chemical composition of the coal ash, deposits, and fly ash was determined using $\mathrm{x}$-ray fluorescence (XRF) analysis.

- Laboratory-Scale Experimentation: The first objective of this work was to develop a.bench-scale cyclone furnace to simulate the slag-forming and ash-partitioning environment of a full-scale cyclone. This work was abandoned after field work showed only minor differences in the particulate ash reaching the convective pass in cyclone versus pc-fired boilers. The second objective was to develop data on the rates of strength development and the types of species that form. when calcium-rich fly ashes are sintered as a function of temperature, fly ash composition, and gas composition $\left(\mathrm{SO}_{2}\right)$. The third objective was to identify ways to interrupt the sintering processes and to identify the conditions necessary for severe sintering to occur. The conditions used and the transformations identified as keys were the focus of the laboratory-scale studies. The results of the laboratory work are described more fully in the following sections. 
- Modeling: The objective was to incorporate the information gained as a result of the work performed in this project into a computer code designed to predict lowtemperature ash deposition based on coal analyses and some system operating parameters. The code allows the sponsors to more effectively use the information generated in this project. The code is called Low-Temperature Engineering Advisor of Deposition Risk (LEADER). The program is described more fully in Appendix A.

- Extended reports were written for each of the first power plant sampling trips detailing the sampling efforts, analyses performed, and clata produced. No report was written for SWEPCO Welsh Station testing because of the proximity to the end of the Project. However, much of the data developed from testing at that plant is detailed in the final report. In addition, two conference articles detailing general Project Calcium results have been written to date. A series of technical articles that describe in detail the low-temperature deposition problem and results of deposition and strength development determinations will be prepared and submitted to technical journals with the permission of the sponsors.

\section{Results of Field and Laboratory Testing}

- Project Calcium testing determined that five types of ash. fouling deposits occur in the convective pass of boilers burning high-calcium, low-sulfur coals. They include conventional, or high-temperature fouling deposits, and four types of lowtemperature deposits known as upstream massive, upstream enamel, doublecrested upstream, and downstream powder deposits. The low-temperature deposits contain large amounts of sulfur fixed from the gas stream by alkaline (basic) elements. The sulfation occurs after ash deposition at temperatures below $1900^{\circ} \mathrm{F}$, not because of sulfate condensation, but because of thermodynamic reasons. Calcium sulfate is favored below $1900^{\circ} \mathrm{F}$ over calcium silicate or calcium oxide which are favored above that temperature. Sodium, potassium, and phosphorus are also enriched in deposits formed below $1900^{\circ} \mathrm{F}$, whereas other elements show no temperature-dependent concentrations.

- Conventional fouling deposits form on the upstream (windward) side of steam tubes in secondary superheater regions. They are massive and appear much like sandstone, although in certain cases they have completely fused into molten masses. They are formed primarily of particles with aerodynamic diameters of greater than 10 microns. Because they are formed of larger particles, they are usually enriched in silicon and depleted in calcium compared to the bulk ash because silicon tends to concentrate in larger ash particles and calcium in smaller. The particles bond through viscous sintering of silicate material, little or no sulfur is present.

- Massive upstream deposits form on the upstream side of the lead tubes in the reheat steam banks as temperatures drop below $1900^{\circ} \mathrm{F}$ and sulfation occurs. The massive deposits are less lustrous than conventional fouling deposits. They are often dull reddish or brownish in color. They can be very massive and hard, almost always occurring as a fin whose base covers the tube, and extending a foot or more into the gas stream forming a sharp ridge. These deposits sulfate and become hard quickly, making them difficult to soot blow. Soot-blower paths are 
common in boilers burning high-calcium western U.S. coals. They tend to be approximately 10 to 15 feet in total height, and indicate that soot blowers need to be more closely spaced vertically in this region to prevent the accumulation of these deposits. Such deposits do not normally grow dramatically in width to close off the flow through the region unless the boiler design permits a region of gas turbulence that will make the direction of growth transverse to the bulk gas stream, or unless a piece of a deposit breaks off and lodges between plenums. If this occurs, the broken piece acts as a seed that initiates rapid growth of blocking deposits. Few data were obtained in Project Calcium detailing formation rates for these deposits, but it is believed that they could be weakened by including an inert additive of the appropriate size range in the fuel.

- Upstream enamel-like deposits form on all tubes downstream of the region in which the massive deposits form. The enamel deposits are created through the deposition of ash particles with aerodynamic diameters of less than 3 microns. These particles are highly enriched in calcium and depleted in silicon as compared to the bulk ash. When formed at higher temperatures, the enamel layer is essentially hard upon deposition; i.e., strength does not need time to develop. At lower temperatures, strength is not immediate, but does develop quickly. Therefore, soot blowing of these deposits is less effective than with most other types of deposits. Effectiveness could be improved if thermal shocking is significant, such as when using water as the blowing medium. Off-line removal of the deposits is equally difficult. One Project Calcium sponsor reports great difficulty in removing them with high-pressure water sprays, although another reports that an overnight soaking with acidic river water sprayed with lawn sprinklers made them easily removable. Because these deposits are well sintered in a short time and because they tend to be thin and build slowly, they do not dramatically impede heat transfer. However, the layer can act as a capture surface which absorbs the energy of incoming ash particles so that they stick to the steam tubes at lower temperatures than if the layer were not present. In this way, they can initiate the formation of a massive deposit. This is believed to be the method of initiation of the upstream massive low-temperature deposits. In addition, because the enamel layers are rich in sulfur, they can corrode the tubes at higher temperatures, although at the lower skin temperatures of the primary superheater and economizer tubes, corrosion is usually not a problem. Approximately $0.04 \%$ of the ash in the less-than-three-micron size range that was originally moving toward a steam tube will actually end up on this tube. This deposition fraction is directly proportional to the ratio of the square of the gas velocity to its absolute temperature.

- A third type of upstream-side deposit is composed of small crests or humps that form on either side of the center line of the tube, leaving the center line clear. These most often form in primary superheater regions of a boiler. The shape of these deposits indicates that they are formed from a specific size range of particles that begin to flow around the tube with the gas, but then separate from the gas flow and impact the tube surface. No data are available about the specific size or composition of the ash that forms these deposits. They are expected to have the same influence on boiler performance as the upstream enamel layer and can most likely be removed in the same way as the upstream enamel layer. 
- The fourth common type of low-temperature deposit is a powder that deposits on the downstream side of the steam tubes. The deposits cover many times more surface area than all the other deposits and are, therefore, the greatest detriment to heat transfer of any of the low-temperature deposits. Downstream deposits are formed from ash particles with aerodynamic diameters of less than $10 \mu \mathrm{m}$ that get trapped in the eddies of gas swirling behind the tubes. Such deposits are usually not more than a half of an inch thick on vertically oriented tubes because they tend to shed under their own weight, although in some cases, especially on horizontal tubes, they become massive. Although easily soot blown, the tubes in front of them protect them from soot blowing. Soot-blower effectiveness can be increased to several tubes deep in a bank by angling the blower nozzles $15^{\circ}$ from the perpendicular to the path. In areas of turbulence, the deposits can grow to block the passage of gas. The propensity of these depositis to shed is given by a relative number known as the shedding index, which equals the rate of deposit growth divided by the rate of strength development. The shedding index is increased at low gas velocities because larger particles deposit. However, the velocities that give high shedding indices are usually too low to reach in a 500-MW boiler. The shedding index may be doubled for a typical Powder River region coal by adding $26 \mathrm{lb}$ of commercially available kaolin per ton of coal. This amount of commercial kaolin would cost $\$ 0.81$ per ton of coal FOB the kaolin mine. However, kaolin may also be available in coal mine overburden. At an average load in that size of boiler, about $0.4 \%$ of the ash with aerodynamic diameters of less than 10 microns will deposit on a tube that it approaches. Like the upstream deposits, the deposition fraction increases as the square of the gas velocity and inversely as the absolute temperature.

- Laboratory tests of strength development in pellets of particulate ash show that the presence of $\mathrm{SO}_{2}$ in the gas strengthens the compressive strength of the deposits. Strength develops in one to two days at $1850^{\circ} \mathrm{F}$, but took up to five days at lower temperatures. The differences in strength caused by temperature differences were minor, indicating that deposits formed at high temperatures are slightly weaker than those formed at low temperatures. Strength often decreased after the first day at $1850^{\circ} \mathrm{F}$, possibly due to crystal formation in the interacting ash. The rate of initial strength development at $1850^{\circ} \mathrm{F}$ was found to be related to a constant times the ratio of total alkali to silicon.

- Scanning electron microscope observations of the ash pellets showed that for ash with higher alkali-to-silicon ratios, calcium sulfate crystals formed that acted as cement to bind the ash into a strong (presumably) aggregate. The calcium sulfate crystals form through the same phenomena as the upstream massive deposits. However, the upstream massive deposits sulfate as the ash is deposited. In the ash pellets, $\mathrm{SO}_{2}$ transport is too slow to have the pellet completely sinter in 10 days. Therefore, the ash pellets do not become extremely hard in 10 days because continuous channels of unsulfated ash which permit fracture are still present in the pellet. Over very long periods of time, the sulfate crystals in the pellets will become more continuous and make the pellets harder, but the rate will always be limited by the rate of $\mathrm{SO}_{2}$ diffusion through the pellets. Electron spectroscopy analyses showed that the initial strength development in the pellets is somewhat due to sulfate sintering, but may also be due to increased surface tension caused by the presence of a small amount of sulfate in the silicate glasses. Increased surface 
tension implies increased sintering rate, but sintering evidently stops in a day or two, possibly because only a very thin skin of sulfate-rich layer develops, and once this skin forms necks, no more material is available. This also explains why temperature makes little difference in deposit strength; i.e., strength is limited by the amount of fined material and not by the sintering rate, since even at lower temperatures sintering of the small amount of fined material is essentially complete in 1 day (the shortest test). Downstream deposits never become as hard as upstream massive deposits because in downstream deposits the deposition rate is high compared to the sulfation rate, whereas in the upstream deposits, sulfation rates are higher.

\section{Modeling}

- A computer code entitled LEADER, low-temperature engineering algorithm of deposition risk, was created to aid the sponsors in determining the propensity a coal or coal blend may have in producing low-temperature deposits. The program is designed specifically for use in modeling deposition in larger utility boilers of approximately 500-MW load and firing a high-calcium western U.S. coal. LEADER is a FORTRAN-based code designed to run on a $386 \mathrm{PC}$ or higher with a math coprocessor and VGA graphics.

- The LEADER program uses information about the inorganic chemistry of a specific coal gained through advanced analysis of the coal by computer-controlled scanning electron microscopy, $\mathrm{x}$-ray fluorescence, and ultimate analysis. The chemistry of the inorganic constituents is used to predict the size and chemistry of entrained ash that will pass into the convective pass of a utility boiler. The resultant ash and boiler parameters are used to determine the deposition rate, strength development rate, and heat exchange efficiency loss from low-temperature deposition.

- LEADER can be used as a valuable asset in choosing a coal for combustion purposes. By running LEADER on a number of coals, the coals can be ranked by plant engineers based on their potential to produce low-temperature deposits and thus decrease the efficiency of the boiler. In addition, the use of additives or coal blends to reduce fouling problems can be modeled. By weighing the deposition impacts with efficiency losses, soot-blowing operation, possible outages, and economic factors, more profitable operations decisions can. be made. 


\section{PROJECT CALCIUM}

\subsection{INTRODUCTION}

\subsection{Background}

Low-temperature sulfate-based ash fouling of the convective passes of utility boilers which fire western U.S. subbituminous coals is a serious problem. These deposits form at temperatures below approximately $2000^{\circ} \mathrm{F}$. Preliminary investigations of deposits collected from full-scale utility boilers have shown that they contain an abundance of calcium- and sulfur-rich phases that appear to be the materials bonding the particles together (1). The mechanism of formation of these hard-bonded deposits appears to involve the sintering of calcium sulfate-rich ash material. Most of the past research on ash deposition has focused on deposit growth and strength development mechanisms where liquid phases are responsible, but this temperature regime is below that necessary for a calcium sulfate liquid phase to be responsible for deposit growth and strength development.

In general, fouling problems in utility boilers have been classified into two principal types: conventional high-temperature fouling and low-temperature fouling. This distinction is needed since the bonding mechanisms of the deposits differ. In hightemperature fouling the bonding of particles is due to silicate- and iron-rich liquid phases, while in low-temperature fouling the bonding is a result of the formation of sulfates. Condensed sulfur species, principally in the form of $\mathrm{CaSO}_{4}$, are stable and are the matrix or bonding material in the low-temperature deposits.

While utility use of high-calcium subbituminous coals is increasing due to their low sulfur content, very little information is available on the ash behavior of these coals in utility boilers. Of specific concern is efficiently utilizing them in utility boilers that are designed for bituminous coals. The type, association, and abundance of inorganic components in Powder River subbituminous coals differ dramatically from bituminous coals. For example, the subbituminous coals contain a higher oxygen content that is predominantly in the form of carboxylic acid groups. The acid groups provide sites for the association of cations such as calcium, sodium, and other alkali and alkaline earth elements. In addition, these coals contain a wide range of discrete mineral grains. As a result, the ash derived from firing subbituminous coal will differ significantly from the ash derived from bituminous coal, both in particle size and chemical composition. Therefore, the ash deposition problems are significantly different between U.S. subbituminous and bituminous coals.

Several key processes must be better understood in order to develop methods to predict and mitigate the deposition problem.

- The first process is ash formation. This process influences the composition and state of the inorganic components in the boiler and is a result of the mode of firing, the firing conditions, and the association of the inorganic components in the coal. The ash formation process involves a complex series of chemical and physical transformations of the coal's inorganic components during combustion to produce ash intermediates of inorganic vapors, liquids, and solids. The chemical 
composition of the intermediate ash particles varies widely. The final ash product has a bimodal (modes at $\approx 0.1$ and $\approx 12 \mu \mathrm{m}$ ) particle-size distribution.

- The second process is the condensation/solidification of the entrained intermediate ash species in the gas stream during gas cooling. A significant portion of the submicron-sized particles form as a result of homogeneous condensation of flamevolatilized species. The flame-volatilized species may also condense heterogeneously on the surfaces of larger particles. The larger particle-size mode, sometimes referred to as residual ash, is largely derived from mineral grains.

- The third process involves the transport of ash particles to the heat-transfer surface and the reactions that occur upon deposition to create large, strong deposits.

- The transport of intermediate ash species is a function of the state and size of the ash species and system conditions such as gas-flow patterns, gas velocity, and temperature. Several processes are involved in the transport of ash particles. They include inertial impaction, thermophoresis, electrophoresis, Brownian motion, and diffusion. Before Project Calcium, the relative importance of each process in the formation of different types of deposits was not known.

- The development of strength in ash deposits is a dynarnic and complex process that can be explained through sintering theory. Sintering of ash particles can involve solid-state interaction and viscous flow. The sclid-state sintering mechanisms include vaporization and condensation, bulk diffusion transfer, and surface diffusion. Viscous flow sintering is when two particles coalesce as a result of the flow of a liquid phase. The liquid phase component is the primary contributor to conventional deposit-strength development. The abundance and viscosity of the liquid phases are primary factors needed to assess sintering potential. However, the temperatures associated with low-temperature fouling are in the deposits. Therefore, strength development in these deposits is not well understood.

The ultimate goal of Project Calcium was to develop a better understanding of the processes associated with low-temperature deposition, which would lead to a better means of predicting and mitigating deposition. In order to obtain the necessary information to achieve this goal, detailed sampling of utility boilers coupled with state-of-the-art methods to characterize the inorganic components in coal and coal ash was conducted. As a result, these efforts have led to a better method of predicting low-temperature ash deposition behavior using a computer program called LEADER, Low-Temperature Engineering Advisor of Deposition Risk.

\subsection{Project Description and Goals}

A multiclient-sponsored program entitled "Project Calcium: Calcium-Based Ash Deposition in Utility Boilers" was initiated at the Energy and Environmental Research Center (EERC) and was sponsored by the U.S. Department of Energy (DOE), Electric Power Research Institute (EPRI), Northern States Power Company (NSP), Northern Indiana Public Service Company (NIPSCO), Cyprus Coal Company, Wisconsin Power and Light 
Company, AMAX Coal Sales Company, Otter Tail Power Company, Ontario Hydro, and Babcock and Wilcox Company (B\&W). The goals of Project Calcium were to identify the calcium-based components responsible for the formation of calcium sulfate-bonded deposits in utility boilers, develop ways to predict their formation, and identify possible methods to mitigate the formation of these deposits. The specific objectives were approached as follows:

1. Determine the effect of the forms of calcium and other ash-forming materials in the coal on their ability to form calcium sulfate-bonded deposits.

2. Determine the forms of calcium and other components in the entrained ash in the boiler flue gas just prior to deposition.

3. Determine the partitioning of inorganic components when firing calcium-rich coals in a cyclone-fired combustor.

4. Determine the mechanism(s) of strength development in calcium sulfate-based deposits.

5. Identify ways to alter the strengthening processes and weaken deposits.

In order to meet these goals and objectives, the research program was divided into four tasks. Task objectives are summarized as follows:

Task 1. Boiler Sampling and Characterization. The objective of this task was to better define low-temperature deposition phenomena and determine the partitioning and transformations of inorganic constituents in full-scale utility boilers firing highcalcium coals. The work involved sampling coal, entrained ash, slag, convective pass deposits and hopper ash from five full-scale utility boilers as; well as detailed advanced characterization of the materials. The results of this work aided in identifying the key phenomena for focusing the laboratory studies and verifying the model.

Task 2. Modeling. The objective of this task was to incorporate the information gained in Tasks 1 and 3 into a computer code designed to predict calcium-based ash deposition. This computer code, designated LEADER, allow:s the sponsors to more effectively use the information generated in this project.

Task 3. Laboratory-Scale Studies. The first objective of this task was to develop a bench-scale cyclone furnace to simulate the slag-forming and ash-partitioning environment of a full-scale cyclone. The second objective was to develop data on the rates of sintering and the types of species that form when calcium-rich fly ashes are sintered as a function of temperature, fly ash composition, and gas composition $\left(\mathrm{SO}_{2}\right)$. The third objective was to identify ways to interrupt the sintering processes and to identify the conditions necessary for severe sintering to occur. The conditions used and the transformations identified as keys were the focus of the laboratory-scale studies. 
Task 4. Reporting. Several reports were written as a result of this work detailing the results, conclusions, and recommendations of methods that could be used to predict and mitigate the deposition problem.

\subsection{Project Calcium Approach and Accomplishments}

\subsubsection{Task 1. Boiler Sampling and Characterization}

The field test work allowed us to better define low-temperature deposition phenomena and also provided samples that allowed us to the determine which of the components cause low-temperature ash deposition. Sampling involved collecting coal, entrained ash, slag, convective pass deposits, and hopper ash for detailed characterization using advanced inorganic analysis techniques. The sampling equipment consisted of a high-velocity thermocouple for temperature profiling, probes that collect entrained ash samples and can readily be attached to a multicyclone to size-classify samples, and cooled probes for simulating a convective pass tube for deposit collection. One of the deposition probes was designed, built, tested, and patented under Project Calcium. Shown in Figure 1, it is the long-duration deposition probe (LDDP), which was developed to acquire deposit samples on a removable coupon from a utility boiler over extended periods of time. This allowed the determination of factors affecting long-term, low-temperature deposit growth. The LDDP was designed to operate autonomously, with minimal on-site attention, and to retract automatically during soot-blower operation. The end of the probe holds a sample coupon that retracts into an electrically heated tube furnace to minimize thermal shock to the ash

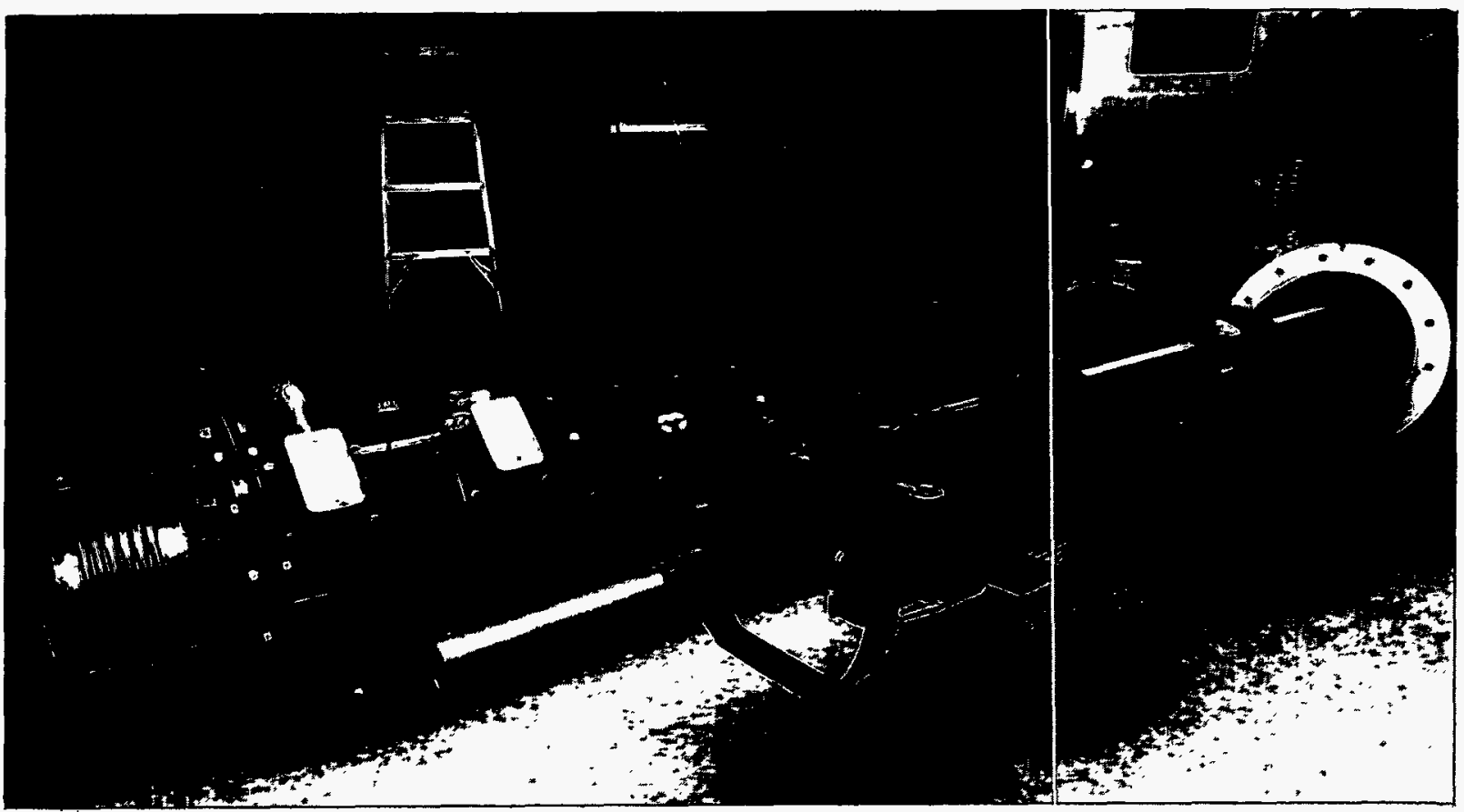

Figure 1. Long-duration deposition probe. 
deposit while it is out of the boiler. The outer surface of the probe is kept with air cooling at a temperature simulating a steam tube. The removable sample coupon attached to the end of the probe permits an undisturbed portion of the ash deposit to be removed for physical and chemical analysis.

The overall objectives of the field tests were to define low-temperature deposition phenomena and to determine the inorganic components that are responsible for the formation of low-temperature deposits in the convective passes of utility boilers. Once the deposition phenomena were defined, the specific objectives of on-line testing were to:

1. Determine the mechanisms of formation and strength development in the deposits.

2. Determine boiler conditions that contribute to the formation of the deposits. The aim is to develop criteria that will alert operations personnel to the presence of conditions that lead to the formation of the deposits so that soot-blower schedules can be adjusted.

3. Determine the deposition rates for the different types of deposits.

4. Determine the inorganic species in the original coal that contribute to the formation of the deposits. The aim is to develop a method to predict the propensity of a coal to form such deposits based only on coal analyses.

Coal samples collected during the test periods were examined to determine the size, abundance, and composition of the mineral grains. In addition to the mineral grains, the abundance of organically associated inorganic constituents was also determined. Computercontrolled scanning electron microscopy (CCSEM) was used to determine the size, quantity, and composition of the mineral grains in the coal. Chemical fractionation was used to determine the abundance of organically associated elements in the coal based on their extractability with various aqueous solutions. In addition to these techniques, standard methods of coal characterization were used such as proximate, ultimate, ash fusion, and ash composition.

The CCSEM technique was used to determine the size, quantity, and semiquantitative composition of mineral grains in coals (2). The semiquantitative chemical composition data obtained were used to classify the particle into mineral or chemical categories.

After the minerals are identified, the CCSEM program classifies the minerals by average diameter into six separate, user-defined size bins. The number of mineral grains and their areas are tallied in each size bin for each mineral type. As a result, the size distributions for individual mineral species can be ascertained.

Chemical fractionation (3) was used to selectively extract elements from the coal based on their association in the coal. This technique involves exiracting the coal with water to remove water-soluble elements such as the $\mathrm{Na}$ in $\mathrm{Na}_{2} \mathrm{SO}_{4}$ or those elements that were most likely associated with the groundwater in the coal. This is followed by extraction with $1 \mathrm{M}$ ammonium acetate to remove elements such as $\mathrm{Na}, \mathrm{Ca}$, and $\mathrm{Mg}$ that may be bound as salts of organic acids. The residue of the ammonium acetate extraction is then extracted with $1 \mathrm{M} \mathrm{HCl}$ to remove acid-soluble species such as $\mathrm{Fe}$ and $\mathrm{Ca}$ which may 
be in the form of hydroxides, oxides, carbonates, and organically coordinated species. The components remaining in the residue after all three extractions are assumed to be associated with the insoluble mineral species such as clays, quartz, and pyrite.

The scanning electron microscope point count (SEMPC) routine was used to quantitatively determine the distribution of phases in fly ash, deposits, and slag. This method involves microprobe analysis of a large number of random points in a polished cross section of a sample. The quantitative analysis of each point is transferred for database analysis. The software is used to calculate molar and weight ratios for each point. Using these ratios, the points which have compositions of phases common to ashes and coal minerals are identified and counted. The software then finds the relative percents of all the identified points. All other points are classified as unknown and are assumed to be amorphous. In addition, the average chemical composition of all the points in the sample is calculated. Work at the EERC has shown that the SEMPC average composition corresponds very well to the bulk chemical analysis. A major advantage of analyzing the microprobe data by the spreadsheet is that the compositions can be further analyzed to determine the chemical interactions that have taken place. The quantitative ability of the SEMPC allows for detailed comparisons to be made between different samples.

The bulk chemical compositions of the coal ash, deposits, and fly ash were determined using $\mathrm{x}$-ray fluorescence (XRF) analysis (4). This technique determines the abundance of the major ash constituents: $\mathrm{SiO}_{2}, \mathrm{Al}_{2} \mathrm{O}_{3}, \mathrm{Fe}_{2} \mathrm{O}_{3}, \mathrm{TiO}_{2}, \mathrm{P}_{2} \mathrm{O}_{5}, \mathrm{CaO}, \mathrm{MgO}, \mathrm{Na}_{2} \mathrm{O}, \mathrm{K}_{2} \mathrm{O}$, and $\mathrm{SO}_{3}$. $\mathrm{X}$-ray diffraction (XRD) was used to identify the crystalline phases in bulk samples. ASTM methods were used to perform proximate, ultimate, and ash fusion analyses on the coals.

\subsubsection{Northern States Power Company (NSP) Allen. S. King Station Unit 1}

On-line sampling was conducted at the NSP Allen S. King Station from February 28 through March 2, 1990. The Allen S. King Station Unit 1 is a B\&W cyclone-fired, pressurized, supercritical boiler rated at $600 \mathrm{MW}$, gross. The unit; came on-line in 1968 and is located near Bayport, MN. The boiler was designed to produce $3.873 \times 10^{6} \mathrm{lb} / \mathrm{hr}$ of steam at $1000^{\circ} \mathrm{F}$ and $3675 \mathrm{psia}$, while burning an Illinois bituminous coal. The original design provided for both flue gas recirculation and tempering; however, the recirculation ducting was subsequently closed off. Gas tempering is still used to limit furnace exit gas temperature (FEGT) and to adjust heat absorption. Spray attemperation is used to control steam temperatures at the outlets of both the superheat and reheat circuits. All wall blowers and retractable soot blowers use steam as the blowing medium. King Unit 1 uses a low-temperature electrostatic precipitator (ESP) for particulate control and has no $\mathrm{SO}_{2}$ control equipment.

The King Station has experienced ash deposition problems on the reheat and primary superheater surfaces when firing select high-calcium Powder River Basin coals. Coals from the Antelope and Black Thunder mines were used in the tests. Both coals have similar chemical composition, but exhibited different fouling propensities. The ash deposition problems can severely limit the ability of the unit to maintain load. Similar samples were obtained, and conditions were monitored for both coals during the testing. Samples of coal, slag, entrained ash, convective pass deposits, and hopper ash from the economizer and ESP were obtained during test periods for both coals.

The samples obtained are summarized as follows: 
1. Coal samples were collected by the station's continuous composite sampler ahead of the main feed hopper. During the test period, coal samples were collected over 2-hour periods. Coal sampling started two hours before testing in the boiler began to accommodate the estimated delay in the coal bunkers. In addition, approximately 1000 pounds of each coal was collected during the test period in order to have sufficient quantities for possible future pilot-scale testing.

2. Slag samples were collected at approximately 4-hour intervals during the testing.

3. Convective pass temperature profiling and sample collecting were performed at three locations in the convective pass. The sampling involved collecting a) an entrained ash sample with the extractive probe coupled with a multicyclone, and b) an ash deposit on a deposition probe inserted into the boiler.

4. Fly ash samples from the economizer hopper and ESP hoppers were collected at 2-hour intervals during the testing.

Details of the results of the testing are provided in the Field Testing Allen S. King Station report.

\subsubsection{Northern Indiana Public Service Company (NIPSCO) R.M. Schahfer Station Unit 14}

Field testing was conducted at the NIPSCO R.M. Schahfer Station September 10-13, 1990. R.M. Schahfer Station Unit 14 is a B\&W cyclone-fired, balanced-draft, supercritical boiler currently rated at $468 \mathrm{MW}$, gross. The unit came on-line in 1976 and is located near Wheatfield, Indiana. The unit was designed to generate $501 \mathrm{MW}$ while burning an Indiana bituminous coal. The original design conditions were the production of $3.23 \times 10^{6} \mathrm{lb} / \mathrm{hr}$ of steam at $1005^{\circ} \mathrm{F}$ and 3635 psig. Changes in sulfur emission standards prompted a change in fuel supply to a Hanna Basin Wyoming bituminous, which resulted in an effective derate to $468 \mathrm{MW}$. Reheat and superheat spray attemperation, gas tempering, and gas recirculation are all available on this unit. All wall blowers and retractable soot blowers use air (315-360 psig) as the blowing medium. Prior to the present test program, the original high-temperature ESP had been modified to operate at low-temperature. The initial start-up of an $\mathrm{SO}_{3}$ conditioning system was in progress during this test program. Schahfer Unit 14 had no $\mathrm{SO}_{2}$ control equipment.

In order to better define the convective pass ash deposition problems associated with burning Wyoming coal at the Schahfer Unit 14 as well as permit comparisons to be drawn between deposits collected directly from boiler steam tubes with those that are collected online using the EERC sampling equipment, steam-tube deposit samples were collected from the Schahfer Unit 14 in January 1990 during a scheduled outage. Coal, slag, and ESP hopper samples were collected during the week before the shutdowm. Twenty ash deposit samples were collected from the box and convective pass during the off-line sampling in January 1990. Of those, six were chosen to illustrate and help define the types of deposits that form in Schahfer Unit 14 while burning Shoshone coal.

In order to ascertain the mechanisms of deposit formation, the program required samples of coal, slag, entrained ash, convective pass deposits, and hopper ash from the economizer and ESP. This test focused on determining the effects of load on the deposition 
problem. Therefore, the entrained ash and convective pass deposits were collected at a low and high load. One set was obtained on September 10 and 11, 19190, while the boiler was operating at 460-MW gross output. The other set was collected on September 12 and 13, 1990, while the boiler output was $290 \mathrm{MW}$. Shoshone mine coal was fired for both tests.

The samples obtained are summarized as follows:

1. Coal samples were collected as coal was fed into the cyclones every 2 hours during sampling. In addition, a sample of coal was taken at 8-hour intervals during the time when sampling was not conducted in order to follow variations in coal characteristics.

2. Slag samples were collected at approximately 4-hour intervals during testing, i.e., three samples per 8-hour sampling period (start, middle, end).

3. Convective pass temperature profiling, gas velocity measuring, and sample collecting were performed at three locations in the convective pass. The locations are near the front of the secondary superheater, between the secondary superheater and the reheat superheater, and above the primary superheater. Temperature measurements at each sampling point were made using a highvelocity thermocouple. The sampling involved collecting a) entrained ash with a quenching, particulate-extraction probe coupled to a multicyclone, and b) an ash deposit on a sacrificial surface that is part of an air-cooled deposition probe.

4. Fly ash samples from the economizer hopper and ESP hoppers were collected during each of the two tests. All inlets and all hoppers on one side, as well as one hopper in each intermediate row, were sampled. A total of ten ESP hopper samples per sampling run were collected. In addition, one of the hoppers from both the economizer and ESP were sampled every 8 hours around the clock in order to have a reference point to follow any changes that might occur.

Details of the results of the testing are provided in the Field Testing at R.M. Schahfer Station report.

\subsubsection{Northern States Power Company (NSP) Sherburne County (Sherco) Station Unit 1}

Field testing was conducted at the NSP Sherco Station Unit 1 over the period October 1-4, 1990. Sherco Station Unit 1 is a Combustion Engineering (CE) pulverizedcoal, tangentially fired, balanced-draft boiler rated at $750 \mathrm{MW}$, gross. It came on-line in 1976 and is located near Becker, Minnesota. The boiler was designed to produce $4.985 \mathrm{x}$ $10^{\circ} \mathrm{lb} / \mathrm{hr}$ of steam at $1007^{\circ} \mathrm{F}$ and 2640 psia, while burning a Montana subbituminous coal. The unit has a split furnace design and was provided with superheat and reheat spray attemperation. Burner tilt can be used to adjust temperature dist:ibution. All wall blowers and retractable soot blowers use steam as the blowing melium. Particulate and $\mathrm{SO}_{2}$ emission control is achieved by means of a venturi design limestone wet scrubber.

Testing was conducted using two Powder River Basin subbituminous coals: Antelope and Black Thunder. Similar samples were obtained and conditions were monitored for both coals during the testing. An additional objective of this work was to compare the results 
obtained from the King Station when firing these same coals. This comparison provides information on the effects of firing conditions, cyclone versus pulverized coal, or ash partitioning and deposition.

The samples obtained are summarized as follows:

1. Coal samples were collected at the main feed hopper. During the test period, coal samples were collected every 2 hours. Coal sampling began 2 hours before testing in the boiler started.

2. Convective pass temperature profiling, gas velocity measuring, and sample collecting were performed at three locations in the convective pass. The sampling involved collecting a) an entrained ash with an extractive probe coupled with a multicyclone, and b) an ash deposit on a deposition probe inserted into the boiler.

3. Fly ash samples from the economizer hopper were collected at 4-hour intervals during the collection of high-volume samples.

Details of the results of the testing are provided in the Field Testing of Northern States Power's Sherburne County Unit I report.

\subsubsection{Otter Tail Power Company Hoot Lake Station Unit 2}

Field testing was conducted at Otter Tail Power Company Hoot Lake Station in Fergus Falls, Minnesota, during May 15-28, 1991. Hoot Lake Station Unit 2 is a CE pulverized-coal, tangentially fired boiler rated at $53 \mathrm{MW}$, gross. The unit, while burning a North Dakota lignite coal, has a steam capacity of $4 \times 10^{5} \mathrm{lb} / \mathrm{hr}$ at; $1000^{\circ} \mathrm{F}$ and 1450 psig. Particulate control is achieved by an ESP.

Testing was conducted using Eagle Butte subbituminous cozl. Samples of coal, slag, entrained ash, convective pass deposits, hopper ash, and high-volume samples at the economizer outlet from the economizer were obtained during test burns for both coals. The objectives of this test were twofold: 1) to shake down the LDDP, and 2) to obtain ash formation and deposition data on another coal. Operation of soot blowers 7-14 and 16A was halted during sampling periods except for the testing of the LDDF. The plant operators in the control room were responsible for the retractation of the LDD? from the boiler until the soot blowing was completed.

The samples obtained are summarized as follows:

1. Two composite mill coal samples were collected during the testing period. Samples from the feeder belts were collected daily.

2. Convective pass temperature profiling, gas velocity measuring, and sample collecting were performed at three locations in the convective pass. Temperature measurements at each sampling point were made. The sampling involved collecting a) an entrained ash with an extractive probe coupled with a multicyclone, and b) an ash deposit on a deposition probe inserted into the boiler.

3. ESP ash samples were collected from the inlet and outlet hoppers daily. 
Details of the results of the testing are provided in the Field Testing of Hoot Lake Unit $\$ 2$ report.

\subsubsection{Southwestern Electric Power Company SWE:PCO Welsh Station}

Field testing was performed at the SWEPCO Welsh Station from January 23 through February 5, 1992. The Welsh Station is a CE pulverized-coal boiler rated at $528 \mathrm{MW}$ located in Pittsburg, Texas. The boiler was designed to produce $3.792 \times 10^{6} \mathrm{lb} / \mathrm{hr}$ of steam at $1000^{\circ} \mathrm{F}$ and 2620 psia, while burning a Wyoming subbituminous coal.

Testing was conducted using Wyoming subbituminous coal. The objective of this test was to verify the results of LEADER and to obtain additional information about deposit formation rates. Samples of coal, entrained ash, convective pass deposits using LDDP for different lengths of time, hopper ash, and bottom ash were obtained during test burns.

The samples obtained are summarized as follows:

1. Three composite mill coal samples were collected during the testing period.

2. Convective pass temperature profiling and sample collecting were performed at three locations in the convective pass. Temperature measurements at each sampling point were made. The sampling involved collecting a) entrained ash with an extractive probe coupled with a multicyclone at a 250 - and 500-MW load, and b) an ash deposit on a deposition probe inserted into the boiler during 8-hour lowload, 8-hour high-load, 1-day, and 5-day cycles.

3. ESP ash samples were collected from outlet hoppers.

The results were used in the formulation of deposition rate algorithms for the LEADER computer code, but no separate report was prepared.

\subsubsection{Task 2. Predicting Low-Temperature Ash Deposition}

Prior to the efforts of Project Calcium little data existed on the formation of lowtemperature deposits in coal-fired systems. The available methods for predicting this type of deposition used ASTM bulk ash compositions. It was found that coals with similar compositions could have dramatically different depositional tendencies, and thus the previous methods became frustrating at best. With the analytical methods developed over the past few years and with a mechanistic grasp of the deposition problem, it became evident that these predictive methods could be greatly improved. Therefore, algorithms were formulated to predict ash formation, transport, deposit growth, and deposit strength development for low-temperature deposition. The algorithms developed under this project were incorporated into a personal computer-based FORTRAN code entitled LEADER.

The code is based on four mechanistic algorithms. The first algorithm, inorganic transformations, uses CCSEM data, along with a mass balance of the other inorganic constituents, to create a large database of intermediate particles passing through the convective pass of a boiler. The second algorithm determines the potential for a particle to impact a deposition surface and form either an upstream enamel layer or downstream deposit based on its aerodynamic diameter. It is used to calculate initial deposit growth 
rates of upstream enamel and downstream deposits based on the data generated from the LDDP testing. The third algorithm, strength development, is based on the experimental findings of the field and laboratory tests. Both the deposition and strength development models are based on measured deposition phenomena but also use a great deal of empirical relations. The final algorithm is used to predict the rate of change of thermal conductance of two types of deposits due to deposit growth.

\subsubsection{Task 3. Laboratory-Scale Studies}

The first objective of laboratory-scale studies was to develop a bench-scale cyclone furnace to simulate the slag-forming and ash-partitioning environment of a full-scale cyclone. The second objective was to develop data for LEADER on the rates of sintering and the types of species that form when calcium-rich fly ashes are sintered. The third objective was to determine ways to interrupt the sintering processes and to identify the conditions necessary for severe sintering to occur.

A laboratory-scale cyclone furnace simulator, shown in Figure 2, was constructed and tested. The primary goal of the simulation effort was to achieve a segregation of ash components representative of that occurring in full-scale cyclone units. After field testing, it was found that the differences between cyclone-fired and pc-fired fly ash were not as significant as expected. Therefore, the cyclone furnace was discontinued, and efforts were focused on the LDDP.

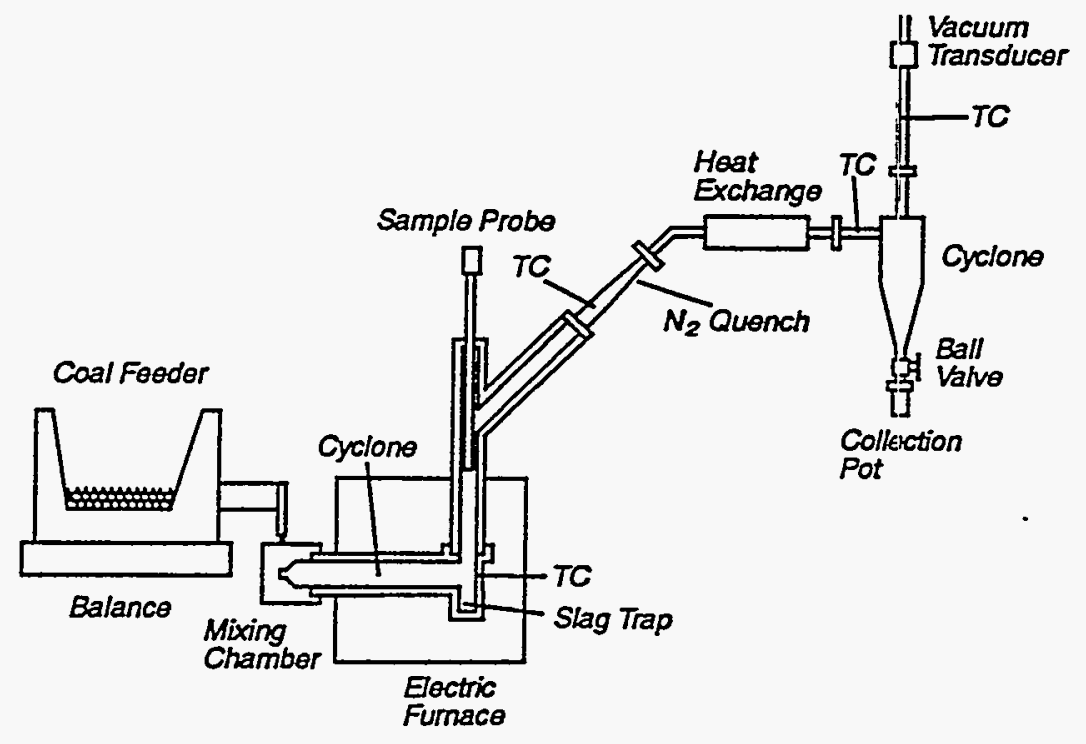

Figure 2. Laboratory-scale cyclone furnace. 
Fundamental studies of the mechanism of sulfation and sintering reactions were conducted. Understanding and developing ways to mitigate ash deposition require basic knowledge of solid-solid, solid-gas, and solid-liquid chemical reactions; phase transformation; and physical properties such as viscosity and surface tension. The first phase of the sulfation and sintering experiments was to measure (as a function of temperature using thermal gravimetric analysis [TGA]) the adsorption of $\mathrm{SO}_{2}$ on fly ash collected from the utility boiler. This provided the temperature range in which sulfation does occur and an indication of the stability of the sulfates at higher temperatures. The second phase of the sintering studies was to sinter pellets of fly ash collected from the fullscale utility boilers in carefully controlled atmospheres and temperatures. Densities and compressive strengths were also determined for each pellet to determine the degree of sintering. The test matrix involved sintering the pellets between the temperatures of $800^{\circ}$ and $2000^{\circ} \mathrm{F}$ for times ranging from 0.5 hours to 10 days. Selected samples were airquenched and subjected to detailed analysis using XRD, SEM morphology, and SEMPC.

\subsubsection{Task 4. Reporting}

The reports generated throughout the project were submitted to the project sponsors. Bimonthly letter reports provided updates on the overall project status. Project review meetings were held twice each year of the program. The information presented in the reports included field test data, detailed analytical results, interpretations, and conclusions. Listed below are the field reports and papers:

- Field Testing Allen S. King Unit 1

- Field Testing R.M. Schahfer Station

- Field Testing at Northern States Power's Sherburne County Unit 1

- Field Testing Hoot Lake Unit 2

- Studies on Calcium-Based Ash Deposition in Utility Boilers. Presented at the Conference on the Effects of Coal Quality on Power Plants, St. Louis, MO, September 19-21, 1991

- Ash Deposition at Low Temperature in Boilers Firing Western U.S. Coals. Presented at International Joint Power Generation Conference, San Diego, CA, 1991

- LEADER Software Package

The final report includes a description of the different types of low-temperature ash deposits, rates and mechanisms of deposition and strength development, the use of LEADER to predict the behavior of high-calcium coals with respect to low-temperature ash deposition, and recommendations of methods to mitigate the problems. Conclusions are given at the end of each relevant section of the report. The executive summary provides a succinct collection of the most important conclusions. 


\subsection{DEFINITION OF LOW-TEMPERATURE DEPOSITION PHENOMENA}

Two main types of fouling problems have been identified in the convective passes of utility boilers. They are grouped as high-temperature or conventional fouling, and lowtemperature fouling. The principal physical difference between the two types is the ash particle-to-particle bonding mechanism that strengthens the deposit. In high-temperature fouling, the bonding of particles is due to silicate liquid phases that flow and cement the deposit into a hard mass. Before Project Calcium was initiated, prarticle bonding in lowtemperature deposits was believed to be due to calcium sulfate because it dominated the deposit composition, and was believed to act as a matrix material that held the inert or aggregate ash particles together. Conventional high temperature deposits most often form in the secondary superheater region of the convective pass. Low-temperature deposition was known to occur often downstream of the secondary superheater, especially in boilers firing high calcium subbituminous coals. While low-temperature deposits form at a relatively slow rate compared to high-temperature fouling, some types are resistant to soot blowing because they develop strength very rapidly. Moreover, low-temperature fouling occurs in convective pass zones which typically have less soot-blower coverage than highertemperature zones. Utility experience has shown that low-temperature fouling can cause long-term deterioration of convective pass heat transfer surfaces, leading to an inability to reach reheat steam temperatures, boiler derates resulting from high gas exit temperature from the boiler convective pass, and also forced outages from convective pass plugging. It is especially significant in boilers designed for eastern U.S. coals that had switched to burning the lower-sulfur, high-calcium, western coals.

As the use of western coals in utility boiler systems grew rapidly in the early 1980s, the recognition of the low-temperature deposition phenomena also grew. However, the slow growth of the deposits and relatively frequent switching of fuels made it difficult to define the fuel and boiler operational parameters that led to the formation of the deposits. Reports of different deposition locations, as well as different types of deposits, were primarily anecdotal and were often contradicted by engineers in the same plant. Therefore, one of the first tasks of Project Calcium research was to define where in a typical utility boiler the low-temperature deposition problems occur. Once the a:eas were defined, the types of deposits peculiar to a given area, along with its formation mechanisms, were delineated. Then the rates of deposition and strength development in the deposits were determined for use in the predictive model.

\subsection{Problem Definition}

The definition of the types of low-temperature deposits and the regions of the convective pass in which they form were determined by intensive sampling efforts at the first three utility boilers tested in Project Calcium. These sampling efforts included collecting deposits during a scheduled outage from the convective pass of the NIPSCO Schahfer Unit 14 (468-MW cyclone), and collecting on-line samples at the Schahfer Station as well as at the NSP King Unit 1 (600-MW cyclone) and Sherco Unit 1 (750-MW pc). Parameters investigated included the effects of coal type, firing method (cyclone versus pulverized coal), and load changes on deposit types, compositions, and deposition rates versus position within the convective pass. The effects of coal type and firing mode were determined by firing the King and Sherco plants on coals from the Black Thunder and Antelope mines of the Powder River Basin, Wyoming. The effect of load on the deposits was determined by firing the Schahfer Station at two loads while burning coal from the 
Shoshone mine, Hannah Basin, Wyoming. Sampling involved collecting coal, convective pass deposits, entrained ash, fly ash, slag in cyclone-fired systems, and hopper ash for detailed characterization using advanced inorganic analysis techiniques.

Figure 3 is a schematic of the top of Schahfer Unit 14 that shows the locations where off-line deposit samples were collected, along with approximate gas temperatures at the typical daytime load of the previous month. The temperatures were interpolated based on load by comparing with data collected during on-line testing. All deposits were taken from the upstream sides of tube surfaces except Number 5, which was collected from the downstream side of a steam tube. Figure 4 shows the concentrations of silicon, calcium, and sulfur in the off-line deposits as a function of approximate gas temperature at the sampling point. The values are listed as oxide weight percents on an $\mathrm{SO}_{3}$-free basis, except for the $\mathrm{SO}_{3}$ value which is normalized with the other major oxides. The data for Sample 5 were not connected with a line to the other data because Sample 5 was collected from the downstream side of a tube. The data show that the concentrations of silicon and calcium in the upstream deposits increase slightly with temperature in the pass, possibly because calcium silicate particles are stickier at higher temperatures and so are more likely to stick to the boiler surfaces they contact than other ash particles. The changes in sulfur concentration are much more dramatic. The deposits collected from positions that were at or below approximately $1900^{\circ} \mathrm{F}\left(1038^{\circ} \mathrm{C}\right)$ contain much higher concentrations of sulfur than those collected from higher temperature regions. Through laboratory studies performed as part of Project Calcium (discussed in Section 3.0), it was found that the increase occurs not because the dewpoint of sulfate species has been

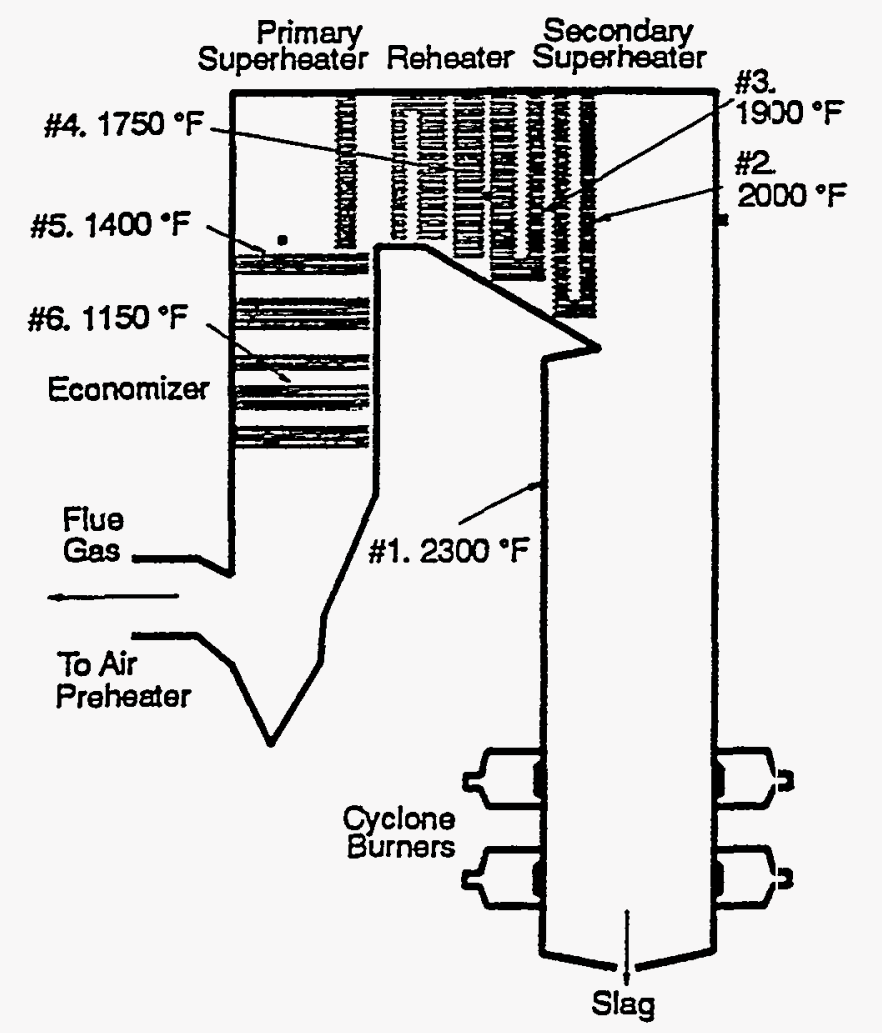

Figure 3. Locations and baseload gas temperatures where off-line deposits were collected. 
reached, but because below that temperature some of the alkaline elements are more stable as condensed sulfates than at higher temperatures. Sample 5, collected from the downstream side of a tube, has the highest sulfur content, most likely because it could not be eroded or soot blown and so had the most time to sulfate. The $\mathrm{CaO} / \mathrm{SO}_{3}$ ratio indicates that the calcium was fully sulfated in Sample 5. Because it presents an easy demarcation parameter, the sulfur content of the deposits is used to define the zones of high- versus lowtemperature fouling. By this definition, low-temperature fouling occurs below approximately $1900^{\circ} \mathrm{F}$ in a boiler firing a high-calcium subbituminous coal. Some viscous sintering of silicate glasses in the ash may continue below this temperature, but the deposit is dominated by the presence of sulfated ash.

Figure 5 shows the concentrations of phosphorus, sodium, and potassium in the offline deposits on an $\mathrm{SO}_{3}$-free oxide basis. Like sulfur, phosphorus, sodium, and potassium are depleted in the higher-temperature deposits, but relatively eririched in the lowtemperature deposits. Those elements, like sulfur, are primarily present in the fuels in an organic or other association that causes them to be vaporized during combustion of the coal. As the gas temperature drops below approximately $1900^{\circ} \mathrm{F}$, the elements are fixed from the gas stream either because they are more thermodynamically stable in a condensed form (like sulfur), or because the dewpoint of a compound has been reached. The concentrations of aluminum, iron, and magnesium in the deposits are shown in ligure 6 on an $\mathrm{SO}_{3}$-free oxide basis. Unlike sulfur, phosphorus, sodium, and potassium, these elements are not stable in a gaseous form and so exist as solids everywhere in the boiler. Therefore, like silicon and calcium, their concentrations in the deposits change little with temperature, although the chemical associations of the elements may change.

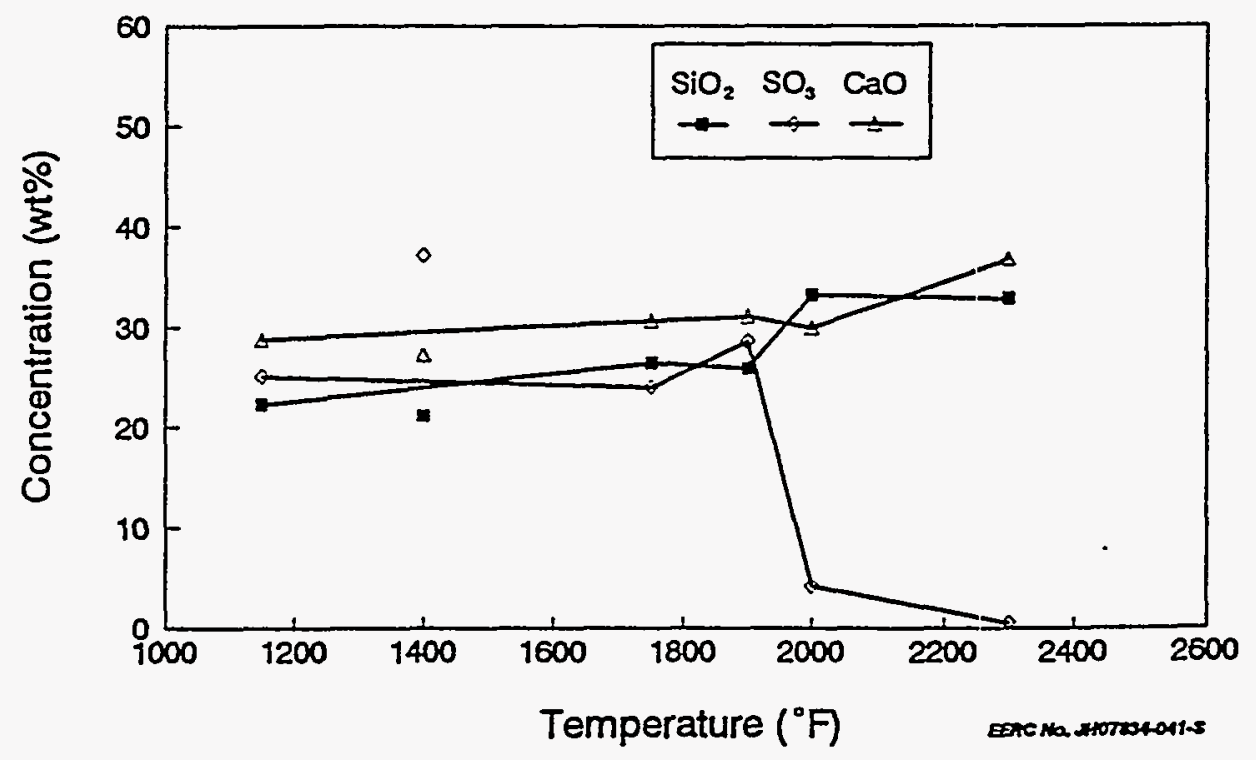

Figure 4. Concentrations of silicon, calcium, and sulfur in off-line deposits $\left(\mathrm{SO}_{3}\right.$-free oxide basis). 


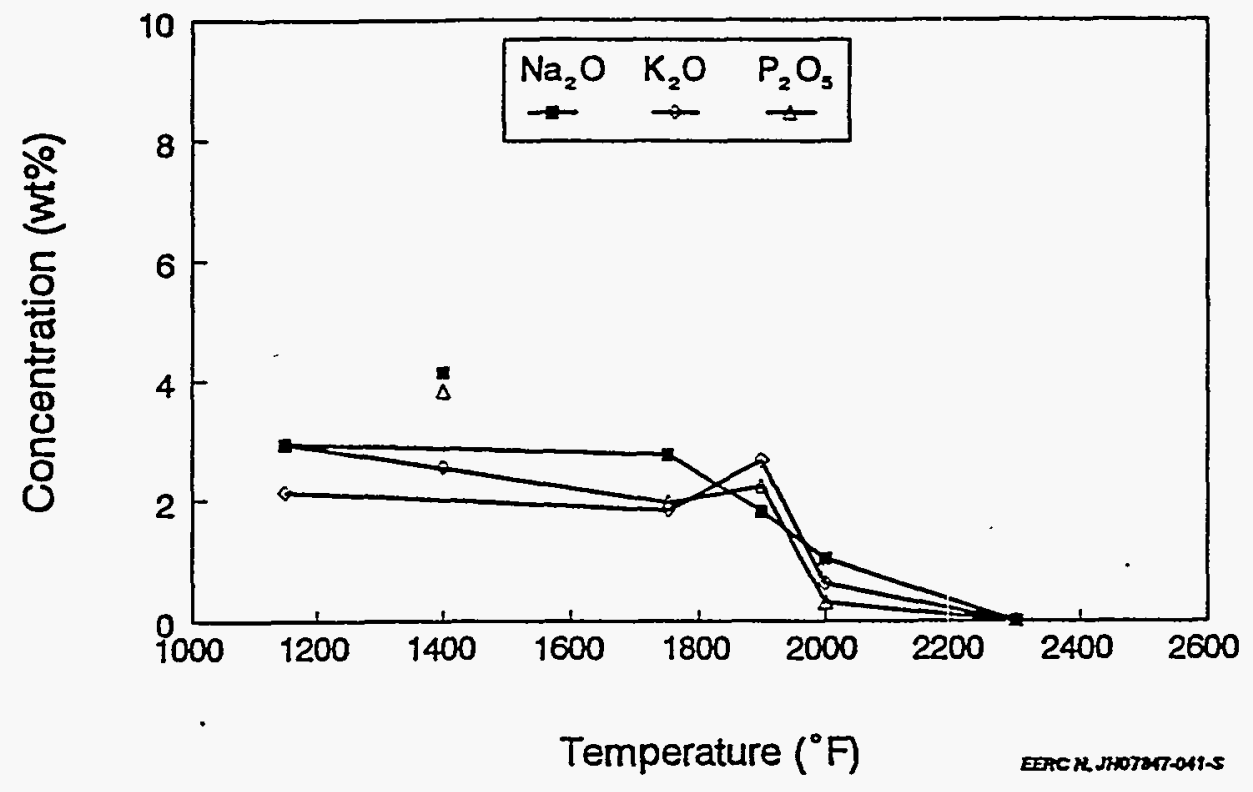

Figure 5. Concentrations of phosphorus, sodium, and potassium in off-line deposits ( $\mathrm{SO}_{3}$-free oxide basis).

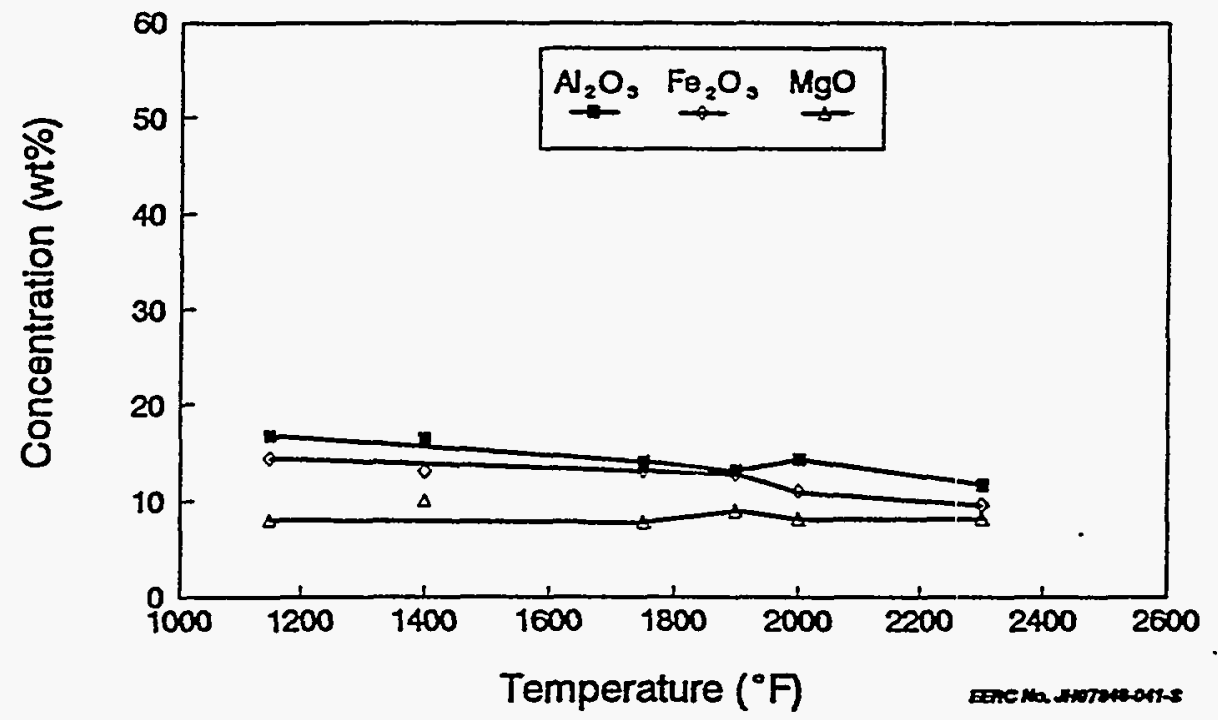

Figure 6. Concentrations of aluminum, iron, and magnesium in off-line deposits (SO-f $_{3}$-free oxide basis). 
As is true for the chemical composition of the deposits, the physical nature of ashfouling deposits varies dramatically through the convective pass. Four or five distinct deposit morphologies were commonly found in boilers burning high-calcium western U.S. coals. They include conventional, or high-temperature fouling deposits, and four types of low-temperature deposits known as upstream massive, upstream enamel, double-crested upstream, and downstream powder deposits. The conventional fouling deposits formed on the upstream (windward) side of steam tubes in secondary superheater regions are massive and appear much like sandstone, although in certain cases they have completely fused into molten masses. By the definition given here they do not contain sulfur, and they form at temperatures above approximately $1900^{\circ} \mathrm{F}$. Figure 7 shows sintered islands of ash on the upstream side of the short-duration deposition probe coupon that are examples of precursors to the formation of massive deposits. The light patches are areas from which sintered islands have fallen, exposing the inner powder layer of the deposit. With time, the islands grow and contact each other to form massive sintered deposits. As Figures 4 through 6 indicate, they are composed primarily of silicon and aluminum glasses that are fluxed with sodium, magnesium, calcium, or iron depending on the concentrations of those elements in the coal. As the ash passes back into the convective pass and cools, the fundamental nature of the deposits changes.

In the reheater region, temperatures drop below $1900^{\circ} \mathrm{F}$ allowing $\mathrm{SO}_{2}$ in the gas to react with calcium and other elements in the deposits to form sulfates which are indicative of low-temperature deposits. The massive deposits that form on the upstream side of the reheater tubes are less lustrous than conventional fouling deposits. They are often dull reddish or brownish in color. They can be very massive and hard, almost always occurring

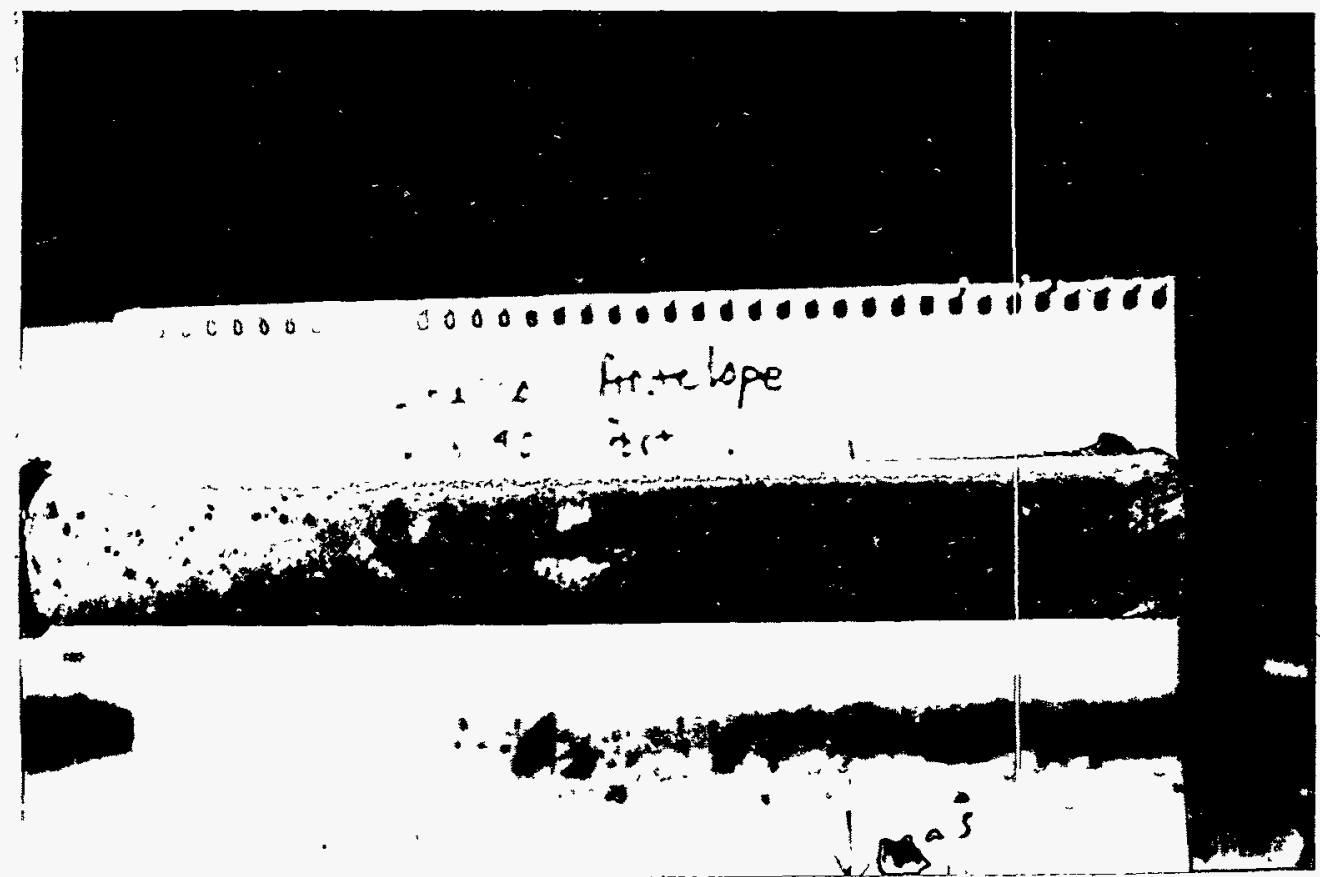

Figure 7. Upstream side of the deposition probe coupon showing the presence of conventional fouling deposit islands formed at a gas temperature above $2000^{\circ} \mathrm{F}\left(1093^{\circ} \mathrm{C}\right)$. 
as a fin whose base covers the tube, and extending a foot or more into the gas stream forming a sharp ridge. Figure 8 shows a side view of such deposits at the NIPSCO

Schahfer Station. The area at the bottom of the figure where the workman is standing and the deposits have been cleared shows the path of a soot blower. Such paths are common in boilers burning high-calcium western U.S. coals. They tend to be approximately 10 to 15 feet in total height, and indicate that soot blowers need to be more closely spaced vertically in this region to prevent the accumulation of these massive upstream deposits. Such deposits do not normally grow dramatically in width to close off the flow through the region unless the boiler design permits a region of gas turbulence that will make the direction of growth transverse to the rest of the gas stream, or unless a piece of a deposit breaks off and lodges between plenums. If this occurs, the broken. piece acts as a seed that initiates rapid growth of blocking deposits.

Farther back in the pass, gases cool to the point that the ash particles are no longer sticky and massive deposits on the upstream sides of tubes no longer form. Instead, a thin, hard, enamel-like coating forms on the upstream sides of the tubes. Figure 9 shows the removable coupon from the short-duration deposition probe after collecting a deposit at the NSP Sherco Station above the economizer of Unit 1. When formed at higher temperatures, this layer is essentially hard upon deposition; i.e., strength does not need time to develop.

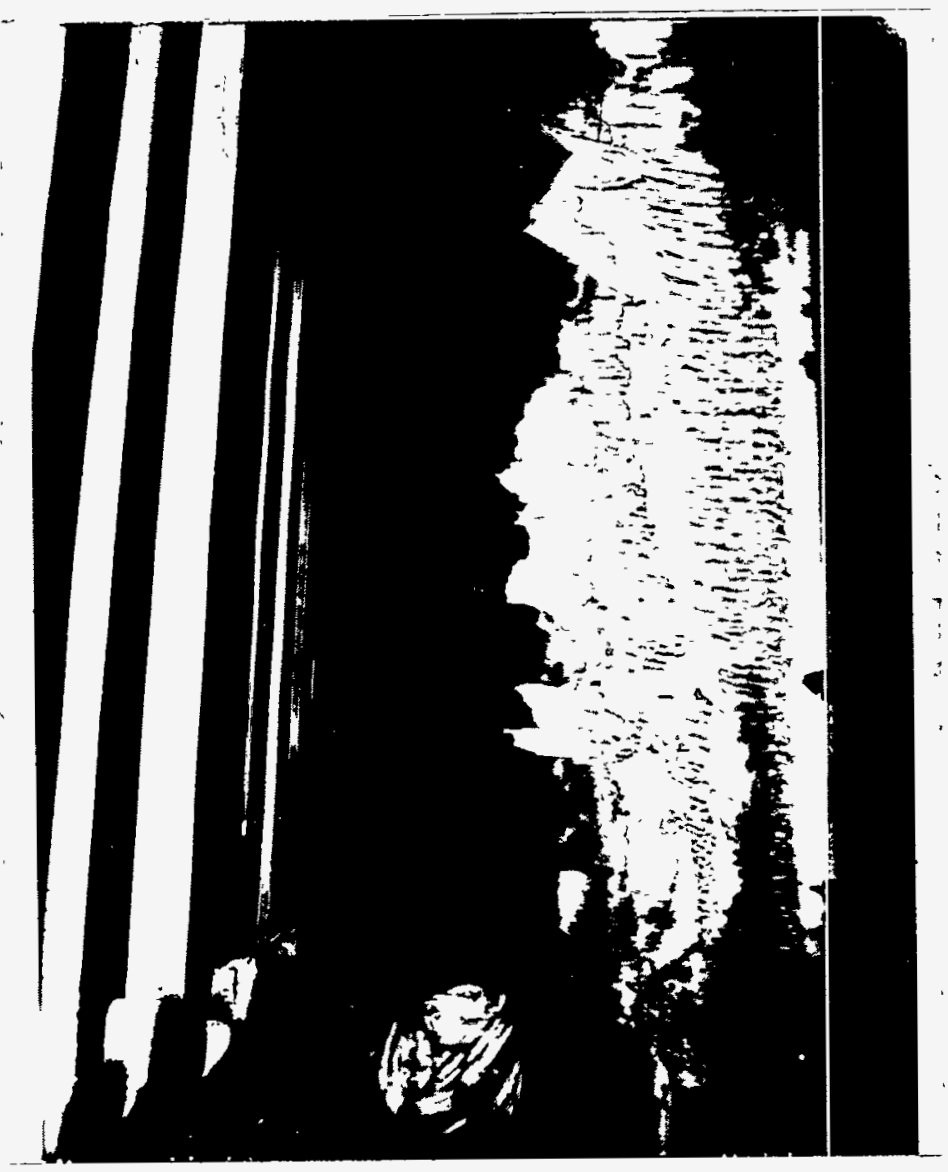

Figure 8. Massive upstream deposits on lead tubes in the reheater tube banks of a boiler burning a high-calcium western U.S. coal. 
At lower temperatures, strength is not immediate, but does develop quickly. Therefore, soot blowing of these deposits is less effective than with most other types of deposits.

Effectiveness could possibly be improved if thermal shocking is significant, such as when using water as the blowing medium. Off-line removal of the deposits is equally difficult. One Project Calcium sponsor reports great difficulty in removing them with high-pressure water sprays, although another reports that an overnight soaking with acidic river water sprayed with lawn sprinklers made them easily removable. Because these deposits are well-sintered in a short time, and because they tend to be thin and build slowly, they do not dramatically impede heat transfer. However, the layer can act as a capture surface which absorbs the energy of incoming ash particles so that they stick to the steam tubes at lower temperatures than if the layer were not present. In this way, they can initiate the formation of a massive deposit. This is believed to be the method of initiation of the upstream massive low-temperature deposits. In addition, because the enamel layers are rich in sulfur, they can corrode the tubes at higher temperatures, although at the lower skin temperatures of the primary superheater and economizer tubes, corrosion is usually not a problem.

The third type of low-temperature deposition occurs on the downstream sides of steam tubes all through the convective pass. An example can be seen on the downstream side of the sample coupon shown in Figure 9. Such deposits occur all through the convective pass of a boiler, but usually become much thicker in the horizontal steam- and water-tube banks of the primary superheater and economizer. These deposits do not bond to the tube surface.

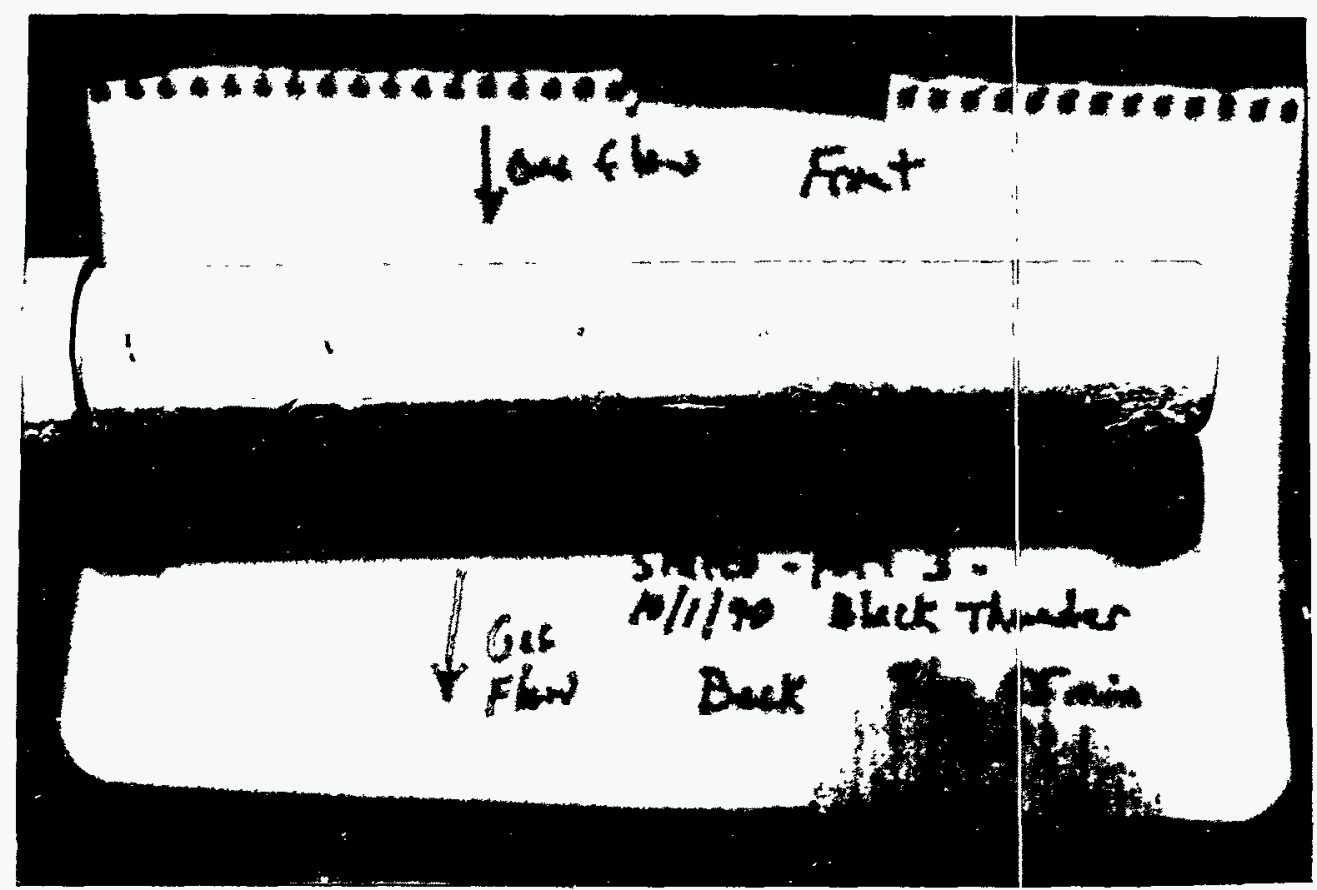

Figure 9. Short-duration deposition probe coupon showing both upstream enamel and downstream powder low-temperature deposits. 
Sintering of this type of deposit collected on probes is only evident on the outer edges as they become thicker, although light sintering is evident in deposits formed in utility boilers over periods of months. Instead, the deposits are usually powdery or very friable, and often shed from vertical tube banks. However, they can completely fill the interstitial spaces between steam tubes in a plenum, especially in horizontal banks. If soot-blower coverage is not available and if there is some turbulence so that the deposits grow between plenums, they can grow to block flow. Also, because these deposits are poorly sintered and can cover over one half of the tube surface in a bank, they significantly reduce heat transfer in banks where they are prevalent. Because the lead tubes in a bank protect them from the sootblower blast, they can form in the immediate vicinity of soot blowers, although in such cases they will not grow between plenums. One Project Calcium sponsor reports that the deposits can be removed 3 to 5 tubes deep in a bank by angling the soot-blower nozzles 15 degrees from the perpendicular to the soot-blower path.

The last type of low-temperature deposit does not form often and usually would not impede heat flow significantly, although they are very hard and exceptionally difficult to remove. The deposits are composed of two crests or humps that form on either side of the upstream center line of the tube, often leaving the center line bare. They most likely form from a specific size range of ash particles that diverge slightly with the gas around the tube, but then separate from the gas flow and impact the tube. Removal of these deposits is expected to be similar to that of the upstream enamel deposits.

Three types of deposits were routinely formed on the EERC ash-deposition probes in the convective passes of each of the utility boilers. High-temperature conventional upstream deposits, low-temperature upstream enamel coatings, and low-temperature downstream powder layers. None of the massive, low-temperature deposits that develop on the upstream side of the lead tubes in reheater banks have been developed on the EERC probes, despite targeting some later sampling efforts specifically at growing these deposits with the LDDP. Also, none of the less common double-crested deposits were collected.

High-temperature conventional upstream deposits formed on the probe when sampling in secondary superheater regions and near the front of reheaters when operating at baseload. Larger deposits formed only at the end of the sample coupon, most likely because of the turbulence at the confluence of the cooling air and boiler gas. When sampling for longer times, massive deposits would also form all along the upstream side of the coupon. Over shorter times, most of the upstream side of the coupon would be covered with a thin, sintered coating upon which "islands" of more sintered ash were beginning to grow. The presence of deposit islands indicated that the growth stage was changing from that of inner to outer sinter layer formation. At lower temperatures, only the thin enamel coating formed on the upstream sides of the coupons. In contrast, powder layers formed on the downstream sides of the coupons at all sampling locations. The downstream deposits were up to several millimeters thicker than the upstream enamel coatings. During sampling for periods of up to five days with the LDDP, it was found that downstream deposits reached a critical thickness at which time shedding would occur. Although only one coal was tested with the LDDP, the critical thickness for shedding is coal specific and related to the rate of deposition versus the rate of strength development in the deposit. 


\subsection{Ash Deposition Mechanisms}

Figure 10 is a backscattered electron SEM micrograph of a polished cross section of the interface between the short-duration deposition probe sample coupon and a sintered ash island of a high-temperature conventional upstream deposit. The deposit formed so rapidly that a typical inner layer of fine dust had not had a chance to deposit. The micrograph indicates that only larger particles make up these deposits. However, the field of view of the SEM is very limited, and determining the size distributions of sintered particles is difficult. Therefore, a better indicator of the size range of particles that make up these deposits is a comparison of the bulk composition of the deposits with the aerodynamically sized ash particles collected during on-line sampling at the same boiler locations as where the deposits were collected.

Figure 11 shows the concentrations of the major elements in each aerodynamic size range as compared to the composition of the bulk deposit shown in Figure 10. The figure illustrates a point that is typical of ash particles formed during combustion of high-calcium western U.S. subbituminous coals. That is, larger particles tend to have higher concentrations of silicon and lower concentrations of calcium than smaller particles. The effect is particularly strong for the Powder River Basin (PRB) coals and much weaker for the Hannah Basin coal tested (Shoshone). The higher concentrations of silicon in the larger particles are due to the fact that quartz occurs in the coal as larger particles. The higher concentration of calcium in the smaller particles is because most of the calcium in the coals (especially the PRB coals) is organically associated. During combustion, this calcium is vaporized, but immediately condenses as small oxide particles. The variation in average composition of the particles with size has profound effects on the composition of deposits formed from a particular size range of particles. Deposits formed from smaller particles will have low silicon-to-calcium ratios, whereas deposits formed from larger particles will

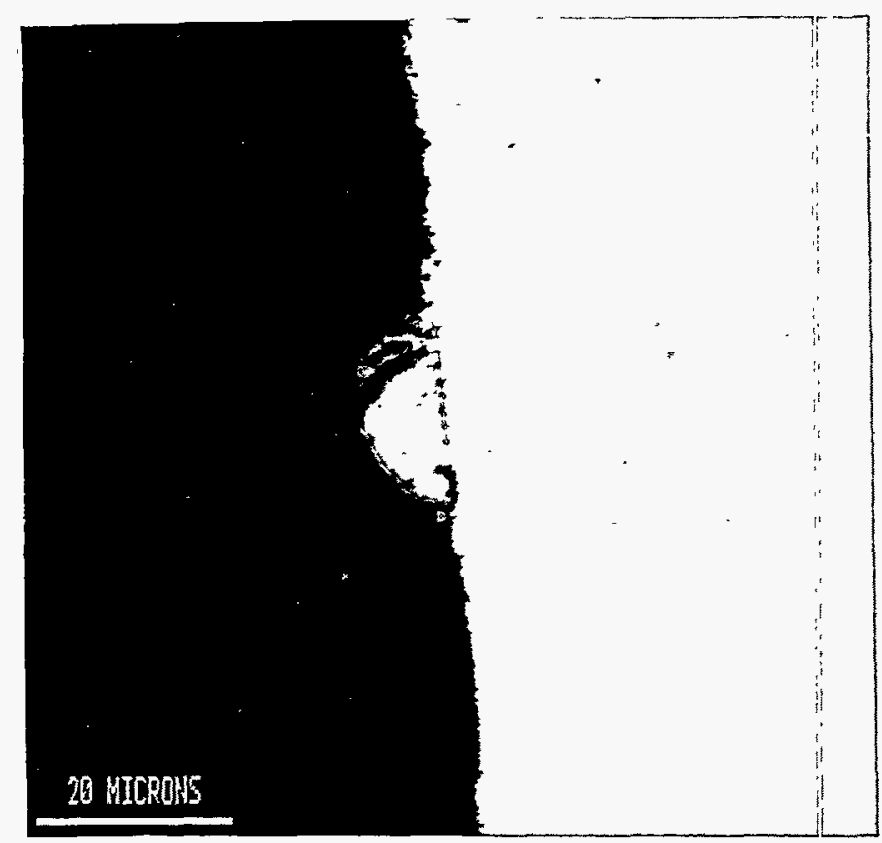

Figure 10. Backscattered electron micrograph of the interface between a conventional sintered ash island and the deposition coupon. 


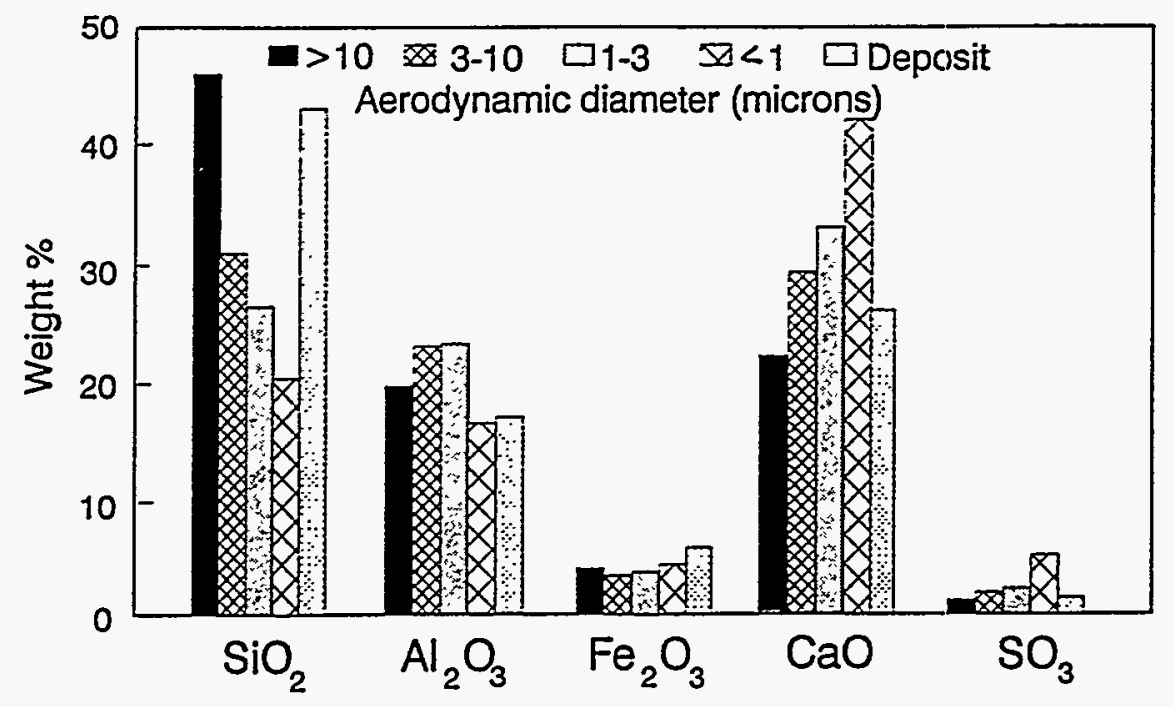

Figure 11. Comparison of the compositions $\left(\mathrm{SO}_{3}\right.$-free) of the aerodynamically sized entrained ash particles and a conventional fouling deposit.

have much higher silicon-to-calcium ratios. This effect can not be anticipated by standard ASTM analyses of the coal. The effect is strongly evident in the composition of the conventional fouling deposits. The SEM micrographs and compositions of the conventional fouling deposits indicate the deposits are formed primarily of ash particles with aerodynamic diameters over $10 \mu \mathrm{m}$. The relatively high inertia of such particles causes them to separate from the flow of gas as it diverges around the tube, and impact the tube surface. Figure 12 illustrates the process. The fractional efficiency for particle impaction is given by the ratio of the width of the gas stream from which a particle will impact (d) to the width of the tube (D). It is a function of the aerodynamic diameter of the particle and the gas velocity. At the relatively high temperatures in the region in which conventional fouling deposits form, the surfaces of the ash particles are sticky, so they adhere to the steam tube. The sticky material is composed primarily of silicate and aluminosilicate glass containing sodium, calcium, and/or iron which flux the glass making it considerably less viscous than if the flux were not present. The propensity for sticking is a function of the kinetic energy of the particle $\left(\mathrm{KE}_{\mathrm{p}}\right)$, the viscosity of the particle $\left(\mathrm{ML}_{\mathrm{p}}\right)$, and the viscosity of the deposit surface $\left(\mathrm{M}_{\mathrm{s}}\right)$.

At gas temperatures below $2000^{\circ} \mathrm{F}$, the conventional deposits did not form on the upstream side of the sample coupon. Instead, the thin, hard, enamel-like coatings formed. Figure 13 shows a cross section of the interface between such a deposit and the sample coupon. It shows that such deposits are formed of very small particles that have sintered together. Figure 14 shows a comparison of the compositions of the deposit and the aerodynamically sized ash particles collected at the same sampling position. The enamellike deposits have compositions very similar to particles with aerodynamic diameters of less 


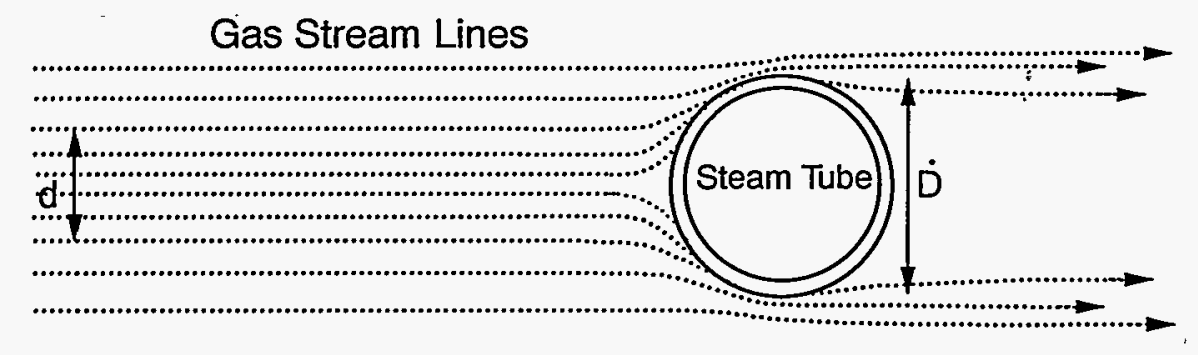

$$
\begin{aligned}
& \mathrm{d} / \mathrm{D}=\text { Impaction efficiency of system }=\mathrm{f}\left(A D_{p}, V\right) \\
& \text { sticking }=\mathrm{f}\left(\mathrm{KE}_{\mathrm{p}}, \mu_{\mathrm{p}}, \mu_{\mathrm{s}}\right)
\end{aligned}
$$

Figure 12. The inertial impaction process that leads to the formation of conventional fouling deposits.

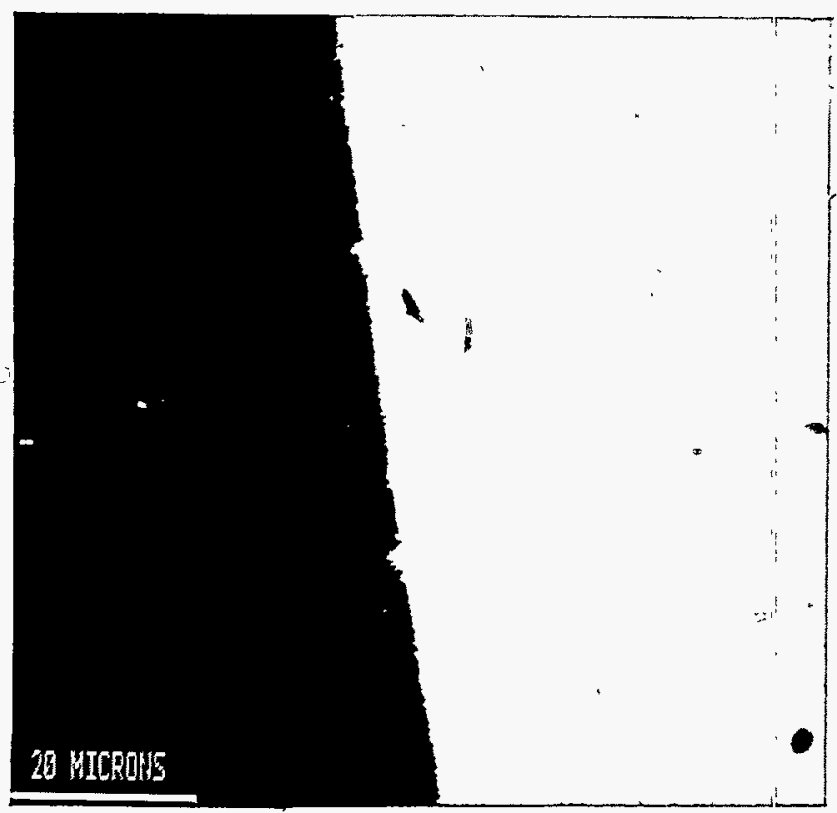

Figure 13. Backscattered electron micrograph of the interface between an upstream enamel deposit and the deposition coupon. 


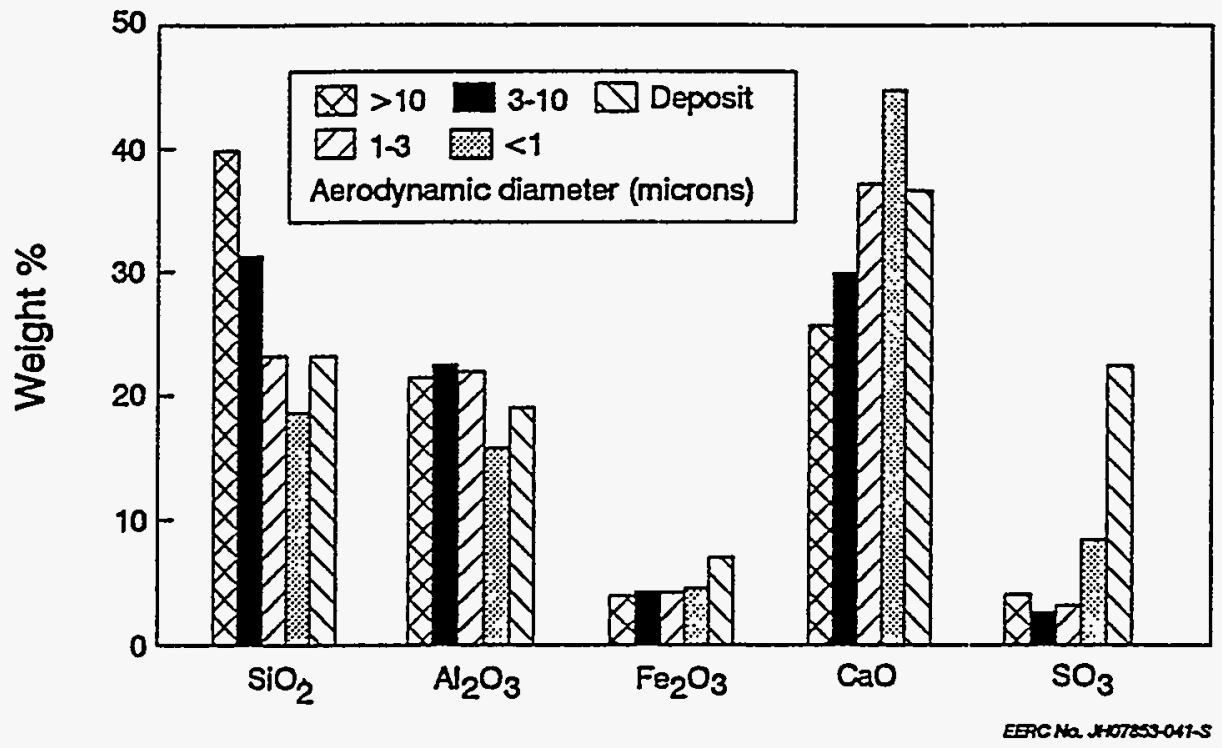

Figure 14. Comparison of the compositions ( $\mathrm{SO}_{3}$-free) of the aerodynamically sized entrained ash particles and an upstream enamel deposit.

than three microns. Particles this small separate from the flow of the gas under the influence of forces different from the simple inertial mechanism of the larger particles. Collectively termed small particle deposition mechanisms, they operate only in the boundary layer of stagnant gas immediately adjoining the heat-transfer surface. The mechanisms include thermophoresis which is caused by a temperature gradient, electrophoresis which is caused by an electrical gradient, and simple diffusion which is due to Brownian motion. Thermophoretic and electrophoretic deposition cease when the deposit has grown to the extent that it insulates the tube from the gas st:eam, preventing a gradient from occurring in the boundary layer. In contrast, diffusion will continue as long as incoming ash particles stick to the deposit. Since the small particles stick primarily through electrical or Van der Waals forces, it is believed that essentially all small particles that reach the enamel layer will stick. Another important property of high-calcium western U.S. subbituminous coal ash illustrated in Figure 14 is that the sulfur concentration in the low-temperature deposits is much higher than in the particulates entrained in the flue gas. This shows that most of the sulfation of the deposit occurs after deposition of the ash.

Figure 15 is an electron micrograph of a polished cross section of the interface between the sample coupon and a downstream powder deposit. The particles are generally smaller than those that form conventional fouling deposits, but much larger than those that form the upstream enamel deposits. Figure 16 shows a comparison of the compositions of the deposit and the aerodynamically sized ash particles collected at the same sampling position. The two figures show that the downstream powder deposits are composed 


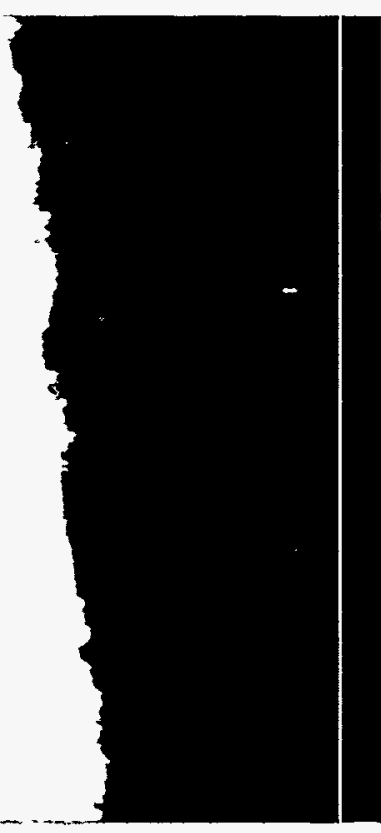

Figure 15. Backscattered electron micrograph of the interface between a downstream powder deposit and the deposition coupon.

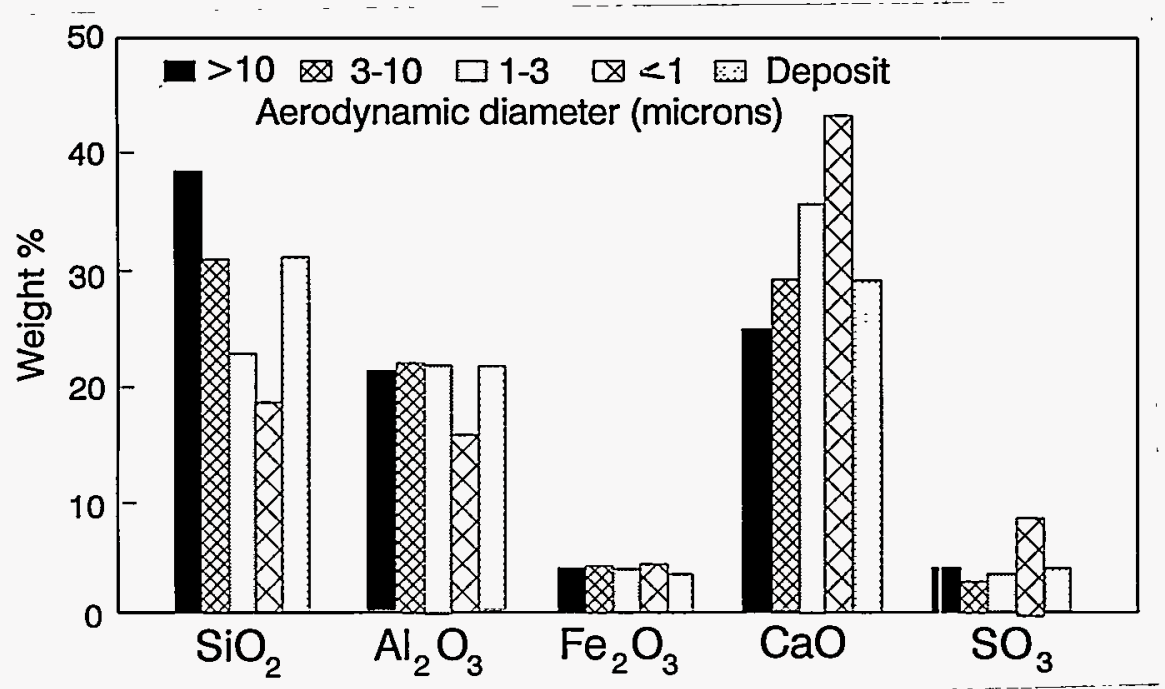

Figure 16. Comparison of the compositions $\left(\mathrm{SO}_{3}\right.$-free) of the aerodynamically sized entrained ash particles and a downstream powder deposit. 
primarily of particles with aerodynamic diameters of less than $10 \mu \mathrm{m}$, although some larger particles do deposit. The particles separate from the main gas flow in turbulent eddies that occur downstream of each tube. The particles are small enough that their inertia does not prevent them from being captured in the eddies.

At no time during the Project Calcium testing were massive, sulfate-based deposits formed on the upstream sides of sample coupons, even when sampling in regions of convective passes where such deposits are common. This indicates that they form over periods of greater than five days, which was the longest time that the LDDP was tested, at least when starting with smooth tubes. Analyses of this type of deposit collected from Project Calcium sponsor boilers show that the deposits are highly sulfated and highly sintered. Figure 17 is an SEM micrograph of a cross section of such a deposit illustrating the high degree of sintering. The deposits form in regions of the convective passes of boilers where temperatures are close to the critical sulfation temperature of the ash which is approximately $1900^{\circ} \mathrm{F}$. The authors believe that near this gas temperature, larger ash particles inertially impact the upstream sides of the tube and stick because the surface viscosity is low enough to permit sticking. Although low enough for sticking, the viscosity of the silicates is not low enough to permit rapid sintering because the gas temperature is relatively cool for that type of strength development. However, when gas temperatures are below $1900^{\circ} \mathrm{F}$, sulfation can occur, and strength develops through a combination of viscous flow sintering of the silicate matrix (caused by the presence of a small amount of sulfate in the silica) and the formation of a sulfate-based matrix that binds the ash aggregate into a

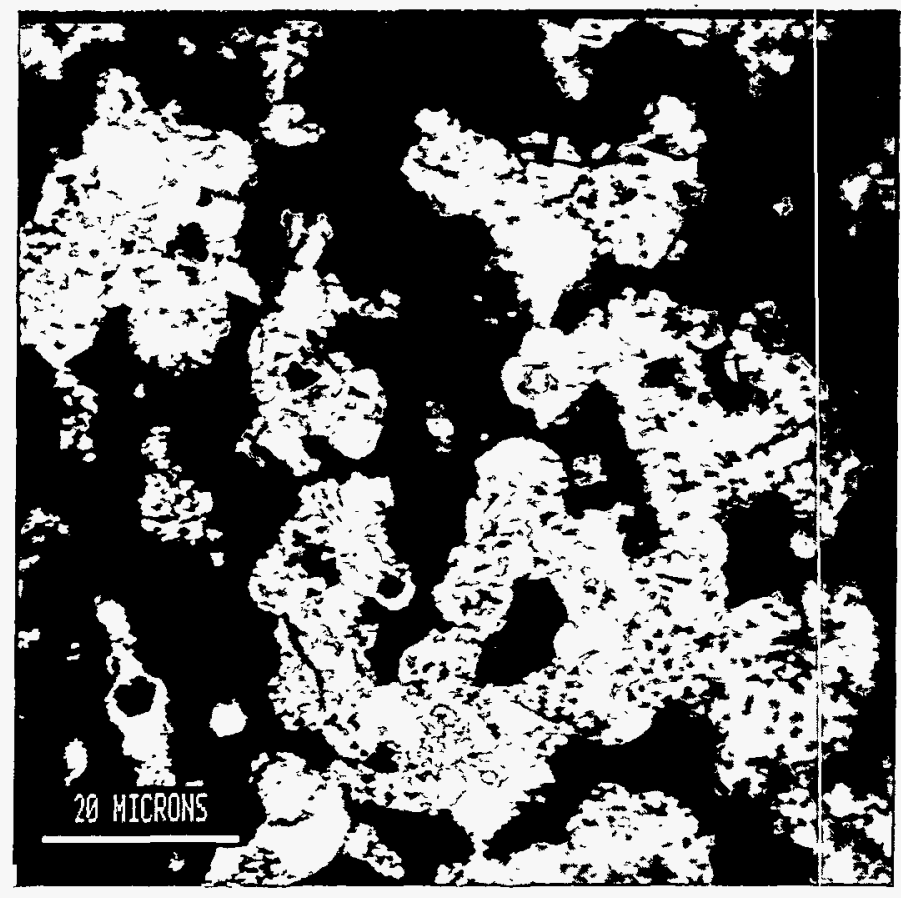

Figure 17. Backscattered electron micrograph of a cross section of an upstream massive deposit collected from a utility boiler. 
hard deposit. The presence of a small amount of sulfate in the silicate glass is believed to increase its surface tension and increase the rate of sintering. This process is exploited in the glass-making industry in a process known as "fining" where small amounts of sulfates are added to increase surface tension and cause small bubbles in the glass to dissolve. Sintering caused by the formation of sulfates is rapid at these temperatures and likely occurs almost as fast as the deposition of ash, causing the deposit to become hard as it forms. Unfortunately, this process is difficult to simulate in laboratory tests, so bench-scale measurements of the rates of strength development in this kind of deposit were not made in Project Calcium. If, after deposition, load is raised and the gas temperature increases above $1900^{\circ} \mathrm{F}$, sulfation ceases to occur, and some decomposition of sulfates takes place. If decomposition is not complete by the time of the next reduction in load, then a net gain in sulfate matrix occurs, and the deposit is stronger than if no load reduction had occurred because of increased silicate sintering caused by the presence of the sulfate and because of the additional sulfate matrix. However, such decomposition may also weaken the deposits for a short time. Therefore, it may be possible to reduce the formation of such deposits by blowing soot in regions where the gas temperature has either recently risen above or dropped below $1900^{\circ} \mathrm{F}$ due to load changes.

\subsection{Low-Temperature Deposition Rates}

Deposition rates of the upstream enamel and downstream powder deposits were determined through LDDP testing at the Ottertail Power Company Hoot Lake Station and the SWEPCO Welsh Station when firing on Eagle Butte Wyoming subbituminous coal. No data are available for deposition rates for the upstream massive or double-crested deposits. At Hoot Lake, the boiler was kept at a constant load for the entire duration of the tests. The short-duration and long-duration deposition probes were used to collect deposits in the reheater region of the convective pass for time periods of 11/2 hours, 8 hours, 11/2 days, and 5 days. No massive upstream deposits were formed on the probes during these times. It was, therefore, believed that they did not form because the load was not cycled to cause the gas temperature at the sampling point to fluctuate above and below the critical sulfation temperature (approximately $1900^{\circ} \mathrm{F}$ ). Temperature cycling was considered important because comparisons of the compositions of off-line deposits collected at the NIPSCO Schahfer Station with gas temperatures measured during on-line testing indicated that massive upstream low-temperature deposits had formed in regions; where the gas temperature was much above the critical sulfation temperature during operation at baseload, but below the critical sulfation temperature during lower, nighttime loads. It was later found that the Schahfer Station boiler was operating at much less than baseloads before the outage during which the deposits were collected. By interpolating linearly between the temperatures measured at high and low load to the middle load at which the boiler operated before the outage, it was found that the massive deposits had formed at a temperature much closer to the critical sulfation temperature than originally believed. This weakened, but did not eliminate, the hypothesis that load swing was important in the development of the massive upstream deposits.

Because the question of the importance of load swing in the formation of upstream massive deposits was still open, the tests at the SWEPCO Welsh Sitation were designed to definitively determine load-swing importance and to gather data on deposition rates at different loads. The Welsh Station was operated during testing at a generally constant daily schedule with the load being held close to $500 \mathrm{MW}$ for approximately 11 hours, then $250 \mathrm{MW}$ for the remaining 13 hours in a day. Deposit samples were collected for periods of 
8 hours at low load, 8 hours at high load, 1 day (complete load cycle), and 5 days (5 cycles). At no time were upstream massive deposits formed. In fact, existing upstream deposits on steam tubes in the vicinity were eroded during the testing with Fagle Butte coal. This indicates that load swings are not the decisive factor in the development of those deposits. Instead, it is believed that temperatures must be near, but below, $1900^{\circ} \mathrm{F}$, and enough time (longer than 5 days) must be given to generate a sufficiently thick upstream enamel layer to permit the capture of larger particles that are believed to make up the bulk of those deposits.

Although upstream massive deposits were not developed during the Welsh Station testing, many valuable data were gained about the formation rates for upstream enamel layers and downstream powder deposits. Understanding the downstream deposition rates is especially important because those deposits can drastically reduce heat transfer to horizontal primary superheater and economizer tubes.

Figure 18 shows the weight of upstream enamel deposit per square inch of coupon cross section versus time for the tests at Hoot Lake and Welsh Station. The two data points at 8 hours for the Welsh Station tests are for the high load (upper point) and low load (lower point) tests. The deposition rates are given by the slopes of the curves. A constant upward slope implies that the deposit grew at a steady rate over the 5 days of the longest test. A curve that increases initially and then levels out to stay at a constant weight implies that deposition has ceased because the deposit weight has reached a critical maximum value. Such critical weights may be reached due to deposit shedding, or because the force driving deposition has been removed. If the dominant deposition mechanism is thermophoresis or electrophoresis, deposition will slow and stop when the coupon becomes insulated from the surrounding gas so that there is no temperature or electrical gradient through the boundary layer of gas next to the tube. If the dominant mechanism is diffusion, the particles will continue to deposit and, it is assumed, stick to the deposit to make it grow. If the dominant mechanisms are related to aerodynamics such as inertial impaction and eddy deposition shown in Figure 19, then deposit growth rate will change as the aerodynamics of the growing deposit change.

It should be noted that the measured ash flux at most of the boilers was only around $50 \%$ of the ash flux calculated from coal and air feed. The ash fiux is the rate at which ash passes through a unit area of the pass in a unit time. Although some of the ash undoubtedly fell to the bottom of the boiler, in our opinion the average ash flux still should have been higher than $50 \%$ to $60 \%$ of the input. The low measured value indicates that the ash flux near the walls of the convective pass is lower than the average. Therefore, the deposition rates presented here, or calculated by LEADER, should be used for relative comparisons of coals or firing conditions, rather than for calculating actual deposit weights.

The generally increasing enamel-layer weights shown in Figure 18 indicate that the deposits steadily grew over the 5 days of the longest test. Shedding is not believed to be significant for these deposits, but it was originally thought that deposit growth would slow because thermophoretic and electrophoretic deposition would decrease as the deposit became thicker. The relatively constant growth of the deposits indicates that diffusion may play a more significant role in deposition of these fine particles than originally thought. 


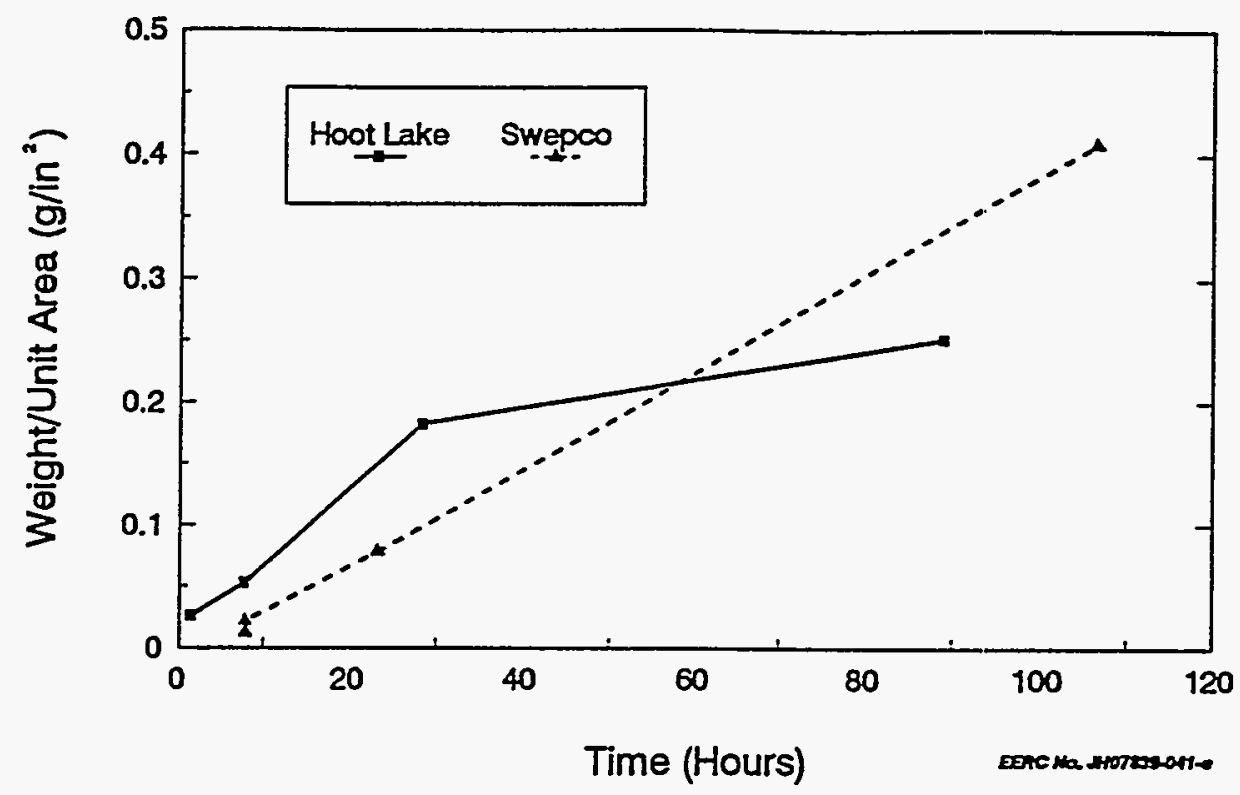

Figure 18. Weight of upstream enamel deposit per unit area of tube versus time as measured in LDDP tests at Hoot Lake and Welsh Stations.

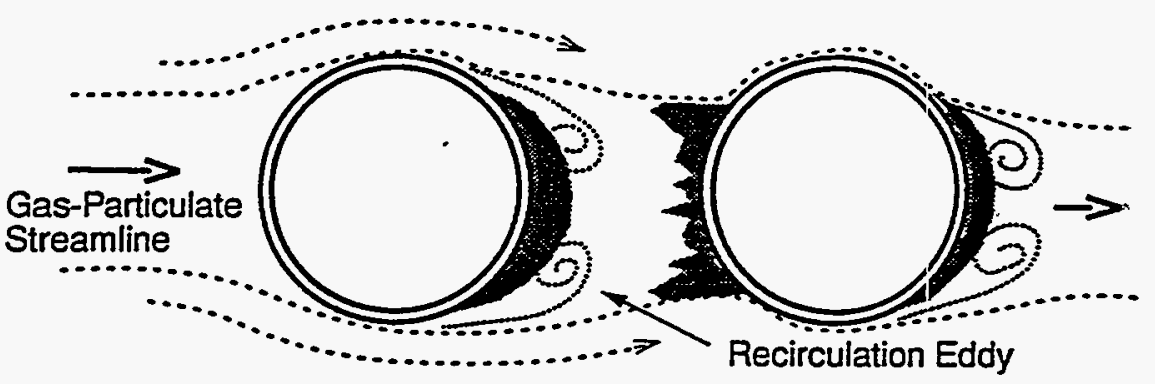

Figure 19. The eddy impaction process that leads to the formation of downstream powder deposits.

Figure 20 shows the weight of downstream powder deposit per unit cross sectional area of LDDP coupons versus time for tests at the Hoot Lake and Welsh stations. The deposition rates for this type of deposit are the most important to power plant operation since these deposits can greatly reduce heat transfer, especially in the horizontal tube banks. The decrease in slope of the Hoot Lake deposits after the \&-hour test is most likely due to shedding of the deposits after they reached a density of approximately 2 grams/square inch. Shedding was observed by the sampling crew. 
In contrast, the Welsh Station deposits did not shed, even after 5 days.

Understanding why the Hoot Lake deposits shed and the Welsh Station deposits did not, when both plants were firing coal from the same mine, gives us an important insight into the mechanism of strength development. Comparisons of the compositions of the deposits with the compositions of the ash collected at the same locations show that the Hoot Lake downstream deposits were somewhat enriched smaller particles, but generally formed from all size ranges of particles. At Welsh Station, as was common at the other plants tested, the compositions of the downstream deposits indicate that they were formed primarily from particles with aerodynamic diameters of less than 10 microns.

In general, larger ash particles such as in the Hoot Lake deposits sinter more slowly than smaller particles, therefore they build strength less quickly such as in the Welsh Station deposits. In addition, ash from a broader size range was depositing at Hoot Lake, so the deposition rate was higher (at least initially) than at Welsh Station. In other words, the rate of deposition compared to the rate of strength developmeint was higher at Hoot Lake than at Welsh Station, so the deposits were more likely to shed. This ratio is important in understanding the potential for shedding of a deposit and so has been defined as the shedding index. For reference it is given as Equation 1:

$$
\text { Shedding Index }=\frac{\text { Depositition Rate }}{\text { Strength Development lRate }}
$$

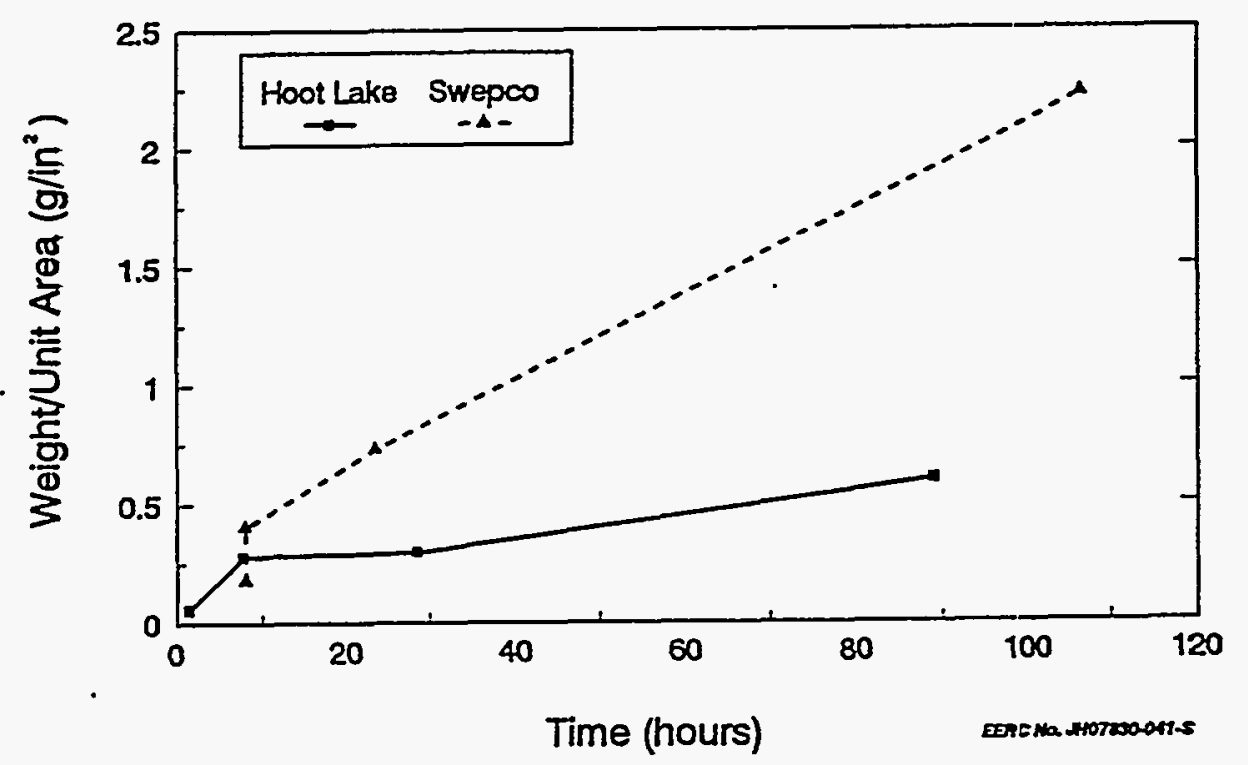

Figure 20. Weight of downstream powder deposit per unit area versus time as measured in LDDP tests at Hoot Lake and Welsh Stations. 
A high shedding index implies deposits will form quickly, but shed under their own weight. A low shedding index implies that deposits will form slowly, but develop more strength and will be less likely to shed under their own weight. It is very unlikely, however, that a downstream deposit will get as hard as a massive upstream deposit. But it is possible that in a region not covered by soot blowers where there is some turbulence, the deposits could grow outward to block gas flow.

An important question remains: what was different about Hoot Lake and Welsh Station that allowed larger ash to deposit on the downstream side? In addition, could this difference be exploited to increase the shedding index? The reason for the increased size of ash depositing on the downstream side of the coupon at Hoot Lake is most likely the slow gas velocity in the convective pass at the relatively low load at which the tests were performed. At Hoot Lake the gas velocity was approximately 27 feet/second for all tests, whereas at Welsh Station it was 43 feet/second at low load and 71 feet/second at high load. At the lower Hoot Lake velocities, the larger particles have less inertia and so can get trapped more easily in the downstream eddies which form the deposits. Can this be exploited to increase the shedding index? Most likely not, since load will need to be dropped much below the normal low-load range of a 500-MW boiler in order to push the depositing size range sufficiently high. However, as discussed in Section 3.0, it may be possible to introduce additives that will increase the shedding index.

In order to use the deposition rate data effectively in LEADER, the computer model for predicting low-temperature deposition rates based on coal analyses, it is necessary to compare the rate of ash deposition with the measured ash flux to determine the fraction of ash moving toward a tube that actually deposits. Only the flux of ash in the size range of particles that form the deposits is used to calculate the deposition fractions. The ranges are less than 10 microns aerodynamic diameter for the downstream cleposits and less than 3 microns for the upstream enamel deposits. Figure 21 shows the fraction of the ash of the proper size range initially moving at the LDDP coupons that actrially deposited on either the upstream or downstream sides. Only Welsh Station data is available for this calculation since the supply of Eagle Butte coal was inadvertently exhausted before ash flux determinations could be made at Hoot Lake. The three data points for each of the upstream and downstream sides correspond to the 8-hour tests at high load (highest point), low load (lowest point), and average of the two (middle point). For time periods longer than 8 hours, the load was cycled between approximately $500 \mathrm{MW}$ for 11 hours and $250 \mathrm{MW}$ for 13 hours a day. Each of the longer tests began at the start of a period of high load and ended at the end of a low-load period. The ash flux used in calculating the deposition fractions for these tests is the weighted average of the high- and low-load fluxes.

The relative flatness of the upstream deposition fraction curve indicates that a constant fraction of the ash deposits on the upstream side of a steam tube for at least the first 100 hours of operation after starting with clean tubes. During this time, the enamel layer grew to a thickness of several tens of microns. The constant deposition fraction indicates that diffusion may play a dominant role in the formation of these deposits since thermophoretic and electrophoretic deposition should decrease as the deposit thickness increases. In contrast, the deposition fraction for the downstream side decreases with time, most likely because the presence of the deposit makes the tube more aerodynamic, reducing downstream turbulence. 


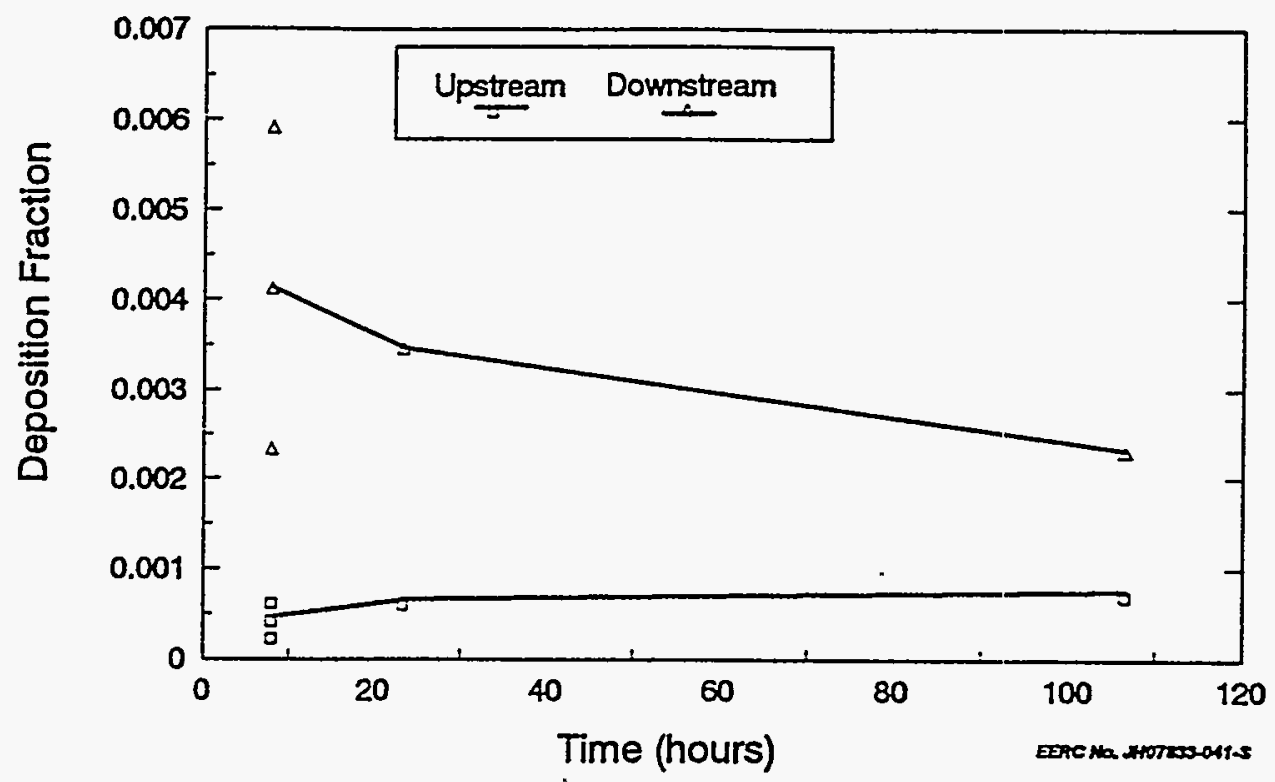

Figure 21. The fraction of the ash initially flowing at the LDDP coupons that actually deposited on both the upstream and downstream sides while testing was done at the Welsh Station.

The deposition fractions used for LEADER calculations are the averages of the highand low-load values measured at Welsh Station. The high-load fraction for the upstream deposits was $6.2 \times 10^{-4}$, in other words, $0.062 \%$ of the less than 3-micron-aerodynamicdiameter ash originally moving toward the coupon actually ended. up stuck to the upstream side. The low-load fraction was $2.2 \times 10^{-4}$, or $0.022 \%$, so the average value used in LEADER is $4.2 \times 10^{-4}$ or $0.042 \%$.

The downstream deposition fractions were much higher than those measured on the upstream side. The downstream deposition fraction at high load was $5.9 \times 10^{-3}$; in other words, $0.59 \%$ of the less than 10-micron-aerodynamic-diameter ash moving toward the coupon actually deposited on the downstream side. At low load, the fraction was $2.3 \times 10^{\mathrm{s}}$, so the average value used in LEADER is $4.1 \times 10^{-3}$.

The reason for the difference in deposition fraction at different loads is due to different gas flow patterns around the tube, in particular the variation in turbulence and boundary layer thickness, and somewhat due to temperature differences. At higher loads, the gas velocities and temperatures are higher which increases turbulence and the propensity of the particles to deposit. The relationship between turbulence and deposition rate has not been determined, but we hypothesize that an indication of the relationship is the friction of the gas against the coupon; i.e., if the friction is higher, then the deposition rate is higher. The gas velocities and temperatures in a typical 500-MW utility boiler convective pass place the gas in a region of conditions known as the Newtonian flow region. Under these conditions, the friction of the gas against an object is proportional to the 
square of the velocity and to the gas density. Since gas density is inversely proportional to absolute gas temperature, then friction is inversely proportional to absolute temperature as well. Therefore, friction, hence deposition fraction, is proportional to the square of the gas velocity and inversely proportional to the absolute gas temperature. This relationship is used in LEADER, using the Welsh Station data as a baseline, to determine deposition fractions in boilers operating under different velocity and temperature regimes than at the SWEPCO Welsh Station during average load. Using these approximations, deposition fractions calculated for the high- and low-load Welsh Station data were off by an average of less than $10 \%$ from the measured values. For both upstream and downstream deposits, the calculated high-load deposition fractions were closer to the measured values than the calculated low-load fractions, indicating that the hypothesis is more accurate in upscaling than in downscaling the deposition fraction.

\subsection{Conclusions About the Types of Low-Temperature Fouling and Deposition Rates}

Low-temperature fouling is characterized by high-sulfur ash deposits that form in utility boilers on steam-tube surfaces from the reheater section of the convective pass back through the economizer banks. It is most problematic when burning low-ash, high-calcium coals in boilers designed for eastern coals. Research performed under Project Calcium has shown that the deposits do not form at temperatures above $1900^{\circ} \mathrm{F}$, although the sulfate matrix may exist for short periods above that temperature. The research has shown that sulfation of the deposits occurs after deposition of the ash. Either three or four types of low-temperature fouling deposits are common. The most massive are the hard, fin-shaped deposits that form on the lead steam tube in banks that experience gas temperatures below $1900^{\circ} \mathrm{F}$ for most of the daily load cycle of a boiler. This region is most typically in the reheater tube banks. Although massive, they have little effect on heat transfer and form slowly. Soot-blower effectiveness is limited usually to a path ten feet or less from the blower. It is believed that using water as a blowing medium would increase effectiveness; otherwise, blowers should be spaced less than 15 feet apart vertically in this region. Little information on rates of growth or strength development was gained during Project Calcium on these deposits because they begin formation only after very long periods of tube seasoning.

In cooler regions, the deposits on the upstream (windward) side of the tubes consist of thin, hard, enamel-like layers that can be very difficult to remove, although some off-line success with soaking them overnight with acidic river water has been reported. They are formed from particles that are less than $3 \mu \mathrm{m}$ in aerodynamic diameter and hence have very high calcium-to-silicon ratios. They become highly sintered due to sulfation and are extremely difficult to remove by soot blowing, although the use of water as a blowing medium should significantly improve their removability. The ash particles that form these deposits are transported to the tube surface through the boundary layer of still gas next to the tube somewhat due to thermal and electrical gradients, but more importantly by simple diffusion. Approximately $0.04 \%$ of the ash in this size range that was originally moving toward a steam tube will actually end up on the tube. This deposition fraction is directly proportional to the ratio of the square of the gas velocity to its absolute temperature. These deposits have little effect on heat transfer, but do serve as anchoring platforms for the massive deposits at temperatures near $1900^{\circ} \mathrm{F}$, and may cause some corrosion of more mild steels. 
A third type of upstream-side deposit is composed of small crests or humps that form on either side of the center line of the tube, leaving the center line clear. These most often form in primary superheater regions of a boiler. The shape of these deposits indicates that they are formed from a specific size range of particles that begin to flow around the tube with the gas, but then separate from the gas flow to impact the tube surface. No data are available about the specific size or composition of the ash that forms these deposits. They are expected to have the same influence on boiler performance as the upstream enamel layer and can most likely be removed in the same way as the upstream enamel layer.

The fourth common type of low-temperature deposit is a powder that deposits on the downstream side of the steam tubes. The deposits cover many times more surface area than all the other deposits and are, therefore, the greatest detriment to heat transfer of any of the low-temperature deposits. Downstream deposits are formed from ash particles with aerodynamic diameters of less than $10 \mu \mathrm{m}$ that get trapped in the eddies of gas swirling behind the tubes. Such deposits are usually not more than a half of an inch thick on vertically oriented tubes because they tend to shed under their own weight, although in some cases, especially on horizontal tubes, they become massive. Although friable, the tubes in front of them protect them from soot blowing. Soot-blower effectiveness can be increased to several tubes deep in a bank by angling the blower nozzles $15^{\circ}$ from the perpendicular to the path. In areas of turbulence the deposits can grow to block the passage of gas. The propensity of these deposits to shed is given by a relative number known as the shedding index, which equals the rate of deposit growth divided by the rate of strength development. The shedding index is increased at very low gas velocities because larger particles deposit. However, the velocities that give high shedding indices are usually too low to reach in a 500-MW boiler, although some additives may be employed as discussed in Section 3.4. At an average load in that size of boiler, about $0.4 \%$ of the ash with aerodynamic diameters of less than 10 microns will deposit on a tube that it approaches. Like the upstream fraction, the downstream deposition fraction increases as the square of the gas velocity and inversely to the absolute temperature.

Because of the size-specific nature of the ash that forms most types of low-temperature deposits, analyses of bulk coal or ash samples are usually not suficient to determine the propensity of the coal to form low-temperature fouling deposits. More advanced analyses, such as computer-controlled scanning electron microscopy, that provide size and composition distribution data are required. Also, modeling of this type of deposition must include the size and composition distributions of the ash, as does LEADER, which is described in Section 4.0. 


\subsection{STRENGTH DEVELOPMENT IN LOW-TEMPERATURE DEPOSITS}

\subsection{Introduction}

It was generally known before Project Calcium research that low-temperature deposits contained highly sulfated material. The sulfate was assumed to be somewhat molten and acted as a matrix that bound the deposit, making it strong and difficult to soot blow. This scenario appeared logical since coals containing high levels of calcium, which forms calcium sulfate in the deposits, tended to have more-severe low-temperature fouling problems than low-calcium coals. However, the melting point of pure calcium sulfate is $2400^{\circ} \mathrm{F}$, and sodium sulfate melts at approximately $2070^{\circ} \mathrm{F}$, temperatures much higher than those at which low-temperature deposits occur. Therefore, a hypothesis was developed that assumed that sintering occurred through gas/solid reactions, or through viscous flow of undefined low melting point sodium/calcium sulfates or more exolic sulfate glasses. Whatever the scenario, the formation and strength development mechanisms have to account for the different levels of sulfur and different strengths of the various types of lowtemperature deposits.

In the early stages of Project Calcium, the conditions and mechanisms of formation of low-temperature deposits were defined as described in Section 2.0. The Project Calcium sponsors believed that this information could be used to focus research on key strength development issues in order to better understand what could be done in terms of weakening or soot-blowing low-temperature deposits to reduce their impact on boiler operation. Because of the variety of possible mechanisms of strength development, and the inherent uncertainties about the conditions in which deposits form in the field, most of the Project Calcium strength development research focused on laboratory testing of ash collected from the power plants that were sampled under Project Calcium. Downstream powder deposits were targeted because they cause the greatest decrease in heat transfer and because the most field data had been accrued for them. However, much corollary information about other types of low-temperature deposits was also gained.

The first tests centered on using thermogravimetric analysis to better define, than is possible in the power plant tests, the critical maximum temperature at which sulfation occurs. This information was then used to formulate an experimental matrix to determine the influences of coal type, temperature, and time on the rate of sirength development. Finally, an advanced analytical technique termed electron spectroscopy for chemical analysis (ESCA) was used to define the chemical changes in the asih that caused the physical changes that led to the development of strength in the deposits.

\subsection{Thermogravimetric Analysis}

The effects of ash composition and particle size on sulfation rate and maximum sulfation temperature were determined by thermogravimetric analysis (TGA). TGA is a measurement of the weight of a sample versus its temperature. It is used to define the temperatures of chemical and physical reactions that involve fixation (weight gain) or evolution (weight loss) of gases. In the TGA experiments, approximately 50 milligram samples of ash were heated or cooled in a simulated flue gas atmosphere containing 1000$\mathrm{ppm} \mathrm{SO} \mathrm{SO}_{2}$ to a maximum temperature of approximately $2000^{\circ} \mathrm{F}$. The ash was collected from ESP or economizer hoppers during power plant sampling. In some cases, it was sizeclassified to provide ash of the size distribution that forms specific types of deposits. 
Figure 22 indicates the TGA heating curve in air for -400 -mesh Shoshone coal ash collected at the NIPSCO Schahfer Station. The ash had been previously sulfated in a simulated flue gas atmosphere containing $1000-\mathrm{ppm} \mathrm{SO}_{2}$ at $1850^{\circ} \mathrm{F}$. The $\mathrm{y}$-axis shows the weight of the sample as a percent of the weight at the start of heating. The weight loss beginning at approximately $1875^{\circ} \mathrm{F}$ is caused by conversion of alkali sulfates to $\mathrm{SO}_{2}$ gas and alkali silicates. The weight loss is not due to simple vaporization or decomposition since most pure alkali sulfates are stable to considerably higher temperatures. Instead, the. decomposition reactions are driven by chemical thermodynamics. In other words, above $1875^{\circ} \mathrm{F}$, the alkali and sulfur in the ash are more chemically stable as alkali silicates and $\mathrm{SO}_{2}$ gas than as alkali sulfates. Note that this decomposition would not occur if silicate material was not present. In similar experiments performed with the Shoshone ash, the stability of the sulfate was found to depend on the sulfation temperature. If the ash was sulfated at lower temperatures, the decomposition temperatures dropped. Ash sulfated at $1650^{\circ} \mathrm{F}$ began decomposing at approximately $1825^{\circ} \mathrm{F}$, while ash sulfated at $1450^{\circ} \mathrm{F}$ began decomposing at approximately $1725^{\circ} \mathrm{F}$. Although sulfates formed at lower temperatures are less stable than those formed at higher temperatures, the difference between formation and decomposition temperatures increases as sulfation temperature drops. This implies that sulfate material formed in deposits in the reheat steam tube banks of the convective pass while the boiler is at low load may decompose as the load is increased and gas temperatures rise. However, sulfate material formed farther back in the convective pass while at low load will not decompose as temperatures rise with load increases.

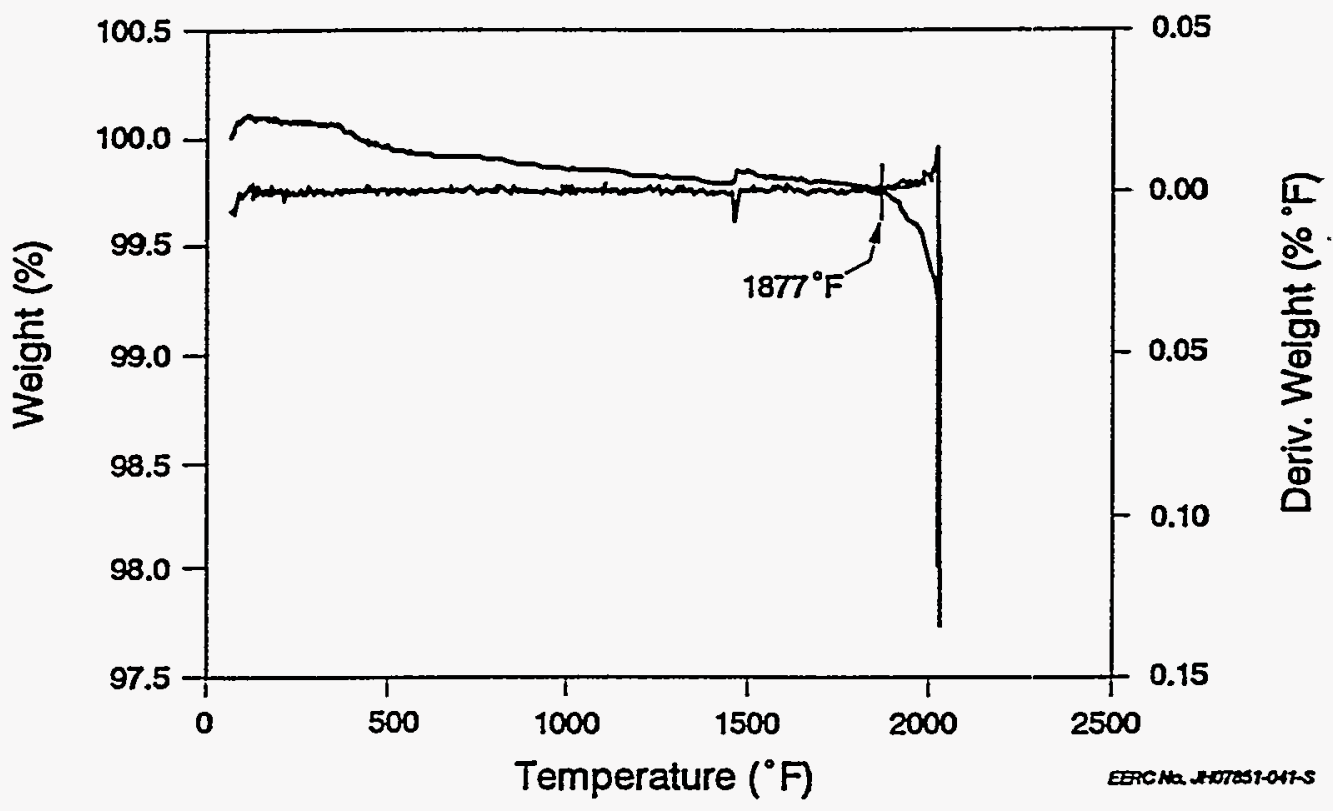

Figure 22. The TGA curve for heating sulfated Shoshone coal ash in air. 
In an operating boiler system, of course, ash is not slowly heated in air. Instead, it cools from a high temperature as it enters the convective pass to a lower temperature below which sulfation can occur. Therefore, to more closely determine critical events in the sulfation process experienced by ash as it passes through the convective pass, fly ash was rapidly heated to a temperature above the highest measured sulfation temperature, allowed to decompose to drive off sulfate that had already formed, then slowiy cooled in the presence of simulated flue gas containing 1000-ppm SO $\mathrm{SO}_{2}$. Figure 23 shows the TGA curve of weight versus time and the time-derivative of that curve for Black Thunder ash collected from the NSP King Station ESP hoppers. The ash was classifiel to remove particles with aerodynamic diameters of over 15 microns to better simulate the ash that forms downstream deposits. Unfortunately, some of the smallest ash was lost during classification so the size range tested fell between approximately 5 and 15 microns. The solid weight change curve shows that the ESP ash lost approximately $10 \%$ of its weight upon heating to $2000^{\circ} \mathrm{F}$. This represents essentially complete decomposition of the sulfate that was in the ash. As the ash was cooled below $1885^{\circ} \mathrm{F}$, it began to gain weight by fixing gaseous $\mathrm{SO}_{2}$ as solid sulfate. Sulfur fixation was essentially finisihed below $1150^{\circ} \mathrm{F}$, not because the ash was completely sulfated, but because below this temperature the chemical kinetics of sulfation are such that the fixation reaction is very slow over the time frame of the TGA experiment. In a boiler system in which many months are usually spent between off-line cleaning of downstream deposits, more sulfation of the ash may occur below $1150^{\circ} \mathrm{F}$, although it would be very slow compared to the ash deposition rate. The derivative of the weight change curve, shown as a jagged line, indicates the rates of weight change. A positive derivative indicates weight gain, negative indicates weight loss. The

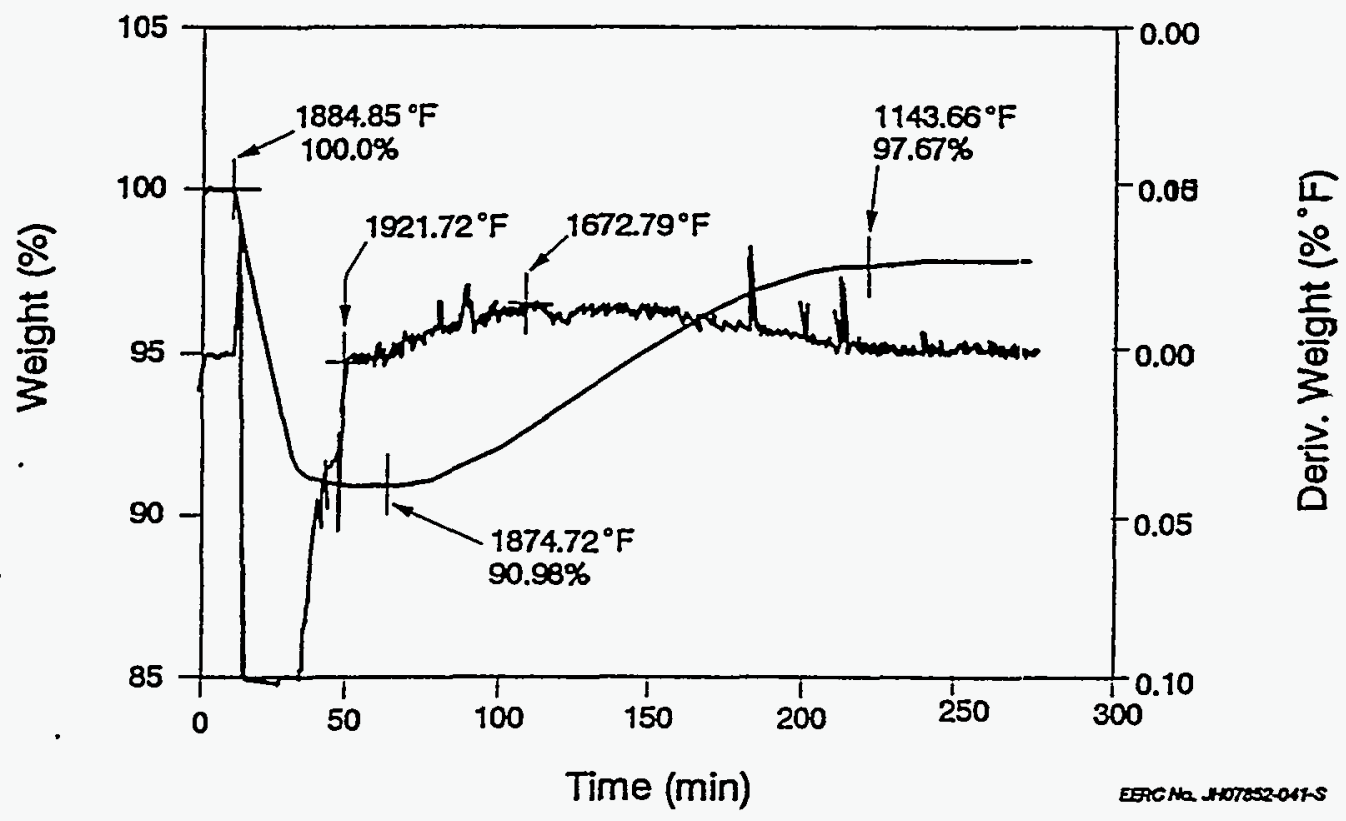

Figure 23. The TGA curve for rapid heating then slow cooling of sulfated 5- to 15-micronaerodynamic-diameter Black Thunder ash. 
curve shows that while the ash was being heated, additional sulfation occurred, peaking around $1885^{\circ} \mathrm{F}$. However, as the critical sulfation temperature was passed, decomposition occurred rapidly. During cooling, the derivative curve again became positive below $1920^{\circ} \mathrm{F}$, indicating the sulfur fixation. At $1670^{\circ} \mathrm{F}$, the rate of weight gain was at a maximum, although once sulfation began, the derivative curve was relatively flat, indicating a slow and relatively temperature-independent reaction rate. Such temperature independence normally indicates an experimental limitation, not a chemical one. Effective reaction rates would be higher in a boiler system where the ash is suspended in the gas and not packed in a bed as it is in the TGA. The other ash collected at King Station, produced while firing coal from the Antelope mine, showed similar reaction temperatures, although it contained somewhat more sulfate at the start.

\subsection{Low-Temperature Sintering}

All of the low-temperature sintering experiments were carried out with lightly compressed pellets of ash in simulated flue gas atmospheres containing $1000-\mathrm{ppm}^{\mathrm{SO}} \mathrm{S}_{2}$. The initial experiments used gas containing $\mathrm{CO}_{2}$ with the thought that some calcium carbonate material may form at temperatures below $1550^{\circ} \mathrm{F}$. In later experiments, $\mathrm{CO}_{2}$ was no longer added because thermodynamic calculations and determinations of the amount of carbon dioxide fixation indicated that the fixation did not occur in the presence of $\mathrm{SO}_{2}$. In other words, the calcium is more stable as a sulfate than as a carbonate in the presence of $\mathrm{SO}_{2}$. In the earlier sintering experiments -400 -mesh ash was used. After field work had shown that most low-temperature deposits were formed of smaller ash, the ash was aerodynamically classified to remove larger particles, although much of the smaller ash was also lost. Therefore, the ash used for the later sintering determinations fell in the aerodynamic diameter range of approximately 5 to 15 microns. Slize differences are known to play an important role in sintering since different sizes of particles sinter at different rates. Although inadvertent, the removal of the smallest ash particles in those samples assured that sintering differences between the ashes were due primarily to composition differences and less to size distribution differences. This information is necessary in developing an algorithm to relate composition to strength development rate for use in LEADER, the computer program developed to predict low-temperature fouling problems based on coal analyses. However, removal of the smaller ash changed the inherent characteristics of the ash. This means that the following information cannot be used to rate the low-temperature fouling potential of the coals used in the tests.

Ash pellets were prepared by hand for the sintering tests using a punch and die. The die was 0.5 -inch diameter, and pellets 0.75 inch in length were prepared. Methanol was used as a binder due to the difficulty in preparation without it. Five pellets were prepared for each sintering test: four were crushed to determine strength, and one was used for chemical analysis. The pellets were crushed using a hydraulic press fitted with a proving ring and a feeler gauge to read the deflection at fracture as load was applied. The load for each deflection was determined from the calibration curve supplied with the proving ring. The pellet used for chemical analysis was embedded in epoxy, sectioned and polished, then photographed using optical microscopy. The pellet was then carbon-coated and analyzed in a scanning electron microscope to take note of morphology and to determine the chemical composition of the phases which could be observed. The crushed remains of some of the pellets were also analyzed by electron spectroscopy for chemical analysis (ESCA) to determine the changes in the chemical association of calcium that occurred during strength development. 


\subsection{Strength}

Figure 24 illustrates the importance of sulfation in the development of strength in low-temperature deposits. It shows the compressive strength versus sintering time of pellets of 5- to 15-micron-aerodynamic-diameter Eagle Butte ash sintered in air and simulated flue gas containing $1000-\mathrm{ppm} \mathrm{SO}_{2}$. The plotted points are the average strengths of four pellets prepared at each condition. The vertical lines through each point are the standard deviations for the measured strengths. The points have been displaced horizontally somewhat from the actual lengths of the tests to allow the standard deviations for specific length tests to be seen more clearly. For each sintering time, the pellets prepared in $\mathrm{SO}_{2}$ are stronger than those prepared in air. In both cases, pellet strength develops rapidly over the first day. For the pellets sintered in $\mathrm{SO}_{2}$, strength dropped considerably after 1 day, but then remained relatively constant. The reason for the drop in strength is not clear, but is believed to be due to the formation of crystalline material from amorphous phases present at the start of the tests. Most of the coal ashes tested exhibited similar trends, but the loss of strength was not of the magnitude seen in the Eagle Butte pellets. In contrast, the pellets sintered in air do not lose significant strength, although they are significantly weaker than those sintered in $\mathrm{SO}_{2}$, indicating that sulfur definitely plays a role in the development of strength in low-temperature deposits.

Figure 25 illustrates the importance of sintering temperature to the development of strength in low-temperature deposits. The figure shows the compressive strength versus sintering times for pellets of 5- to 15-micron-aerodynamic-diameter Shoshone coal ash

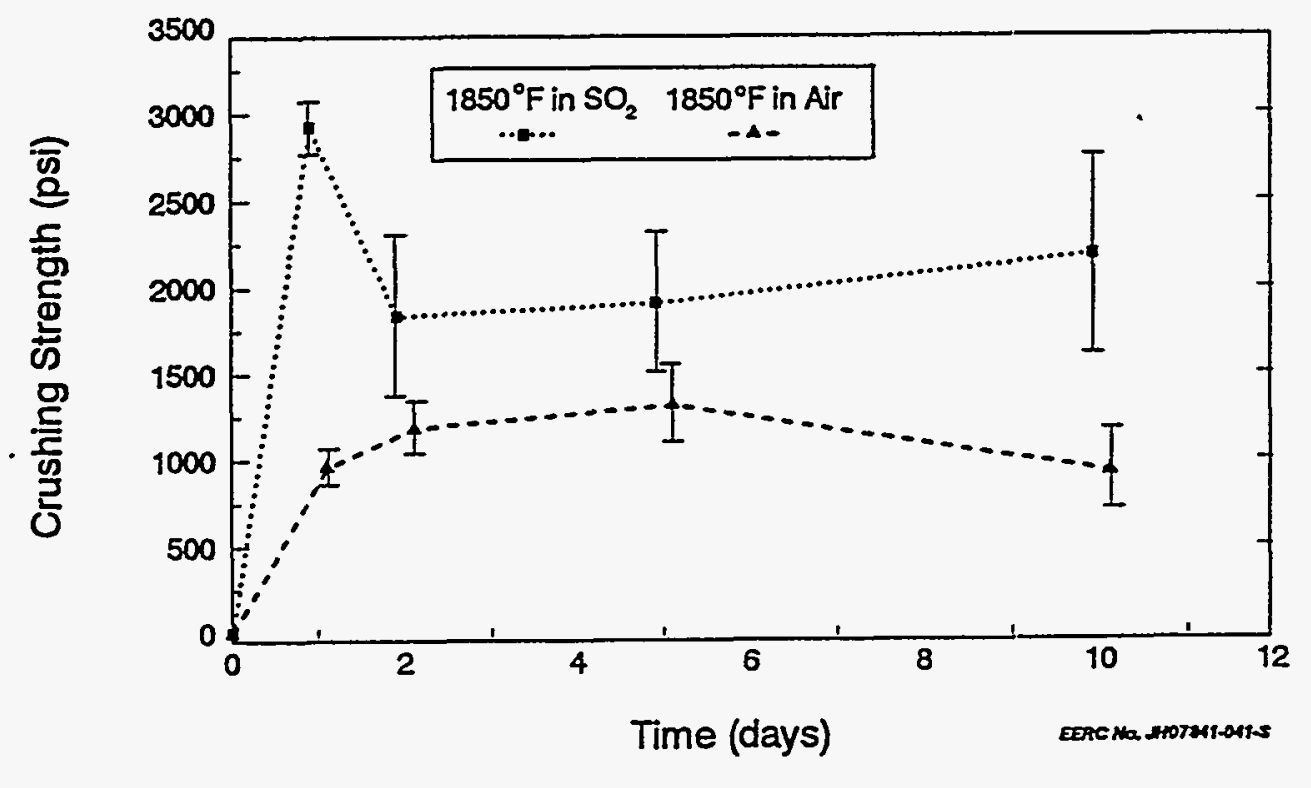

Figure 24. Compressive strength versus sintering times for pellets of 5- to 15-micronaerodynamic-diameter Eagle Butte ash sintered in air and simulated flue gas containing 1000-ppm $\mathrm{SO}_{2}$. 


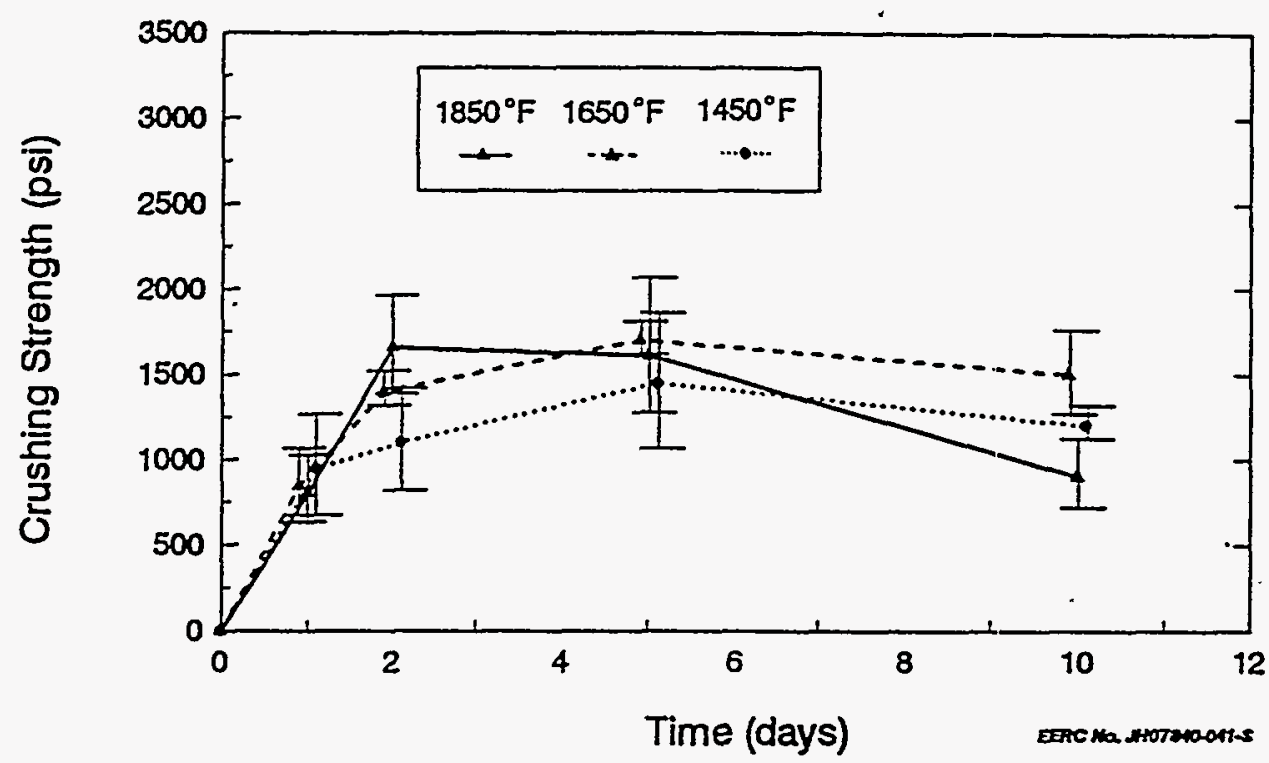

Figure 25. Compressive strength versus sintering times for pellets of 5- to 15-micronaerodynamic-diameter Shoshone ash sintered in simulated flue gas containing $1000-\mathrm{ppm} \mathrm{SO}_{2}$ at $1450^{\circ}, 1650^{\circ}$, and $1850^{\circ} \mathrm{F}$.

sintered in simulated flue gas containing $1000-\mathrm{ppm} \mathrm{SO}_{2}$ at $1450^{\circ}, 1650^{\circ}$, and $1850^{\circ} \mathrm{F}$. The shapes of the curves are similar for the three temperatures, indicating the phenomena related to strength development does not change, but the rates of strength increases are higher at higher temperatures. For the Shoshone ash, peak strength was reached at $1850^{\circ} \mathrm{F}$ in two days, whereas it took closer to 5 days at lower temperatures. Maximum strength was similar for the two higher temperatures, and lower for the lowest temperature. The rate of loss of strength was decreased at lower temperatures as well, probably because crystalline phase formation is reduced at lower temperatures.

The influence of ash composition on low-temperature deposit strength is shown in Figure 26. The figure shows the compressive strength versus sintering times for pellets of 5- to 15-micron-aerodynamic-diameter Eagle Butte, Antelope, Black Thunder, and Shoshone ash sintered in simulated flue gas containing $1000-\mathrm{ppm} \mathrm{SO}_{2}$. It should be remembered that the ash used for these tests is representative only of the 5- to 15-micron-aerodynamicdiameter range, and not of the totality of ash that would deposit in a boiler. Therefore, these data should not be used to rank the propensity of the coals to form low-temperature fouling deposits. The compositions of the sized ashes used for the sintering tests are given in Table 1.

In general, the curves have similar shapes but differ in magnitude. The Eagle Butte ash developed the strongest pellets and also has the highest alkaline element-to-silicon ratio. This ratio is believed to be important because alkaline or basic elements react with 


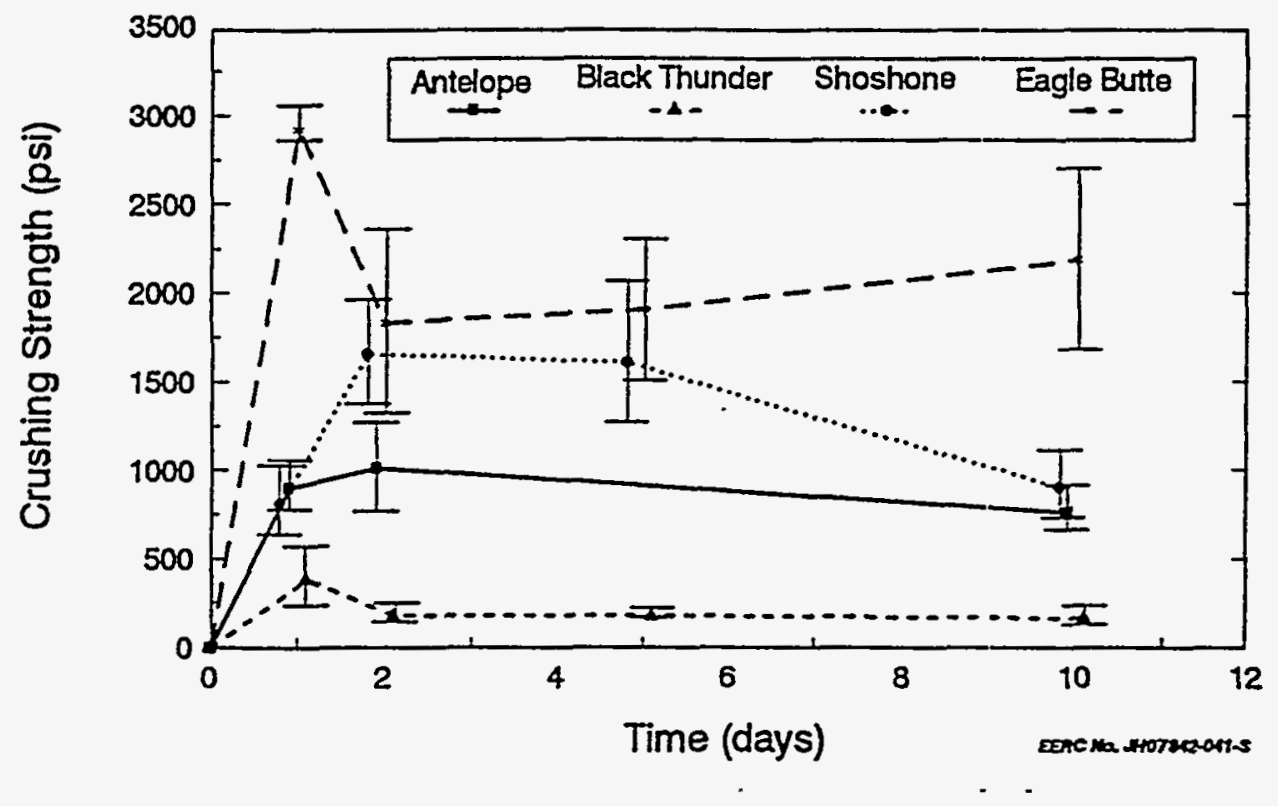

Figure 26. Compressive strength versus sintering times for pellets of 5- to 15-micronaerodynamic-diameter Eagle Butte, Antelope, Black Thunder, and Shoshone ash sintered at $1850^{\circ} \mathrm{F}$ in simulated flue gas containing $1000-\mathrm{ppm} \mathrm{SO}_{2}$.

gaseous $\mathrm{SO}_{2}$ to form sulfate. However, they can also be present in a silicate glass form. The ratio of alkaline elements $(\mathrm{Na}, \mathrm{K}, \mathrm{Mg}$, and $\mathrm{Ca}$ ) to silicate gives an indication of the freedom of the elements to react to form sulfates. Aluminum may play a similar role to silicon, but was left out of the correlation because its concentration in each pellet was essentially the same, so no data about its importance were available. Therefore, a regression analysis was performed to find the constants relating the alkaline element-tosilicon ratio to the rate of strength development. Since the strength rapidly peaks then remains constant, the rate of strength development over the first day was used in the equation. The regression equation with calculated constants is given as Equation 2.

$$
\text { . Strength Increase over the First Day }=4090 \frac{\left(\mathrm{Na}_{2} \mathrm{O}+\mathrm{K}_{2} \mathrm{O}+\mathrm{MgO}+\mathrm{CaO}\right)}{\mathrm{SiO}_{2}}-4306
$$

The correlation coefficient for the equation is 0.81 . Figure 27 illustrates the measured rate of strength development versus that predicted by Equation 2 . If the prediction is exact, the points fall on the diagonal line $y=x$. This equation is used as an algorithm in LEADER, the computer code developed to predict low-temperature fouling and to predict strength development versus composition. There were, however, other equations that did provide better correlations. For example, by grouping the alkaline elements into alkali metal and alkaline earths, i.e., $\left(\mathrm{Na}_{2} \mathrm{O}+\mathrm{K}_{2} \mathrm{O}\right)$ and $(\mathrm{MgO}+\mathrm{CaO})$, a considerably better correlation with a coefficient of 0.96 can be achieved. Unfortunately, since the concentration of sodium and potassium in the deposits is low, small errors in predicting the amounts of those elements in the deposits would have large consequences in the prediction 
of the rate of strength development. Therefore, the less precise but more forgiving relationship given in Equation 2 is used in LEADER.

The relationship between composition and strength development can be used to determine additives or coal blends that may be useful in reducing the strength development rate and increasing the deposition rate, thereby increasing the shedding index. Additives high in $\mathrm{Si}$ and low in $\mathrm{Na}, \mathrm{K}, \mathrm{Mg}$, and $\mathrm{Ca}$ are indicated. Simple silica sand is too abrasive for most systems and also may become fluxed and cause a hightemperature fouling problem. Also, the additive must be pulverized to, or originally available as, particulates less than 10 microns in aerodynamic diameter to prevent the formation of inertially impacted deposits and to increase the efficiency with which the additive deposits on the downstream sides of tubes. We suggest kaolin clay as a good first choice for an additive to increase the shedding index of downstream deposits. Its addition would also slow the development of strength in upstream enamel layers, providing more time for them to be soot blown.

Kaolin is composed primarily of kaolinite $\left(\mathrm{Al}_{2} \mathrm{Si}_{2} \mathrm{O}_{5}[\mathrm{OH}]_{4}\right)$. It occurs in relatively pure deposits in many regions of the United States, and is often found in the overburden at coal mines. It pulverizes easily, and is commercially available with a mass median

aerodynamic diameter of 1.1 microns at a cost of about $\$ 0.03 / \mathrm{b}$ FOB the kaolin mine (J.M. Huber Corporation, Macon, Georgia). For coal producing 5\% ash, of which $30 \%$ has an aerodynamic diameter of less than 10 microns and a composition like the Black Thunder ash in Table 1, approximately $26 \mathrm{lb}$ of kaolin would have to be added per ton of coal to double the shedding index. The cost would be $\$ 0.81 /$ ton of coal FOB the kaoline mine, although there are somewhat less expensive kaolins available, and it may be much less expensive in bulk. To prevent coalescence with other ash particles, kaolin should be added in a lower temperature zone such as with the tempering air, as long as it mixes well with the combustion gas. Adding it with secondary air may also be sound in a tangentially fired system, less so in opposed wall firing because of the higher turbulence which would increase collisions between ash particles. Some testing would be required to find the most appropriate method and dosage rate for a specific boiler.

\section{TABLE 1}

The Composition of the 5- to 15-Micron-Aerodynamic-Diameter Ash Used in the Sintering Tests ( $\mathrm{SO}_{3}$-free)

\begin{tabular}{lcccc}
\hline & Shoshone & Antelope & Black Thunder & Eagle Butte \\
\hline $\mathrm{SiO}_{2}$ & 32.8 & 33.7 & 32.5 & 28.6 \\
$\mathrm{Al}_{2} \mathrm{O}_{3}$ & 16.5 & 15.3 & 15.9 & 15.7 \\
$\mathrm{Fe}_{2} \mathrm{O}_{3}$ & 10.8 & 6.9 & 6.0 & 4.8 \\
$\mathrm{TiO}_{2}$ & 1.0 & 1.1 & 1.2 & 0.9 \\
$\mathrm{P}_{2} \mathrm{O}_{5}$ & 0.9 & 1.3 & 1.3 & 0.9 \\
$\mathrm{CaO}$ & 24.0 & 31.7 & 33.1 & 36.5 \\
$\mathrm{MgO}$ & 9.8 & 8.0 & 8.5 & 8.6 \\
$\mathrm{Na}_{2} \mathrm{O}$ & 2.0 & 1.5 & 1.1 & 3.4 \\
$\mathrm{I}_{2} \mathrm{O}$ & 2.2 & 0.5 & 0.4 & 1.4 \\
$\mathrm{SO}_{3}{ }^{a}$ & 4.0 & 11.2 & 8.3 & 4.8 \\
\hline
\end{tabular}

\footnotetext{
a For comparison purposes.
} 


\subsection{Composition and Morphology}

The changes in morphology of the sintered ash pellets were determined by examining them by both optical and scanning electron microscopy. Typically, the degree of sintering or coalescence of the ash in the pellets increased with temperature and also increased with time. However, the morphology of the sintered material took on two radically different forms. For the Antelope and Black Thunder ash pellets, increased sintering appeared as a general decrease in porosity, with weak indications that sintering was regional, and that sintered area increased with time. Figure 28 shows the edge of the Antelope coal ash pellet heated to $1650^{\circ} \mathrm{F}$ for 10 days. Contrast has been greatly enhanced to bring out the irregular region of increased sintering that appears as a bright region. In general, these areas of increased sintering are slightly enriched in calcium, and highly enriched in sulfur as compared to the rest of the pellet. The calcium. enrichment may be due to migration of calcium ions from the interior of local ash particles to the exterior of the particles where they sulfate and can be measured by SEM analysis, or, more likely, migration of calcium ions from particle to particle until they are trapped in the sulfated areas. Whatever the cause, the variation in sintering from area to area in the Black Thunder and Antelope pellets is small.

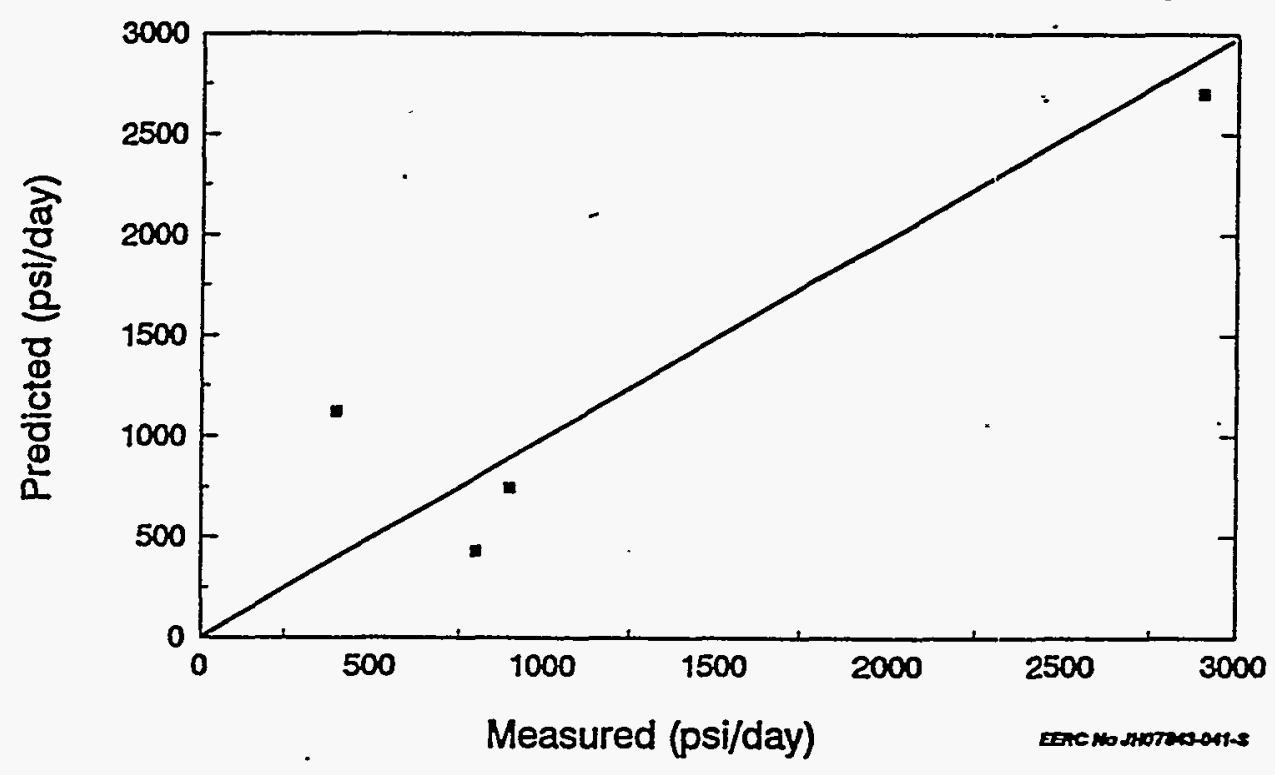

Figure 27. Comparison of the measured 1-day compressive strengths shown in Figure 26 with the calculated compressive strengths. 


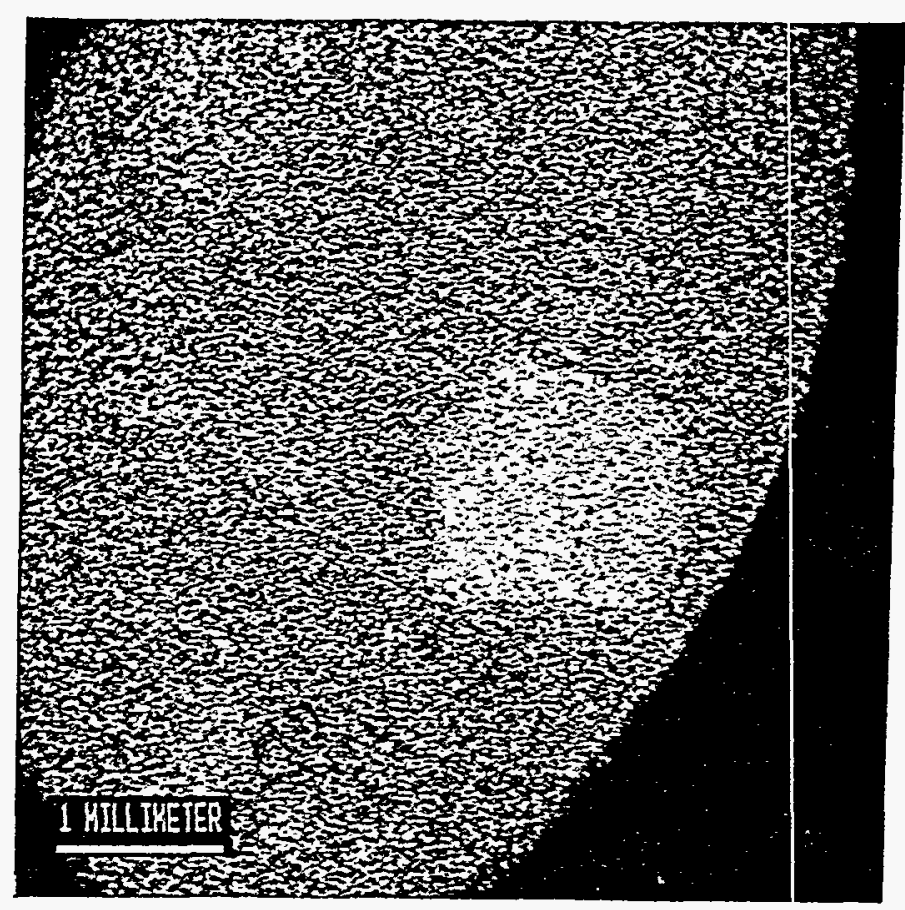

Figure 28. Backscattered electron micrograph of the edge of the Antelope coal ash pellet sintered at $1650^{\circ} \mathrm{F}$ for 10 days in $1000-\mathrm{ppm} \mathrm{SO}_{2}$.

In contrast to the Antelope and Black Thunder ash pellets, the Shoshone and Eagle Butte ash pellets showed spectacular crystal-like regions of nearly complete sintering. Figure 29 shows the edge of the Eagle Butte pellet sintered for 5 days at $1850^{\circ} \mathrm{F}$ in 1000 $\mathrm{ppm} \mathrm{SO}_{2}$. Figure 30 shows a high-magnification view of a crystal formed in the 10-day pellet. It shows that the crystalline areas have very low porosity, typically $5 \%$, whereas the initial ash pellet had porosity of 50\%. The elemental x-ray maps shown in Figure 31 indicate the composition of the crystalline regions. They are formed primarily of a calcium sulfate matrix in which silicate and aluminosilicate particles are embedded.

In general, the amount of crystalline material in the pellets increased with time and temperature, but there did not appear to be a relationship between crystal size and sintering time. Overall, the pellets with the highest strength and greatest alkaline-tosilicon ratio had the most crystalline material. High alkaline-to-silicon ratios are believed to relate to the propensity to form crystals because the alkaline elements would be more likely to sulfate at higher ratios. The presence of crystals is not believed to be related to the strength of the pellets though, since the crystals are not continuous. In fact, their formation may lead to the later weakening of the pellets. However, the magnified appearance of the crystals as shown in Figure 29 is very similar to that of the upstream massive deposits. It is possible that at the higher temperatures where those deposits form, the ash sulfates immediately upon deposition leading to the highly sintered, highstrength nature of the deposits. In other words, the upstream massive deposits are essentially large crystals such as those shown in Figure 29. The downstream deposits never become as hard as the upstream deposits because their rate of sulfation is low compared to the rate of deposition, so crystals may not form or are certainly not continuous. 


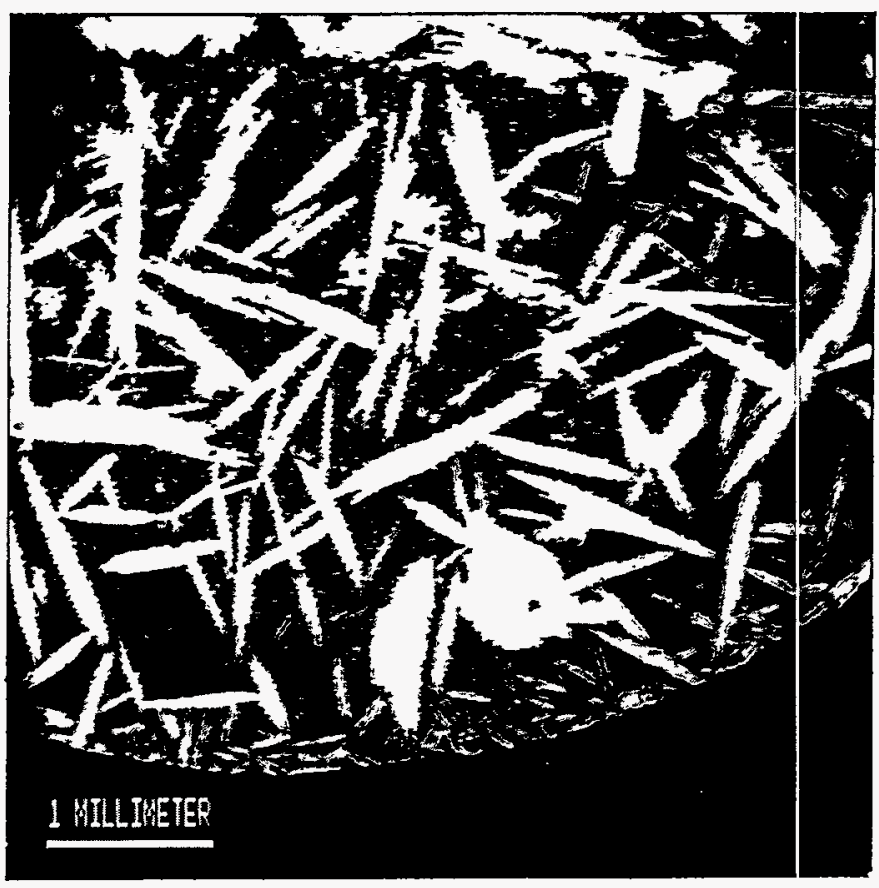

Figure 29. Backscattered electron micrograph of the edge of the Eagle Butte coal ash pellet sintered at $1850^{\circ} \mathrm{F}$ for 5 days in 1000 -ppm $\mathrm{SO}_{2}$.

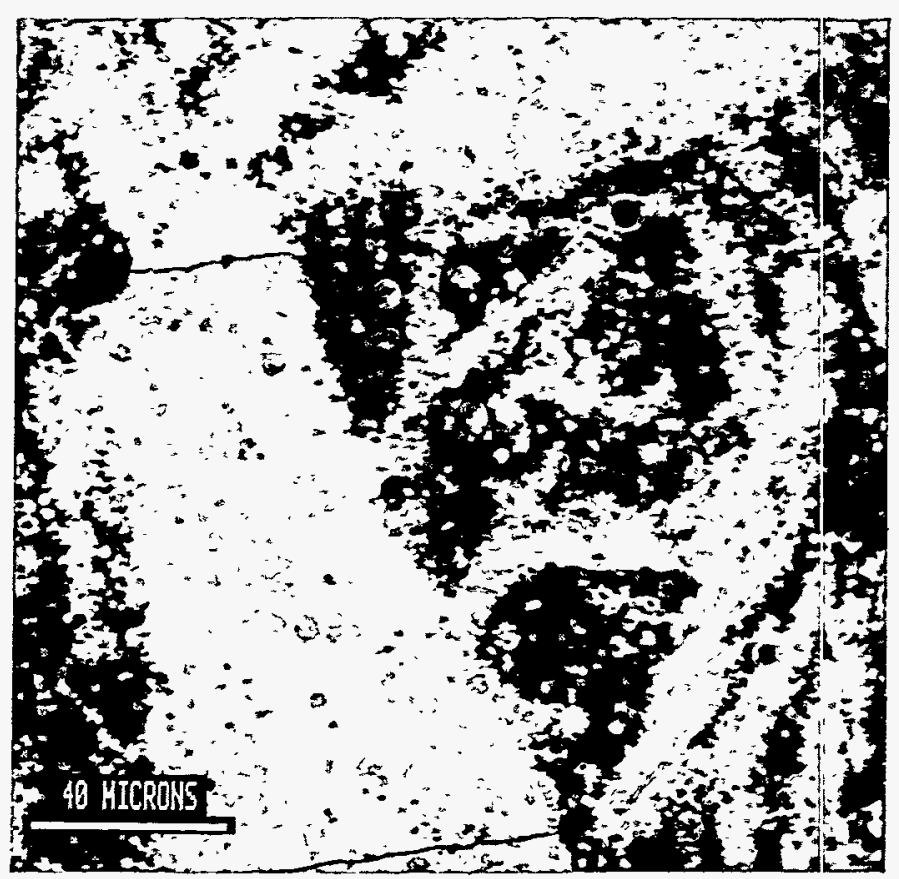

Figure 30. High-magnification micrograph of a crystal-like region in the Eagle Butte ash pellet sintered at $1850^{\circ} \mathrm{F}$ for 5 days. 


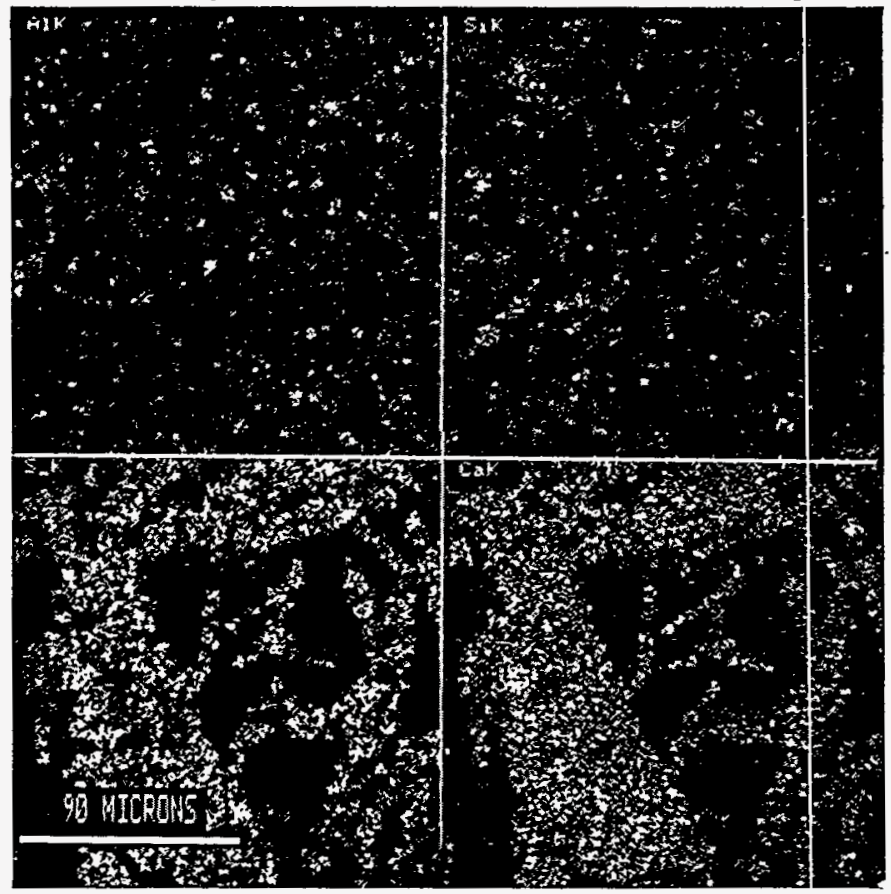

Figure 31. X-ray map of Figure 30 showing the relative concentrations of aluminum, silicon, calcium, and sulfur in the figure.

\subsection{Chemical Association of Calcium}

Electron spectroscopy for chemical analysis (ESCA) was used in an effort to determine the mechanisms of calcium sulfation so that the process of strength development in low-temperature deposits could be more clearly defined. ESCA is an instrumental method that allows us to determine the chemical association of the elements in the ash. It is a nondestructive technique which involves irradiating the sample with $\mathrm{x}$-rays which cause electrons to be emitted from the sample surface. The electrons of different elements have different energies. Also, electrons for a given element have slightly different energies depending on the local chemical envirorment of the source atom. With a suitable electron-energy analyzer and a table of the electronic configuration and binding energies, we are able to identify not only the elements, but also the range of associations of the elements in the sample. We needed this information to determine if calcium is present as a sulfate, oxide, or aluminosilicate glass in the unsintered ash, and how the association changes with strength development. Unfortunately, this has proven difficult due to disagreement in the literature over binding energies of elements in standard compounds. Some of this confusion is the result of using different techniques of instrument calibration. Another problem is that electrons are constantly being emitted from the sample so it begins to acquire a positive charge, and the charging slows down electrons escaping the surface, which shifts their apparent energy. Charging forces constant instrument calibration as data are acquired. This is done by using the hydrocarbon contamination which is always present on the surface of samples after exposure to air. The binding energies of all elements of interest are scanned, along with 
the carbon from the surface contamination. The accepted binding energy of this carbon peak is 284.6 electron volts (eV). If the energy of the carbon appears shifted from this value due to charging, then all other elements are correspondingly shifted the same amount, conserving internal consistency.

Narrow regions of the electron emission spectrum were scanned for calcium and carbon. The carbon region was scanned for calibration. The calcium region was scanned to determine qualitatively the form of calcium present on the surface of the ash left after crushing the strength pellets. The data in Table 2 show the calcium peak positions after charge correction. The 1-1-1 standard sample was prepared using equal amounts by weight of calcium sulfate, calcium oxide, and calcium silicate glass. Figure 32 shows the curves for the 1-1-1 mixture as compared to the ESCA curve for the Eagle Butte 5- to 15micron-aerodynamic-diameter ash heated at $1850^{\circ} \mathrm{F}$ for 10 days in 1000 -ppm $\mathrm{SO}_{2}$. The 11-1 mixture was the only one which had asymmetrical curves, indicating that more than one state is present. The curves of the fly ash and sintered pellets analyzed showed little or no asymmetry. The calcium in the as-received sample appears to be bound in an aluminosilicate-like environment when compared to the standard calcium aluminosilicate crystalline or glass-binding energies. When exposed to air at $1850^{\circ} \mathrm{F}$, the calcium shifts to an oxide or, more likely, a sodium silicate glass-like state at a binding energy of 347.0 $\mathrm{eV}$, possibly indicating some formation of glass or migration of soclium to the surface of the ash particles. On exposure to sulfur dioxide at $1850^{\circ} \mathrm{F}$, the 1 - and 10 -day samples shift toward calcium sulfate at $348.0 \mathrm{eV}$. However, no difference in calcium compounds is seen in the 1- and 10-day pellets, indicating that the reduction in strength over this time is due to a physical change or statistical variation, and not a chemical change.

The lack of asymmetry in the curves indicates that just one state was present at the surface of the ash, unless the curves are too closely spaced to be resolved. Since it is the surface layer that is responsible for sintering of ash, then only one calcium phase is present in the sintering layer. That phase is chemically similar to calcium oxide or, more likely, a sodium-calcium silicate glass in the pellets heated in air. In the pellets heated in the presence of $\mathrm{SO}_{2}$, the phase shifts toward calcium sulfate, but not completely. Possibly a sodalite phase such as haüyne, $(\mathrm{Na}, \mathrm{Ca})_{4-8}\left(\mathrm{AlSiO}_{4}\right)_{6}\left(\mathrm{SO}_{4}\right)_{1-2}$, is formed with a chemical environment between that of sulfate and aluminosilicate. More lilsely, a combination of a sodalite-like phase and calcium sulfate is present. The indication of a sodalite-like phase strengthens the hypothesis that some sulfate dissolves in the silicates to aid in sintering by increasing the surface tension, as occurs in the fining process used by the glass industry.

\section{TABLE 2}

Peak Positions in the ESCA Analyses of the Strength Development Ash Pellets

\begin{tabular}{llll}
\hline <10-Micron Ash, as received & 347.5 & Calcium Sulfate & 348.0 \\
10-day air, $1850^{\circ} \mathrm{F}$ & 347.0 & Calcium Oxide & 347.0 \\
10-day Sulfur Dioxide, $1850^{\circ} \mathrm{F}$ & 347.6 & Ca-Al-Si Glass & 347.4 \\
1-day Sulfur Dioxide, $1850^{\circ} \mathrm{F}$ & 347.6 & $1-1$-1 Mixture & 347.2 \\
Gehlenite $\left(\mathrm{Ca}_{2} \mathrm{Al}_{2} \mathrm{SiO}_{7}\right)$ & 347.3 & & \\
Ca-Na-Si Glass & 346.9 & & \\
\hline
\end{tabular}




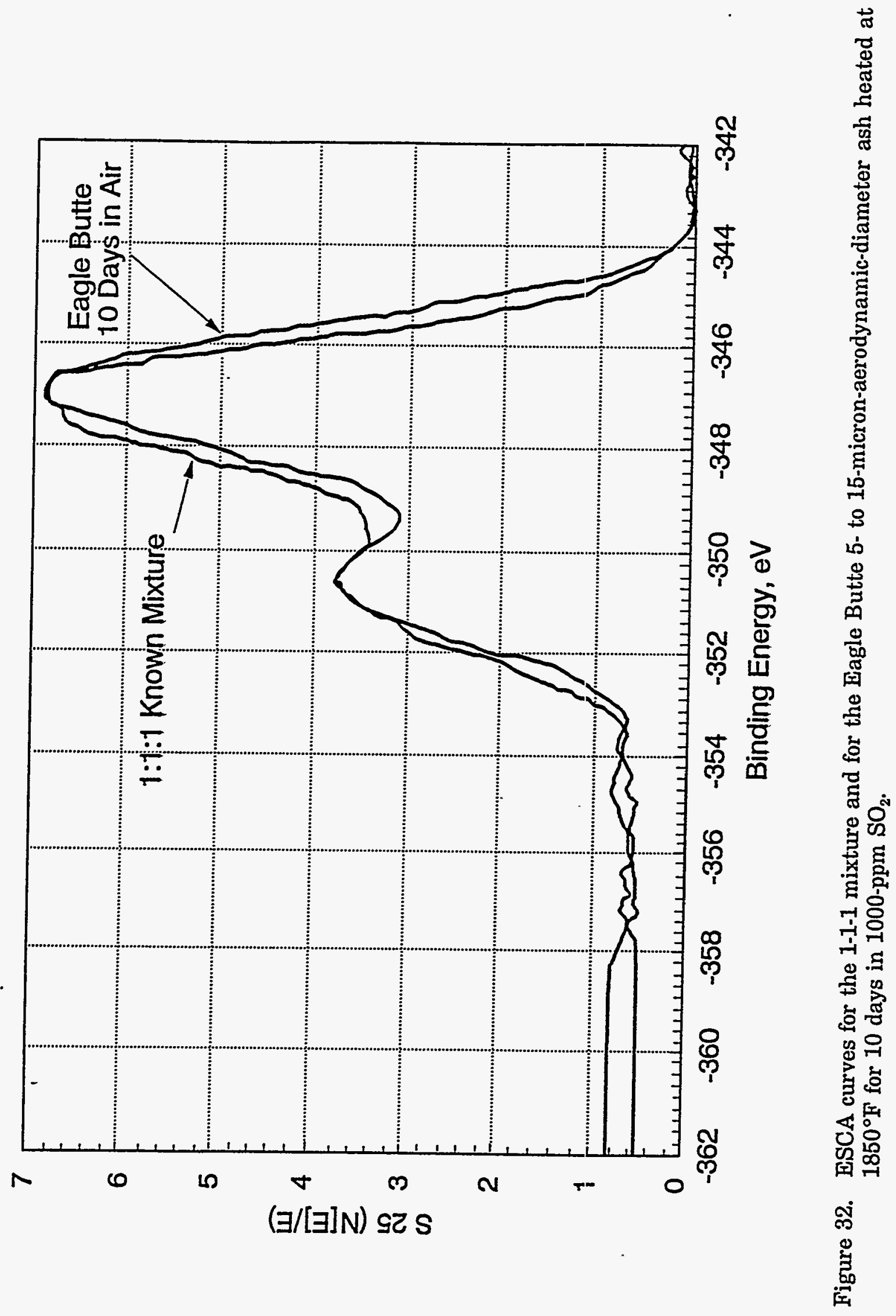




\subsection{Conclusions About the Development of Strength in Low-Temperature Deposits}

Thermogravimetric analysis of ash collected during Project Calcium sampling at sponsor boilers shows that fixation of $\mathrm{SO}_{2}$ by the ash to form sulfates begins as the ash cools below $1900^{\circ} \mathrm{F}$. The rate of sulfation as the ash cools further remained relatively constant, possibly due to an experimental limitation. Sulfation essentially ceased below $1150^{\circ} \mathrm{F}$. Sulfates formed at lower temperatures are less stable than those formed at higher temperatures. Also, the difference between sulfate formation and decomposition temperatures increases as formation temperature drops. This implies that sulfate material formed in deposits in the reheat steam-tube banks of the convective pass while the boiler is at low load may decompose as the load is increased and gas temperatures rise. However, sulfate material formed farther back in the convective pass while at low load will not decompose as temperatures rise with load increases.

To determine the influence of chemical composition in the rate of strength development in downstream deposits, pellets formed from 5- to 15-micron-aerodynamicdiameter ash were heated to different temperatures for periods of up to 10 days in air and in 1000-ppm $\mathrm{SO}_{2}$. Strengths of the pellets heated in $\mathrm{SO}_{2}$ were higher than those heated in air, showing the importance of sulfation to strength development. In all cases, strength increased dramatically initially, then did not increase further. Maximum strength was reached in 1 to 2 days at $1850^{\circ} \mathrm{F}$, but took up to 5 days at lower temperatures. The differences in strength caused by temperature differences were minor, indicating that deposits formed at high temperatures are not much weaker than those formed at low temperatures. Strength often decreased after the first day at $1850^{\circ} \mathrm{F}$, possibly due to crystal formation in the interacting ash. The rate of initial strength development at $1850^{\circ} \mathrm{F}$ was found to be related to the ratio of total alkali to silicon as shown in Equation 2. This relationship is used as the composition versus strength development algorithm in LEADER, the computer program developed to predict low-temperature fouling problems based on coal analyses. SEM observations of the ash pellets showed that for ash with higher alkali-to-silicon ratios, calcium sulfate crystalss formed that acted as cement to bind the ash into a strong (presumably) aggregate.

The calcium sulfate crystals in the sintered pellets form through the same phenomena as the upstream massive deposits. However, the upstream massive deposits sulfate as the ash is deposited. In the ash pellets, $\mathrm{SO}_{2}$ transport is too slow to have the pellet completely sinter in 10 days. Therefore, the ash pellets do not become very hard in 10 days because continuous channels of unsulfated ash which permit fracture are still present in the pellet. Over very long periods of time, the sulfate crystals in the pellets will become more continuous and make the pellets harder, but the rate will always be limited by the rate of $\mathrm{SO}_{2}$ diffusion through the pellets.

ESCA analyses showed that the initial strength development in the pellets is somewhat related to sulfate sintering, but may also be due to increased surface tension caused by presence of a small amount of sulfate in the silicate glasises. Increased surface tension implies increased sintering rate, but sintering evidently stops in a day or two, possibly because only a very thin skin of sulfate-rich layer develops, and once this skin forms necks, no more material is available. This also explains why temperature makes little difference in deposit strength; i.e., strength is limited by the amount of sulfated material and not by the sintering rate, since even at lower temperatures sintering is 
essentially complete in 1 day (the shortest test). Downstream deposits never become as hard as upstream massive deposits because in downstream deposits the deposition rate is high compared to the sulfation rate, whereas in the upstream deposits, sulfation rates are believed to be higher relative to deposition rates.

The relationship between composition and strength development can be used to determine additives or coal blends that may be useful in reducing the strength development rate and increasing the deposition rate, thereby increasing the shedding index. Additives high in $\mathrm{Si}$ and low in $\mathrm{Na}, \mathrm{K}, \mathrm{Mg}$, and $\mathrm{Ca}$ are indicated. The material should not be easily fluxed, should not be abrasive, and should be easily pulverized to less than 10 microns aerodynamic diameter to keep it from forming high-temperature deposits and to improve its deposition efficiency in low-temperature regions. Based on these criteria, kaolin clay is the best candidate. Kaolin is composed primarily of kaolinite $\left(\mathrm{Al}_{2} \mathrm{Si}_{2} \mathrm{O}_{5}[\mathrm{OH}]_{4}\right)$. It occurs in relatively pure deposits in many regions of the United States, and is often found in the overburden at coal mines. It pulverizes easily, and is commercially available with a mass median aerodynamic diameter of 1.1 microns at a cost of about $\$ 0.03 / \mathrm{lb}$ FOB the kaolin mine (J.M. Huber Corporation, Macon, Georgia). For a typical Powder River Region Coal, approximately $26 \mathrm{lb}$ of kaolin would have to be added per ton of coal to double the shedding index. The cost would be $\$ 0.81 /$ ton of coal FOB the kaolin mine, although there are somewhat less expensive kaolins available, and it may be much less expensive in bulk. To prevent coalescence with other ash particles, it should be added in a lower temperature zone such as with the tempering air, as long as it mixes well with the combustion gas. Adding it with secondary air may also be sound in a tangentially fired system, less so in opposed wall firing because of the higher turbulence which would increase collisions between ash particles. Some testing would be required to find the most appropriate method and dosage rate for a specific boiler. 


\subsection{LEADER: LOW-TEMPERATURE ENGINEERING ADVISOR OF DEPOSITION RISK}

As a result of the research conducted through the Project Calcium effort, many of the mechanisms that influence the formation of low-temperature deposits have been determined. To allow the sponsors to use this information better in their day-to-day operations, a computer code was generated to interpret the fouling potential in the lowtemperature region of the convective pass. The computer code LEiADER (LowTemperature Engineering Advisor of Deposition Risk) is comprised of the knowledge gained from this project, as well as an enormous knowledge base developed over the past few years at the EERC.

LEADER is a FORTRAN-based code designed to predict the potential for deposition in the lower-temperature $\left(<1900^{\circ} \mathrm{F}\right)$ sections of the convective pass of a utility boiler as a function of the coal or coal blend. It is designed as a mechanistic model in which each segment of the code is based on a quantitative or qualitative mechanism. Most of the subroutines are based on measurements made during Project Calcium. Therefore, the program focuses only on the formation of upstream enamel layers and downstream powder layers since insufficient data on the formation of upstream massive layers are available. The algorithm on which LEADER is based is shown in Figure 33. The mechanisms and assumptions used throughout the algorithm are addressed below.

\subsection{LEADER Algorithm}

The LEADER algorithm is divided into six sections:

1. Input--Coal Characterization and Mass Balance

2. Inorganic Transformations

3. Transport and Deposition

4. Strength Development

5. Heat-Transfer Characteristics

6. Output--Shedding Index

Each section is comprised of multiple subalgorithms which comprise the whole. None of the sections can be individually run without the input from the previous sections due to their level of integration. Each of these sections is discussed in more detail below.

\subsubsection{Input--Coal Characterization and Mass Balance}

To effectively model the transformations of the inorganics during combustion, the size, abundance, and chemistry of the minerals, as well as the abundance of the organically and water-associated constituents are needed. The required input data for the LEADER algorithm are data obtained from CCSEM, XRF, and ultimate analysis. The CCSEM analysis also includes included/excluded analysis and ZAF' correction of the composition data. The included/excluded analysis determines whether the mineral is locked (included) within the coal matrix or liberated (excluded) from the coal. The ZAF correction is used to achieve highly quantitative data by adjusting for atomic number (Z), absorption (A), and fluorescence (F) effects during analysis. The specific formats of the data and any required analysis parameters can be found in the LEADER operations manual in Appendix A. CCSEM is used to determine the size, composition, 


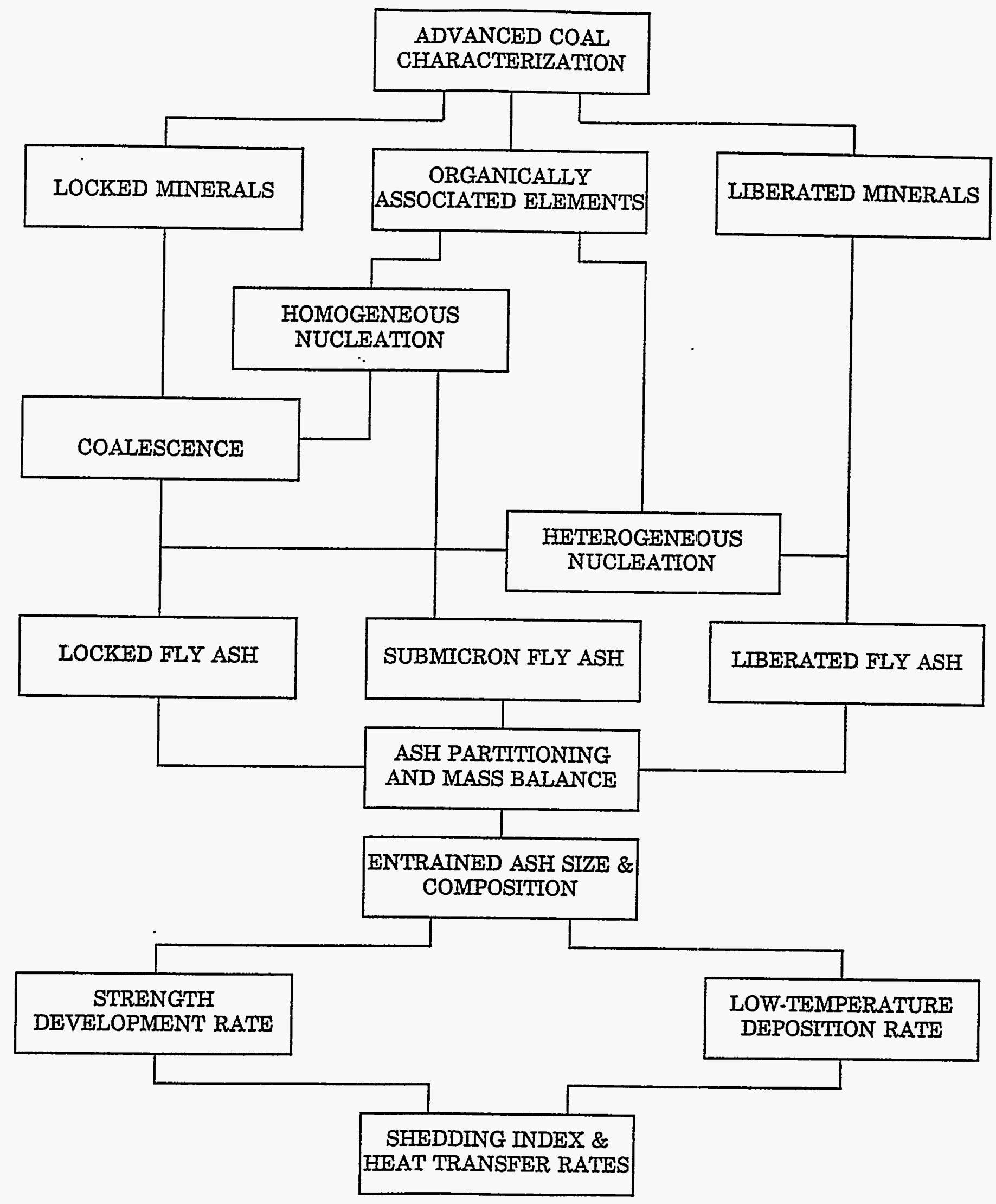

Figure 33. LEADER model algorithm. 
and abundance of the minerals in the coal, while XRF is used to determine the bulk composition of the inorganics in the coal. To determine the abundance of organically and water-associated constituents in the coal, a mass balance is performed between the XRF and CCSEM analyses, in which the organically associated constituents are assumed to be those which are unaccounted for between the two techniques. (It is noted that at the onset of the LEADER algorithm development, chemical fractionation data were used to determine the abundance of organically associated constituents. Since the technology to conduct a proper mass balance from the CCSEM and XRF results was available, and since chemical fractionation is a fairly expensive technique, it was decided to exclude the chemical fractionation data by request of the sponsors.) When a blend of two coals is desired for the input, a set of data files for each coal is required.

\subsubsection{Inorganic Transformations}

The inorganic transformations that occur during coal combustion are highly dependent on the form of the original inorganic constituents in the coal. For the purposes of LEADER, the inorganics are divided into three different groups: locked minerals, liberated minerals, and organically and water-associated inorganics. Since the abundance of organically associated constituents is generally much greater than that of the waterassociated, and since they interact in similar manners, they will both be referred to as organically associated constituents for the remainder of this discussion. Each of the above-mentioned groups of constituents is considered to interact differently throughout the transformation process.

Prior to the separation of the locked and liberated minerals, all of the minerals pass through a mineral fragmentation algorithm. Some minerals will decompose and/or oxidize during the combustion process, causing fragmentation. Each of the mineral types expected to break up is fragmented over a random distribution of varying degrees dependent on the mineral type. The most abundant minerals that may be considered to fragment include pyrite, calcite, kaolinite, and iron carbonate.

\subsubsection{Locked Minerals}

During the combustion process, locked minerals are surrouncled by a burning coal particle which is assumed to combust by the shrinking-sphere model. As the coal particle combusts and its surface recedes, the locked minerals are carried along with the coal surface and allowed to coalesce with other locked minerals. The number of coalescing locked minerals (coalescence factor) is determined by the number in the coal particle prior to combustion, and the potential for the coal to fragment during combustion into multiple char particles or to shed mineral grains. The coalescence factor is believed to be a function of the coal type (rank and petrography), coal size, mineral loading, combustion system (pulverized coal- or cyclone-fired), and combustion conditions (flame temperature, excess air, etc.). In this model, the coalescence factor is assumed to be a random distribution over a given range dependent only on the combustion system (and coal size in an indirect manner). Though they are believed to be important, no convention was made to determine the coalescence factors as a function of coal type or combustion conditions. Under the close range of coals and combustion conditions that were entailed in this study, this assumption should not generate large amounts of error; however, in using broader parameters (different types of systems) the validity of these assumpitions could be 
questionable. The intermediate coalesced particles are then assumed to act as nuclei for condensing gaseous constituents as discussed below.

\subsubsection{Liberated Minerals}

Those minerals which are liberated are assumed to pass unreacted through the initial stages of combustion. Since they are not contained within the boundaries of a coal particle, they do not have a high probability of coalescing with other mineral particles. The liberated minerals are assumed to act as nuclei upon which a portion of the organically associated constituents condense.

\subsubsection{Organically Associated Constituents}

The organically associated constituents are assumed to vaporize during combustion. Some of these vaporized constituents $(\mathrm{Ca}, \mathrm{Fe}, \mathrm{Al}, \mathrm{Mg})$ will condense predominantly as submicron particles before leaving the boundaries of the burning coal particle, thus they will behave similarly to the locked minerals and coalesce with themselves, as well as with the locked minerals on the surface of the receding carbon. Those organically associated constituents which are released from the boundary of the coal particle $(\mathrm{Na}, \mathrm{K})$ will later condense on the surfaces of both intermediate coalesced locked particles and liberated particles as they pass through the lower-temperature areas of the boiler. A small portion of each of the organically associated constituents will homogeneously coalesce and produce predominantly submicron ash particles.

During the combustion of a blend of two coals, the algorithm takes into account the processes of the locked and liberated minerals along with the coal-to-coal interactions between the vapor phase species $(\mathrm{Na}, \mathrm{K})$. Since we assume that the coalescence of minerals occurs within a coal particle, it is not possible for minerals from the two coals to interact.

Locked intermediate particles, liberated intermediate particles, and submicron particles are combined on a weighted basis (as derived during the mass balance) to form the flux of fly ash in the box of a commercial boiler.

\subsubsection{Transport and Deposition}

The ash intermediates that are present in the box of the boiler are carried into the convective pass of the boiler if the drag force of the gas stream on the particles is greater than that of gravity on the particles. In an actual combustion system, there is a great deal of turbulence that can produce any gas velocity in various directions. For the basis of simplification, an aerodynamic cut point was chosen for each of pulverized- and cyclonefired systems. This assumption limits the model to similar gas flow characteristics which could produce a small amount of error in a system if the gas flow is not even across the box. Since the cut point only affects the larger particles, only those areas where the deposition is due to large particle impaction will be affected. Since only upstream enamel and downstream powder deposits are addressed within LEADER, there is no allowance for large particle impaction, thus this error is eliminated.

Those particles that impact on the tube surfaces (upstream and downstream) are dependent on the aerodynamic diameter of the particle and the geometric, aerodynamic, 
and thermodynamic properties of the deposition surface and particle. The two types of deposition at lower temperatures addressed by LEADER are upstream enamel layer and downstream powder deposition. The transport and deposition on a tube are simplified for the model to be a constant range of aerodynamic diameters, dependent on the type of deposit on the tube. In other words, those particles depositing on the upstream side of the tube have an aerodynamic diameter between $d_{0}$ and $d_{1}$, and those particles depositing on the downstream side of the tube have an aerodynamic diameter $<d_{2}$. A moderate amount of uncertainty contributed in either of these two assumptions will produce only a small amount of error in the composition of the depositing particles (sirce composition does not change dramatically except over large size ranges) and a very small error in the deposition rates of the particles (since these rates were originally calculated using the same cut points). The deposition phenomenon is discussed in mole detail in Section 2.0.

\subsubsection{Strength Development}

Strength development in low-temperature deposits and the algorithm used by LEADER to calculate rates of strength development in downstream deposits were discussed in Section 3.0.

\subsubsection{Heat-Transfer Calculations}

The formation of ash deposits on boiler tubes has an adverse effect on heat transfer. Therefore, in addition to modeling the deposition rate and strength of ash deposits, it is desirable to predict the heat transfer through a given deposit. Crucial to the calculation of the heat-transfer rate is the value of the thermal conductivity of the ash deposit. Since the deposition rates and compositions of the upstream inner and downstream deposits are different, the heat-transfer calculations are considered separately for each half of the heat exchange tube.

Calculation of the thermal conductivity of a packed and/or sintered fine particulate material from first principles is an abstruse problem beyond the scope of a practical modeling program. Also, measurements of such thermal conductivities are sparse, and the reported values often widely divergent due to specific properties of the materials. Thus, the algorithm developed in this model is based on the empirical results of Mulcahy, Boow, and Goard (5), and Boow and Goard (6).

This algorithm assumes a characteristic thermal conductivity based on the degree of sintering and the average temperature throughout the deposit. With a known degree of sintering (based on the strength development) and a given temperature, a deposit thermoconductivity can be estimated. The thermoconductivity along with the crosssectional area of the deposit (based on deposition rates and porosity) can be used to calculate the heat transfer across the deposit. The heat transfer across the tube is calculated based on the presence of the deposit as well as on the absence of the deposit. The deposits are assumed to be cylindrical around the tube. This assumption is used to simplify the heat-exchange calculations and should generate little error when making comparisons on a relative basis. The relative amount of heat exchange efficiency lost to the deposit is determined by the ratio of the heat transfer with deposit and heat transfer without deposit. It is noted that due to the assumptions and empirical correlations used, these data are intended for qualitative comparisons only, not as a direct estimate of the loss of heat exchange efficiency. 


\subsubsection{Output--Shedding Index}

The output from the IEADER model predicts the low-temperature deposition rate and strength-development rate as a function of temperature (along with the heat exchange efficiency loss). These two rates can also be expressed as a shedding index that is equal to the ratio of the deposition rate and strength development rate.

To predict the low-temperature deposition potential as a furction of boiler location, a temperature distribution algorithm is also included in the output. By entering an FEGT for the boiler, the algorithm will estimate the temperature distribution throughout. To simplify the boiler algorithm, a standard boiler design was chosen as is shown in Figure 34. If the actual temperature distribution is known throughout the convective pass, it can be entered manually. The program will then predict the deposition and strength development rates as a function of boiler location. The assumption of a standard boiler design is purely for the sake of simplification, in a system inconsistent with this design, the program operator can ignore the heat exchange names and insert appropriate ones on a hard copy. The temperature profile is more dependent on the location of the heat exchange areas than on the type of heat exchange surface, since all systems are based on the concept of optimal heat exchange. In the case where the boiler contains a series of heat exchange panels hanging over the nose of the boiler, the FEGT temperature should be the temperature after those panels just prior to the ent:ance of the convective pass.

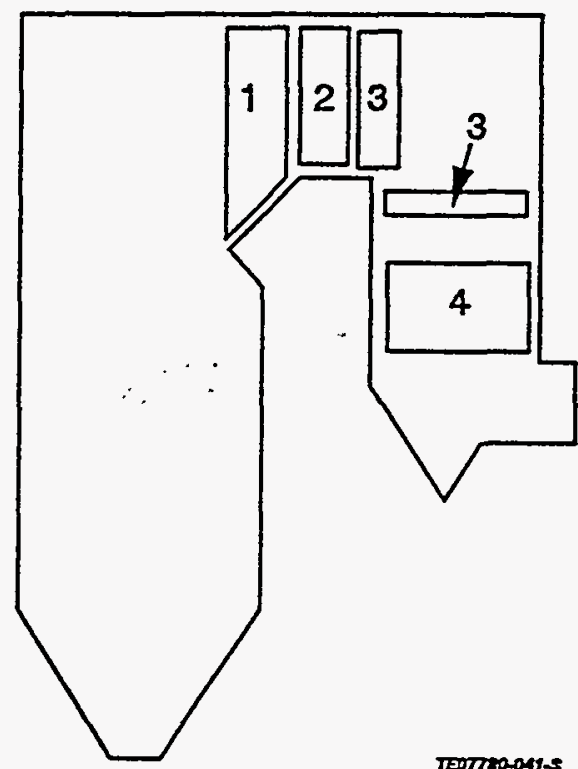

1 Secondary Superheater

2 Reheater

3 Primary Superheater

4 Economizer

Figure 34. Standard boiler design used in boiler algorithm. 


\subsection{LEADER Operation and Interpretation of Resultis}

The operation of the LEADER code and the interpretation of the results are discussed in brevity below and are addressed in detail in the LEADER operations manual in Appendix A. LEADER contains a user-friendly information section complete with graphics and a summary of the interpretation of the results.

\subsubsection{Operation}

The operation of the LEADER code requires both coal-analysis input and operationalparameters input. Each of the inputs is essential to the operation of the program and cannot be excluded. The coal-analysis inputs are:

1. CCSEM High Magnification (240x) File.

2. CCSEM Low Magnification (50x) File.

3. XRF File.

4. Ultimate File.

Each coal data set for the model will contain one of each of these. The user interface will request the file name for each of these during the operation of the program.

The operational parameter inputs are used in the depositional algorithms to define the deposition limits. The required inputs are:

1. Coal Feed Rate (ton/hr).

2. Cross-Sectional Area of Convective Pass ( $\left.\mathrm{ft}^{2}\right)$.

3. Air Feed Rate (Klb/hr).

4. Temperature Profile.

Upon entry of all of the above parameters, the program will commence operation. The total time required for completion of the code is dependent on the speed of the computer being used. Estimated times for completion are shown in the opes:ations manual and in the graphic interface of the program. Upon completion of the program, the results can either be printed or viewed through the computer graphics program.

\subsubsection{Interpretation of Results}

The results generated from the LEADER program are all relative to a given data set. They are not intended to be quantitative amounts, but rather relative indices. The output produces a deposition rate, strength development rate, shedding index, and heat exchange efficiency loss.

The heat exchange loss represents the relative decrease in thermal efficiency of a specific heat exchange area due to the presence of a deposit. A heat exchange efficiency loss of $0.0 \%$ would be expected for a system containing no deposits. The efficiency loss is expressed for both the upstream inner layer and downstream deposits. This parameter can be used to compare the thermodynamic effects of deposits produced by different coals. The heat loss is dependent on the amount and physical characteristics of the deposit. The higher the heat exchange efficiency loss, the greater the decrease in thermal efficiency of 
that exchange surface. All values should be treated as relative, for ranking coals or coal blends according to potential low-temperature deposition problems.

\subsection{Results}

To ensure the validity of the LEADER model, it was tested against data taken from the full-scale utility tests conducted throughout the project. The inorganic transformations and temperature-distribution algorithms are compared with the actual data sampled. Since insufficient data are available to quantify the deposition and strength development in a full-scale utility boiler, those comparisons are not discussed here. Instead, the output must be used in conjunction with boiler experience to bring out their full potential for comparing coals and coal blends. See Sections 2.0 and 3.0 for discussions of these processes.

\subsubsection{Inorganic Transformations}

The inorganic transformations algorithm of the LEADER program was run on the following six coals: Black Thunder (King), Antelope (King), Black: Thunder (Sherco), Antelope (Sherco), Eagle Butte (Welsh), and Shoshone (Schahfer). Each of these coals had a convective pass ash sample collected from the corresponding facility during Project Calcium testing. The comparisons of the predicted ash size and composition distributions versus the actual distributions are discussed below, with a list of the assumptions used in generating them.

The particle-size and composition distributions representing the actual distribution were derived from an average of convective pass particulate samples when more than one was available. The size and composition distributions of the ash throughout the convective pass should change only minimally by the amount of material lost to deposition; thus, by averaging the convective pass samples, any overall errors attributed to sampling can be decreased. The ash samples used for each of the comparisons are from Black Thunder (King), Ports 2 and 3; Antelope (King), Port 2; Black Thunder (Sherco), Ports 1 and 2; Antelope (Sherco), Ports 1 and 2; Shoshone (Schahfer), Ports 2 and 3; and Eagle Butte (Welsh), Port 1. Refer to field test reports for more information about ports and sampling techniques).

During the sampling of the convective pass ashes, the ability to sample isokinetically with respect to the convective pass velocities as well as at constant intake flow rates can be difficult to achieve. A deviation from the isokinetic sampling rate will cause a change in the size distribution entering the sampling train. A deviation in the intake flow rates will result in a change in the actual sampling train cut points. For comparative purposes, all samples are assumed to have been collected at 100\% isokinetic and 100\% of optimal intake flows.

The graphical representation of the size and composition distributions for all of the coals can be found in Appendix B; for brevity, only a few examples will be discussed here. Figures 35 and 36 compare the particle-size distributions of the predicted and actual convective pass ash for the Black Thunder (Sherco) coal in a pc-fired system and the Black Thunder (King) coal in a cyclone-fired system, respectively. Both sets of predicted values compare well with the actual values, as is common among all six of the coal data sets (Figures B-1 to B-6 in Appendix B). 


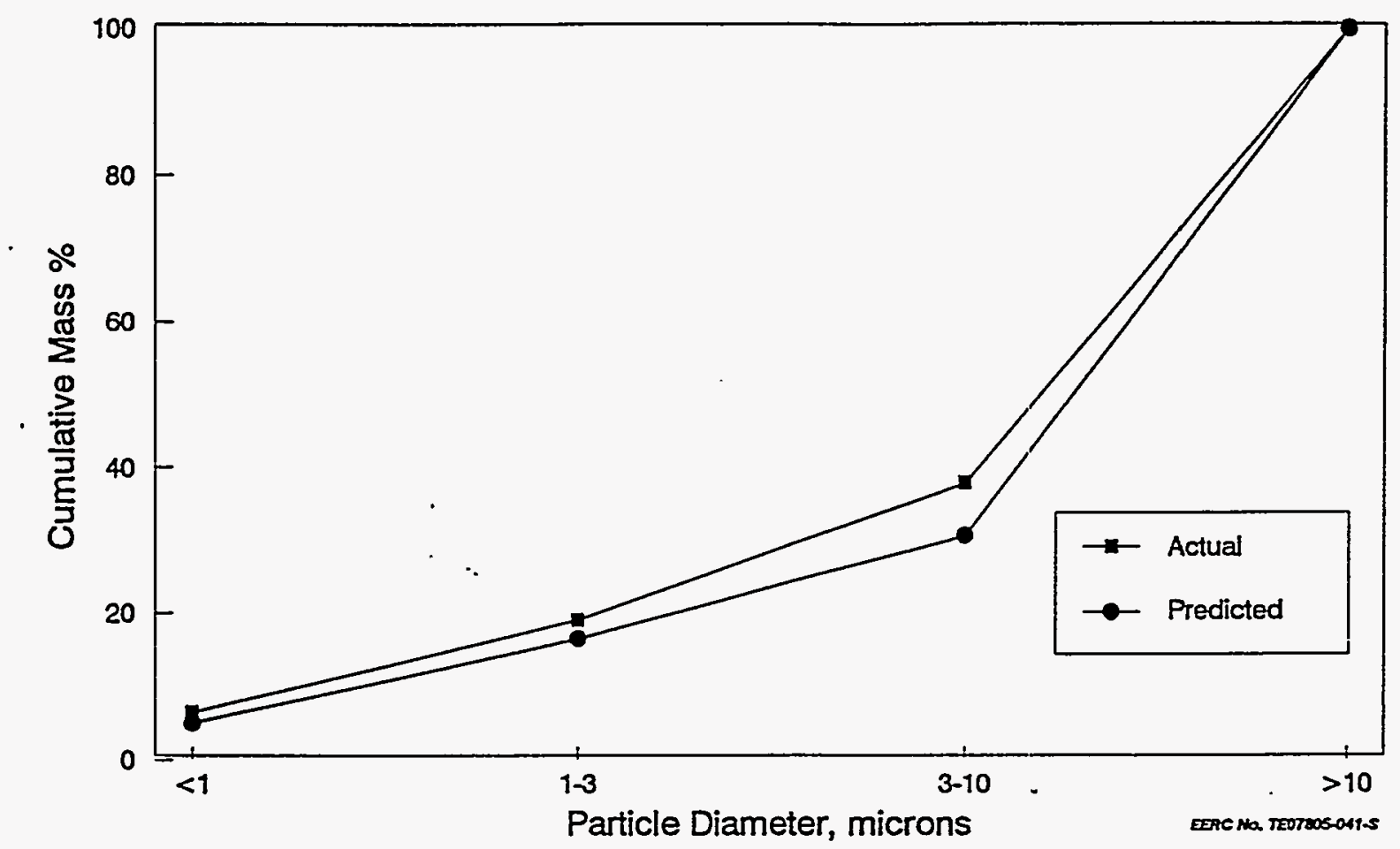

Figure 35. Comparison of measured and predicted particle-size distribution for Black Thunder coal burned in a pe unit (Sherco).

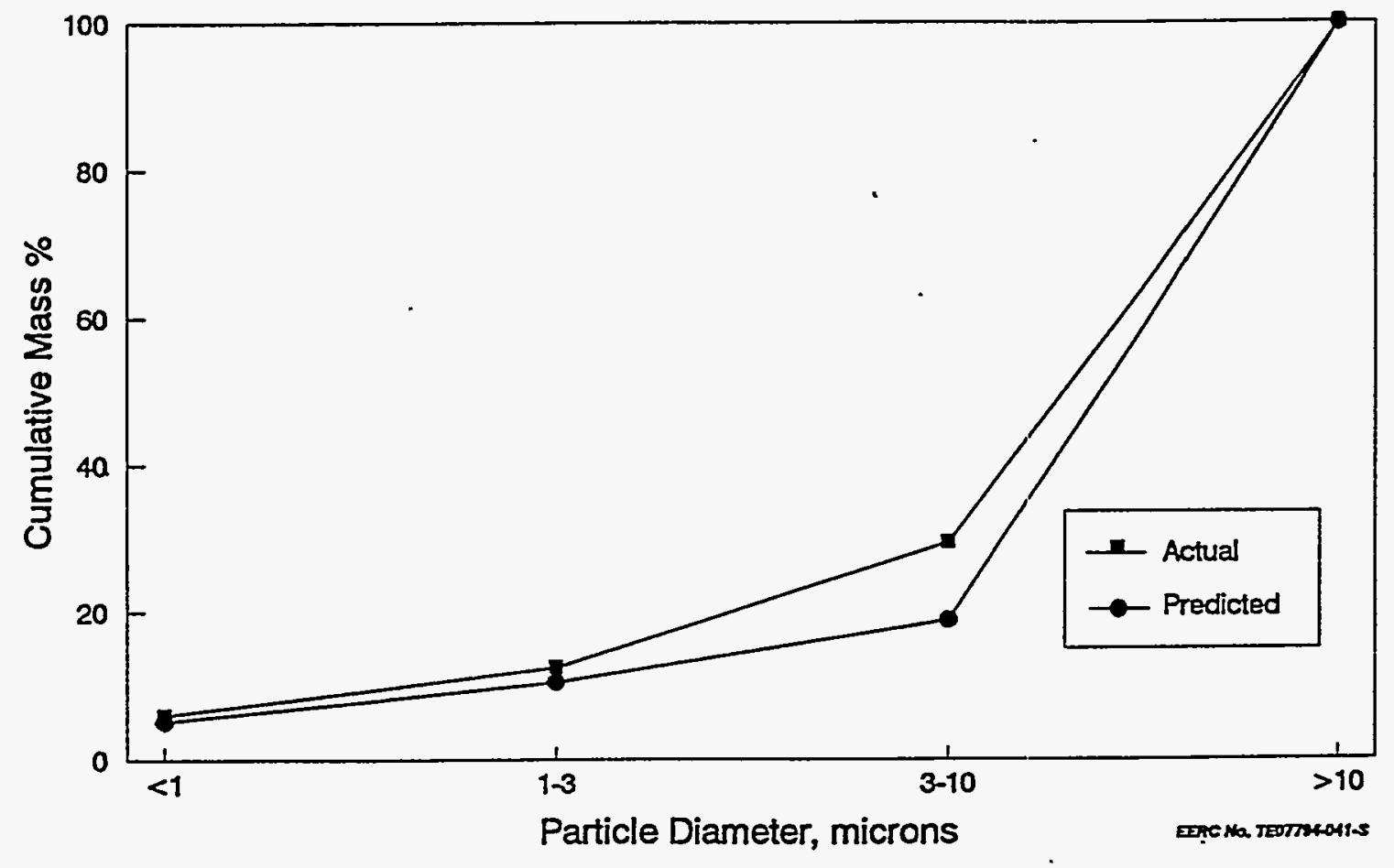

Figure 36. Comparison of measured and predicted particle-size distributions for Black Thunder coal burned in a cyclone unit (King). 
Figures 37 and 38 show the composition distributions for the Black Thunder (King) 3to 10-micron particles and the bulk ash sample, respectively. Also added to Figure 38 is the bulk composition of the coal prior to combustion as determined by XRF. The predicted compositions compare farorably to the actual compositions as shown in these two figures as well as in the majority of the other samples (Figures B-1 to B-36 in Appendix B). The coal system with the largest discrepancies between the predicted and actual data is the Eagle Butte (Welsh) coal. One of the assumptions in using any data for modeling purposes is that it is representative of the sample. In the case of the Eagle Butte (Welsh) coal, the CCSEM data do not seem consistent with the bulk composition of the coal as determined in the mass-balancing steps of the model. The CCSEM was duplicated on a separate coal plug with approximately the same results. The actual cause of the error is not certain, but a few of the most probable causes are listed below.

1. The coal sample used in the CCSEM analysis was not a representative sample of the overall coal. It is. possible that the coal was somehov contaminated or enriched with a large amount of excluded kaolinite. This is fairly probable since past analyses of Eagle Butte coals had much lower clay contents, but higher pyrite and quartz contents.

2. The CCSEM technique in some way is skewing the mineralogy results in favor of the clay-type minerals. This was not evident in any of the other coals, but since the CCSEM technique can be operator-biased, this may have occurred.

3. The mass-balance routine of the LEADER model does not respond favorably under these circumstances. Once again, this was not evident from the other coals, but may be true for a coal high in clay content.

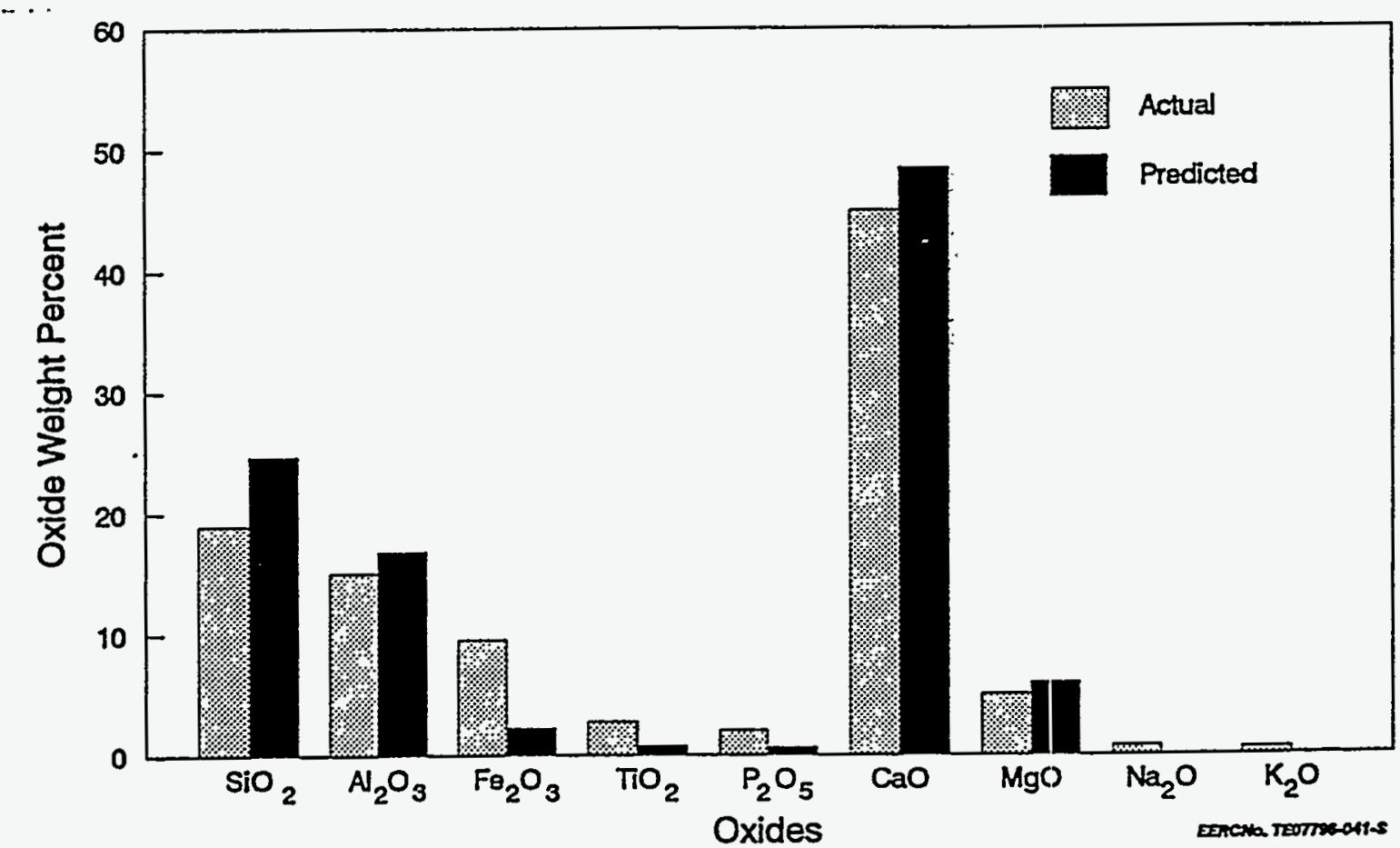

Figure 37. Comparison of measured and predicted composition distributions for the Black Thunder (King) 3- to 10-micron ash particlesi. 


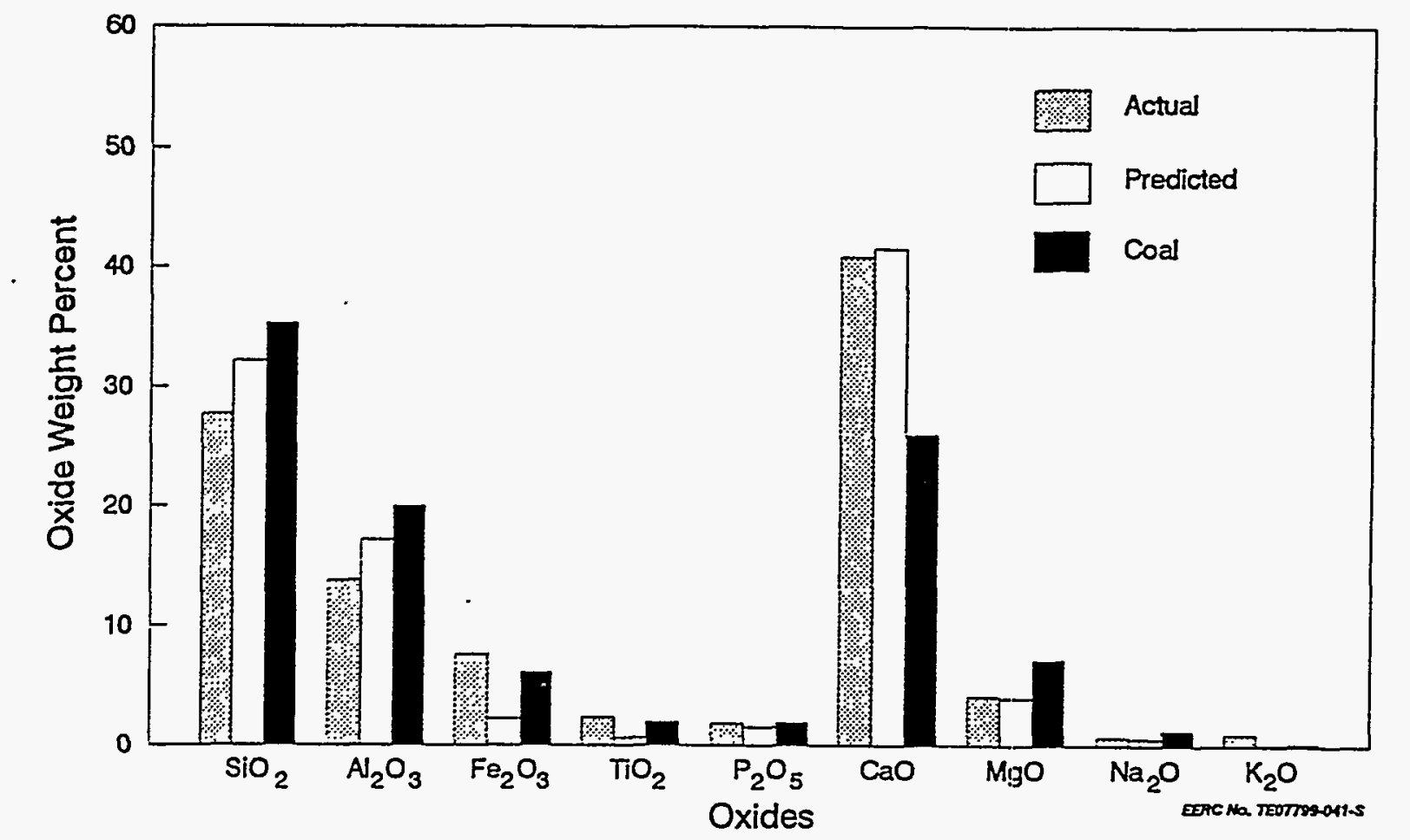

Figure 38. Comparison of the measured and predicted composition distributions for the Black Thunder (King) bulk ash.

Overall, with the exception as previously noted, the comparison of the actual and predicted size and composition distributions of the six coal systems tested look very good. Though it is difficult to assess the validity and precision of the strength and deposition rates, we can account positively for the data entering into their algorithms.

\subsubsection{Temperature Distribution in Convective Pass}

The algorithm for predicting the temperature distributions arross the convective pass of a utility boiler was tested against the sampled temperatures from the site visits. Only King, Sherco, and Schahfer had adequate temperature profile data to compare to the predicted values. The algorithm predicts temperature as a function of the FEGT and boiler location. A standard boiler design is chosen for the algorithm for visual purposes. For a system not matching the given system, the location and not the heat exchange type is used for comparison. The actual locations of the sampling ports and the temperature profiles can be found in the field test reports.

Figure 39 shows the predicted temperatures versus the actual temperatures for the above-mentioned systems. The measured temperatures, with a few minor exceptions, fit the predicted values very closely. The two points straying the farthest from the predicted values are those recorded from the King plant. These points were predicted using an FEGT determined from an on-line system different from the system used by the EERC to record the convective pass temperatures. These two systems were not within the same calibration parameters, with the on-line system differing from the EERC method by a minimum of $95^{\circ} \mathrm{F}$ under most situations. Thus, the temperature profile in the convective pass is strongly dependent on an accurate FEGT. 


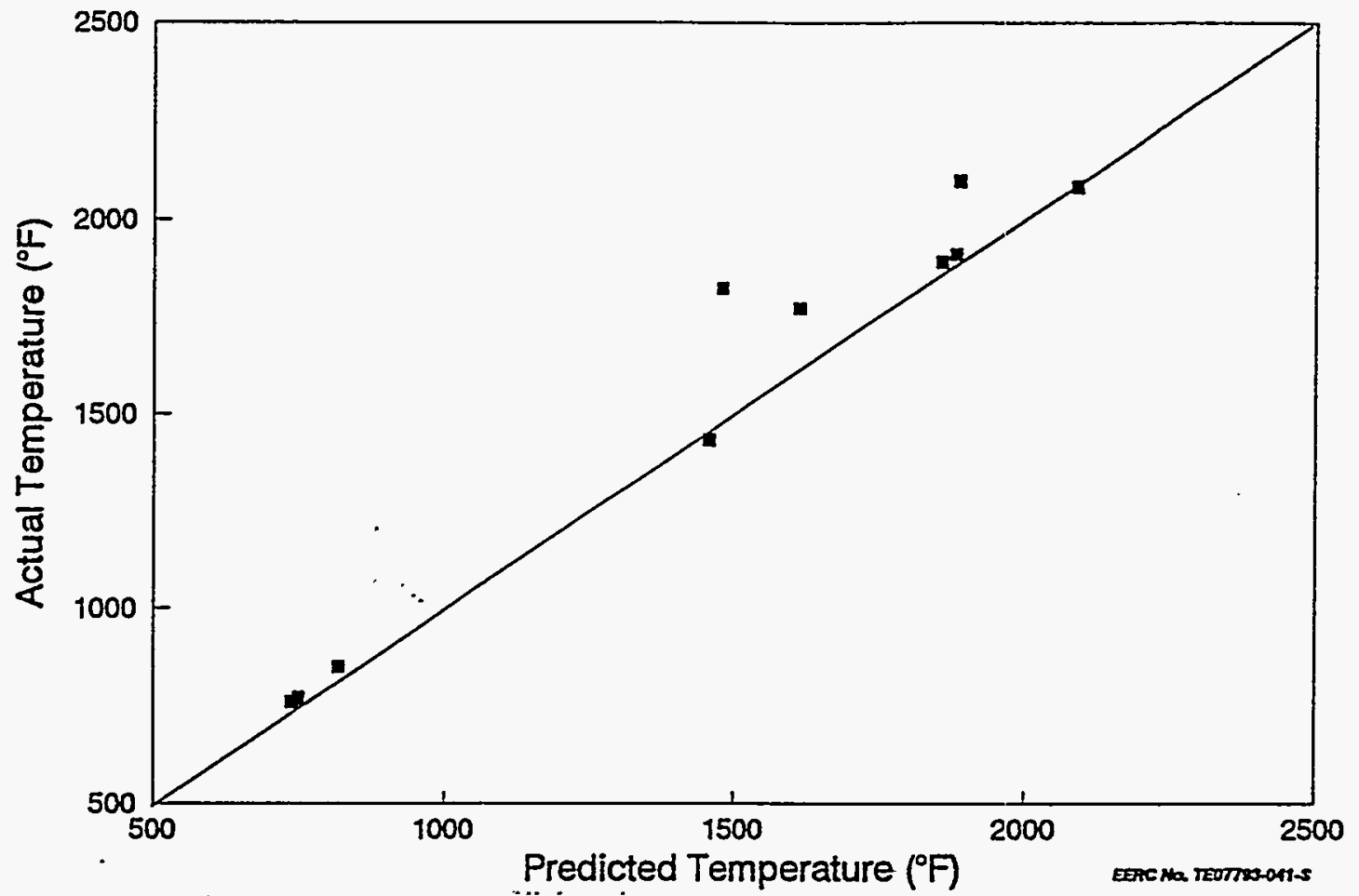

Figure 39. Measured versus predicted temperatures throughout the convective pass of a boiler. 


\subsection{REFERENCES}

1. Benson, S.A.; Kalmanovitch, D.P. "Characterization of Full-Scale Ash-Fouling Deposits Formed From a Subbituminous Coal," JPGC, ASMFi preprint, Dallas, TX, 1989.

2. Jones, M.L.; Kalmanovitch, D.P.; Steadman, E.N.; Zygarlicke, C.J.; Benson, S.A. "Application of SEM Techniques to the Characterization of Cloal and Coal Ash Products," In Advances in Coal Spectroscopy; Meuzelaar, M.I.C., Ed.; Plenum Publishing Co.: New York, 1992.

3. Benson, S.A.; Holm, P.L. "Comparison of the Inorganic Consitituents in Three LowRank Coals," Ind. Eng. Chem. Prod. Res. Dev. 1985, 24, 145-149.

4. Benson, S.A.; Severson, A:L.; Beckering, W. "Application of Energy-Dispersive X-ray Fluorescence Spectrometry in the Analysis of Low-Rank Coal Ashes," Am. Lab. 1980, 12 (11), 35.

5. Mulcahy, M.F.R.; Boow, J.; Goard, P.R.C. "Fireside Deposits and Their Effect on Heat Transfer in Pulverized Fuel Fired Boilers: Part 1. The Radian Emittance and Effective Thermal Conductance of Deposit," Jour. Inst. Fuel 1.966, 39, 385.

6. Boow, J.; Goard, P.R.C. "Fireside Deposits and Their Effect on Heat Transfer in a Pulverized Coal-Fired Boiler: Part 3 - The Influence of the Physical Characteristics of the Deposit on Its Radiant Emittance and Effective Thermal Conductance," Jour. Inst. Fuel 1969, 44, 412. 
APPENDIX A

LEADER OPERATIONS MANUAL 


\section{LEADER OPERATIONS MANUAL}

Low-Temperature Engineering Advisor of Deposition Risk

Operations Manual 


\section{TABLE OF CONTENTS}

Page

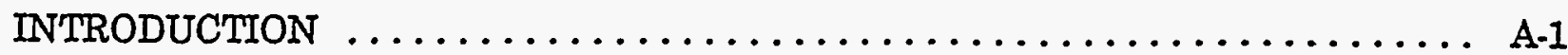

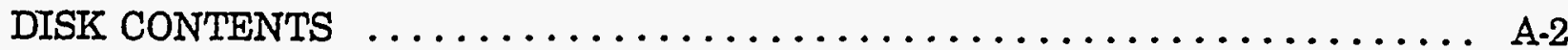

Program Disk 1 of $2 \ldots \ldots \ldots \ldots \ldots \ldots \ldots \ldots \ldots \ldots \ldots \ldots \ldots \ldots \ldots \ldots \ldots \ldots$, A-2

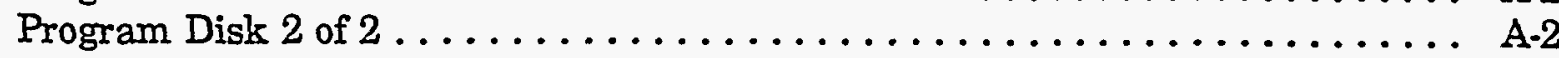

INSTALLATION $\ldots \ldots \ldots \ldots \ldots \ldots \ldots \ldots \ldots \ldots \ldots \ldots \ldots \ldots \ldots \ldots \ldots \ldots \ldots \ldots \ldots$

REQUIRED DATA AND FORMATS $\ldots \ldots \ldots \ldots \ldots \ldots \ldots \ldots \ldots \ldots \ldots \ldots \ldots \ldots \ldots$

CCSEM, ZAF, In/Ex $\ldots \ldots \ldots \ldots \ldots \ldots \ldots \ldots \ldots \ldots \ldots \ldots \ldots \ldots \ldots \ldots \ldots \ldots \ldots$

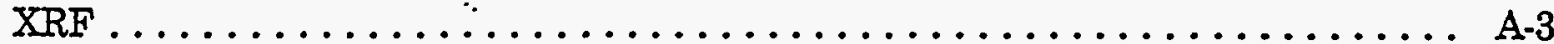

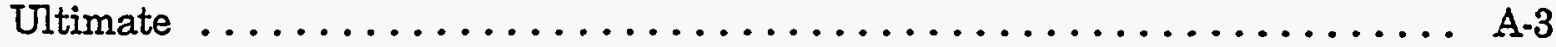

MEMORY AND TIME REQUIREMENTS $\ldots \ldots \ldots \ldots \ldots \ldots \ldots \ldots \ldots \ldots$ A 4 .

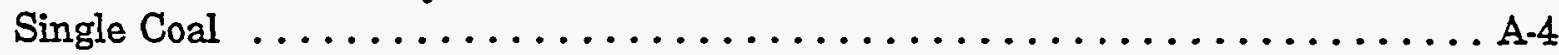

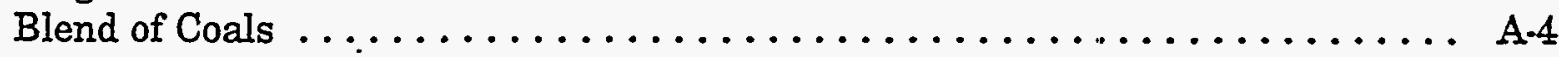

LEADER OPERATIONS $\ldots \ldots \ldots \ldots \ldots \ldots \ldots \ldots \ldots \ldots \ldots \ldots \ldots \ldots \ldots \ldots \ldots \ldots \ldots$

HOW TO INTERPRET LEADER RESULTS $\ldots \ldots \ldots \ldots \ldots \ldots \ldots \ldots \ldots$ A-7

Deposition Rate, Strength Development Rate, and Shedding Index ....... A-7

Heat Exchange Loss $\ldots \ldots \ldots \ldots \ldots \ldots \ldots \ldots \ldots \ldots \ldots \ldots \ldots \ldots \ldots \ldots \ldots \ldots \ldots$

\section{LIST OF FIGURES}

Figure $\quad$ Page

A-1 Standard boiler design used in boiler algorithm $\ldots \ldots \ldots \ldots \ldots \ldots \ldots$ A-5 


\section{LEADER (Low-Temperature Engineering Advisor of Deposition Risk)}

LEADER is a FORTRAN-based computer code designed to predict the lowtemperature deposition potential associated with the combustion of a specific high-calcium western U.S. coal. The program first predicts the particle-size and composition distribution (PSCD) of the entrained ash reaching the convective pass of a commercial boiler and then predicts the low-temperature deposition and strength development potential of the ash, and the heat exchange efficiency loss due to the deposits. All outputs from the LEADER model are on a relative basis and are intended to be used for comparative purposes.

\section{INTRODUCTION}

The entrained ash PSCD is predicted from the distribution of the inorganics in the coal. Computer-controlled scanning electron microscopy (CCSEM), x-ray fluorescence (XRF), and ultimate analysis are used to characterize the coal. The CCSEM analysis is also combined with a locked/liberated particle analysis (to determine if the individual mineral grains are located within a coal matrix or are free mineral grains) and ZAF data reduction of the compositions. The ZAF data reduction produces compositions free of the effects of atomic number (Z), x-ray absorption (A), and $\mathrm{x}$-ray fluorescence (F). A mass balance is compiled on the coal by comparing the CCSEM and XRF data. The resultant balance provides the compositions of the minerals with their associations to the coal, organically associated constituents, and submicron particles. The minerals are divided into two data sets: those locked within a coal particle and those liberated from the coal matrix. The locked minerals are coalesced, on a frequency basis, in a random fashion with other mineral and submicron particles as well as those organically associated constituents that are expected to condense during the combustion of a coal particle. The coalescence produces intermediate, locked fly ash particles. The liberated minerals do not undergo a coalescence step. Both the intermediate locked particles and the liberated minerals are then reacted with those constituents which stay in the vapor phase during the early stages of combustion. During the coalescence and vapor-nucleation steps, the formation of submicron fly ash is predicted. After these steps are completed, three different data sets are formed: locked fly ash, liberated fly ash, and submicron fly ash particles. The three data sets are characterized and combined on a mass basis, giving a distribution of the ash composition as a function of size.

The ash distributions are used to determine the deposition rate of the upstream inner layer and downstream deposits, strength development in these deposits, and the loss of heat exchange efficiency due to the deposits. The deposition rates are a function of the particle-size distribution of the ash and of the gas velocity and ternperature. The strength-development rate is a function of the composition of the deposited ash. The efficiency heat exchange loss due to deposition is a function of the deposit depth and thermoconductivity. The shedding index (SI) is equal to the ratio of the deposition growth and strength development. 


\section{DISK CONTENTS}

The LEADER program is contained on two disks with the following contents:

Program Disk 1 of 2

version2.ltl

ndprun.exe (copyright 1987, 1990 Microway Inc.)

leader.bat

result.lst

default.par

Program Disk 2 of 2

homohet.cyc

homohet.pcf

name.prn

readme.prn

temps.prn

\section{INSTALLATION}

For best results and ease of use, LEADER should be installed in a subdirectory on a hard disk.

1. To create a subdirectory titled LEADER on the $\mathrm{C}$ drive type: $m d c:[L E A D E R \quad$ [return]

2. Enter the subdirectory that was just created by typing: cd c:ILEADER [return]

3. Place program disk 1 into drive $A$ and type: copy a:** [return]

4. Place program disk 2 into drive $A$ and type: copy a:** [return]

5. Place data disk into drive $\mathrm{A}$ and type: copy a:** [return]

6. Repeat for all data disks.

7. To run, type: LEADER [return] 


\section{REQUIRED DATA AND FORMATS}

The three data sets required for the operation of the LEADER program are 1) ZAF. corrected CCSEM with included/excluded (in/ex) analysis, 2) XRF analysis, and 3)

ultimate analysis. The data formats for each of these three data sets are shown below.

\section{CCSEM, ZAF, In/Ex}

There should be two CCSEM files: the first one is run at 240x for particles between 1 and 10 microns, and the second file is run at 50x for those particles between 10 and 100 microns.

Point \#, C-Type, X-ray Counts, Na, Mg, Al, Si, P, S, Cl, K, Ca, Fe, Ba, Ti, X-Coord., Y.Coord., Avg. Diam., Max. Diam., Min. Diam., Area, Perim., Shape, Frame, Loc./Lib.

- Composition is expressed in normalized-elemental weight percent.

- Loc./Lib. is represented by 1-locked, 2-liberated.

XRF

$$
\begin{aligned}
& \mathrm{SiO}_{2} \\
& \mathrm{Al}_{2} \mathrm{O}_{3} \\
& \mathrm{Fe}_{2} \mathrm{O}_{3} \\
& \mathrm{TiO}_{2} \\
& \mathrm{P}_{2} \mathrm{O}_{5} \\
& \mathrm{CaO} \\
& \mathrm{MgO} \\
& \mathrm{Na}_{2} \mathrm{O} \\
& \mathrm{K}_{2} \mathrm{O}
\end{aligned}
$$

- Composition is expressed in normalized-oxide weight percent.

\section{Ultimate}

\section{Hydrogen \\ Carbon \\ Nitrogen \\ Sulfur \\ Oxygen \\ Ash}

- Composition is expressed in "as-received" normalized percents. 


\section{MEMORY AND TIME REQUIREMENTS}

LEADER is comprised of a set of programs which run in succession. Each program passes data to the next section by creating temporary .prn files. Since some of these files are fairly large, the program requires approximately 5 megabytes of hard disk space after installation to run. In addition the program requires approximately 5 megabytes of program memory. Due to advanced 32-bit compiling techniques and graphics capabilities, this program also requires a 386 or higher processor and math coprocessor with a VGA screen.

The time required for LEADER to manipulate a coal or blend of coals depends on the computer size and speed and original coal input data. Approximate time requirements are listed below for a series of systems:

\section{Single Coal}

$386 / 20 \mathrm{MHz}$ - 25 minutes

$486 / 33 \mathrm{MHz}$ - 15 minutes

$486 / 50 \mathrm{MHz} \cdot 12$ minutes

Blend of Coals

$386 / 20 \mathrm{MHz}$ - 40 minutes

$486 / 33 \mathrm{MHz}-30$ minutes

$486 / 50 \mathrm{MHz}$ - 20 minutes

\section{LEADER OPERATIONS}

1. To run the LEADER program, enter the subdirectory in which it was installed: cd c:lleader [return]

2. Type: LEADER [return]

3. Press [return] to view the menu screen. Instructions 4 through 11 all start from the menu screen.

4. To run LEADER on a single coal:

4a. Press S.

4b. Enter the data files and a name for the results file. Enter extensions for the data files but not for the results file. The program rill add the extension ".out" to the results file when it is created. Note: The data files must be located within the LEADER subdirectory.

4c. Enter the operational data, including a decimal point for all numbers.

4d. The user may choose to make the operational data just entered the default parameters. 
4e. Choose and enter the temperature profile technique: manual, predicted, or default. Refer to Figure 1 for the names corresponding to the heat exchange surface. When entering manual temperatures, use the heat exchange location as a guide and not the name of the particular heat exchange type.

4f. LEADER will now run the single coal through the algorithms.

4g. Upon completion, the results can be viewed (Section: 10).

5. To run LEADER on a blend of two coals:

5a. Press B.

5b. Enter the data files for both coals and a name for the results file. Enter extensions for the data files but not for the results file. The program will add the extension ".out" to the results file when it is created. Note: The data files must be located within the LEADER subdirectory.

5c. Enter the operational data, including a decimal point for all numbers.

5d. The user may choose to make the operational data just entered the default parameters.

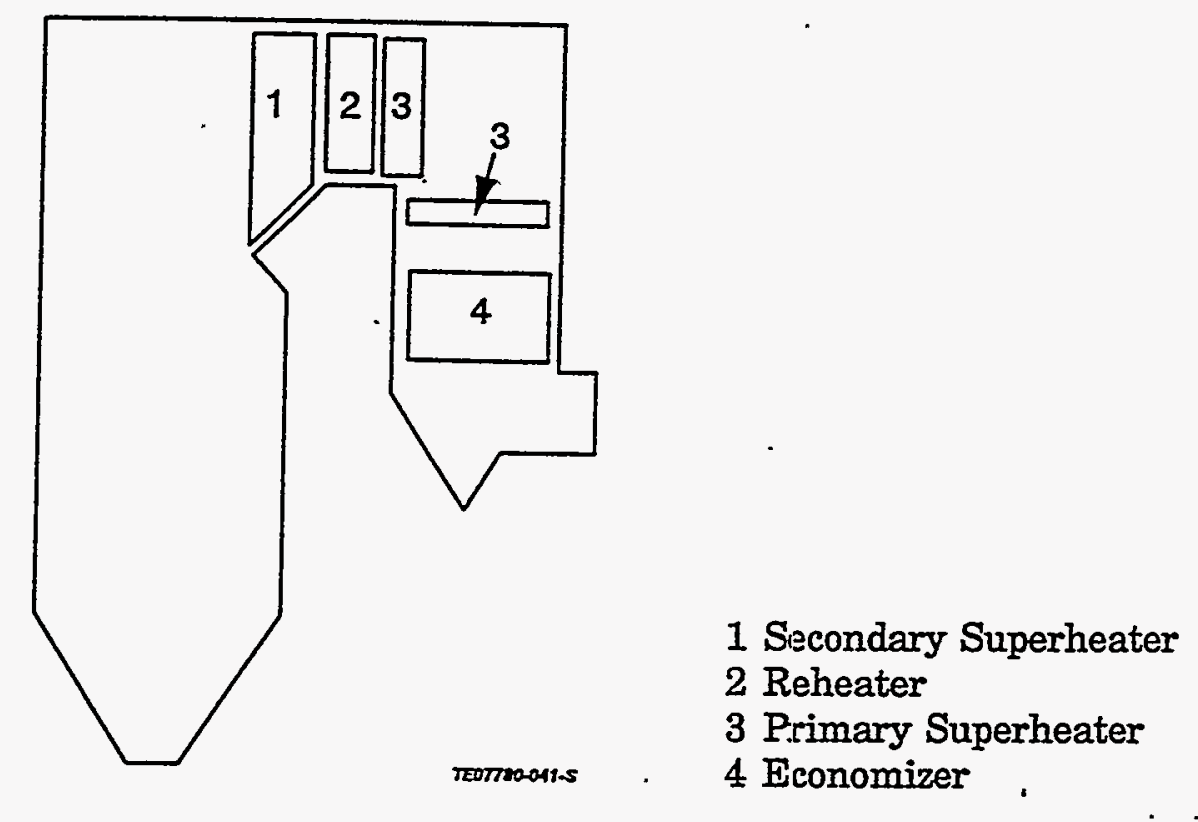

Figure A-1. Standard boiler design used in boiler algorithm. 
5e. Choose and enter the temperature profile technique: manual, predicted, or default. Refer to Figure 1 for the names corresponding to the heat exchange surface. When entering manual temperatures, use the heat exchange location as a guide and not the name of the particular heat exchange type.

5f. LEADER will now run the blended coal through the algorithms.

5g. Upon completion, the results can be viewed (Section. 10).

6. To enter into the introduction and program overview:

6a. Press I.

6b. Follow the on-screen instructions; the information is presented in the following format:

I. Coal Properties

II. Inorganic Transformations
A. Coalescence/Fragmentation
B. Mineral Fragmentation
C. Vaporization/Condensation

III. Transport Properties

IV. Deposition and Deposit Growth

V. Strength Development

VI. Heat-Transfer Properties

7. To enter the required data and formats:

7a. Press $\mathrm{R}$.

7b. Follow the on-screen instructions.

8. To enter into the memory and time-requirements section:

8a. Press M.

8b. Follow the on-screen instructions.

9. To enter into the how-to-interpret-results section:

9a. Press 0.

9b. Follow the on-screen instructions.

10. To enter into the view results section:

10a. Press V. 
10b. Press return to go to the second page.

10c. Choose which LEADER run to view.

10d. This screen can be printed by using the Print Screen key. The results file (with extension ".out"), which was named during the start of the LEADER run, can be printed from DOS after exiting the program.

11. To exit the LEADER program, type E.

\section{HOW TO INTERPRET LEADER RESULTS}

The results generated from the LEADER program are all relative to a given data set. They are not intended to be quantitative amounts, but rather relative indices. The output produces a deposition rate, strength development rate, shedding index, and heat exchange efficiency loss. The results from the model can be viewed within the program or they can be printed by printing the (results).out file which was created using the results name specified by the user. The graphics screen can also be printed by depressing the Print Screen key.

\section{Deposition Rate, Strength Development Rate, and Shed.ding Index}

The rates and indices should be used to rank coals or operating conditions of interest according to their propensity to cause low-temperature fouling. F'or best results, the values should be used in conjunction with observations of performance of a variety of coals for which specific fouling data are available.

\section{Heat Exchange Loss}

The heat exchange loss represents the relative decrease in thermal efficiency of a specific heat exchange area due to the presence of a deposit. A heat exchange efficiency loss of $0.0 \%$ would be expected for a system containing no deposits. The efficiency loss is expressed for both the upstream inner layer and downstream deposits. This parameter can be used to compare the effects of deposits on heat exchange efficiency. The heat loss is dependent on the amount and physical characteristics of the deposit. The higher the heat exchange efficiency loss, the greater the decrease in thermal efficiency of that exchange surface. 


\begin{abstract}
APPENDIX B
COMPARISONS OF MEASURED AND PREDICTED PARTICLE-SIZE AND COMPOSITION DISTRIBUTIONS USING THE LEADER MODEL
\end{abstract}




\section{LIST OF FIGURES}

Figure

Page

B-1 Measured and predicted particle-size distributions for Black Thunder (Sherco) in a pe-fired system . . . . . . . . . . . . . . . . . . . . B-

B-2 Measured and predicted particle-size distributions for Black Thunder

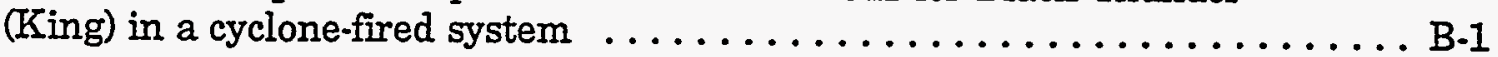

B-3 Measured and predicted particle-size distributions for Antelope (Sherco) in a pc-fired system $\ldots \ldots \ldots \ldots \ldots \ldots \ldots \ldots \ldots \ldots \ldots \ldots . \ldots \ldots$. 2

B-4 Measured and predicted particle-size distributions for Antelope (King)

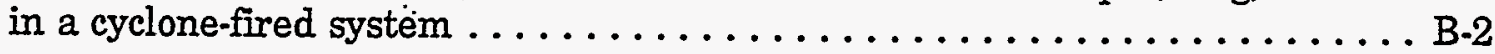

B-5 Measured and predicted particle-size distributions for Shoshone (Schahfer) in a cyclone-fired system $\ldots \ldots \ldots \ldots \ldots \ldots \ldots \ldots \ldots \ldots \ldots \ldots$ B-3

B-6 Measured and predicted particle-size distributions for Eagle Butte (Welsh) in a cyclone-fired system $\ldots \ldots \ldots \ldots \ldots \ldots \ldots \ldots \ldots \ldots \ldots \ldots$ B-3

B-7 Measured and predicted composition distributions for Black Thunder (Sherco), $>10$-micron ash, produced in a pc-fired system . . . . . . . . B-4

B-8 Measured and predicted composition distributions for Black Thunder (Sherco), 10- to 3 -micron ash, produced in a pc-fired systen $\ldots \ldots \ldots \ldots$ B-4

B-9 Measured and predicted composition distributions for Black Thunder (Sherco), 3- to 1-micron ash, produced in a pc-fired system ........... B-5

B-10 Measured and predicted composition distributions for Blacik Thunder (Sherco), <1-micron ash, produced in a pc-fired system . . . . . . . . . B.5

B-11 Measured and predicted composition distributions for Blacks Thunder (Sherco), bulk ash (weighted composite), produced in a pc-fired system . . . . B-6

B-12 Measured and predicted composition distributions for Black Thunder (King), $>10$-micron ash, produced in a pc-fired system $\ldots \ldots \ldots \ldots \ldots$ B-6

B-13 Measured and predicted composition distributions for Black Thunder (King), 10- to 3-micron ash, produced in a pc-fired system

B-14 Measured and predicted composition distributions for Black Thunder (King), 3- to 1-micron ash, produced in a pc-fired system .

B-15 Measured and predicted composition distributions for Black Thunder (King), $<1$-micron ash, produced in a pc-fired system $\ldots \ldots \ldots \ldots \ldots \ldots$ B-8 


\section{LIST OF FIGURES (continued)}

Figure

$\underline{\text { Page }}$

B-16 Measured and predicted composition distributions for Black Thunder (King), bulk ash (weighted composite), produced in a pc-fired system . . . . . B.8

B-17 Measured and predicted composition distributions for Antelope (Sherco), >10-micron ash, produced in a pc-fired system ........... B-9

B-18 Measured and predicted composition distributions for Antelope (Sherco), 10- to 3-micron ash, produced in a pc-fired system .......... B.9

B-19 Measured and predicted composition distributions for Antelope (Sherco), 3- to 1-micron ash, produced in a pc-fired system ......... B-10

B-20 Measured and predicted composition distributions for Antelope (Sherco), <1-micron ash, produced in a pc-fired system . . . . . . . . . B-10

B-21 Measured and predicted composition distributions for Antelope (Sherco), bulk ash (weighted composite), produced in a pc-fired system . . . . B-11

B-22 Measured and predicted composition distributions for Antelope (King), $>10$-micron ash, produced in a pc-fired system . . . . . . . . B-11

B-23 Measured and predicted composition distributions for Antelope (King), 10. to 3-micron ash, produced in a pc-fired system . . . . . . . . B-12

B-24 Measured and predicted composition distributions for Antelope (King), 3- to 1-micron ash, produced in a pc-fired system . . . . . . . . . . B-12

B-25 Measured and predicted composition distributions for Antelope (King), <1-micron ash, produced in a pc-fired system . . . . . . . . . B-13

B-26 Measured and predicted composition distributions for Antalope (King), bulk ash (weighted composite), produced in a pc-fired system ..... B-13

B-27 Measured and predicted composition distributions for Shoshone (Schahfer), >10-micron ash, produced in a pc-fired system .......... B-14

B-28 Measured and predicted composition distributions for Shoshone (Schahfer), 10- to 3-micron ash, produced in a pc-fired system .......... B-14

B-29 Measured and predicted composition distributions for Shoshone (Schahfer), 3- to 1-micron ash, produced in a pc-fired system . . . . . . . B. B.15

B-30 Measured and predicted composition distributions for Shoshone (Schahfer), <1-micron ash, produced in a pe-fired system . . . . . . . B-15 


\section{LIST OF FIGURES (continued)}

Figure

Page

B-31 Measured and predicted composition distributions for Shoshone

(Schahfer), bulk ash (weighted composite), produced in a pc-fired system ... B-16

B-32 Measured and predicted composition distributions for Eagle Butte

(Welsh), >10-micron ash, produced in a pc-fired system

B-33 Measured and predicted composition distributions for Eagle Butte

(Welsh), 10- to 3 -micron ash, produced in a pc-fired systen . . . . . . . . B-17

B-34 Measured and predicted composition distributions for Eagle Butte

(Welsh), 3- to I-micron ash, produced in a pc-fired system . . . . . . . . B-17

B-35 Measured and predicted composition distributions for Eagle Butte

(Welsh), <1-micron ash, produced in a pc-fired system .

B-36 Measured and predicted composition distributions for Eagle Butte

(Welsh), bulk ash (weighted composite), produced in a pc-fired system. 


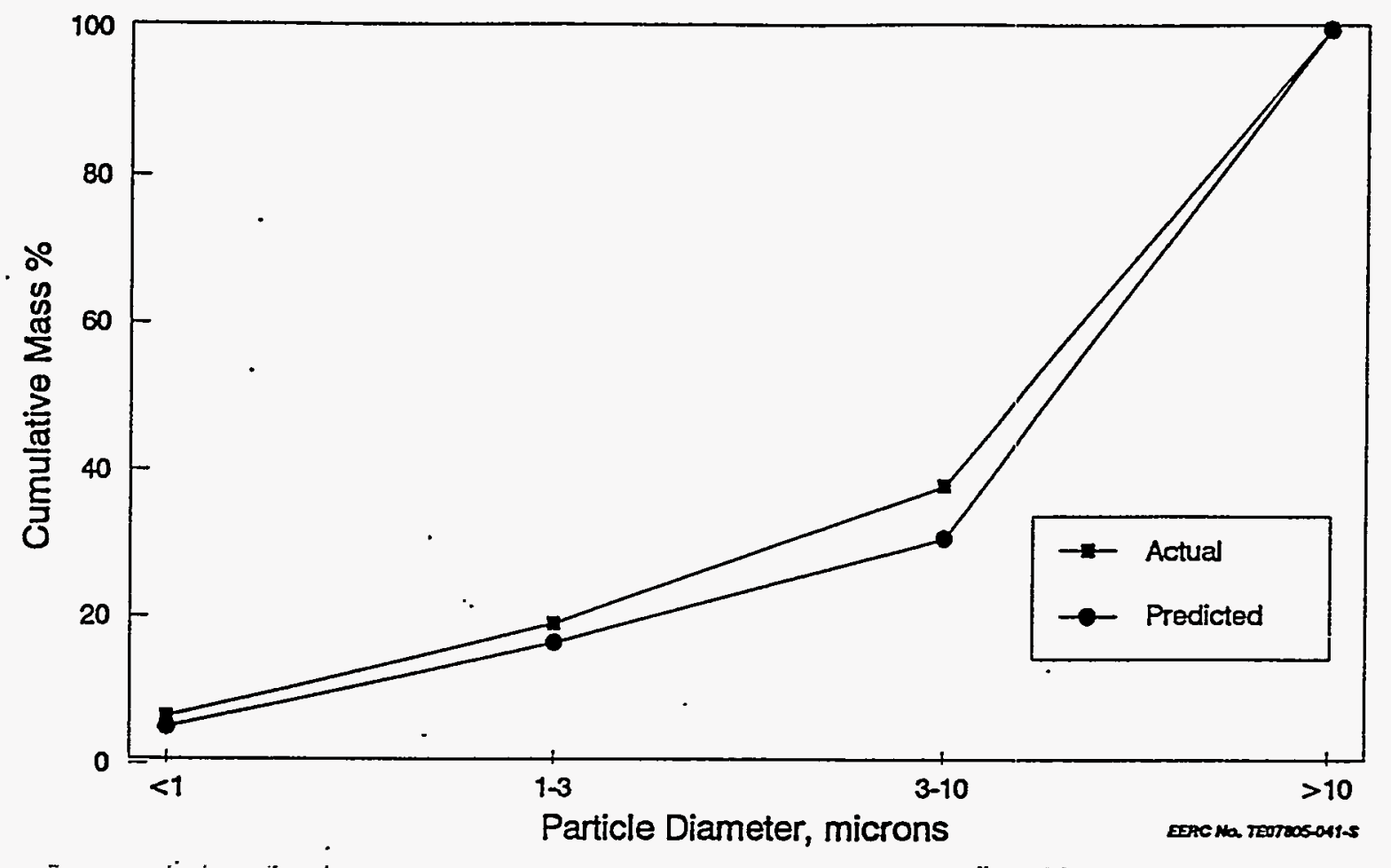

Figure B-1. Measured and predicted particle-size distributions for Black Thunder (Sherco) in a pc-fired system.

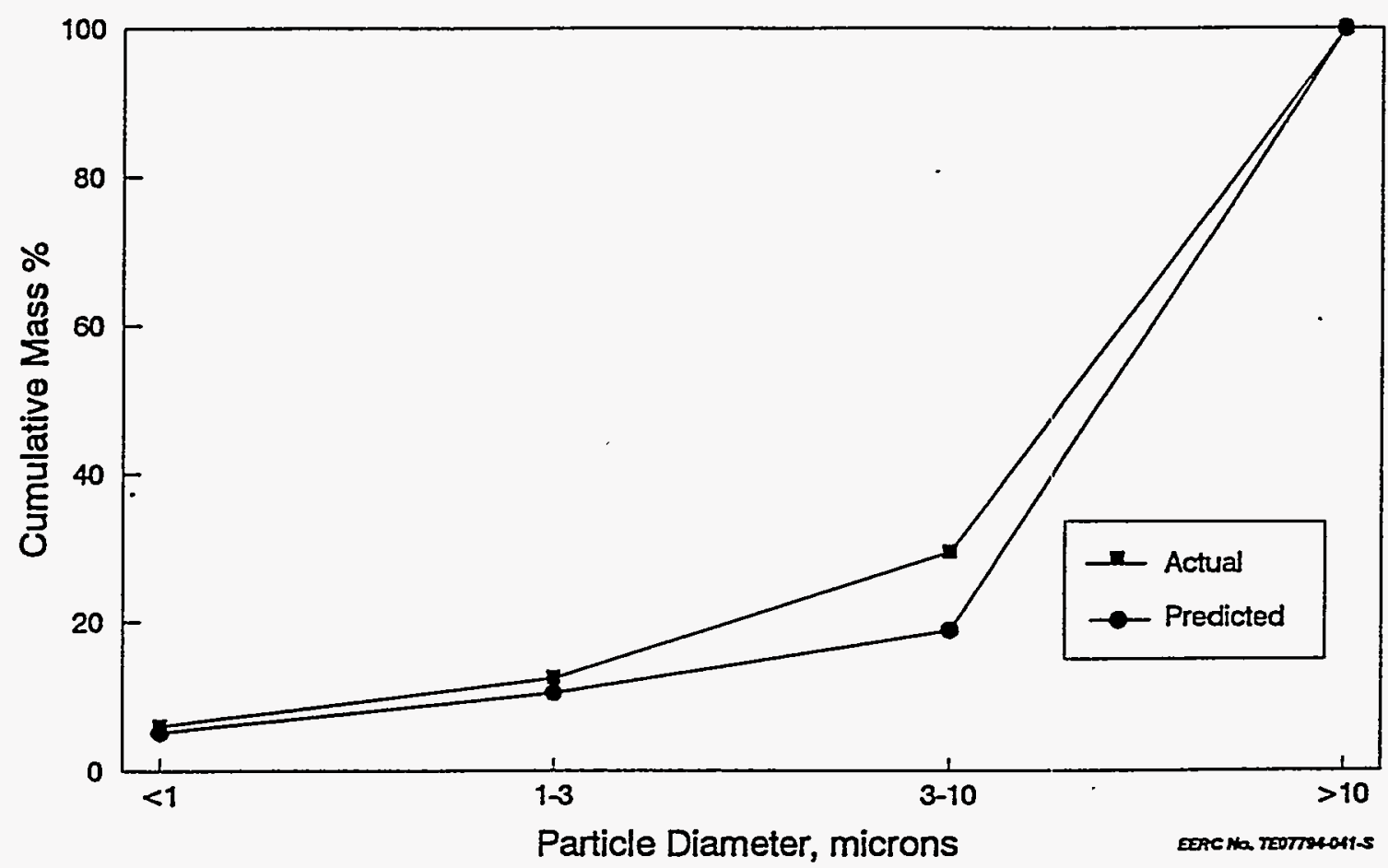

Figure B-2. Measured and predicted particle-size distributions for Black Thunder (King) in a cyclone-fired system. 


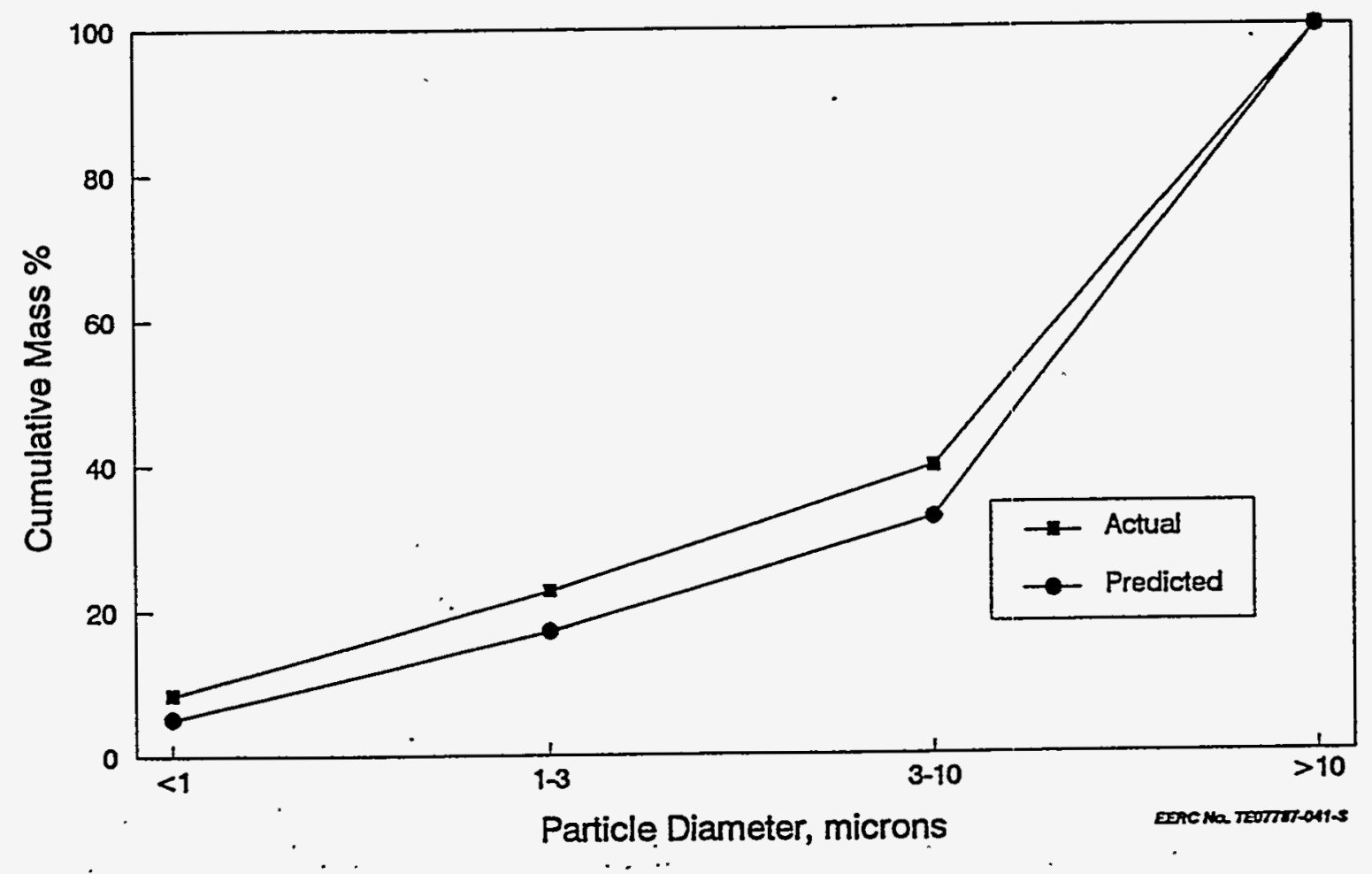

Figure B-3. Measured and predicted particle-size distributions for Antelope (Sherco) in à pc-fired system.

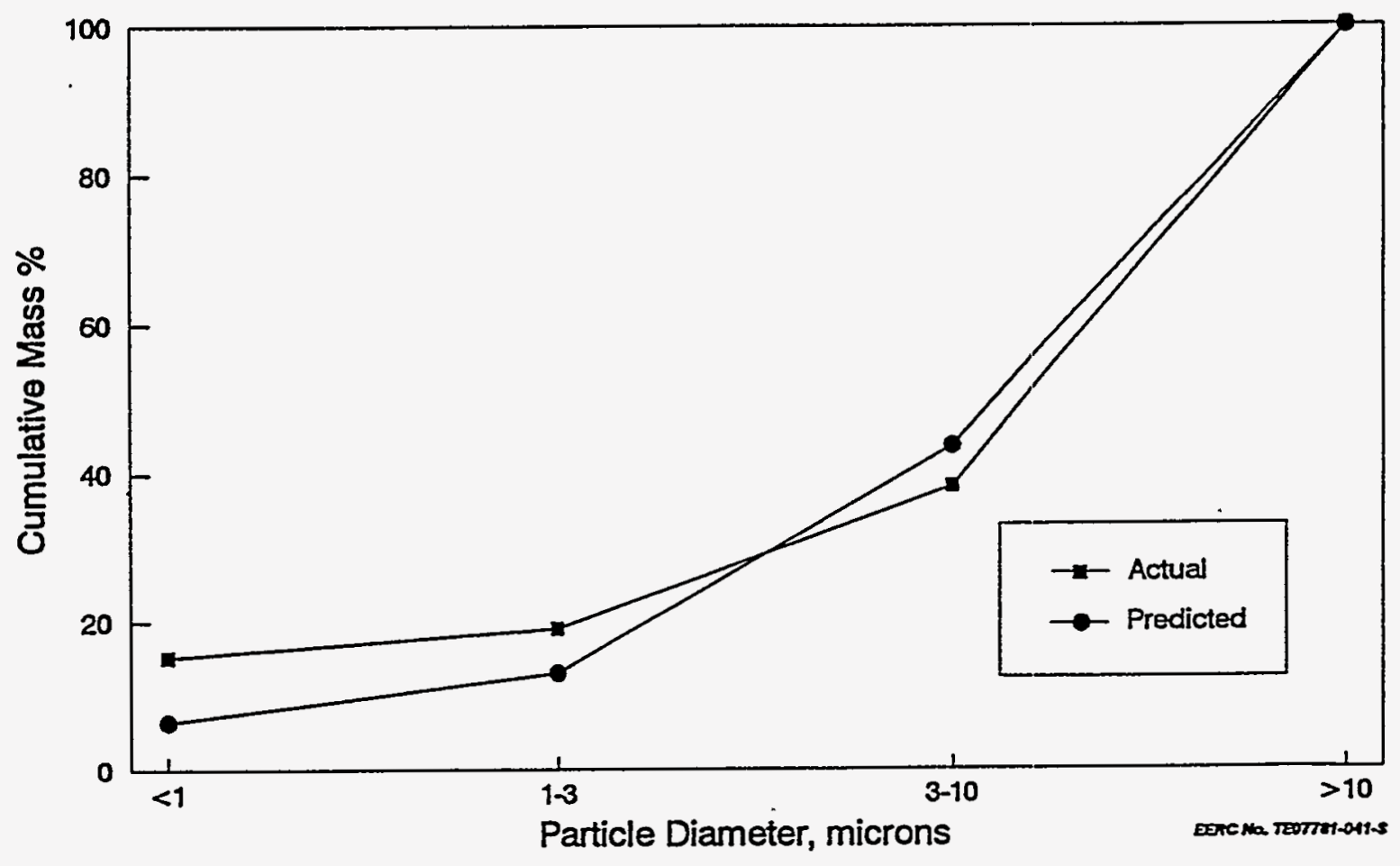

Figure B-4. Measured and predicted particle-size distributions for Antelope (King) in a cyclone-fired system. 


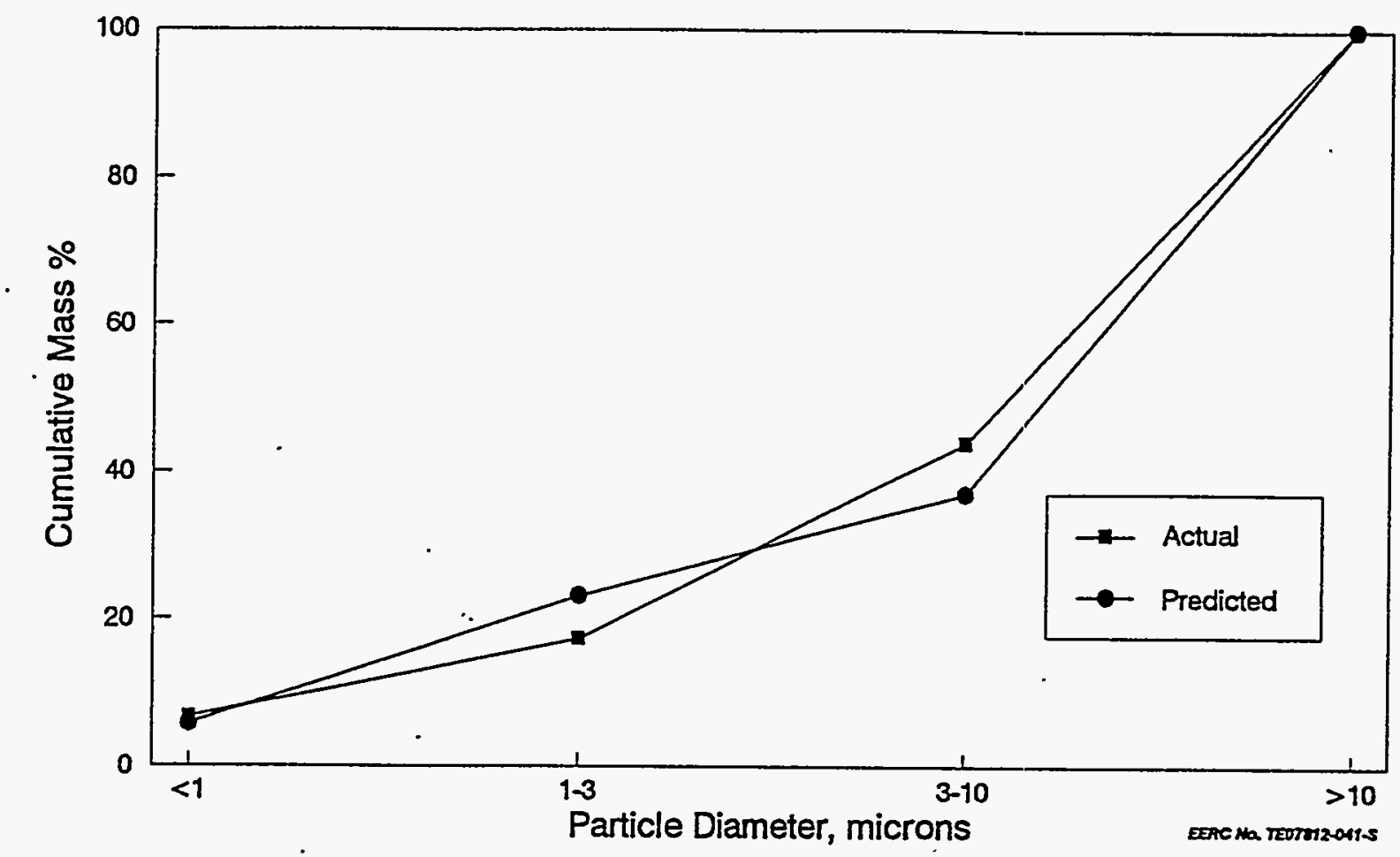

Figure B-5. Measured and predicted particle-size distributions for Shoshone (Schahfer) in a cyclone-fired system.

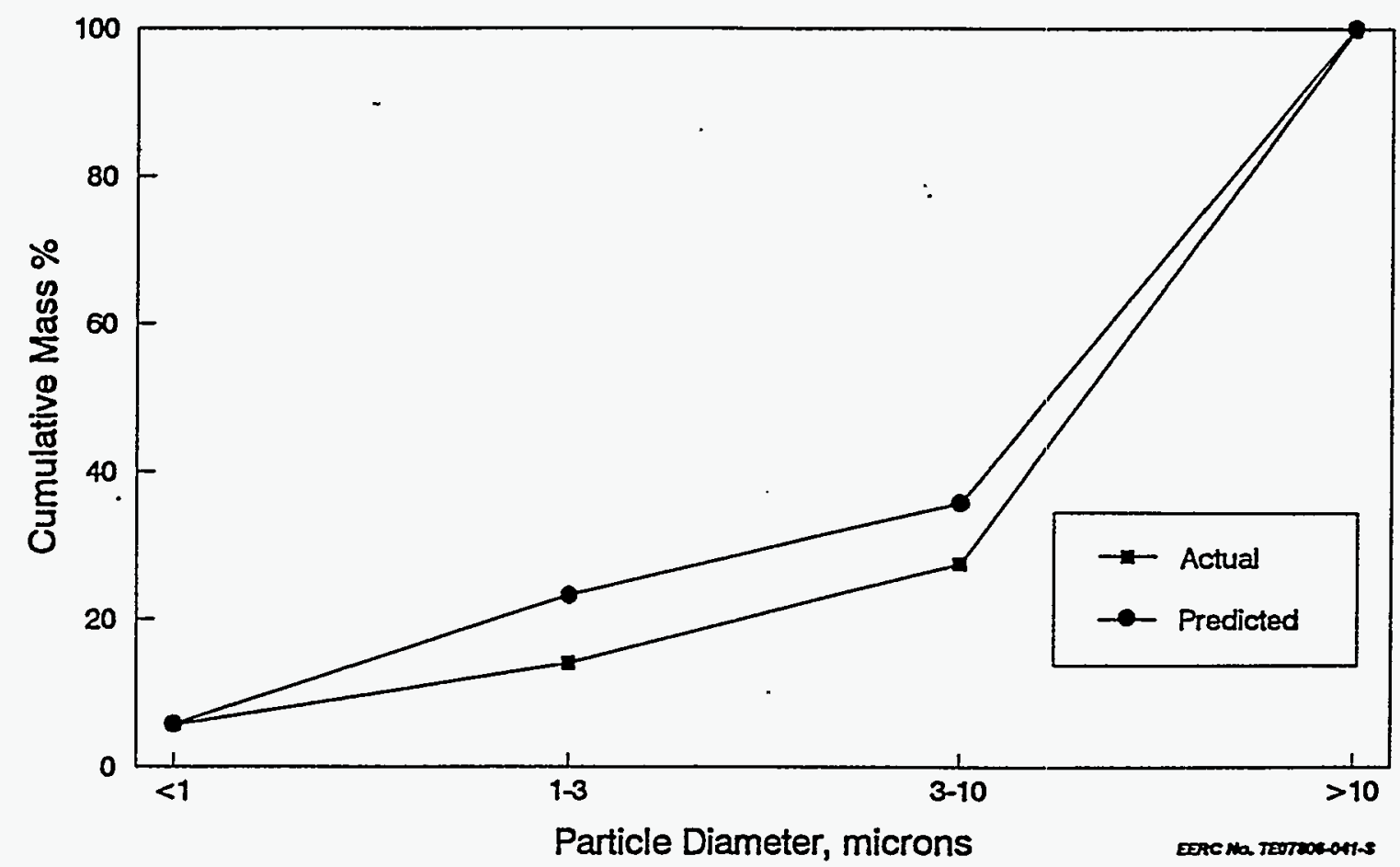

Figure B-6. Measured and predicted particle-size distributions for Eagle Butte (Welsh) in a cyclone-fired system. 


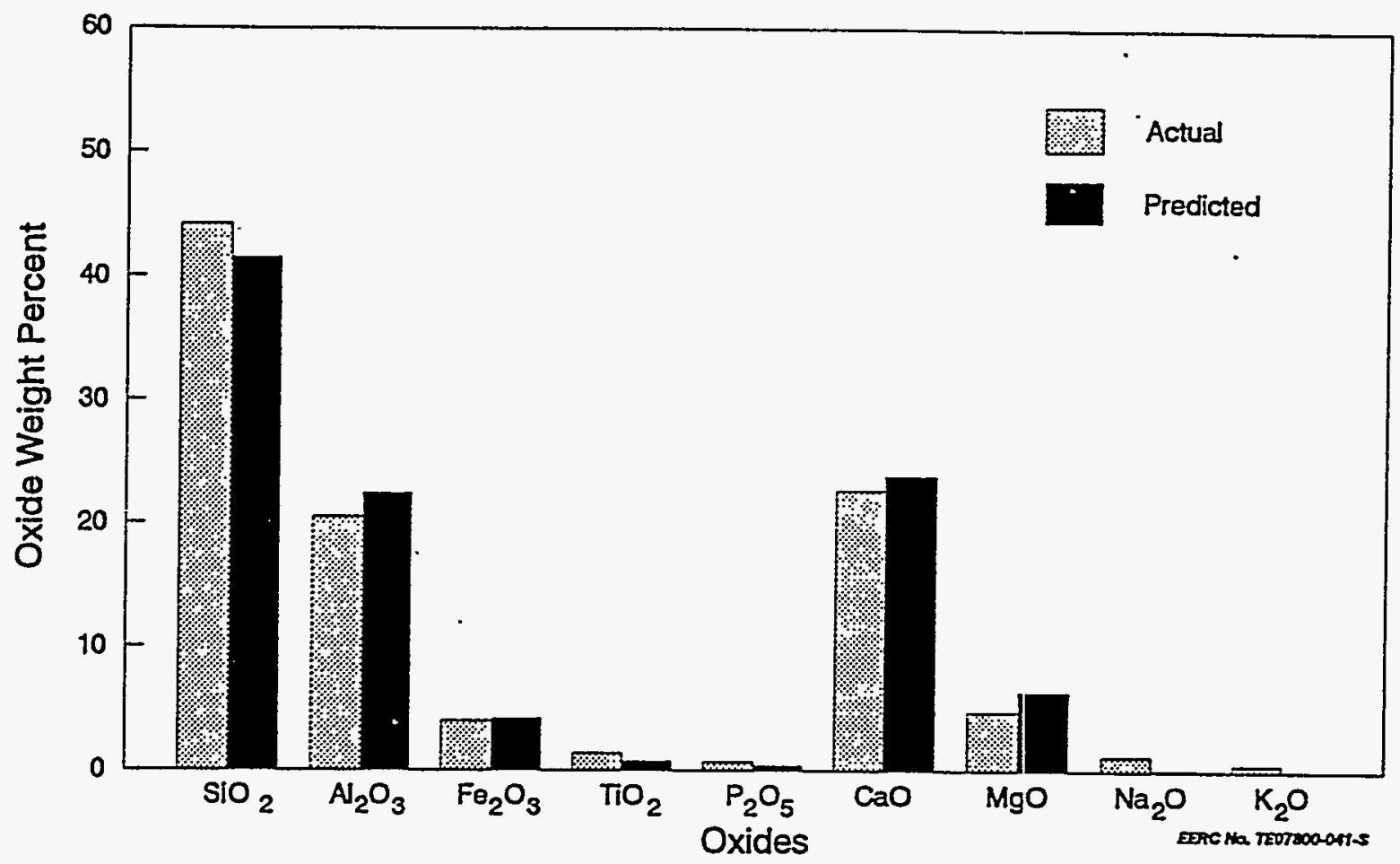

Figure B-7. Measured and predicted composition distributions for Black Thunder (Sherco), >10-micron ash, produced in a pc-fired system.

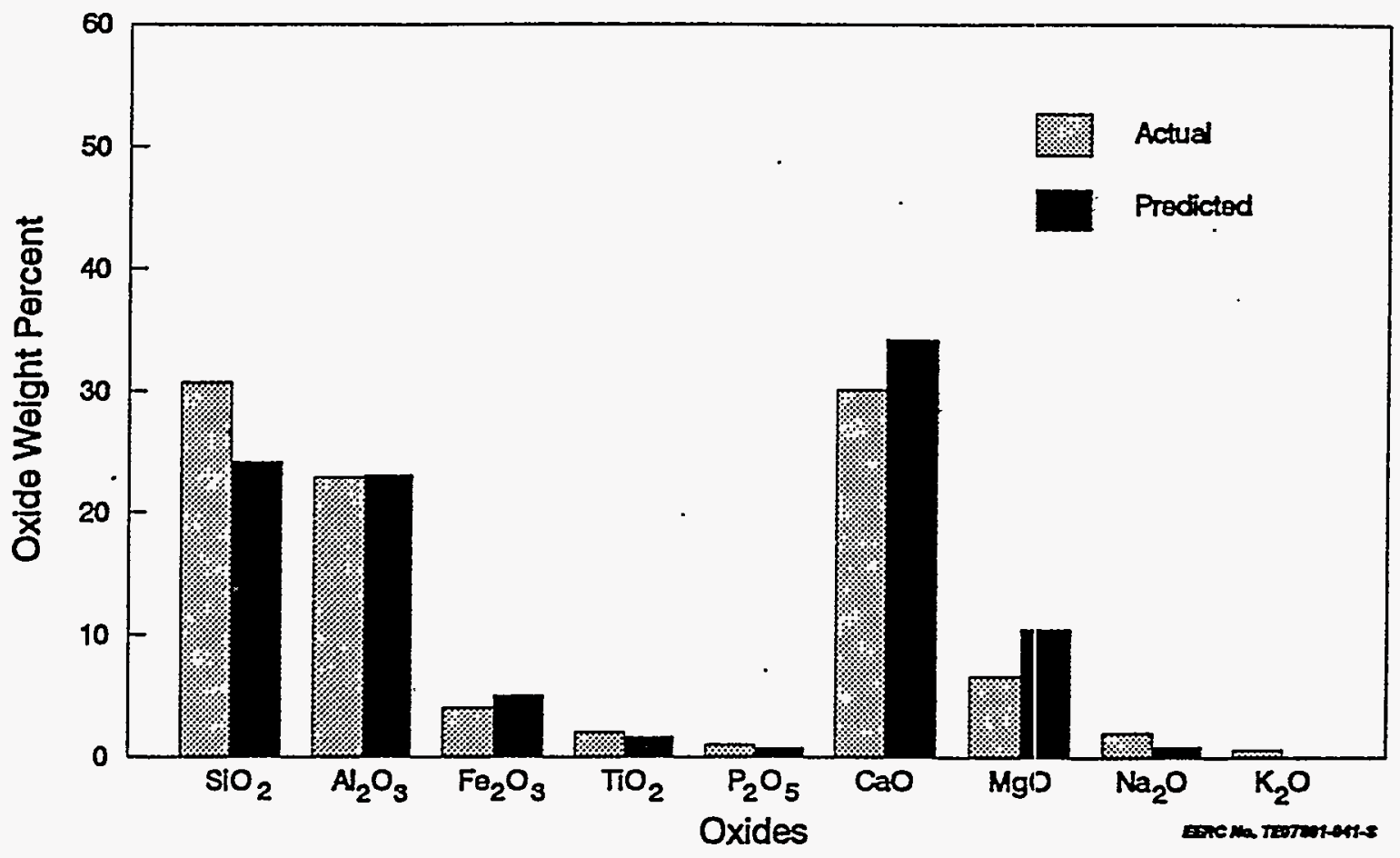

Figure B-8. Measured and predicted composition distributions for Black Thunder (Sherco), 10- to 3-micron ash, produced in a pc-fired system. 


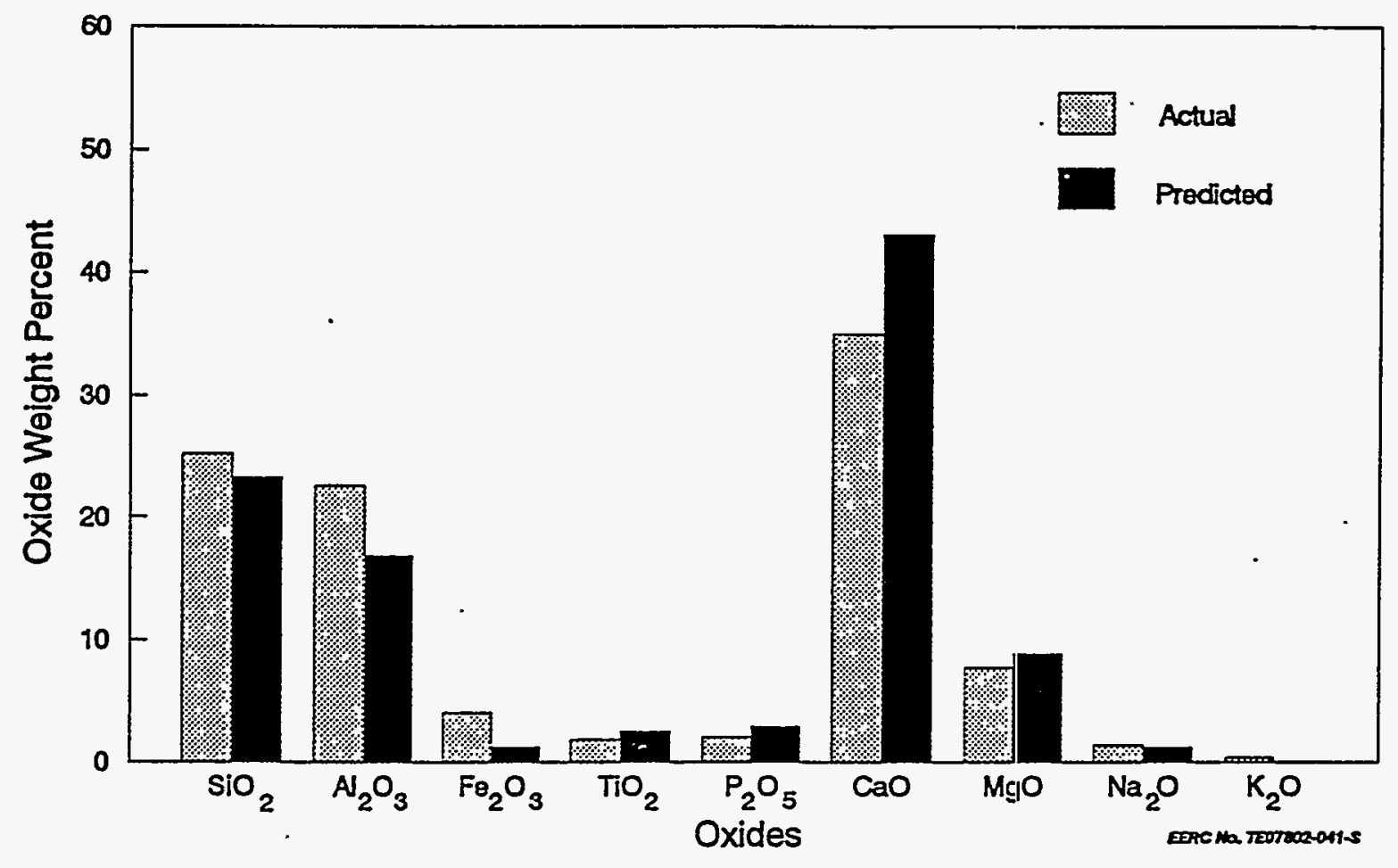

Figure B-9. Measured and predicted composition distributions for Black Thunder (Sherco), 3- to 1-micron ash, produced in a pc-fired system.

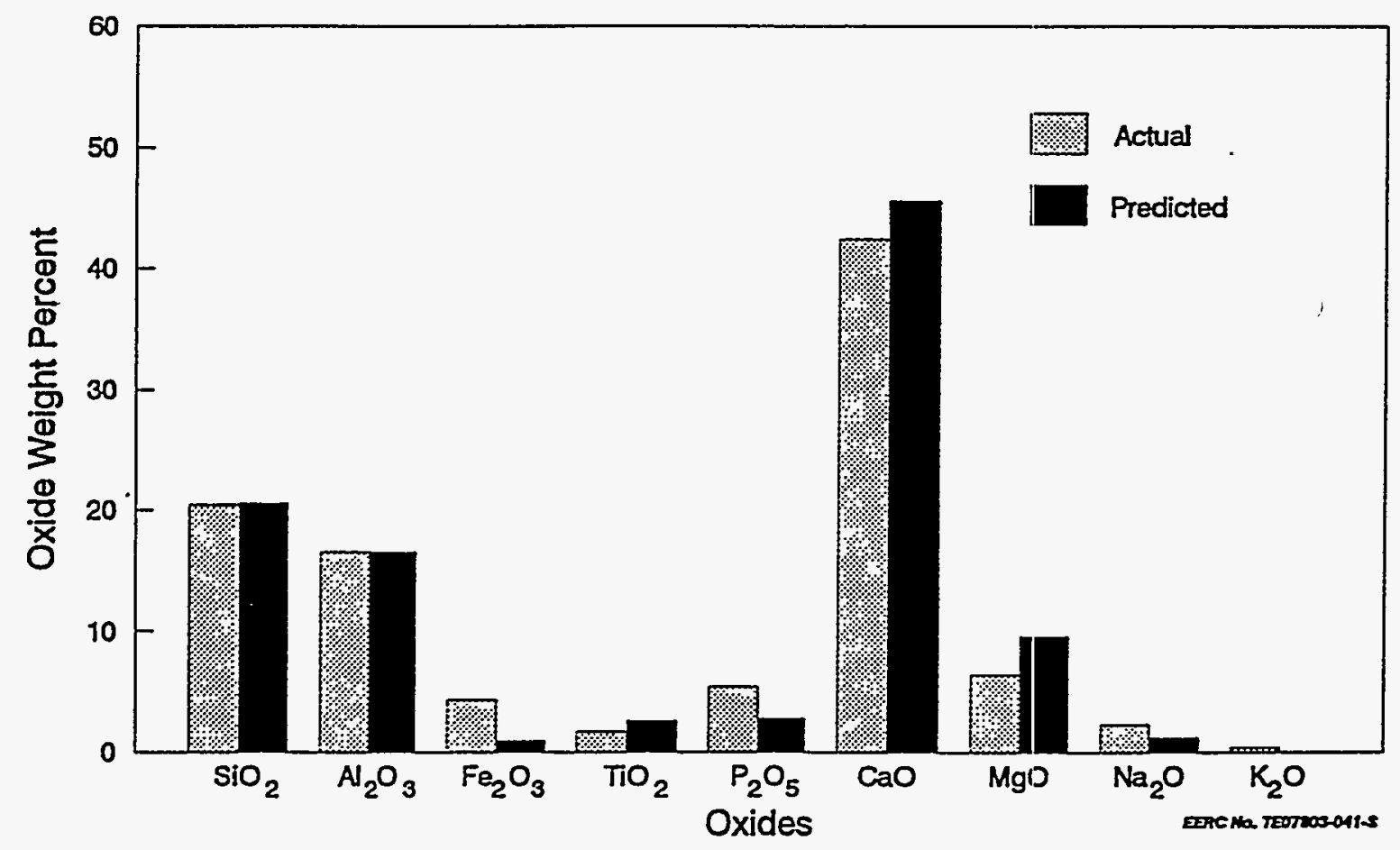

Figure B-10. Measured and predicted composition distributions for Black Thunder (Sherco), <1-micron ash, produced in a pc-fired system. 


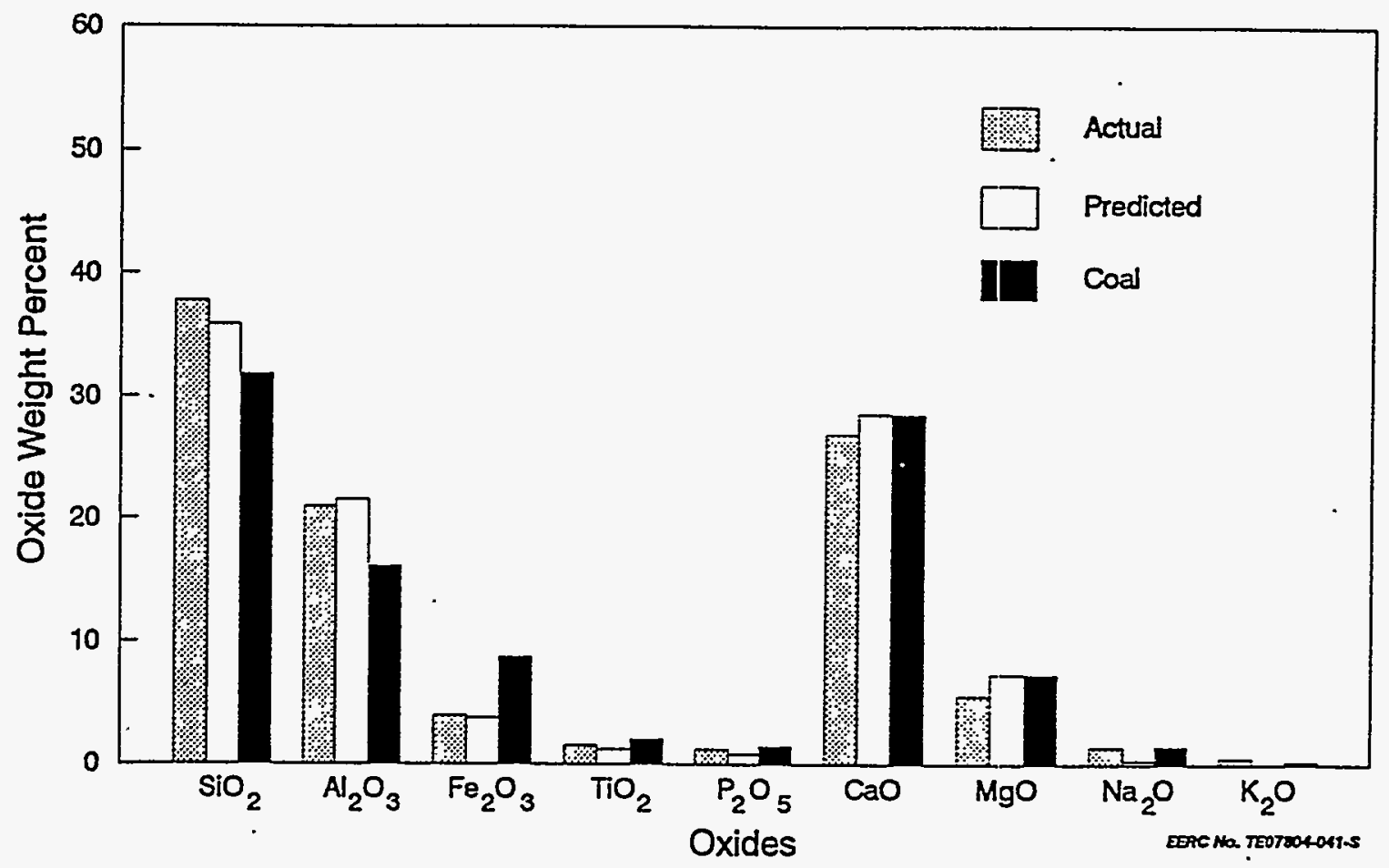

Figure B-11. Measured and predicted composition distributions for Black Thunder (Sherco), bulk ash (weighted composite), produced in a pc-fired system.

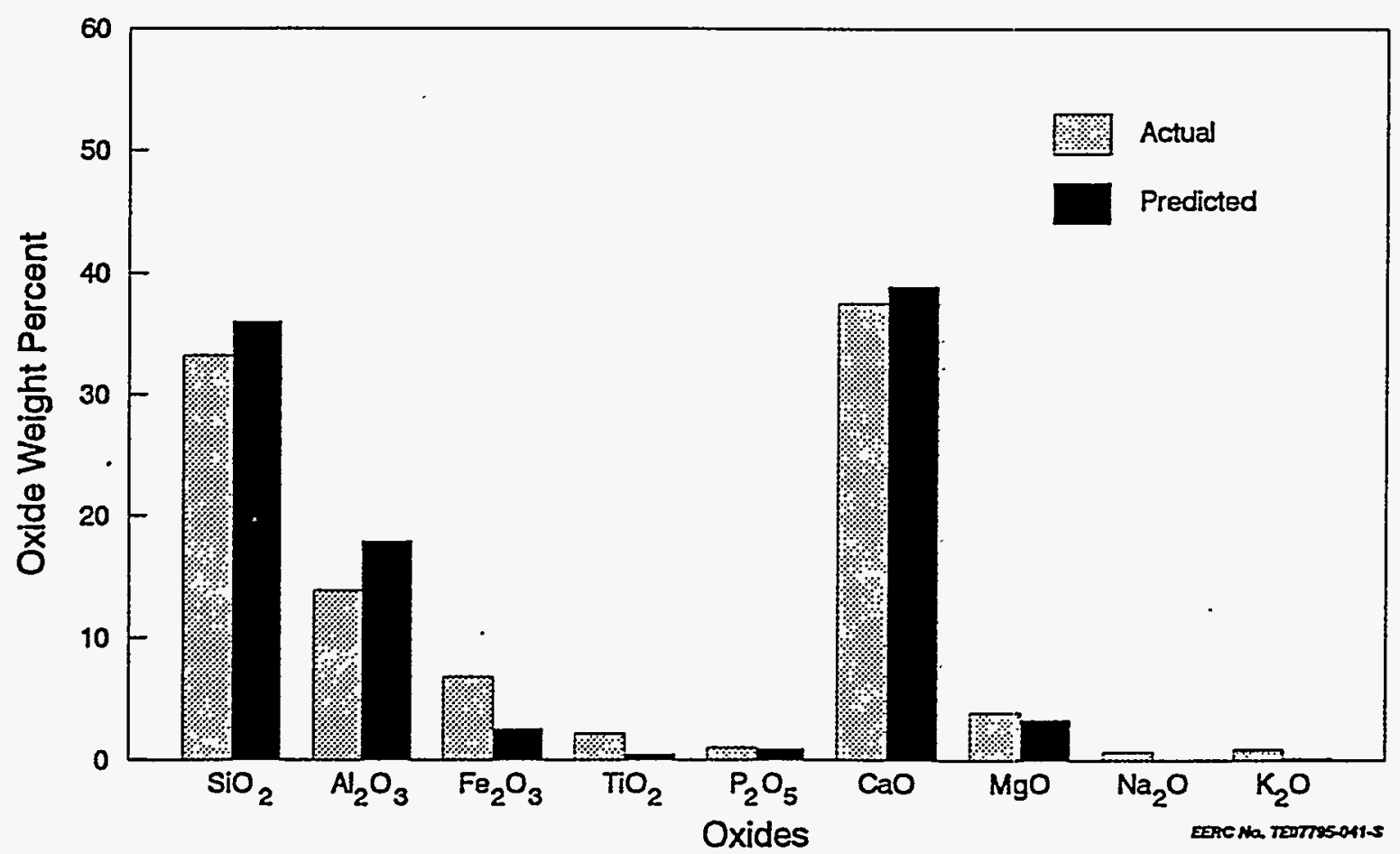

Figure B-12. Measured and predicted composition distributions for Black Thunder (King), >10-micron ash, produced in a pe-fired system. 


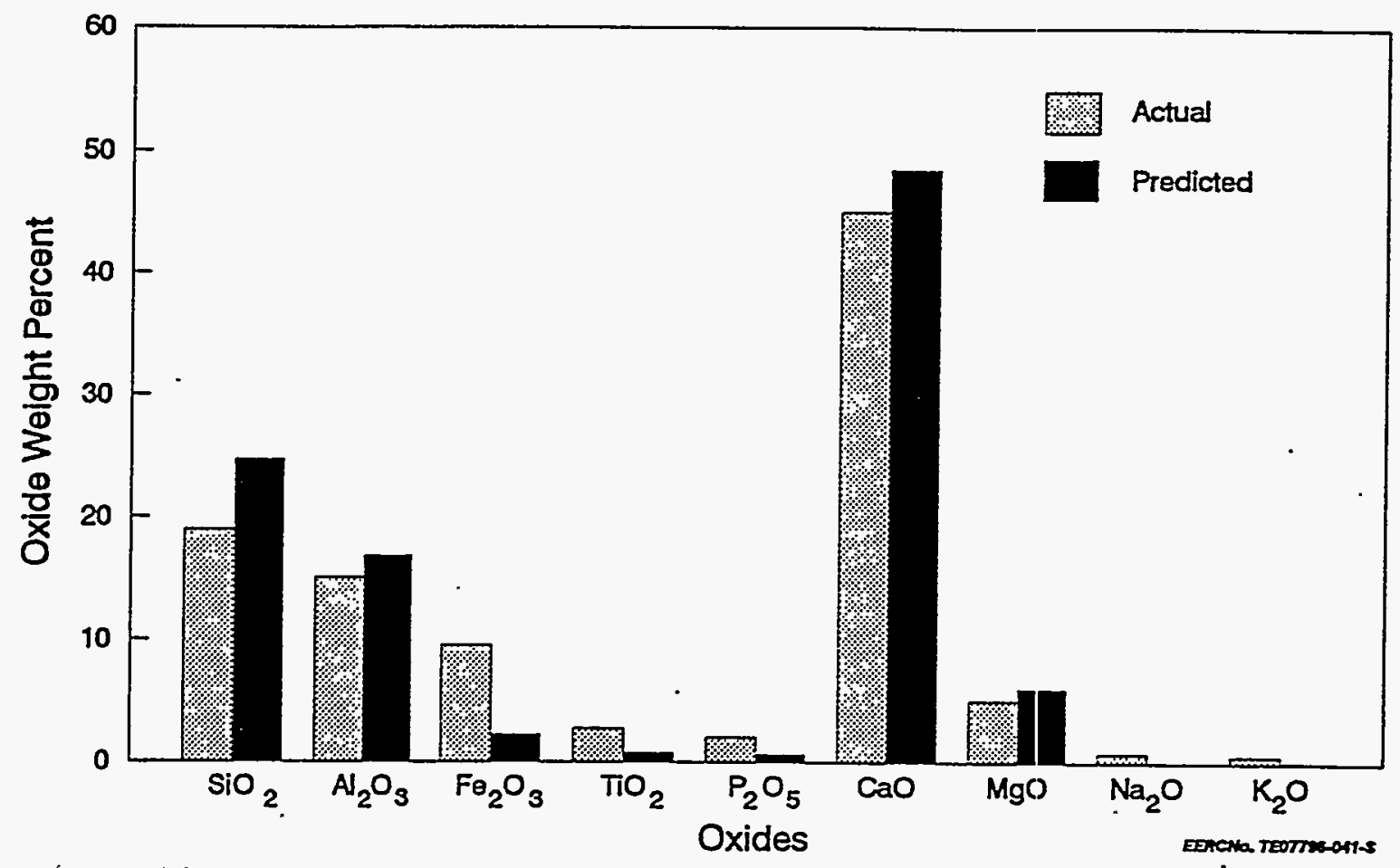

Figure B-13. Measured and predicted composition distributions for Black Thunder (KKing), 10- to 3-micron ash, produced in a pc-fired system.

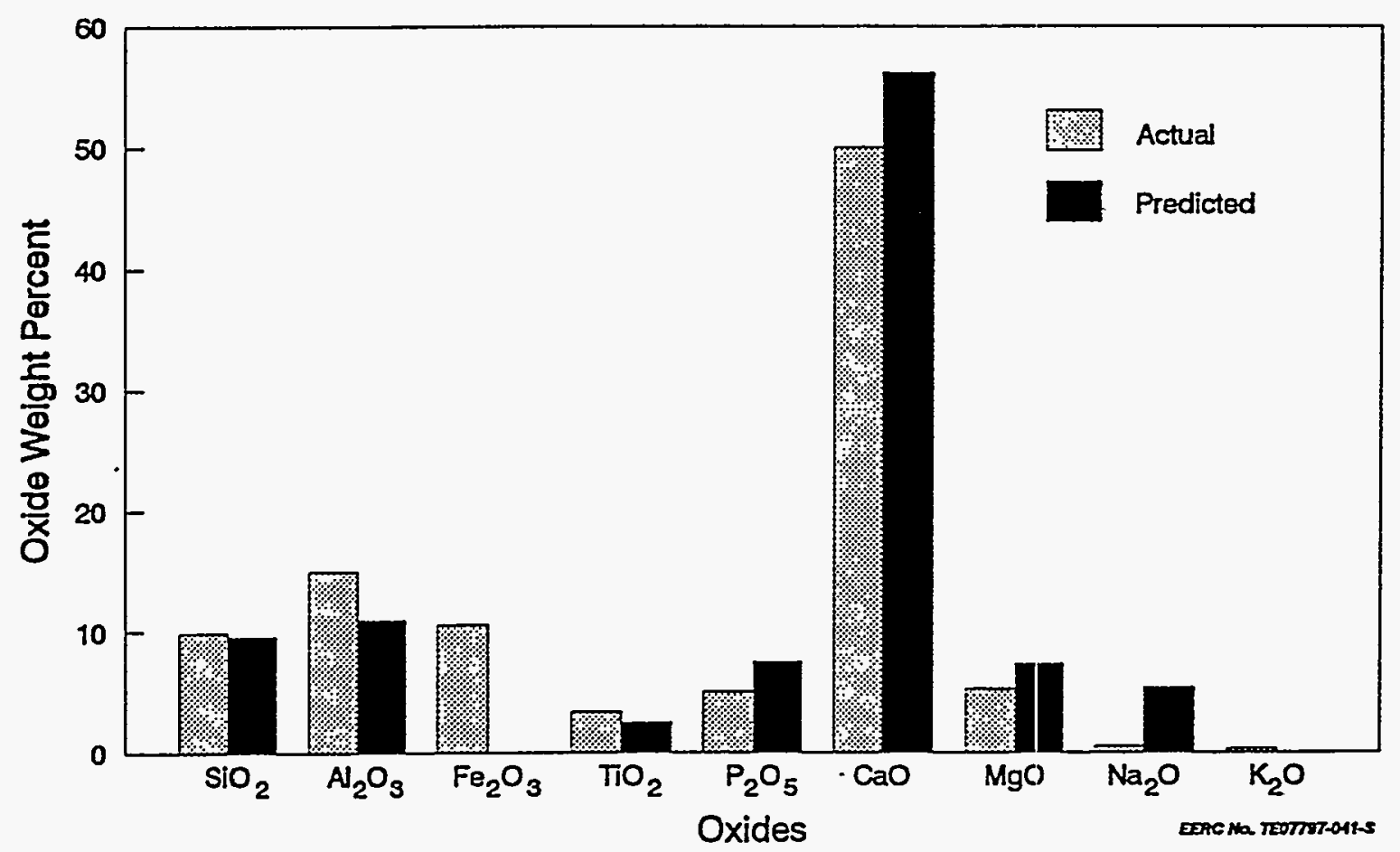

Figure B-14. Measured and predicted composition distributions for Black Thunder (King), 3- to 1-micron ash, produced in a pc-fired system. 


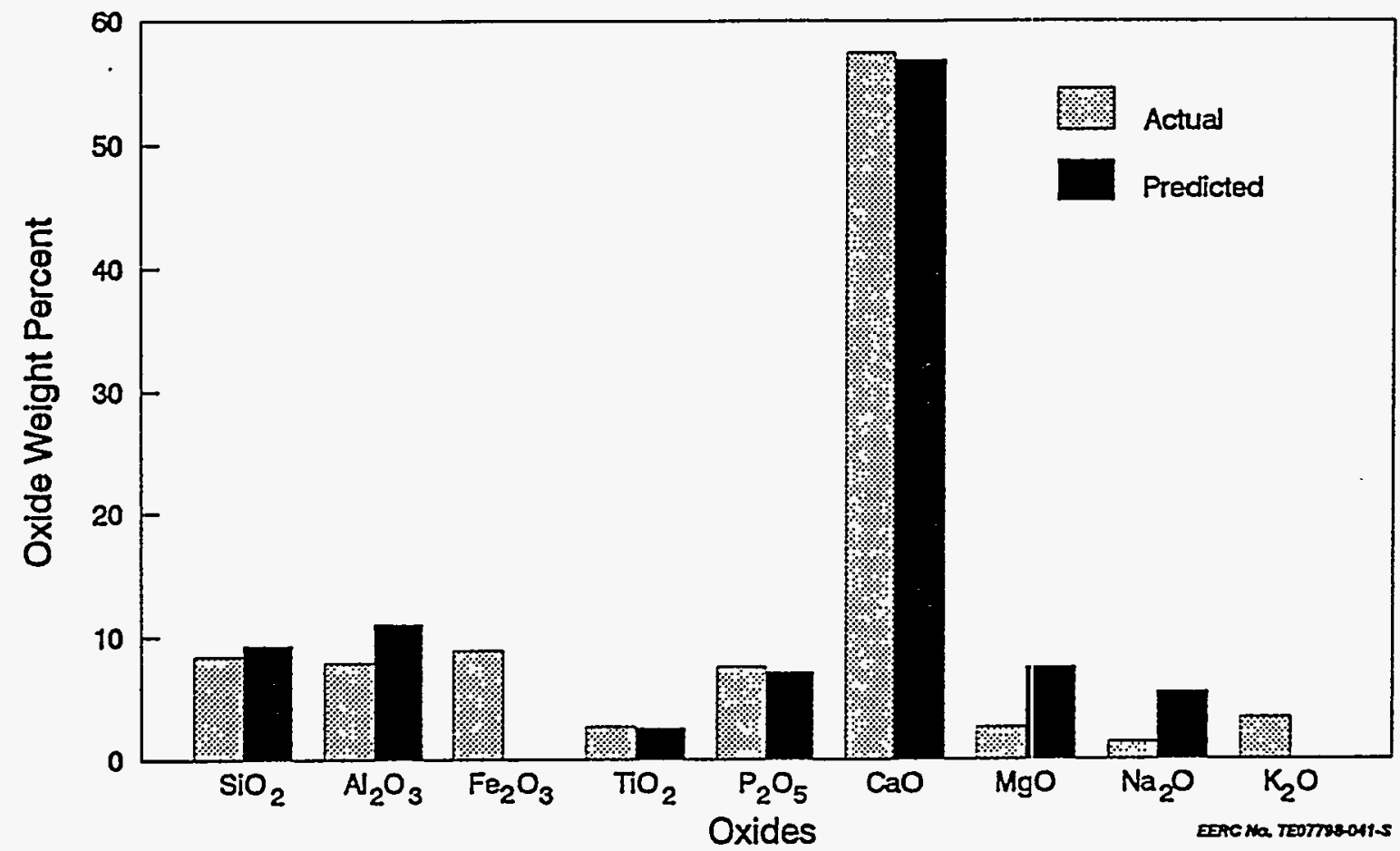

Figure B-15. Measured and predicted composition distributions for Black Thunder (King), <1-micron ash, produced in a pe-fired system.

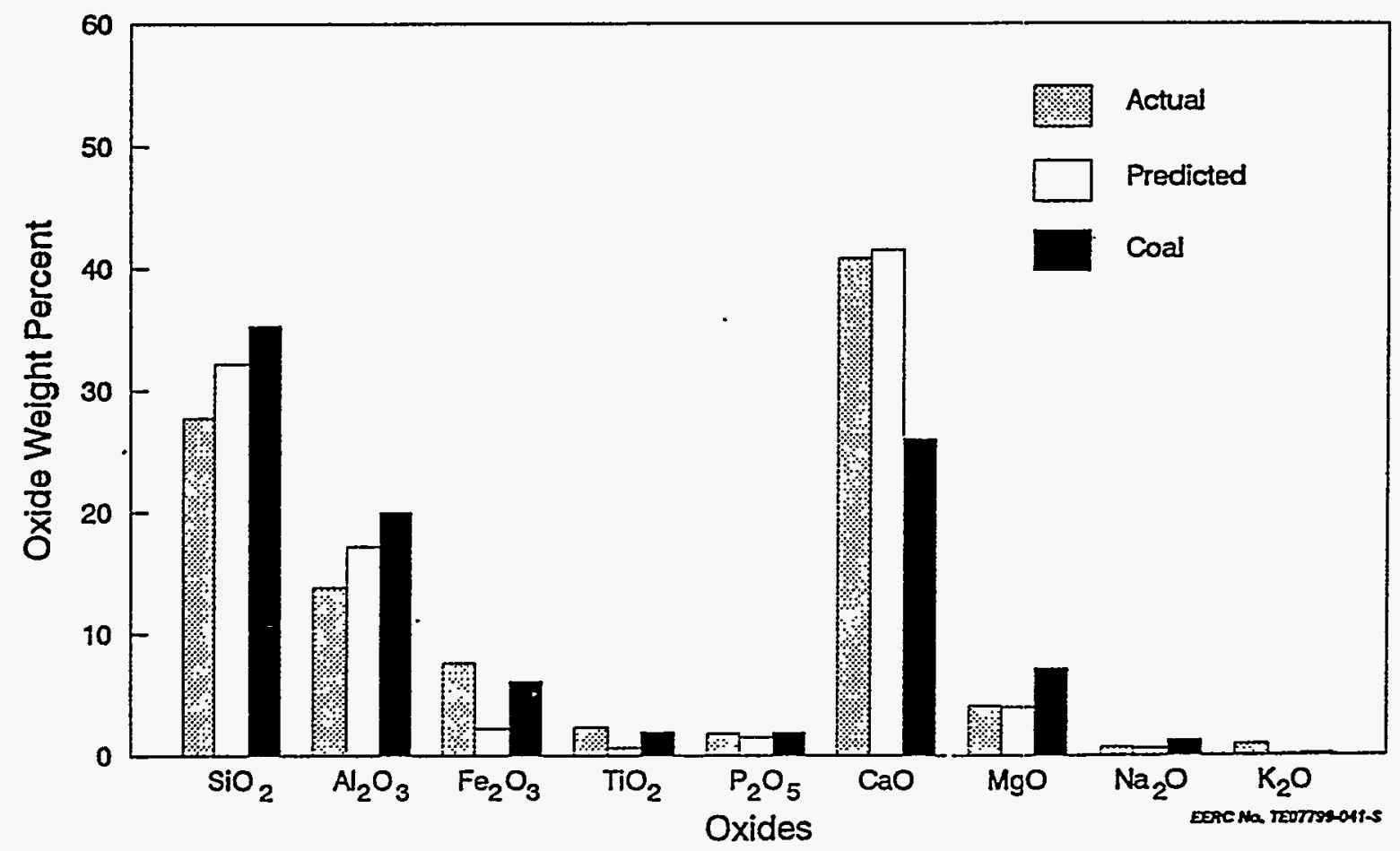

Figure B-16. Measured and predicted composition distributions for Black Thunder (King), bulk ash (weighted composite), produced in a pc-fired system. 


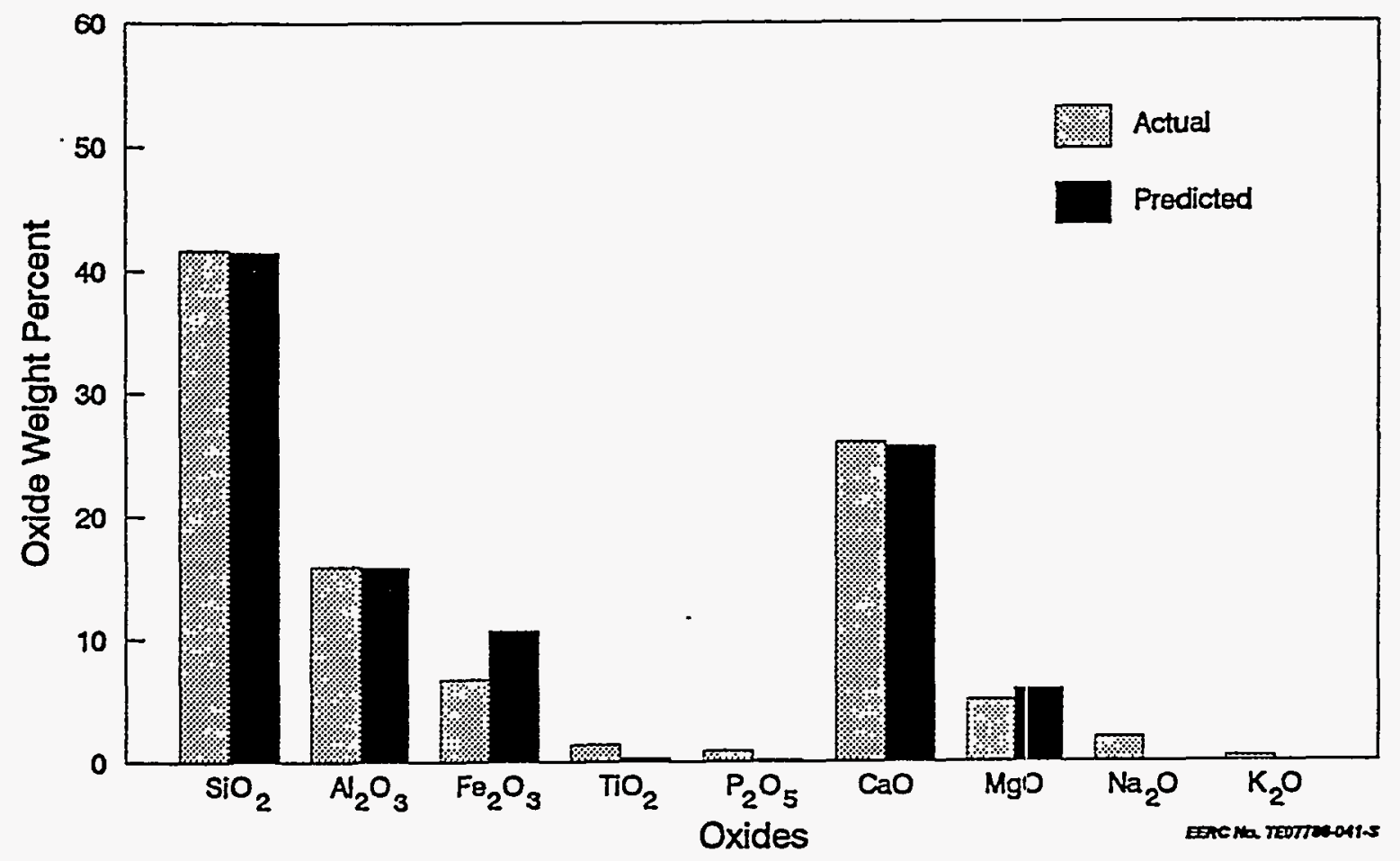

Figure B-17. Measured and predicted composition distributions for Antelope (Sherco), >10-micron ash, produced in a pc-fired system.

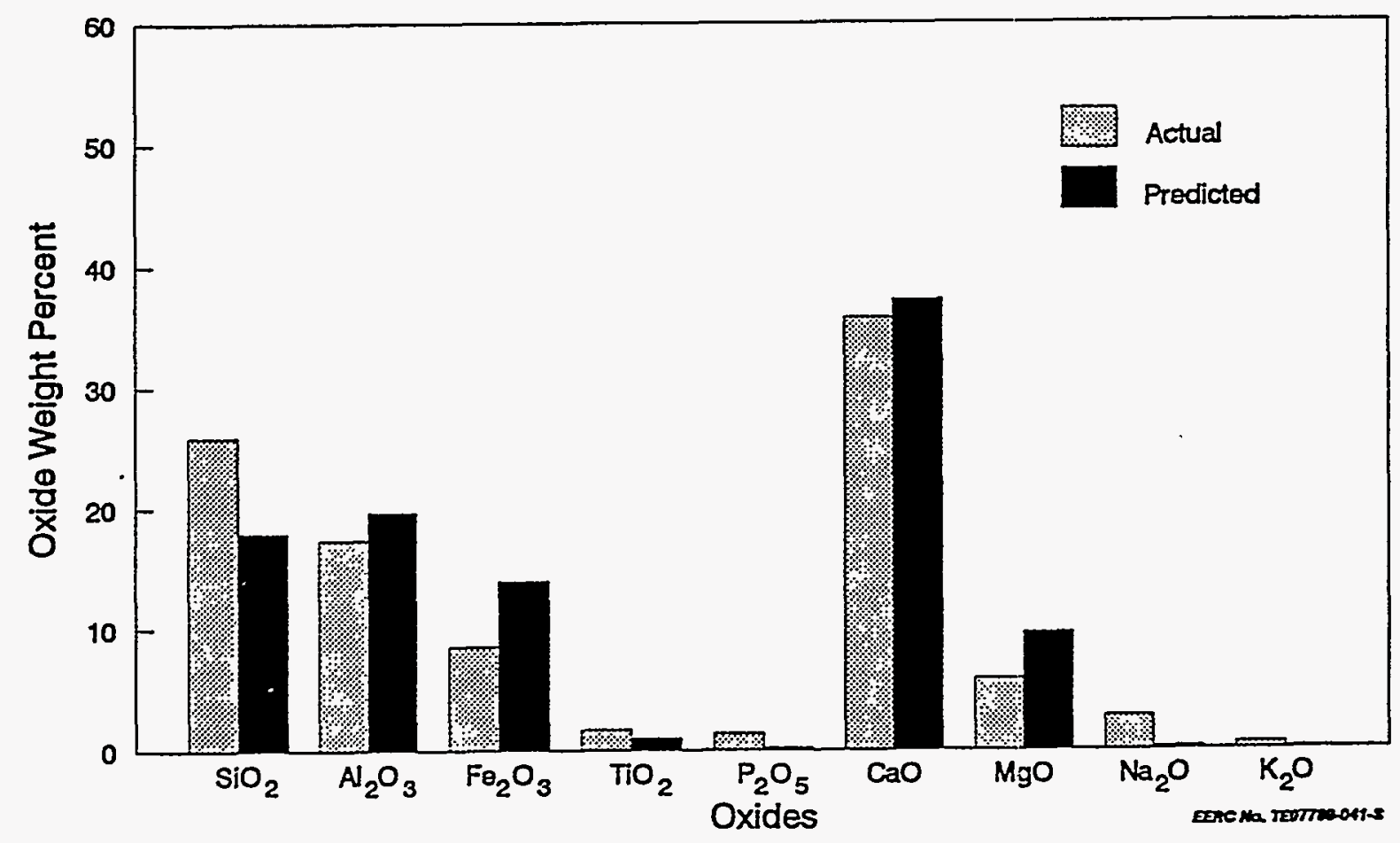

Figure B-18. Measured and predicted composition distributions for Antelope (Sherco), 10- to 3-micron ash, produced in a pc-fired system. 


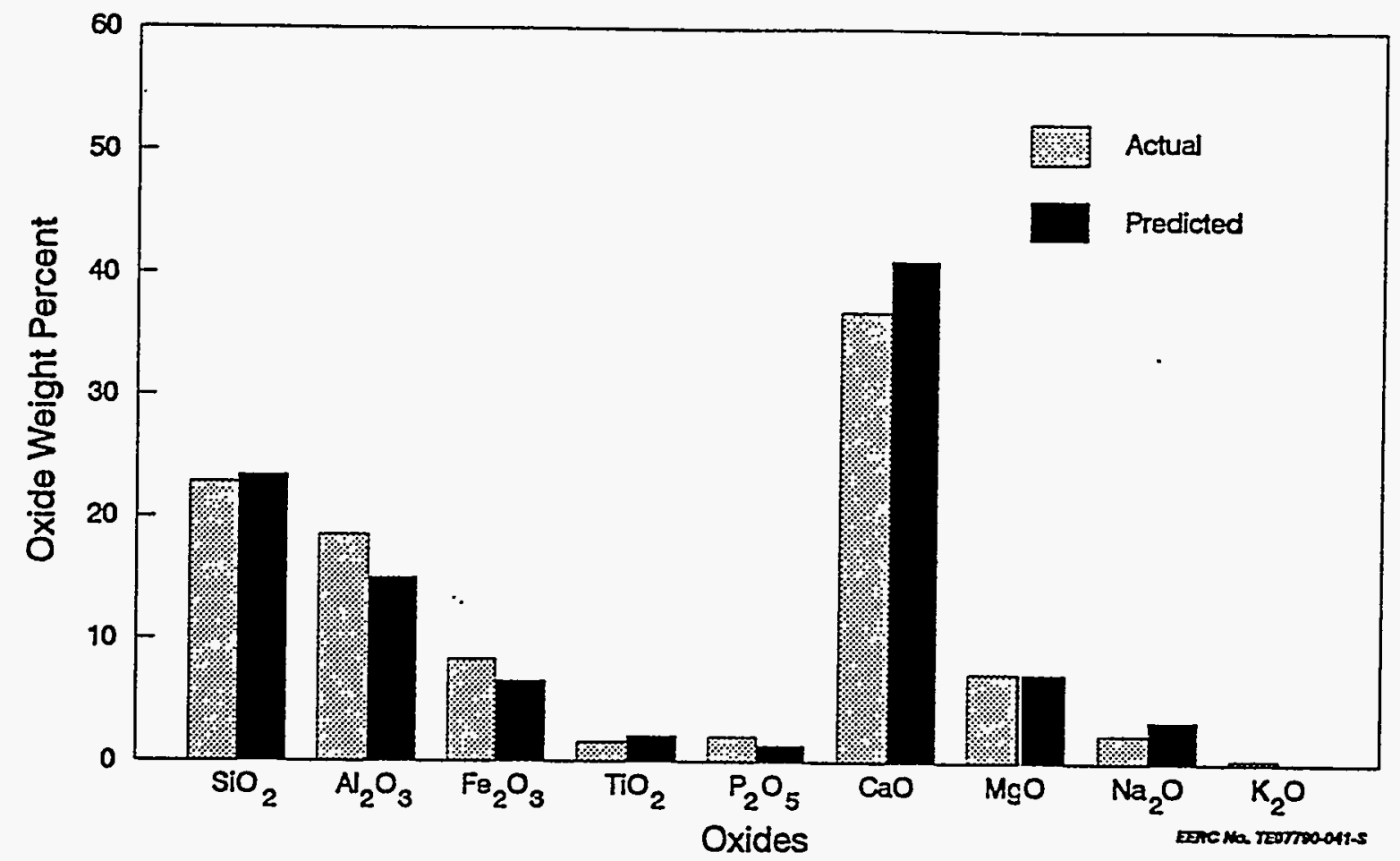

Figure B-19. Measured and predicted composition distributions for Antelope (Sherco), 3- to 1-micron ash, produced in a pc-fired system.

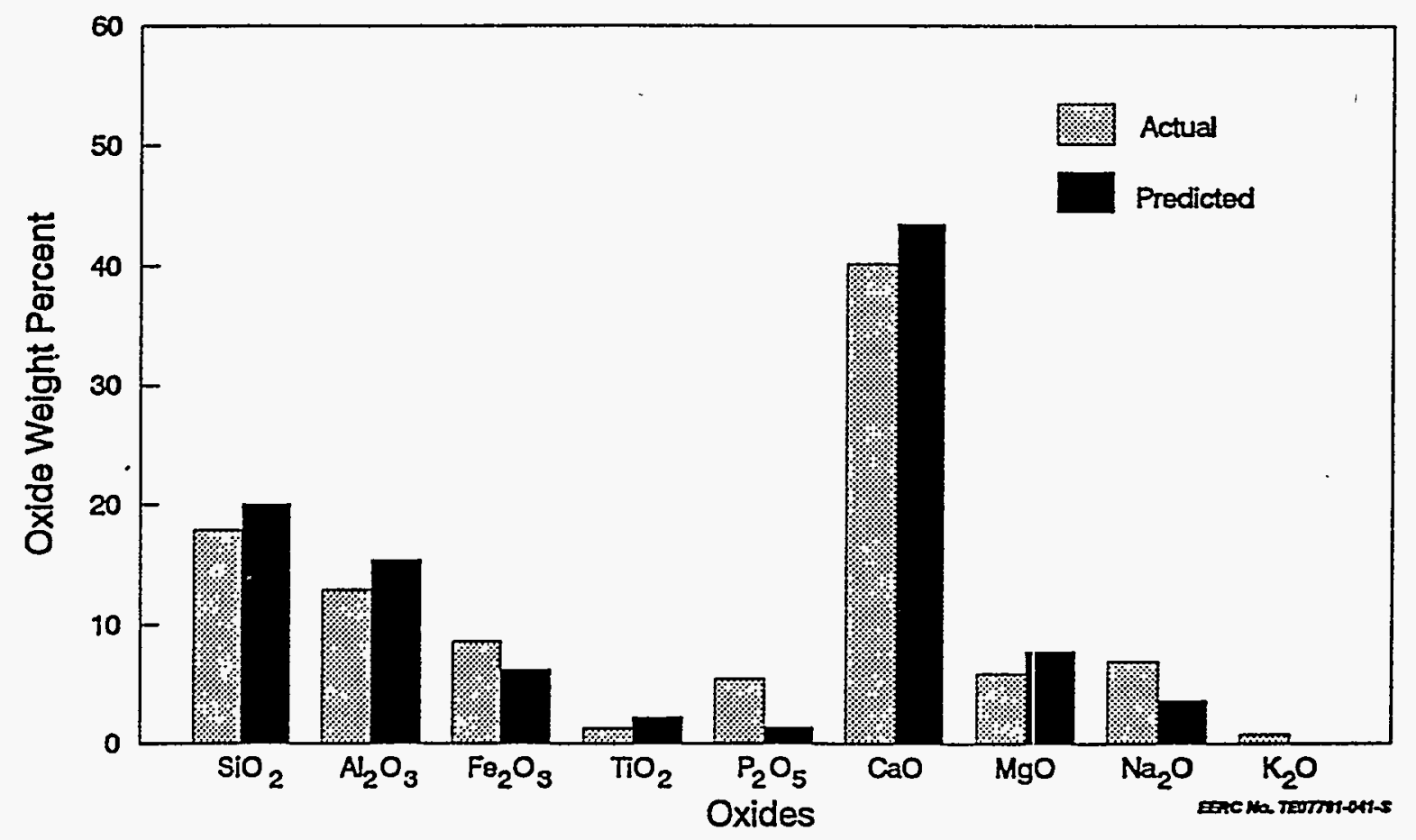

Figure B-20. Measured and predicted composition distributions for Antelope (Sherco), <1-micron ash, produced in a pe-fired system. 


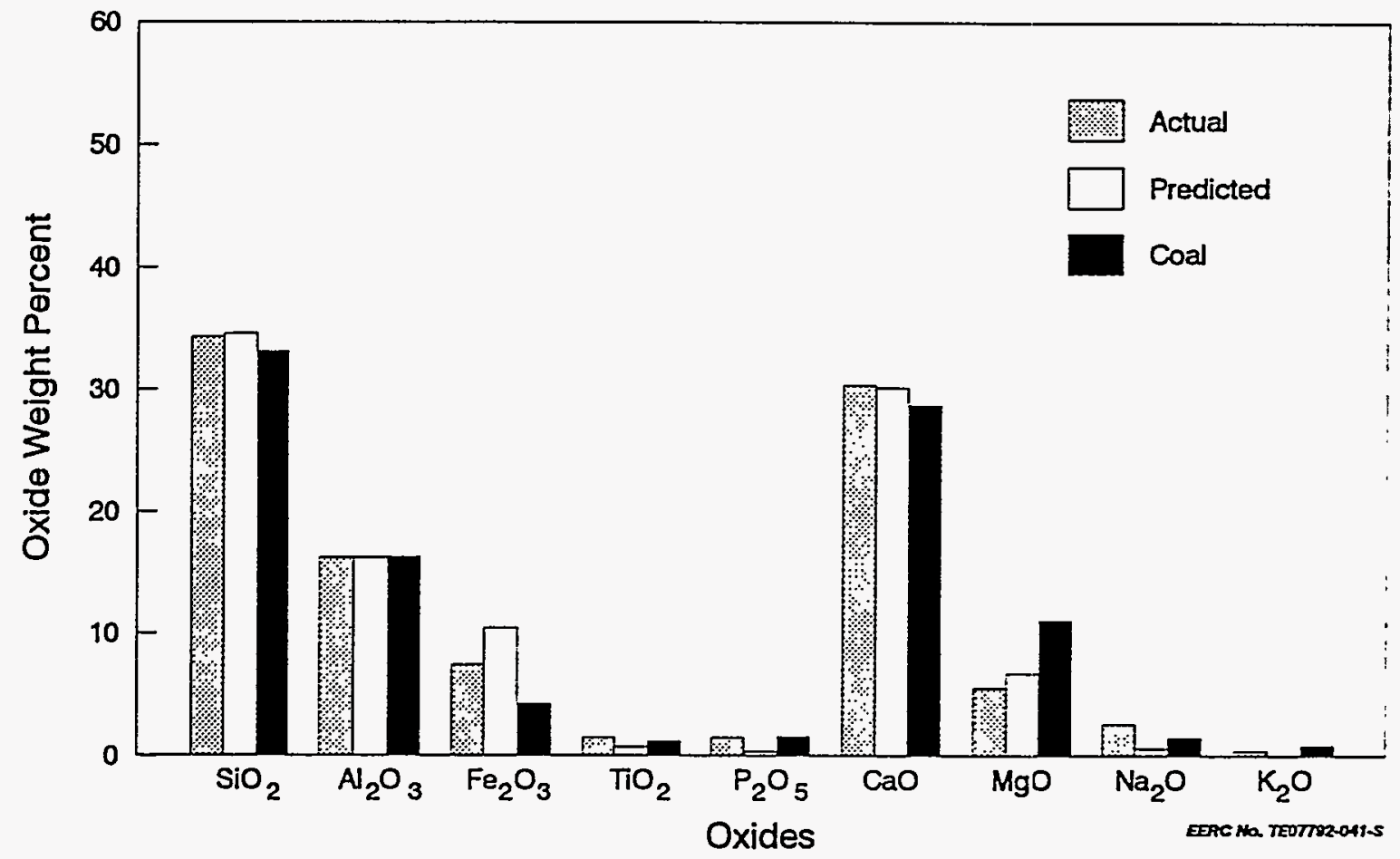

Figure B-21. Measured and predicted composition distributions for Antelope (Sherco), bulk ash (weighted composite), produced in a pc-fired system.

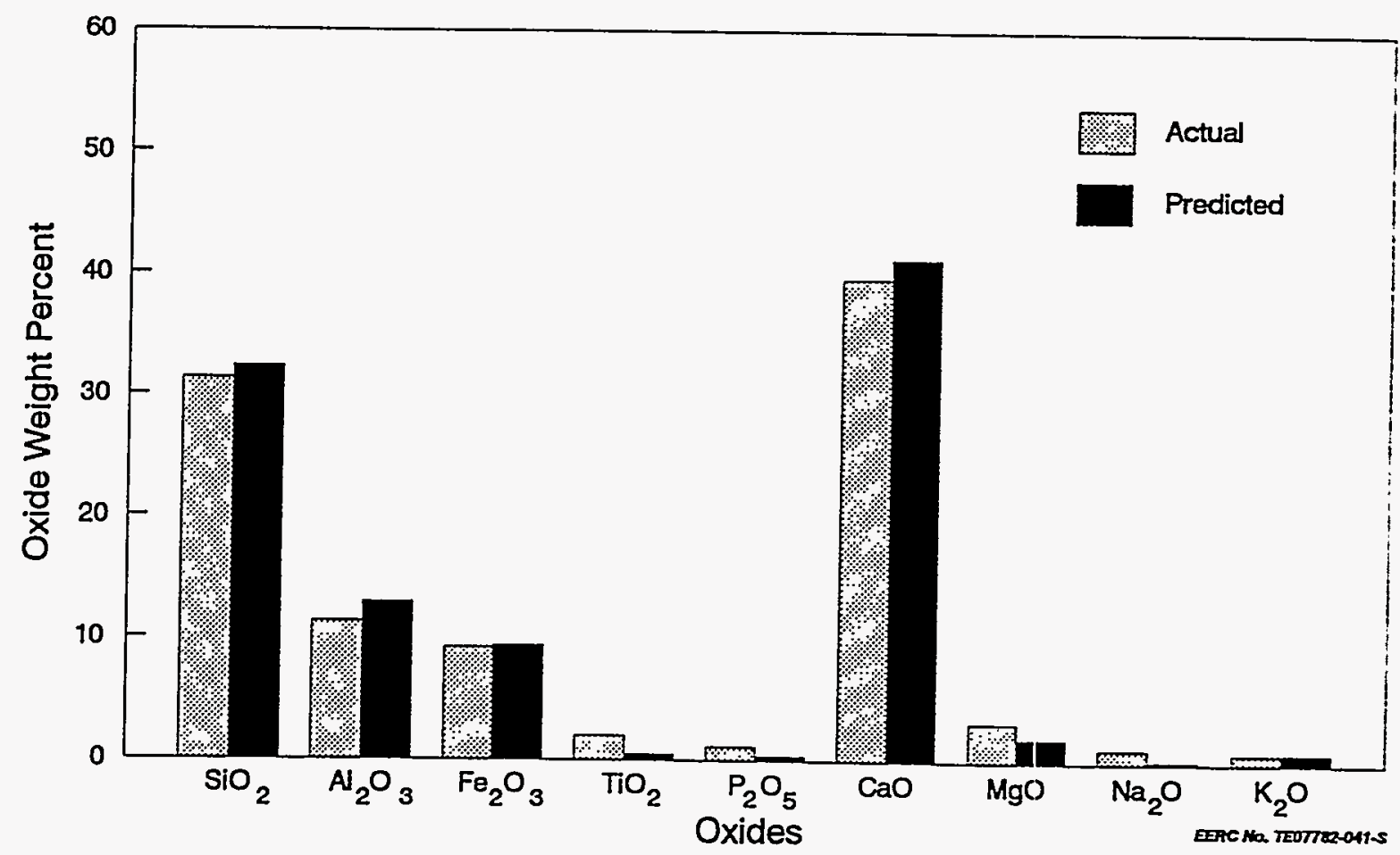

Figure B-22. Measured and predicted composition distributions for Antelope (King), $>10$-micron ash, produced in a pc-fired system. 


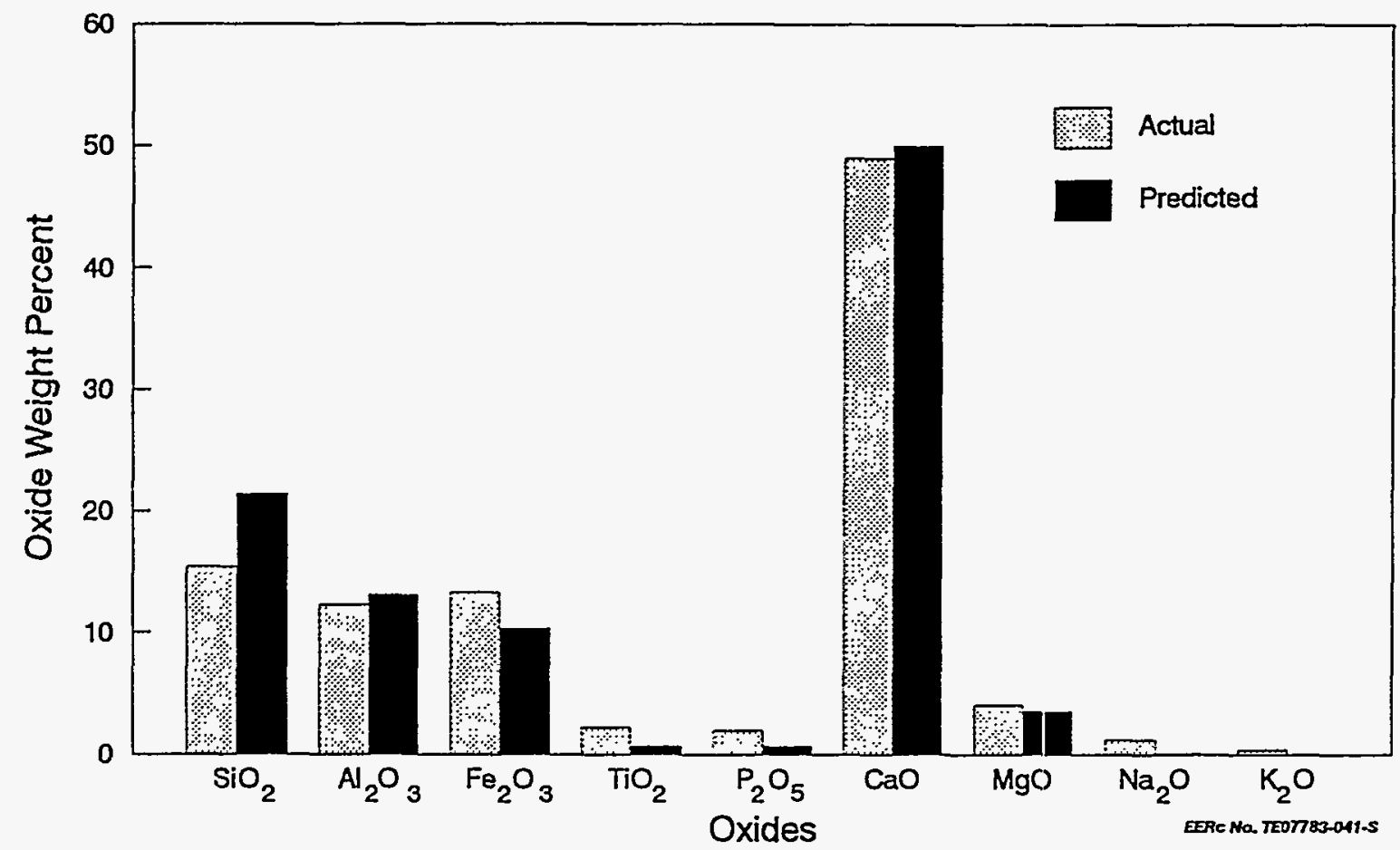

Figure B-23. Measured and predicted composition distributions for Antelope (King), 10- to 3-micron ash, produced in a pc-fired system.

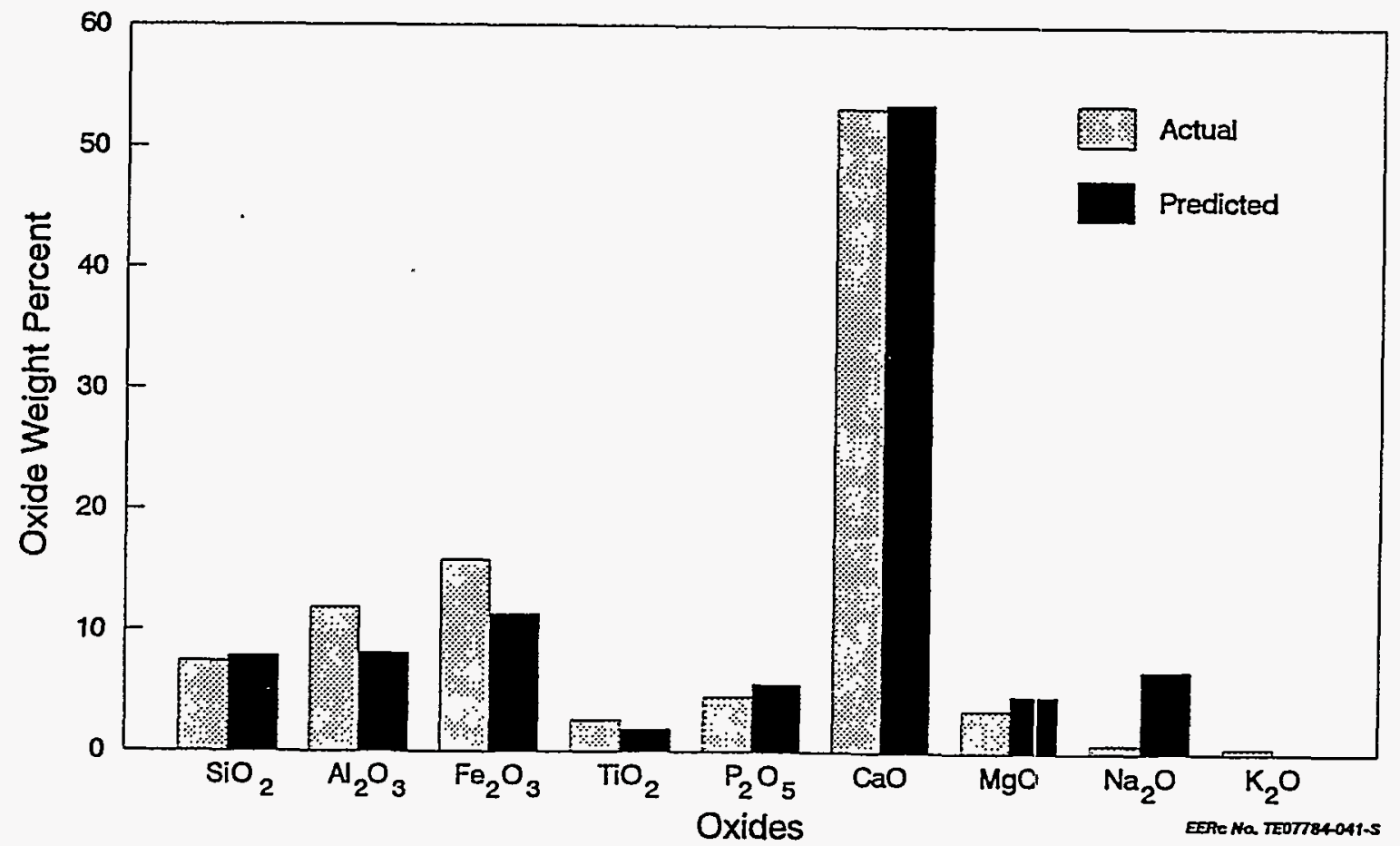

Figure B-24. Measured and predicted composition distributions for Antelope (King), 3- to 1-micron ash, produced in a pe-fired system. 


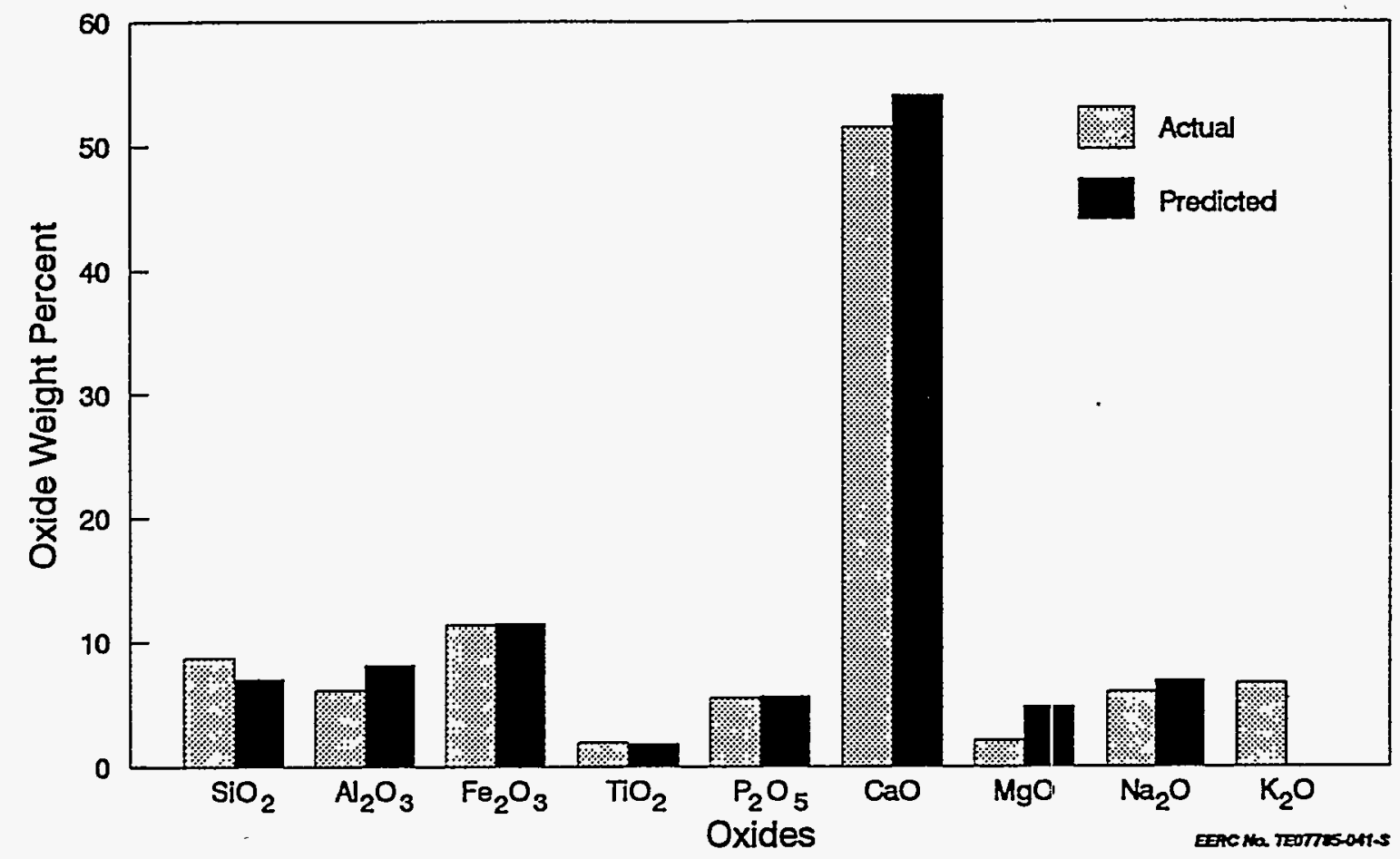

Figure B-25. Measured and predicted composition distributions for Antelope (King), $<1$-micron ash, produced in a pc-fired system.

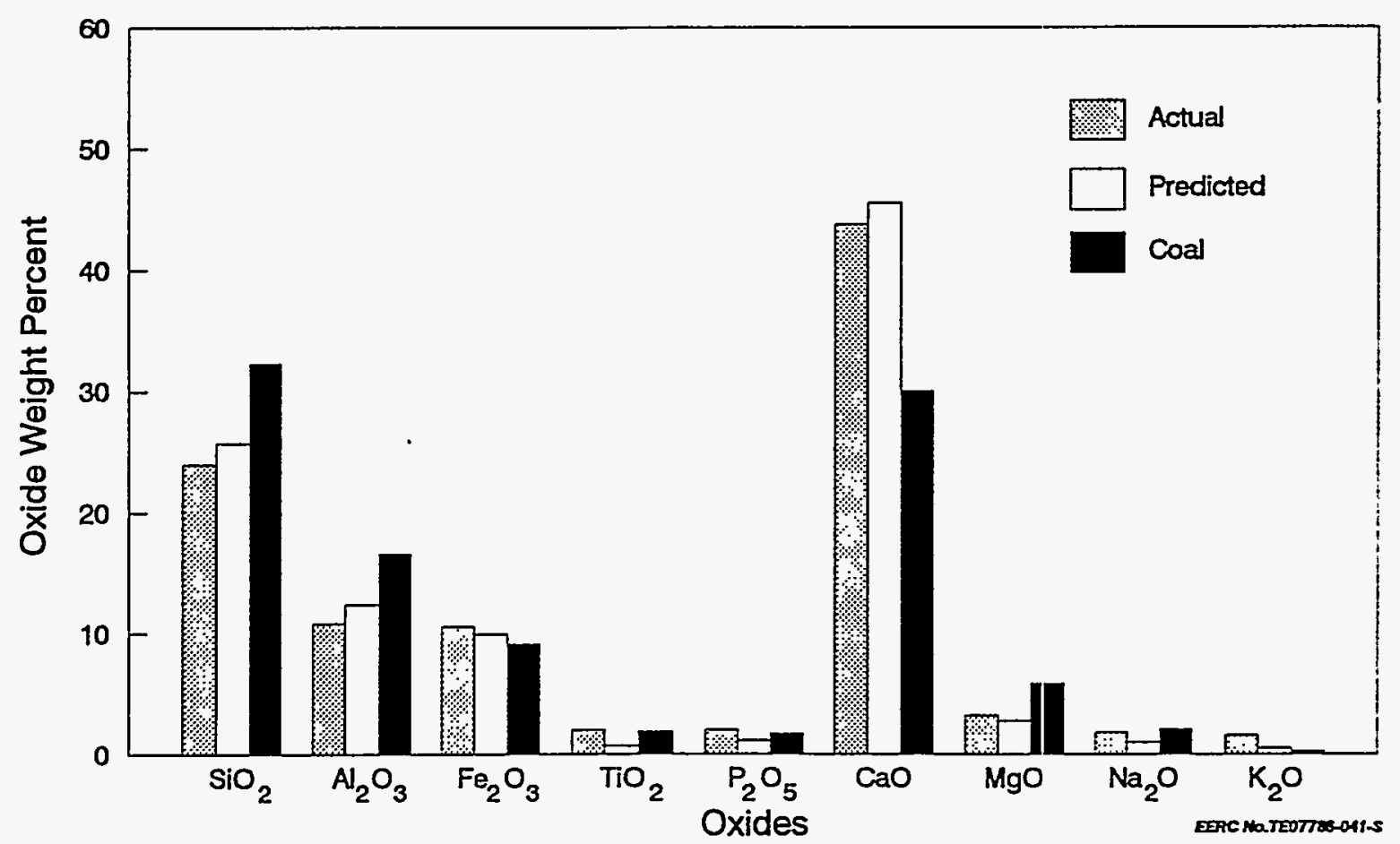

Figure B-26. Measured and predicted composition distributions for Antelope (King), bulk ash (weighted composite), produced in a pc-fired system. 


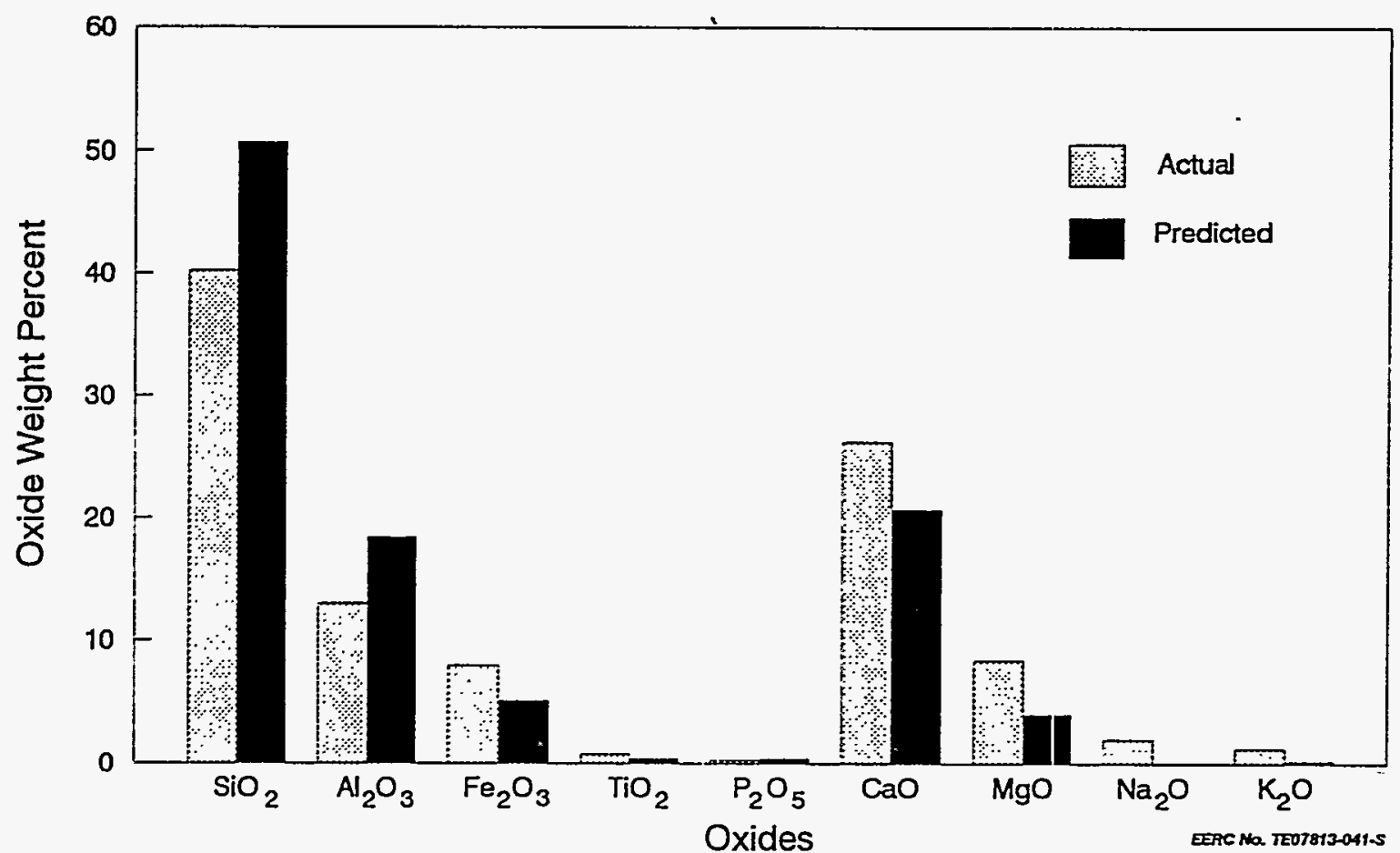

Figure B-27. Measured and predicted composition distributions for Shoshone (Schahfer), >10-micron ash, produced in a pc-fired system.

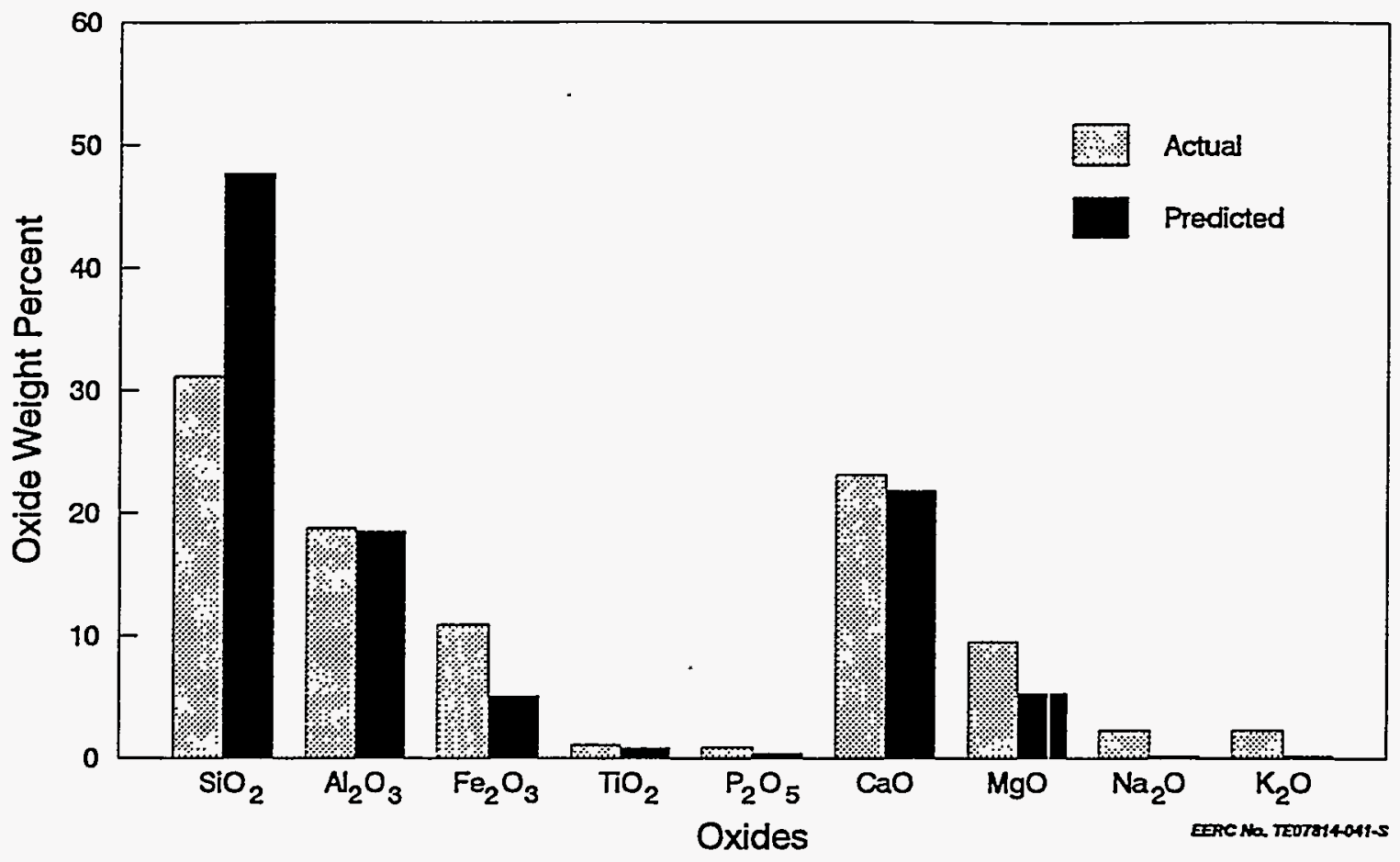

Figure B-28. Measured and predicted composition distributions for Shoshone (Schahfer), 10- to 3-micron ash, produced in a pc-fired system. 


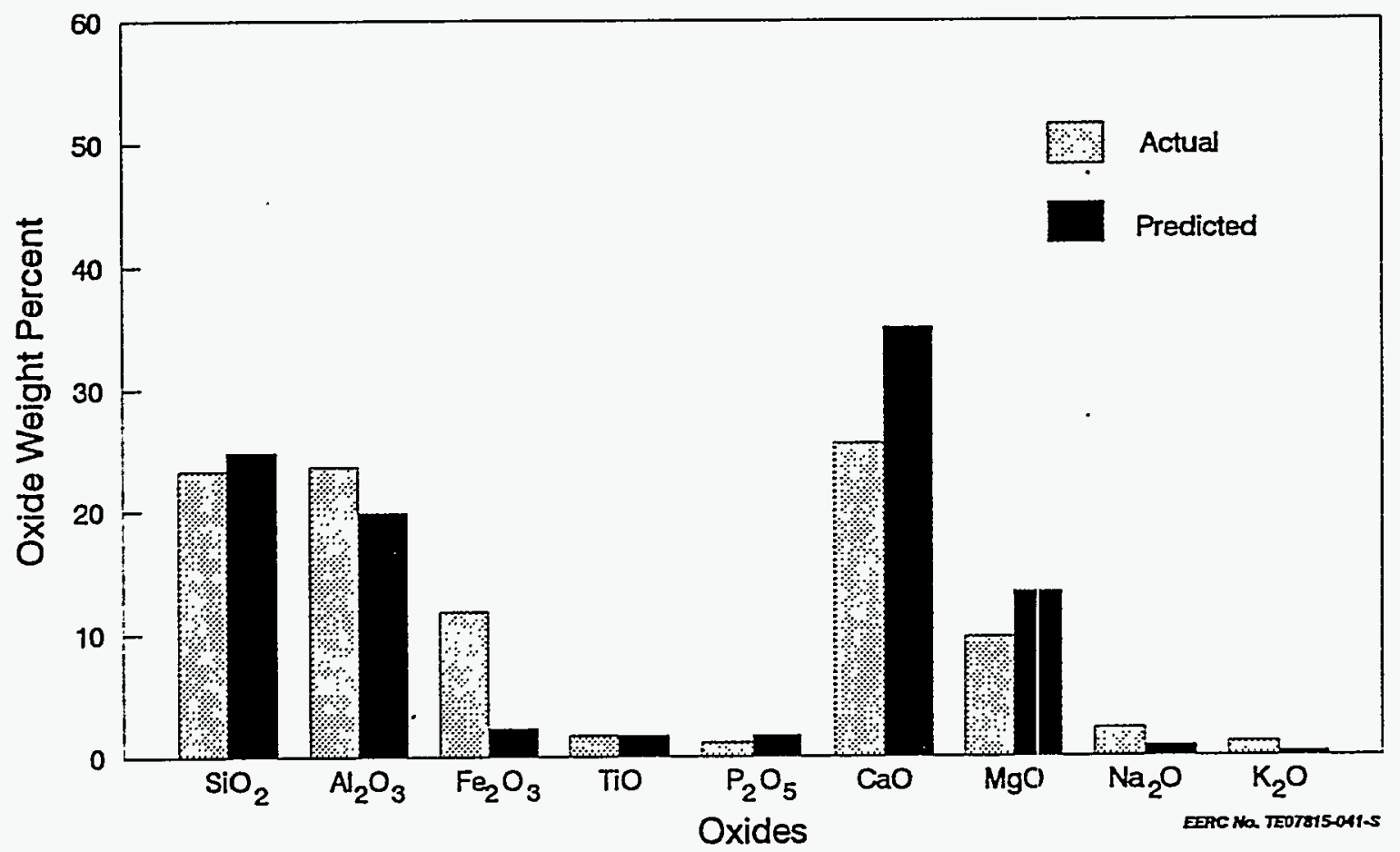

Figure B-29. Measured and predicted composition distributions for Shoshone (Schahfer), 3- to 1-micron ash, produced in a pc-fired system.

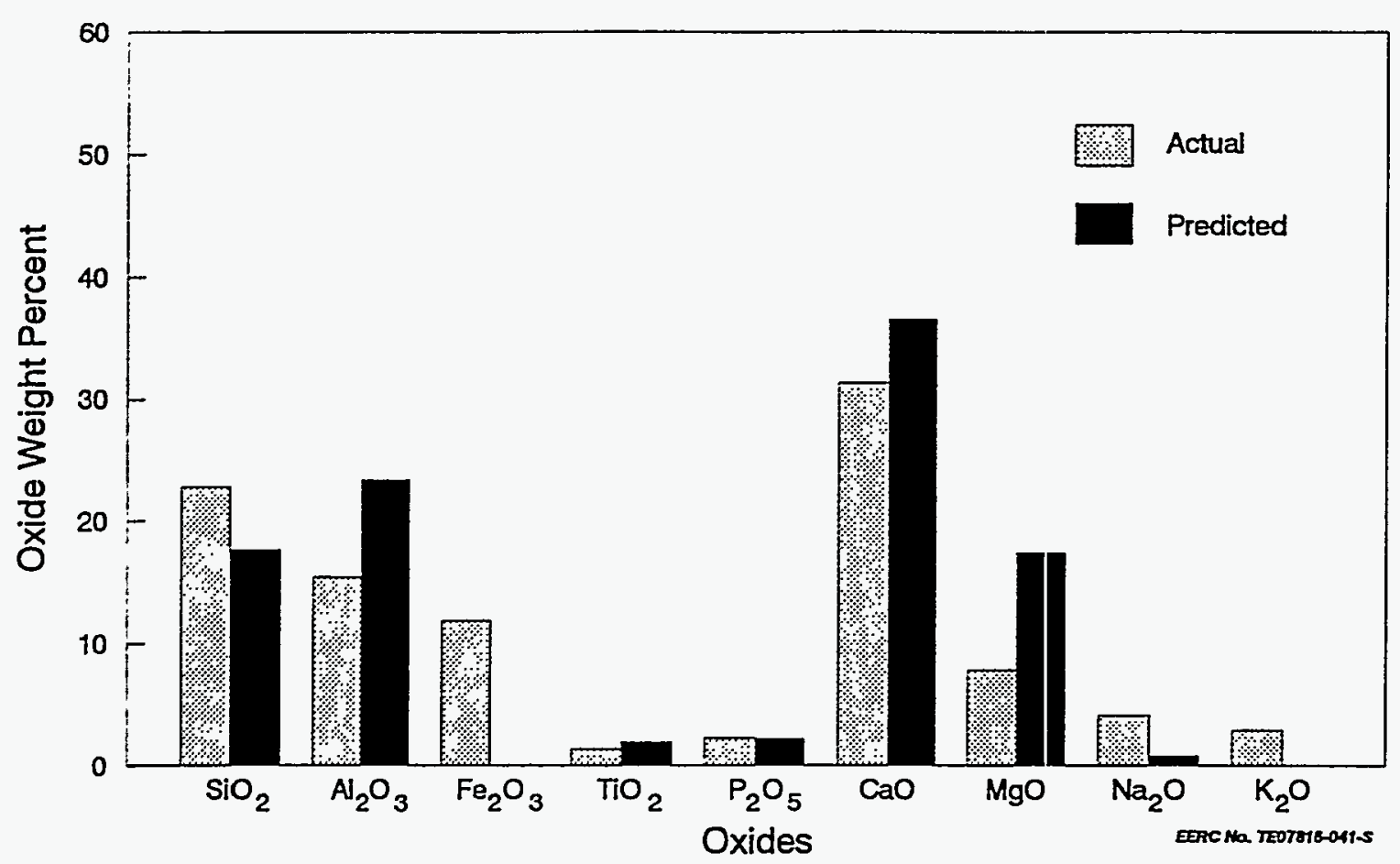

Figure B-30. Measured and predicted composition distributions for Shoshone (Schahfer), <1-micron ash, produced in a pc-fired system. 


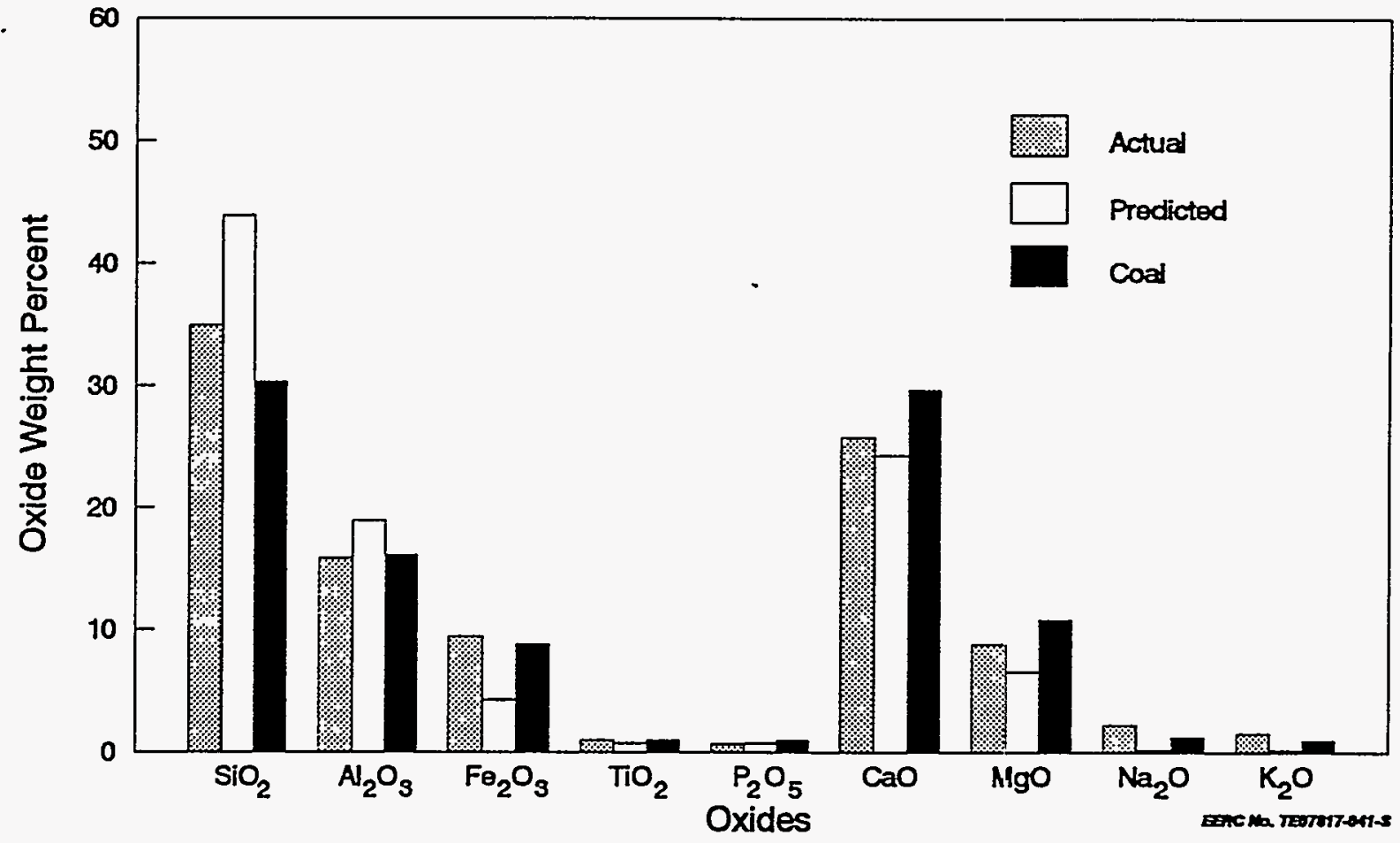

Figure B-31. Measured and predicted composition distributions for Shoshone (Schahfer), bulk ash (weighted composite), produced in a pc-fired system.

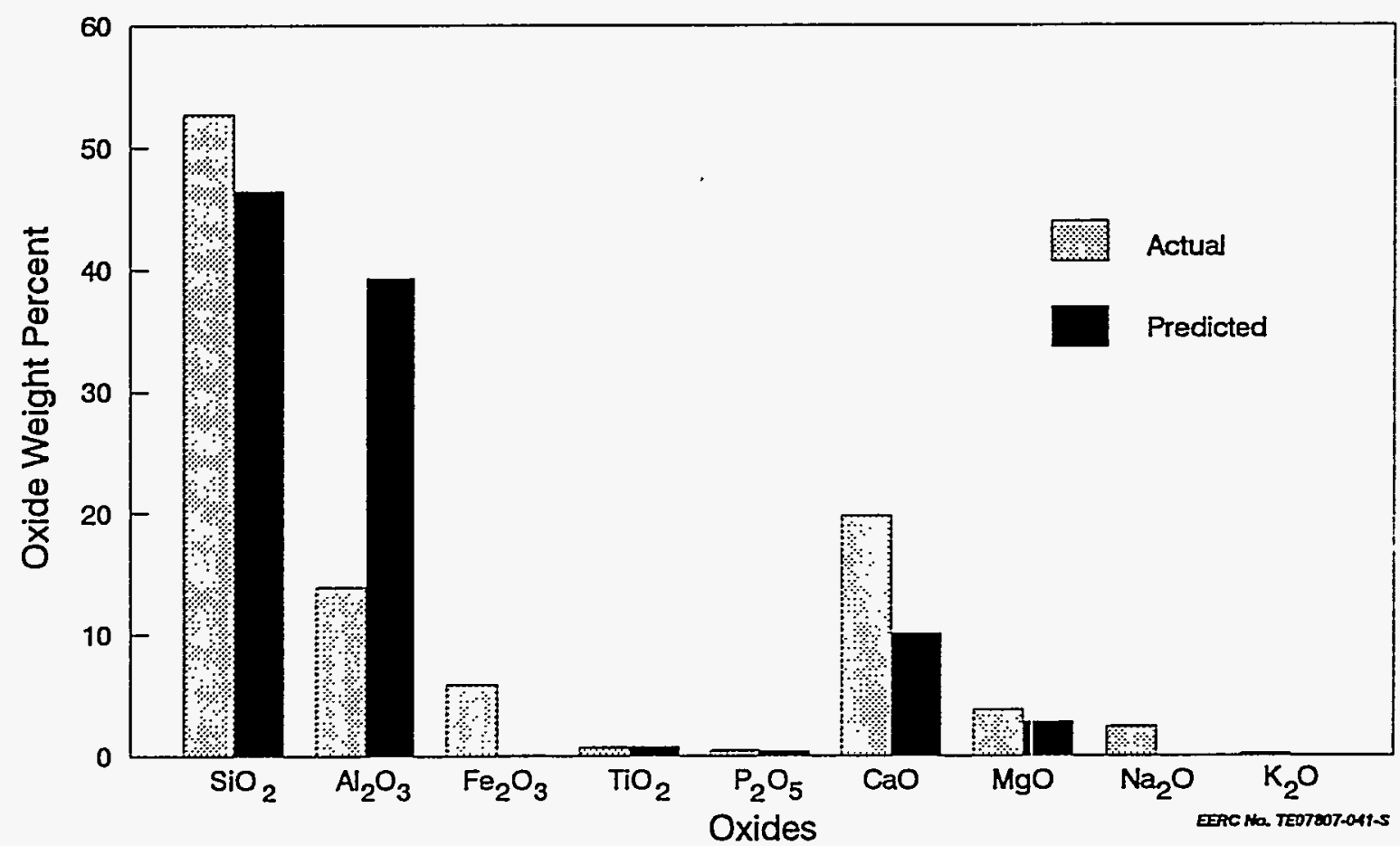

Figure B-32. Measured and predicted composition distributions for Eagle Butte (Welsh), >10-micron ash, produced in a pc-fired system. 


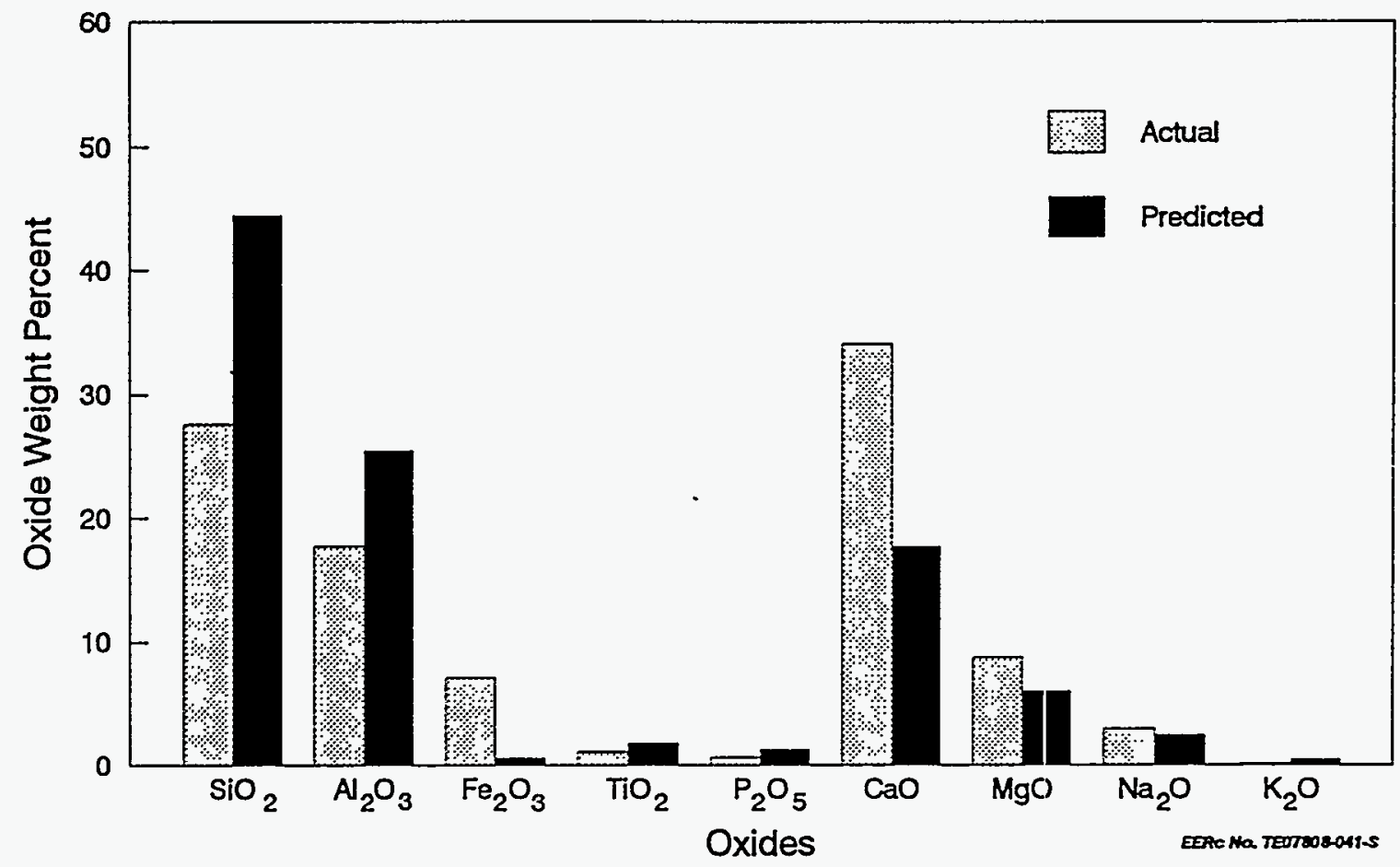

Figure B-33. Measured and predicted composition distributions for Eagle Butte (Welsh), 10- to 3-micron ash, produced in a pe-fired system.

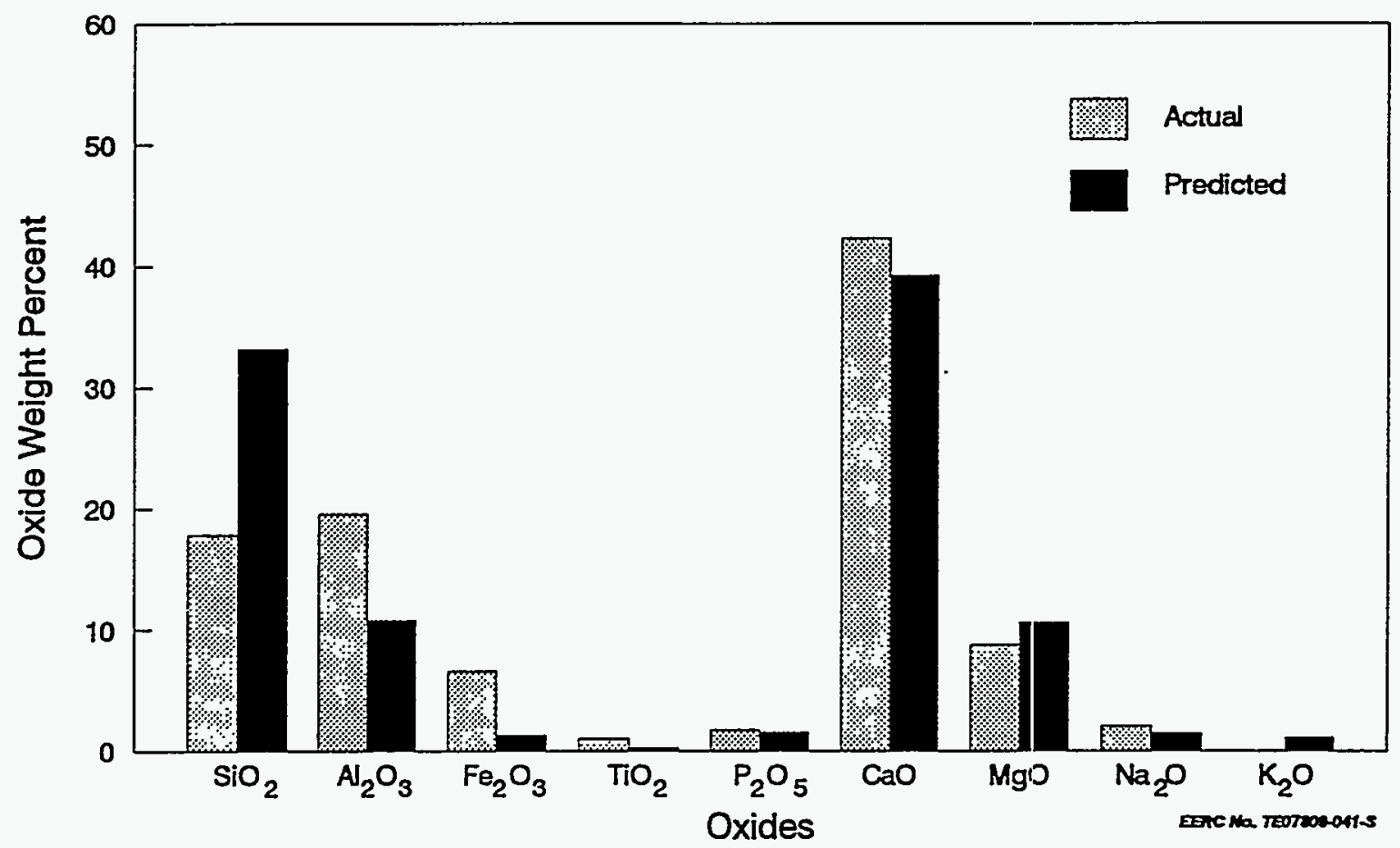

Figure B-34. Measured and predicted composition distributions for Eagle Butte (Welsh), 3- to 1-micron ash, produced in a pc-fired system. 


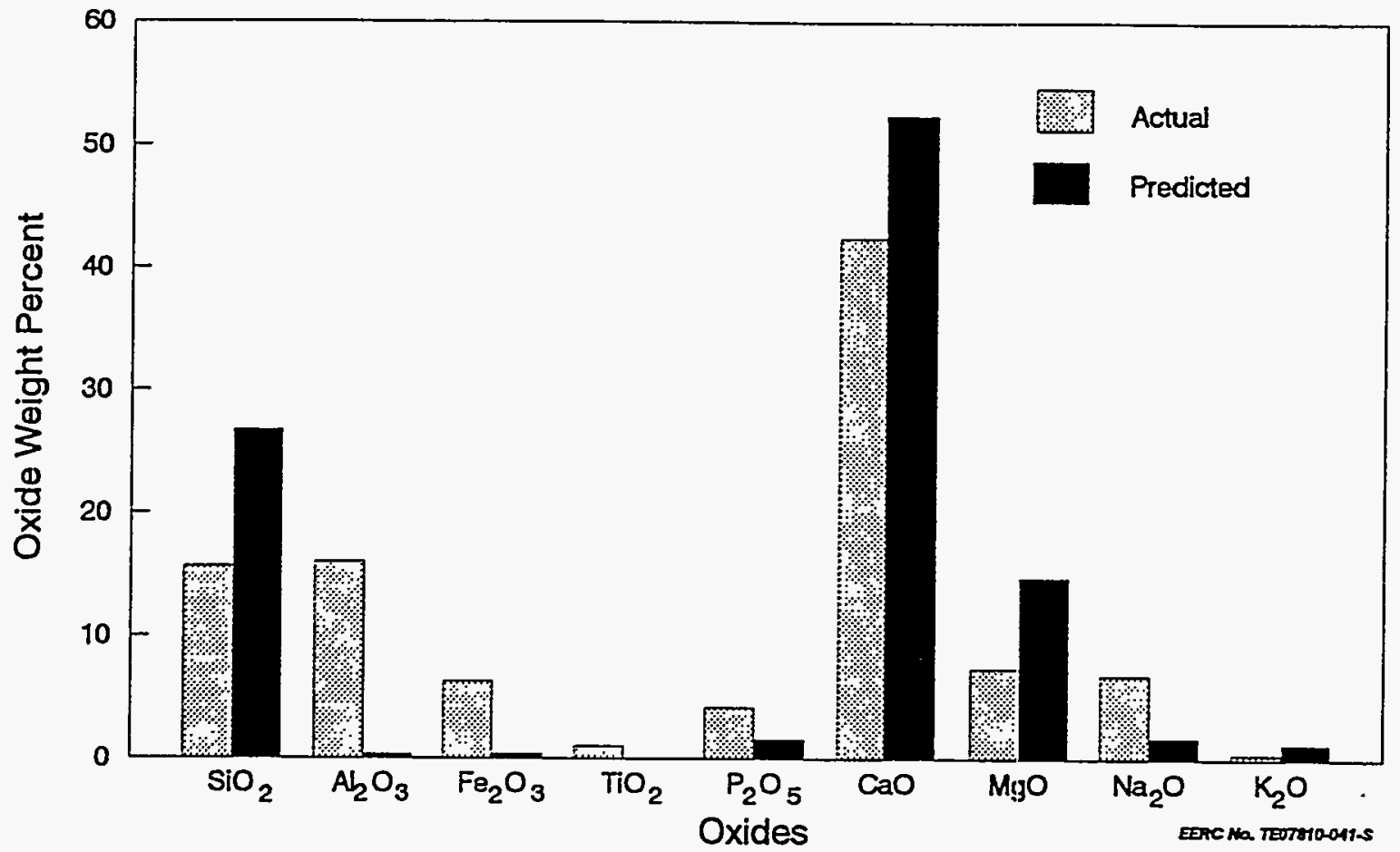

Figure B-35. Measured and predicted composition distributions for Eagle Butte (Welsh), <1-micron ash, produced in a pe-fired system.

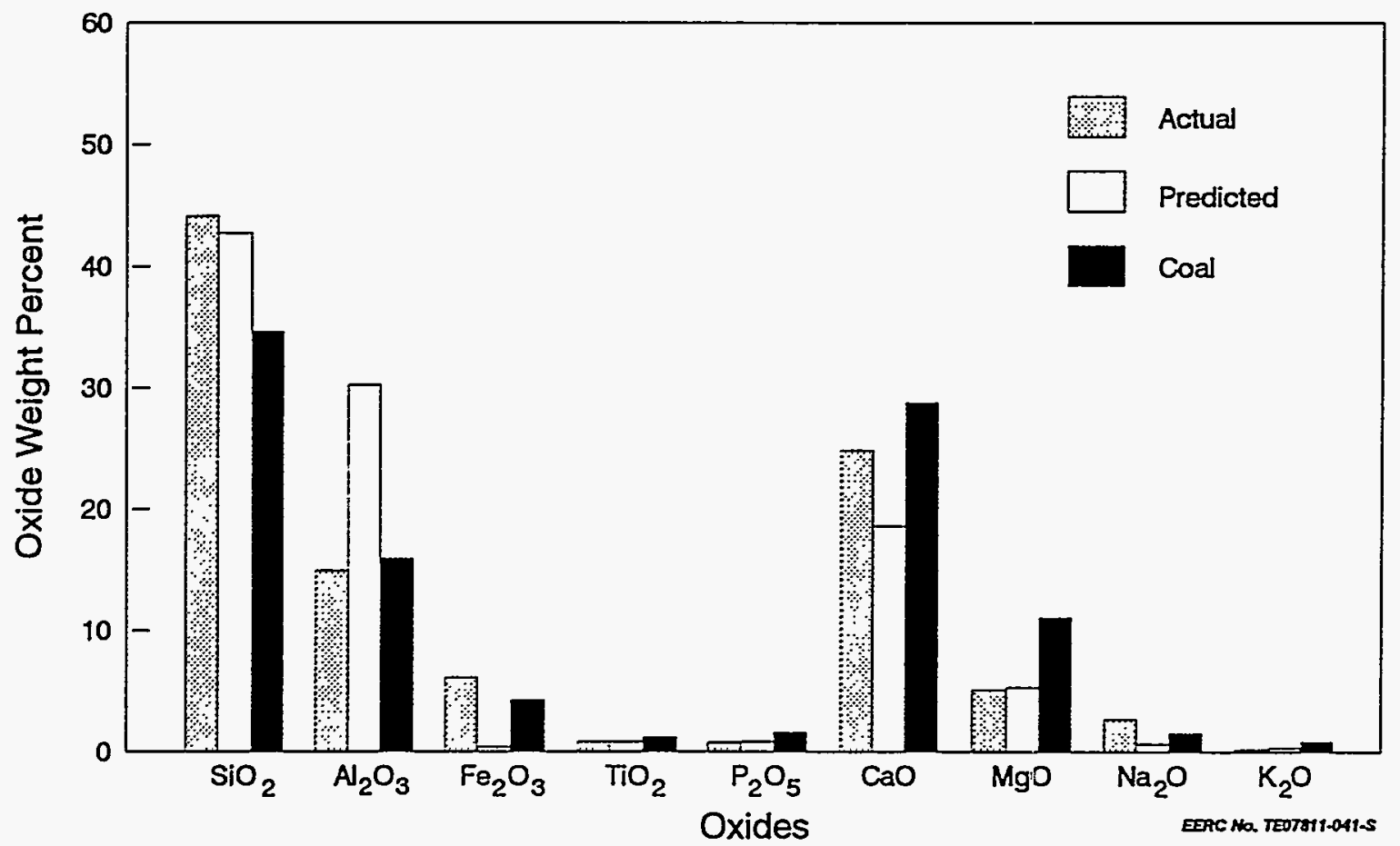

Figure B-36. Measured and predicted composition distributions for Eagle Butte (Welsh), bulk ash (weighted composite), produced in a pc-fired system. 


\title{
MEETING NOTES \\ PROJECT CALCIUM SPONSORS' MEETING
}

\author{
Energy \& Environmental Research Center \\ Grand Forks, North Dakota \\ July 1, 1992
}

Mike Jones opened the meeting and welcomed the participants.

\section{PROJECT HISTORY}

Steve Benson presented an overview of the Project Calcium history, describing the significance of the jointly sponsored research project and its accomplishments.

Don Bull requested the final Project Calcium budget summary be incorporated into the final report.

Joe Brobjorg asked if LEADER was a final commercial project.

Steve Benson and John Hurley replied that LEADER is a commercially viable model for boiler temperatures less than $1850^{\circ} \mathrm{F}$ and with high-calcium coals. It was stated that Tom Erickson would later present plans that would include highertemperature regions and different coals into LEADER.

A brief discussion followed on the use of the LDDP for long-term deposition studies and testing the effect of soot blowing. John Hurley expressed concern over if the LDDP was structurally sound for direct soot blowing.

\section{DEFINITION OF THE LOW-TEMPERATURE DEPOSITIOIN PROBLEM}

John Hurley presented information on the types of low-temperature deposits, formation mechanisms, deposition rates, and removal methods.

Arun Mehta asked if size vs. composition graphs for all povrer plant tests were available. John said that the data to make such graphs are in the plant reports.

\section{STRENGTH DEVELOPMENT}

John Hurley summarized the deposition, strength mechanisms, and methods to mitigate low-temperature fouling.

Phil Goldberg and Bruce Taylor expressed concern about the crystalline compression strength of the sintered ash pellets.

Craig Vogal asked what inert additive increased the shedding index. 
John Hurley replied that kaolinite had been used in pilot-scale studies for higher temperatures, but should work for lower temperatures. He estinated it would take approximately $25 \mathrm{lb}$ of properly applied kaolinite per 1 ton of coal.

\section{LEADER}

Tom Erickson presented predicted results from LEADER versus measured data and gave a brief demonstration of LEADER.

Joe Brobjorg and Arun Metha expressed interest in having a set of examples in the operation manual.

Don Bull said Dick Pelly had done some comparisons on full-scale boilers with earlier versions of LEADER, and the results (rankings) were comparable.

Phil Goldberg would like to see other coal results from DOIE or other sponsors' projects in LEADER given the OK to use these coal results (CCSEM data) in LEADER.

Craig Vogel asked why additives had not been tested in the LEADER program.

John Hurley replied that a number of other things could hive a been incorporated or tested further, but time and order of precedence dictated what could or could not be included into or tested with LEADER.

were given:

After some discussion of the possible next steps for LEADER, the following options

Option 1: Form a working group to add more coals to the IsEADER database, and test the code using additives in the blends.

Option 2: Expand LEADER applicability. This option was presented by the EERC, but many people had to leave to catch their plane and missed this presentation.

This option was covered in more detail in the presentation slides.

Task 1: Construction of a modeling shell and framervork

Task 2: Higher-temperature deposition

Low-temperature deposition, enhancement

Inorganic transformations, enhancement

Slagging, option

Task 3: Soot-blower effectiveness, fouling

Soot-blower effectiveness, slagging

Task 4: Two-dimensional modeling

Dynamic modeling

Task 5: Verification and data gathering

3:15 p.m. Meeting adjourned. 